\title{
Fusion Materials Research at Oak Ridge National Laboratory in Fiscal Year 2020
}

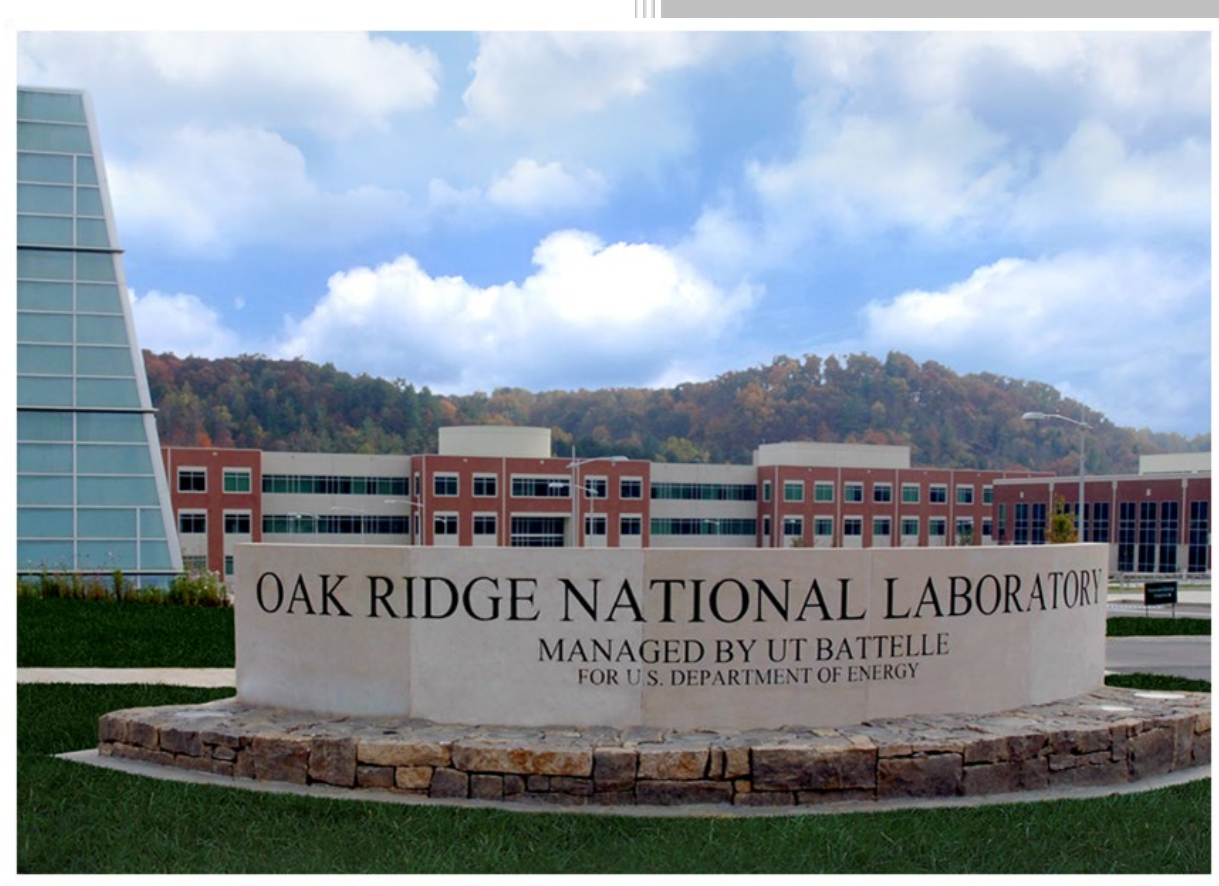

Approved for public release. Distribution is unlimited.

Compiled by:

F.W. Wiffen

Y. Katoh

S. Melton

December 2020 


\section{DOCUMENT AVAILABILITY}

Reports produced after January 1, 1996, are generally available free via US Department of Energy (DOE) SciTech Connect.

Website www.osti.gov

Reports produced before January 1, 1996, may be purchased by members of the public from the following source:

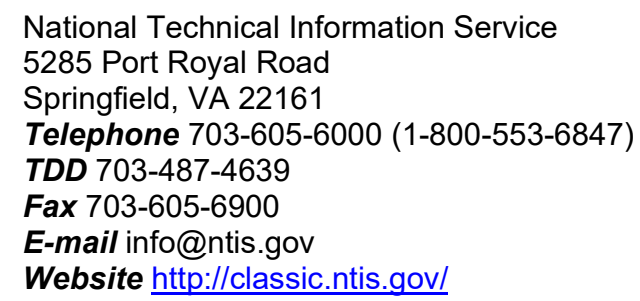

Reports are available to DOE employees, DOE contractors, Energy Technology Data Exchange representatives, and International Nuclear Information System representatives from the following source:

Office of Scientific and Technical Information

PO Box 62

Oak Ridge, TN 37831

Telephone 865-576-8401

Fax 865-576-5728

E-mail reports@osti.gov

Website http://www.osti.gov/contact.html

This report was prepared as an account of work sponsored by an agency of the United States Government. Neither the United States Government nor any agency thereof, nor any of their employees, makes any warranty, express or implied, or assumes any legal liability or responsibility for the accuracy, completeness, or usefulness of any information, apparatus, product, or process disclosed, or represents that its use would not infringe privately owned rights. Reference herein to any specific commercial product, process, or service by trade name, trademark, manufacturer, or otherwise, does not necessarily constitute or imply its endorsement, recommendation, or favoring by the United States Government or any agency thereof. The views and opinions of authors expressed herein do not necessarily state or reflect those of the United States Government or any agency thereof. 

FISCAL YEAR 2020

\author{
Compiled by: \\ F.W. Wiffen \\ Y. Katoh \\ S. Melton
}

Date Published: December 2020

Prepared by OAK RIDGE NATIONAL LABORATORY

Oak Ridge, TN 37831-6283

managed by

UT-BATTELLE, LLC

for the

US DEPARTMENT OF ENERGY

under contract DE-AC05-00OR22725 


\section{CONTENTS}

CONTENTS.

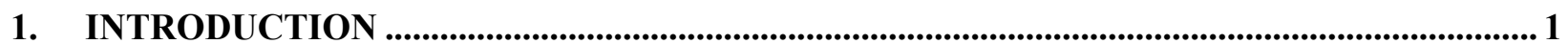

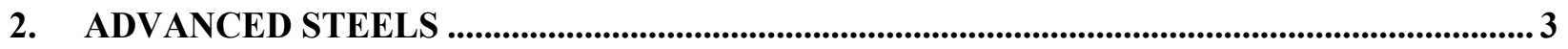

2.1 CASTABLE NANOSTRUCTURED ALLOY DOWNSELECTION FOR SCALE-

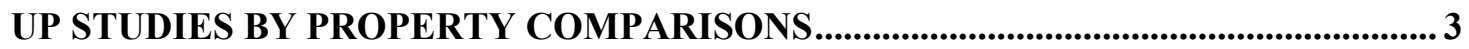

2.2 EFFECT OF CARBON CONTENT ON CARBIDE-VERSION CASTABLE

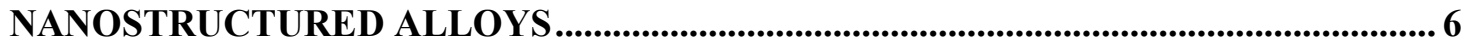

2.3 EFFECTS OF NEUTRON IRRADIATION ON FRACTURE TOUGHNESS OF

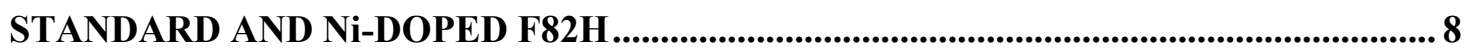

2.4 TENSILE PROPERTIES OF HFIR IRRADIATED EUROFUSION PROJECT ALLOYS ........................................................................................................................................ 11

2.5 MICROSTRUCTURE CHARACTERIZATION OF EUROFUSION ALLOYS AND CORRELATION WITH IRRADIATION-INDUCED HARDENING ................... 15

2.6 BAINITIC STEEL DEVELOPMENT FOR FUSION APPLICATIONS ........................ 19

2.7 IRRADIATION INDUCED PHASE SEPARATION IN OXIDE DISPERSION

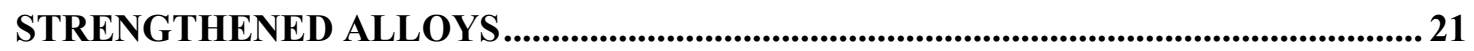

2.8 DEVELOPMENT OF TRANSFORMATION ENHANCED ODS Fe-Cr ALLOYS ....... 25

2.9 Fe-Cr-AI ODS ALLOYS FOR FUSION REACTOR APPLICATIONS ............................ 29

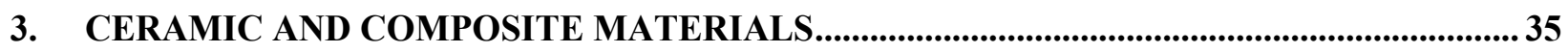

3.1 DESIGN AND STRATEGY FOR NEXT-GENERATION SILICON CARBIDE COMPOSITES FOR NUCLEAR ENERGY .............................................................................. 35

3.2 SiC JOINING TECHNOLOGY FOR FUSION REACTORS.........................................37

3.3 ADVANCED CHARACTERIZATION OF IRRADIATED SILICON CARBIDE: DETERMINATION OF NEUTRON IRRADIATION TEMPERATURES USING ELECTRICAL RESISTIVITY

3.4 DEFECT CHARACTERIZATION IN IRRADIATED TiB ${ }_{2}$ BY ELECTRON MICROSCOPY AND ADVANCED ANALYSIS .................................................................. 42

4. HIGH HEAT FLUX AND PLASMA FACING MATERIALS .............................................45

4.1 IRRADIATION EFFECTS ON THERMAL AND MECHANICAL PROPERTIES OF TUNGSTEN - PHENIX COLLABORATION ........................................................... 45

4.2 TENSILE PROPERTIES OF TUNGSTEN FIBERS FOR APPLICATION IN

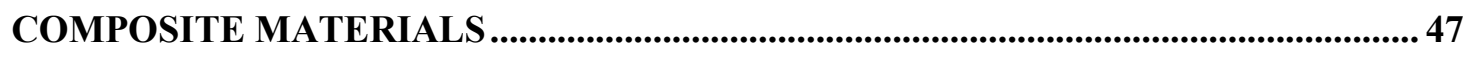

4.3 EFFECT OF IRRADIATION ON THE ELECTRICAL RESISTIVITY OF TUNGSTEN MATERIALS - PHENIX COLLABORATION ............................................50

4.4 MICROSTRUCTURES OF IRRADIATED TUNGSTEN ..............................................54

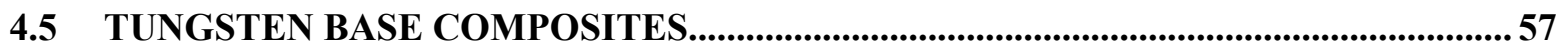

4.6 FABRICATION OF FUNCTIONALLY GRADED TUNGSTEN STEEL

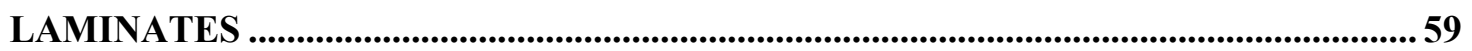

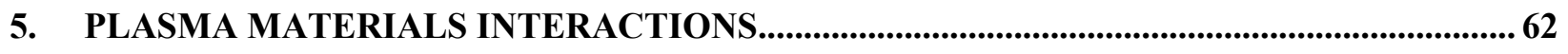

5.1 HELIUM EFFECTS ON THE SURFACE AND SUBSURFACE EVOLUTION IN

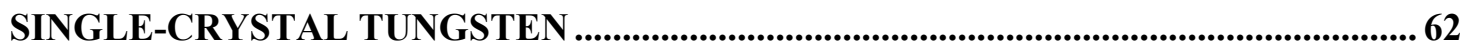

5.2 IMPACT OF HELIUM IMPLANTATION ON THE CRYSTALLOGRAPHIC ORIENTATION CHANGES IN SINGLE-CRYSTALLINE TUNGSTEN .................... 65

5.3 DAMAGE-MECHANISM INTERACTIONS AT THE PLASMA-MATERIALS

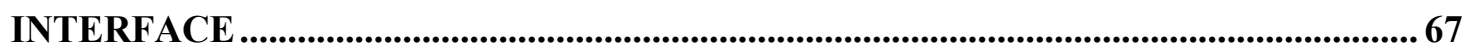

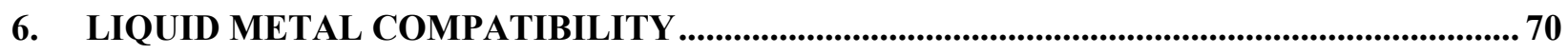

6.1 LIQUID METAL COMPATIBILITY IN FLOWING SYSTEMS ..................................... 70

7. EXPLORATORY, UNIQUE AND INNOVATIVE MATERIALS............................................... 72

7.1 TRITIUM BREEDING MATERIAL - EXPERIMENTAL ........................................... 72 
7.2 TRITIUM BREEDING MATERIAL - THEORETICAL ............................................ 74

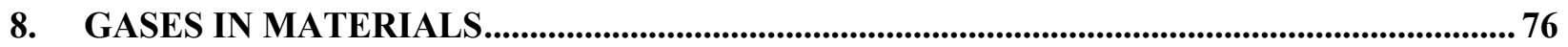

8.1 DEUTERIUM TRANSPORT AND RETENTION PROPERTIES OF

REPRESENTATIVE FUSION BLANKET STRUCTURAL MATERIALS................... 76

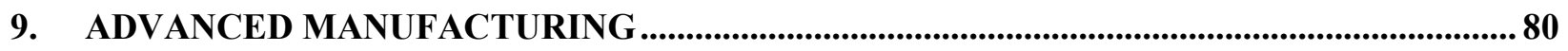

9.1 ADVANCED MANUFACTURING OF TUNGSTEN FOR DIVERTOR COMPONENTS

9.2 ADDITIVE MANUFACTURING OF SILICON CARBIDE FOR NUCLEAR

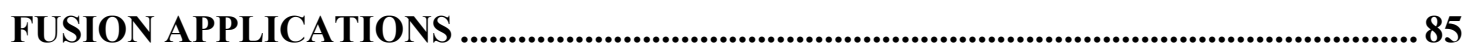

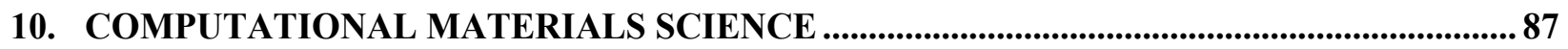

10.1 MECHANICAL PROPERTIES AND RADIATION EFFECTS IN FUSION MATERIALS

10.2 EQUILIBRIUM DISTRIBUTION OF POINT DEFECTS IN Fe-Y-O TAKING INTO ACCOUNT OXIDE-MATRIX INTERFACE AND PRE-EXISTING VACANCIES

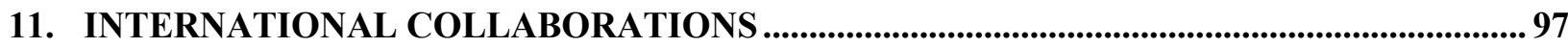

11.1 US-JAPAN (QST) COLLABORATIONS ON STRUCTURAL MATERIALS.................97

11.2 US-JAPAN FRONTIER PROGRAM ................................................................................ 99

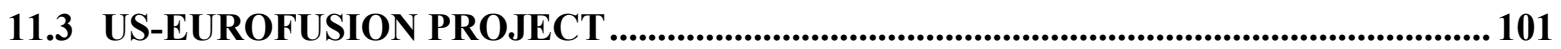

11.4 IAEA SMALL SPECIMEN TEST TECHNIQUE (SSTT) DEVELOPMENT:

MASTER CURVE FRACTURE TOUGHNESS ROUND ROBIN TEST PLAN........... 102

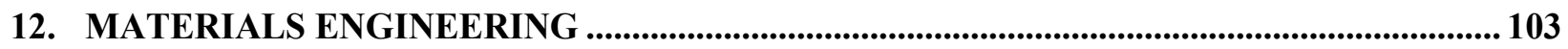

12.1 MATERIALS ENGINEERING SUPPORT FOR THE FNSF CONCEPTUAL DESIGN

13. EXPERIMENTAL TECHNIQUES AND LABORATORY SYSTEMS .................................... 105

13.1 DEVELOPMENT OF MINIATURE MECHANICAL TESTS FOR TUNGSTEN-

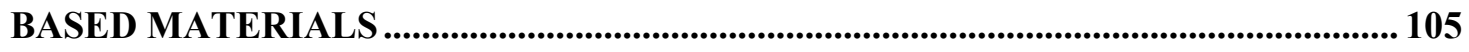

13.2 ADVANCED MICROSTRUCTURE CHARACTERIZATION OF DIBORIDES ........ 108

13.3 FRACTURE MECHANICS LABORATORY TEST SYSTEMS ................................... 111

13.4 UPDATE OF IRRADIATED MATERIALS EXAMINATION AND TESTING

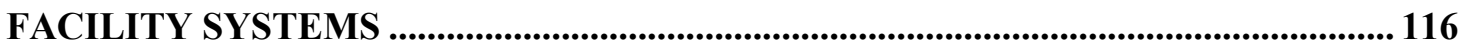

13.5 NEW AND UPGRADED CAPABILITIES OF LAMDA.........................................119

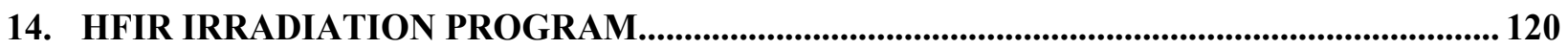

14.1 CAPSULE DESIGN FOR FRONTIER TASK 1 HFIR IRRADIATIONS .....................120

14.2 CAPSULE DESIGN FOR FRONTIER TASK 2 HFIR IRRADIATIONS .................. 121

14.3 CAPSULE DESIGN FOR FRONTIER TASK 3 HFIR IRRADIATIONS ...................... 122

14.4 CAPSULE DESIGN TO IRRADIATE F82H FOR THE ORNL-QST COLLABORATION.

14.5 HFIR IRRADIATION PROGRAM: CAPSULE DISASSEMBLY AND

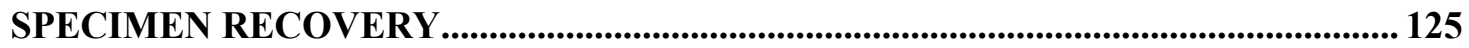

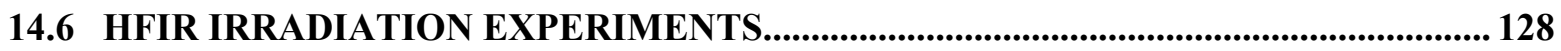

15. AWARDS, HONORS AND RECOGNITION ................................................................. 131

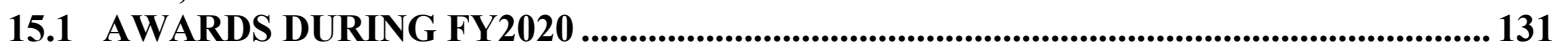

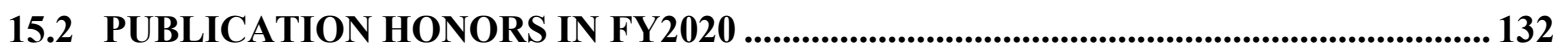

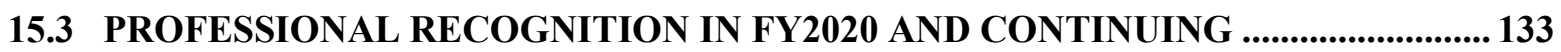

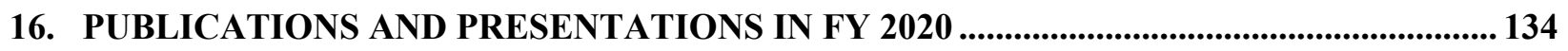

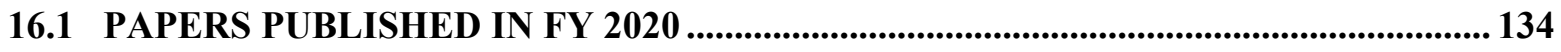

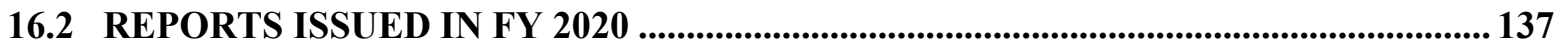

16.3 PAPERS SUBMITTED IN FY 2019 -2020 (Currently awaiting publication) ................. 138

16.4 PRESENTATIONS DELIVERED ......................................................................................... 140 


\section{LIST OF FIGURES}

Figure 1. Contact dose rate of Eurofer 97-2, F82H-BA12, CNA1, and CNA3 after a five-year DEMO reactor service to a damage dose of $55 \mathrm{dpa}$ (solid symbols) and $200 \mathrm{dpa}$ (open symbols). [After W. Zhong, L. Tan, Radiological analysis, and transmutation calculation of representative castable nanostructured alloys, Fusion Engineering and Design 160 (2020) 111899.]

Figure 2. Seven-aspect performance comparison of carbide- and carbonitride-CNAs with Eurofer 97 (E97), F28H, and ODS 14YWT. [After L. Tan, T. Graening, X. Hu, W. Zhong, Y. Yang, S.J. Zinkle, Y. Katoh, Effects of carbonitrides and carbides on microstructure and properties of castable nanostructured alloys, Journal of Nuclear Materials 540 (2020) 152376.]

Figure 3. Calculated temperature-dependent phase mole fraction in CNA8 and CNA9. 4

Figure 4. (a) Temperature-dependent yield and ultimate strength and uniform and total plastic elongation of CNA8 and CNA9. (b) Temperature-dependent Charpy impact absorbed energies of CNA8 (C8) and CNA9 (C9)..

Figure 5. Timeline and target irradiation conditions for $\mathrm{F82H}$ irradiation experiments in HFIR [1].

Figure 6. Comparison of the Master Curve reference temperature $\mathbf{T}_{0 q}$ between JP27 and JP28/29 for F82H IEA, F82H Mod3, F82H+1.4\% ${ }^{58} \mathrm{Ni}$, and F82H+1.4\% ${ }^{60} \mathrm{Ni}$.

Figure 7. Comparison of the YS and UTS of irradiated Eurofusion steels. HFIR samples irradiated to $2.5 \mathrm{dpa}$ at a nominal $300^{\circ} \mathrm{C}$.

Figure 8. A comparison of the UE and TE of the ten Eurofusion steels. HFIR samples irradiated to $2.5 \mathrm{dpa}$ at a nominal $300^{\circ} \mathrm{C}$.

Figure 9. A comparison of RA for the ten EUROfusion steels in unirradiated and irradiated condition, after tensile tests at room temperature.

Figure 10. Dislocation loops in the Eurofusion alloys. Red arrows indicate the on-edge a $<100>$ type loops, imaged using $<110>$ type diffraction vector close to [001] zone axis.

Figure 11. Selected area diffraction pattern from an $M_{23} C_{6}$ carbide in irradiated reference Eurofer97 steel, showing no evidence of amorphization during irradiation.

Figure 12. Comparison of experimentally observed strength change to hardening predicted by DBH for the different Eurofer97 alloys irradiated to 2.5 dpa at $300{ }^{\circ} \mathrm{C}$.

Figure 13. Property screening results of new heats compared to reference materials; (a) creep-rupture life plotted as a function of stress, and (b) temperature dependence of Charpy impact absorbed energy.

Figure 14. Vickers hardness of normalized-and-tempered original 3Cr-3WVTa and MLC02T plotted as a function of tempering temperature.

Figure 15. PCA of STEM-EDX data identifying Cr rich $\alpha$ ' phase formation in PM2000 alloy. Arrows point to the large ODS particles in the alloy that appear as Y rich. $Y$ plus Fe rich regions are collectively shown in blue.

Figure 16. PCA end member analysis revealing (Al, Ti) clustering in PM2000 alloy. (a) HAADF image (b) PCA map showing the Al, Ti rich regions in red. (c) EDX spectrum corresponding to the map where positive peaks contribute to the enriched regions in red. Yttrium peak originates from the large oxide particle. $\mathrm{Cu}$ peak arises from the TEM specimen holder. Arrows point to the large ODS particles.

Figure 17. STEM-EDX raw count maps of neutron irradiated MA957. (a) Y and Cr map showing the $\mathrm{Cr}$ rich precipitates and the nano-oxides, (b) $\mathrm{Ni}$ and (c) $\mathrm{Ti}$.

Figure 18. PCA end member analysis of STEM-EDX data identifying $\mathrm{Cr}$ rich $\alpha$ ' phase in MA957 alloy.

Figure 19. Evidence of Ni,Ti rich phase formation in irradiated MA957. 
Figure 20. Bright-field TEM micrographs showing the ultra-small grains present in (a) M4 containing $1 \% \mathrm{~W}$ and (b) $\mathrm{M5}$ that is $\mathrm{W}$-free.

Figure 21. EFTEM Fe-M jump ratio maps showing the dispersion of nano-size oxide particles present in (a) M4 containing $1 \% \mathrm{~W}$ and (b) $\mathrm{M5}$ that is $\mathrm{W}$-free.

Figure 22. Size distribution of the oxide particle dispersions obtained from Image $J$ analysis of (a) M4 containing $1 \% \mathrm{~W}$ and (b) M5 that is $\mathrm{W}$-free. The $\mathrm{x}$-axis of the number associated with the analyzed oxide particle arranged from smallest to largest.

Figure 23. High-resolution S/TEM images of select nanoscale precipitates in the 4H10C alloy showing examples of precipitates matching the structure of (a) YAM and (b) YAG [7].

Figure 24. a) Comparison of creep lifetimes for ODS FeCrAl tested at $700^{\circ} \mathrm{C}$ or $800^{\circ} \mathrm{C}$, b) Optical image of the $\mathrm{ZY9C}$ specimen creep tested for $25,110 \mathrm{~h}$ at $700^{\circ} \mathrm{C}$ highlighting voids and AIN clusters, c) Scanning electron microscopy (SEM) images of the $125 \mathrm{YZ}$ specimen creep tested at $700^{\circ} \mathrm{C}, 140 \mathrm{MPa}$ for $26,700 \mathrm{~h}$ showing voids related to large grains or alumina stringers.

Figure 25. $125 \mathrm{YZ}$ specimen creep tested at $700^{\circ} \mathrm{C}, 140 \mathrm{MPa}$ for $26,700 \mathrm{~h}$, a) $\mathrm{TEM}$ micrograph, b) Corresponding chemical maps.

Figure 26. LMP plot comparing various ODS FeCr steels with the added $125 \mathrm{YZ}$ and106ZY9C ODS FeCrAl alloys shown in blue [15].

Figure 27. SEM images of pyrolytic carbon interphase in Tyranno SA3 SiC fiber reinforced $\mathrm{CVI} \mathrm{SiC} / \mathrm{SiC}$ composite: (a) unirradiated and (b) neutron irradiated at $600^{\circ} \mathrm{C}$ to 44 dpa. Irradiation-induced interfacial debonding was observed.....

Figure 28. Performance and processing requirements for development of the interphase between fiber and matrix in $\mathrm{SiC} / \mathrm{SiC}$ composites for use in high-dose radiation environments. Reprinted from Journal of Nuclear Materials 540 (2020) 152375.

Figure 29. SiC joints tested in study of the effects of high dose neutron irradiation.

Figure 30. Experimental setup for electric current assisted joining of SiC. Shows absence of graphite die surrounding the specimen and carbon felt used only around the punches.

Figure 31. ULVAC-Riko ZEM-5 electrical resistivity/Seebeck coefficient measurement system. The open optical furnace shows the quartz tube heating elements and the enlargement shows details of the sample and electrical measurement leads centered in the chamber. Scale marks are in inches.

Figure 32. Electrical resistivity of $\mathrm{SiC}$ as a function of peak annealing temperature following neutron irradiation at $\sim 550^{\circ} \mathrm{C}$. The resistivity was measured at $200^{\circ} \mathrm{C}$ after each isochronal annealing step.

Figure 33. Atomic-scale HAADF images showing the arrangement of atomic columns when imaged along [11-20] zone axis in unirradiated and irradiated $\mathrm{TiB}_{2}$. The encircled region shows irradiation induced defects that look like kinks.

Figure 34. Machine learning and local crystallography analysis of irradiated $\mathrm{TiB}_{2}$ data. (a) HAADF image (b) atoms identified in the HAADF image by machine learning, (c) a schematic showing 8 nearest neighbour configurations used for local crystallography analysis and (d) point cloud of atoms from local crystallography analysis.

Figure 35. Atom distributions represented by point clouds compared for the irradiated and unirradiated $\mathrm{TiB}_{2}$. The vertical lines are constituted by the atoms/columns that are slightly displaced from their regular lattice sites.

Figure 36. PCA of irradiated point cloud data, identifying two major components in the HAADF images. Component 2, which is also visible in Component 1 identified a locally defected structure generating strong displacement of lattice atoms from their regular sites. 
Figure 37. Tensile properties of polycrystalline tungsten machined in the " $A$ " orientation and tensile tested before and after irradiation at test temperatures of 500, 700, and $900^{\circ} \mathrm{C}$.

Figure 38. Thermal diffusivity of as-irradiated and unirradiated tungsten materials. The open and black symbols represent unirradiated specimens and the filled and red symbols the irradiated specimens. Reproduced from Masafumi Akiyoshi, Lauren M. Garrison, Josina W. Geringer, Hsin Wang, Akira Hasegawa, Shuhei Nogami, and Yutai Katoh. "Thermal diffusivity of irradiated tungsten and tungsten-rhenium alloys." Accepted by Journal of Nuclear Materials. September 2020.

Figure 39. (a) One neutron irradiated fiber was placed in the epoxy on the bottom half of the paper frame. (b) A second layer of paper was placed on top of the fiber and epoxy. The paper frame provides support when loading the fiber in the test frame. The sides of the frame are cut before the tensile test.

Figure 40. (a) Close up view of a fiber after a successful tensile test. Epoxy fixes the fiber ends inside the paper frame, and the paper plus epoxy ensure that the metal clamp of the fixture does not have any direct contact with the delicate fibers. (b) Camera image of the speckle paint pattern on the fiber surface.

Figure 41. Unalloyed tungsten fiber (Type 3) tensile tested at room temperature. (a) Fracture surface after irradiation to $0.7 \mathrm{dpa}$ at $800^{\circ} \mathrm{C}$ shows brittle cleavage. (b) Fracture surface after $0.2 \mathrm{dpa}$ at $500^{\circ} \mathrm{C}$ shows each grain elongated to a ductile knife edge failure.

Figure 42. Electrical resistivity measuring apparatus. For each image, major gridlines are 1 cm apart. a) Disassembled $3 \mathrm{~mm}$ disk holder. Apparatus on left, example $3 \mathrm{~mm}$ disk and plug on right. b) Assembled $3 \mathrm{~mm}$ disk fixture. The plug is clamped in the apparatus to ensure good contact with the pins. c) Simplified $3 \mathbf{~ m m}$ disk circuit schematic.

Figure 43. (top) Unirradiated grain structure for AT (isotropic grains) and BT (elongated grains) series materials. (bottom) Electrical resistivity as a function of sample rotational orientation relative to the probes for selected polycrystalline samples. Average values are shown with larger, darker icons and individual measurements are given with smaller, lighter icons. Sine waves fit to the BT series samples are shown in aqua alongside the data. The 0 -degree angle is arbitrary for individual samples because the grains are too small to see with the eye when inserting samples in the fixture. Resistivity values are tentative and may change slightly in future reports.

Figure 44. Tentative electrical resistivity of irradiated, AT, BT, and UE series tungsten materials as a function of dpa. Approximate irradiation temperature for each sample is given in the legend. Measurements were taken between $20^{\circ} \mathrm{C}$ and $24^{\circ} \mathrm{C}$ and normalized to $20^{\circ} \mathrm{C}$.

Figure 45. EBSD images of three cycle ( $\sim 0.5$ dpa) HFIR-irradiated, gadolinium-shielded tungsten at $\sim 500, \sim 800$, and $\sim 1000^{\circ} \mathrm{C}$. The $1000^{\circ} \mathrm{C}$ material is fully recrystallized.

Figure 46. STEM images and $X$-ray maps from two samples, $W-0.4 R e / 1000^{\circ} \mathrm{C} 0.6$ dpa and rolled foil, $900^{\circ} \mathrm{C}, 0.7 \mathrm{dpa}$. $\mathrm{Re}$ and $\mathrm{Os}$ transmutant clusters and precipitates are visible.

Figure 47. Initial tensile test of a $W_{f} / W$ composite sample. (a) Engineering stress vs crosshead displacement. (b) SEM image of sample at the load step [S04]. (c) higher magnification showing detail at load step [S04] where some cracks near the end of the specimen gage section are seen. (d) SEM image at step [S05]. (c) detailed view at load step [S05] when the matrix crack reached the surface, but the specimen is still able to support nearly $\sim 90 \%$ of the maximum load.. 
Figure 48. SEM Micrographs of polished cross sections of: (A) Composite 1, (B) Composite 2, (C) Composite 3, and (D) Composite 4. In all the images the $\mathrm{W}$ layers appear brighter and the steel layers appear darker. Note that (A) is at a different magnification than the others three.

Figure 49. Ultimate tensile strength versus percentage of tungsten for room temperature tensile tests. Tungsten foils are shown as diamond markers, and the steel foils are shown in square markers.

Figure 50. Fracture surfaces of composite 1 tensile samples. Section 1 (A-B), Section 2 (CD), Section 3 (E-F).

Figure 51. New $<111>$ grains only formed in He-irradiated $W\{100\}$ and $W\{111\}$ at RT. Left three column images: the in-plane (IPF-X and IPF-Y) and normal directionprojected (IPF-Z) orientation maps. Right column images: the corresponding IPFs of orientation maps IPF-Z.

Figure 52. Bright-field TEM images showing the subsurface He bubbles formed in all Heirradiated W samples after TDS. The superimposed plot is the calculated He concentration profile $C_{H e}$ versus ion penetration depth $L$.

Figure 53. SEM images showing the surface blisters formed only in He implanted (a) W $\{100\}$ and (b) $W\{110\}$ after TDS.

Figure 54. Orientation maps of (a) He-irradiated $W\{100\}$ and (b) He-irradiated $W\{110\}$, in conjunction with selected BKPs patterns from matrix and new grain regions.

Figure 55. Pole figures for He-irradiated (a) $W\{100\}$ and (b) $W\{110\}$, indicating the formation of surface grains via the grain rotation of matrix around an in-plane $<110>$ axis.

Figure 56. Fresnel contrast (left under-focused $\sim 150 \mathrm{~nm}$, center focused, right overfocused $\sim 150 \mathrm{~nm}$ ) and high angle annular dark field (HAADF, far right) of PCW at (a) 600 $\mathrm{K}$, (b) $500 \mathrm{~K}$, (c) $400 \mathrm{~K}$, and (d) $310 \mathrm{~K}$.

Figure 57. Fresnel contrast (defocus $\sim 150 \mathrm{~nm}$ ) and high angle annular dark field (HAADF) of SCW at (a) $1.25 \times 10^{26}$ (b) $2.0 \times 10^{25}$ (c) $2.5 \times 10^{24} \mathrm{~m}^{-2}$.

Figure 58. He bubble relative density distribution and number density in SCW samples.

Figure 59. Specimen mass change of specimens in PbLi of the thermal convection loops as a function of estimated temperature in the hot leg (HL) and cold leg (CL) of the $4^{\text {th }}$ (APMT only) and $5^{\text {th }}$ (multi-material) TCL experiments.

Figure 60. (a) SEM backscattered electron image of the reaction product formed on CVD $\mathrm{SiC}$ after $1000 \mathrm{~h}$ at $647^{\circ} \mathrm{C}$ in the $5^{\text {th }}$ TLC cold leg. EDX maps were collected from the same region of (b) $\mathrm{Cr}$, (c) $\mathrm{Fe}$, (d) $\mathrm{Si}$, (e) $\mathrm{Pb}$ and (f) $\mathrm{O}$.

Figure 61. XRD results of the powdered and bulk LTO materials.

Figure 62. SEM micrograph showing distribution of LTO powder particles a), and the size distribution histogram b). The total number of particles measured to obtain the size distribution was 369.

Figure 63. Optical micrograph showing the $\mathrm{Li}_{2} \mathrm{Be}_{2} \mathrm{O}_{3}$ particles (red circles) produced at McMaster University.

Figure 64. XRD pattern confirming $\mathrm{Li}_{2} \mathrm{Be}_{2} \mathrm{O}_{3}$ single crystal.

Figure 65. Thermal conductivities for $\mathrm{Li}_{2} \mathrm{Ti}_{2} \mathrm{O}_{3}$ and $\mathrm{Li}_{2} \mathrm{BeSiO}_{4}$ calculated using DFT. The unit cell size are $5 \times 5 \times 5$ and $8 \times 8 \times 8$, respectively. The calculated thermal conductivities are found to be close to that of $\mathrm{SiO}_{2}$.

Figure 66. (a) Deuterium permeability of candidate steels measured as a function of temperature; (b) Thermal desorption spectra following static deuterium charging.

Figure 67. In-situ NIR analysis of build 2. a) Calculated relative density per layer for each part. A noticeable increase in density occurs at $7.5 \mathrm{~mm}$, after final parameters begin. b) Comparison of reconstructed part (left) and as-built part (right). For the reconstructed image, white indicates solid material and black indicates porosity. . 
Figure 68. Summary of published results of additively manufactured tungsten. Reported relative density is plotted vs. volumetric energy density, and color indicates ambient temperature at which build was performed.

Figure 69. Study of cracking in Build 3, sample 8. a) EBSD of vertical crack, where the crack appears as random unindexed pixels and b) optical image of same crack. Several small droplets of water are visible at the edge of the crack in the optical image. c) XZ section showing string of pores leading to the crack in Build 1, sample 9 d) XY section of Build 3, sample 8, showing localized regions of high crack density........ 83

Figure 70. Fractographs and representative EBSD maps for samples from EBM with tension parallel (left) and perpendicular (right) to the build direction..

Figure 71. (left) CVI allows gaseous reactants to infiltrate the sample bulk and react, depositing tungsten on the particulate surfaces. High density is achieved by allowing the process to carry out over a long time period. (right) Composite SEM image of a cross section of a sample where CVI was performed at $450^{\circ} \mathrm{C}$. Tungsten particles in the bulk demonstrate extremely limited deposition, while high density is produced to around $70 \mu \mathrm{m}$ depth.

Figure 72. Additively manufactured $\mathrm{SiC}$ component with complex geometry. A combination of binder jet $A M$ and CVI was used for the fabrication.

Figure 73. MD derived CRSS for voids in $W$ at $300 \mathrm{~K}$ and $600 \mathrm{~K}$ as a function of void size $\mathrm{D}$ in linear and semi-logarithmic presentations.

Figure 74. MD derived CRSS as a function of the harmonic mean of $D$ and $L$ for voids in $W$ at $300 \mathrm{~K}$ and $600 \mathrm{~K}$ compared with the BKS model with surface energy parameter $\mathrm{B}$ $=-0.7$.

Figure 75. CRSS data for voids in $\mathrm{W}$ and Fe for the same homologous temperatures 0. 16TM:

Figure 76. Structure of ODS precipitate interface.

Figure 77. Local defect concentration in $\left(\mathrm{Y}_{2 / 5} \mathrm{O}_{3 / 5}\right) \times \mathrm{Fe}_{1-\mathrm{x}-\mathrm{y}-\mathrm{z}} \mathrm{V}_{\mathrm{y}}\left(\mathrm{Fe}_{1 / 2} \mathrm{O}_{1 / 2}\right)_{\mathrm{z}}$ as a function of composition $x$ for set of ODS particle sizes and temperatures with $y=0.15 \%$ and $\mathrm{z}=\mathbf{0 . 5 \%}$. The ODS particle sizes and temperatures are: a) particle radius $\mathrm{R}=100$ (in bec Fe lattice parameters) and $T=600 \mathrm{~K}$, b) $R=10$ and $T=600 \mathrm{~K}$, c) $R=100$ and $T=1200 \mathrm{~K}$, d) $R=10$ and $T=1200 \mathrm{~K}$. The ODS-matrix are joined by Klim interface only. The preexisting vacancies in bulk iron are not shown.

Figure 78. Schematic layout of the vacuum vessel in-wall shield plates for ITER.

Figure 79. Three-point bend test schematic, where the distance between the two pins is 2 $\mathbf{m m}$, the total width of the sample is $3 \mathbf{~ m m}$, and the radius of curvature for the supports is $0.25 \mathrm{~mm}$ [1].

Figure 80. Stress analysis of a simplified model of miniature three-point bend loading on a disk-shaped specimen. (a) Orthographic view, (b) bottom view.

Figure 81. Image of the three-point bend fixture for use in LAMDA universal testing frames. Load is applied to the button, which moves with restricted displacement in button guide. Loading nose is situated in upper half, and the affixed tungsten carbide rod transfers the load to the disk, which is situated in the supports that are centered in the lower half.

Figure 82. Plot showing the laser power (green) and voltage power (Red) over the course of the APT calibration experiment.

Figure 83. Detection rate as a function of ion sequence showing no significant variance.

Figure 84. Detector histograms for specific laser powers: 75pJ (left) and 250pj (right).

Figure 85. Atom maps for Ti (left) and B (right) from a dataset collected with optimized APT parameters showing a uniform distribution of species throughout the matrix in the unirradiated state. The scale shown is in $\mathbf{n m}$.

Figure 86. Lindberg/Blue $M$ box furnaces. 
Figure 87. Servo-hydraulic frames. Load capacities: (a) 10-kip, (b) 22-kip, (c) 50-kip, and

(d) 300-kip.

Figure 88. South laboratory Charpy impact frame with 407 joules capacity.

Figure 89. Instron Charpy impact frame with in-situ heating/cooling stage.

Figure 90. Mitutoyo 2D measuring microscope.

Figure 91. Buehler VH3100 Vickers full-automatic hardness tester.

Figure 92. Newly designed and fabricated SSJ3 tensile fixtures for room temperature testing in (a) and elevated temperature testing in (b).

Figure 93. Mitutoyo HV120B hardness stage for (A) SS-J3 and (B) M4-PCCVN and M5PCCVN.

Figure 94. JEOL JV-6010 SEM stage for fractography of (A) SS-J3 and (B) M4-PCCVN.

Figure 95. Representative thermal analysis of Frontier Task 1 tungsten irradiation capsules with $3 \mathrm{~mm}$ disk design (left) and fracture toughness design (right) for irradiation in HFIR.

Figure 96. Representative thermal analysis of Frontier Task 2 tungsten irradiation capsules design with $6 \mathrm{~mm}$ disks for irradiation in HFIR.

Figure 97. CAD representation (left) with Sn hidden for ease of viewing and representative thermal analysis conduction model (right) of Frontier Task 3 molten Sn corrosion irradiation capsules for irradiation in HFIR.

Figure 98. Components and specimens for the FH51 low dose tensile capsule prior to assembly.

Figure 99. Image of disassembled F13A5 components. Four M3PCCVN bars are pictured center with $\mathrm{SiC}$ TMs to the right of them.

Figure 100. Irradiation capsule F8B1. Dark brown markings believed to be resin residue from fiber tube disintigration.

Figure 101. Irradiation capsule F8B2. Dark brown at bottom of tube believed to be resin residue from fiber tube disintegration.

Figure 102. Irradiation capsule F13B5. The worn housing and broken right support disk are a result of damage suffered during irradiation.

Figure 103. Paint pen marking used to preserve orientation and determine arrangement of specimen within the capsule.

Figure 104. Specimens were divided into white, middle, and yellow rows based on the paint pen markings made during disassembly. The metal cans contain specimen from these rows for storage at IMET and the fiber tubes contain TMs to be shipped to LAMDA. 


\section{LIST OF TABLES}

Table 1. Variants of Eurofer97 steels in these experiments

Table 2. Variants of Eurofer97 steels in these experiments

Table 3. Nominal compositions of the steels

Table 4. Average size and number density measured for oxide particle dispersions in M4 and M5

Table 5. Chemical compositions of alloys (wt\%) provided by DIRATS using ICP-OES

Table 6. Parameters of the tungsten-steel laminate composites

Table 7. Chemical compositions (wt \%) of candidate advanced RAFM steels

Table 8. Analysis results of thermal desorption spectra of RAFM steels

Table 9. HFIR Operating Record for FY2020

Table 10. New Irradiation Capsules Starting Irradiation in FY2020. The eleven that completed irradiation are indicated in bold.

Table 11. The HFIR fusion materials program rabbit capsules to continue irradiation in FY2021 


\section{INTRODUCTION}

\section{F.W.Wiffen, Yutai Katoh(katohy@ornl.gov)}

This ninth annual report of the ORNL Fusion Reactor Materials Program provides a condensed review of accomplishments in Fiscal Year 2020. The year was again productive, but dominated by three events: ICFRM 19, the DPP-CPP, and COVID 19.

a.) The Nineteenth International Conference on Fusion Reactor Materials, ICFRM 19, showcased the program advances of the two years since the previous conference in that series. The more than 40 ORNL presentations at the conference are detailed in section 16.4.

b.) The Community Planning Process led by the Division of Plasma Physics of the American Physical Society, DPP-CPP, encompassed a year-long workshops, review, and discussion of the fusion program, culminating in a report to FESAC as input to their 2020 Long Range Planning Activity. Lauren Garrison of the ORNL program had a lead role in this nation-wide evaluation.

c.) The COVID 19 attack on the US disrupted all program work in mid-March. No program travel, workshops, nor in-person technical meetings occurred for the rest of FY2020. Our program responded with active work from home and videoconferencing replacing the more "normal" workflow. This has increased the flow of technical papers into the publication pipeline. As we adjusted to this new work regime ORNL access has been allowed for use of the experimental equipment. Productivity has steadily returned to near-normal levels over the 6.5 months of FY 2020 as team members adapted to work-from-home challenges and the limitations of COVID precautions.

Preparation of several ARPA-E GAMOW proposals during FY 2020 resulted in final negotiations for two new awards - collaborative work with Lawrence Livermore National Laboratory (LLNL) and Texas A\&M University (TAMU) on the exploration of Additive Manufacturing options for fabrication of Plasma Facing Components, and an ORNL effort on the scale up of the Castable Nanostructured Alloy production. Both projects will be active over the next three years.

Achieving fusion energy is a formidable challenge to the field of materials science, to provide a suite of suitable materials in close integration to the plasma physics and other applied technologies. The technological challenge presented by the conceptual fusion power systems is the inability of current materials and components to withstand the harsh fusion nuclear environment. The overarching goal of the ORNL fusion materials program is to provide the applied materials science support and materials understanding to underpin the ongoing DOE Office of Science - Fusion Energy Sciences (FES) program, in parallel with developing materials for fusion power systems. This effort is integrated with the larger U.S. and international fusion materials communities and the fusion design and technology communities.

Following the pattern of planning used in this program, work in the two years FY 2020 and FY 2021 is focused on having the data and productivity to support a strong ORNL presence at ICFRM 20, scheduled for October 2021 in Granada, Spain. This goal applies whether the biennial conference occurs with personal attendance or as a virtual gathering of the world fusion materials community.

The major elements of this long-running ORNL program continue to pursue development of low activation structural materials, with the greatest effort directed at the Reduced Activation Ferritic/Martensitic Steels, higher strength/higher creep resistant/coolant compatible/radiation tolerant advanced steels, and Silicon Carbide Composites. Tasks within the steels portfolio pursue several options for advanced steels: These 
include development of Castable Nanostructured Alloys, exploratory work on Bainitic steels and Oxide Dispersion Strengthened (ODS) steels, and Aluminum containing alloys that promise improved liquid metal compatibility. Parallel to this is the increased emphasis on radiation effects, high heat flux response and the development of refractory metals, especially tungsten materials. This includes the development and evaluation of new tungsten alloys and composites, and the study and understanding of the irradiation performance of tungsten. Newer efforts also support the FES Blanket and Fuel Cycle Program and Liquid Metal Plasma Facing Components (PFC) Program. In each case the materials are being developed in a design-informed fashion where properties improvements are led by fusion-relevant design studies and directed at advancing the Technology Readiness Level of the material systems.

Continuing work supported by soon-to-end Early Career Award is looking in depth at the materials side of the Plasma Materials Interactions, characterizing the materials response to plasma impingement and determining the controlling mechanisms of the materials behavior.

Effort continues on the investigation of applications of Additive Manufacturing (AM) technologies to the production of materials and components for fusion systems. The production of simulated tungsten divertor components using electron beam powder bed fusion and binder jet technologies are underway, with new exploratory trials of AM to produce silicon carbide composites also undertaken this year.

Limited integrated fundamental modeling is included, directed especially at understanding experimentally observed materials behavior.

This fusion materials program makes heavy reliance on neutron irradiation in HFIR, the High Flux Isotope Reactor at ORNL, complemented by limited use of ion irradiation facilities when these are better suited to explore fundamental aspects of materials behavior under irradiation. Associated with the HFIR irradiations is the infrastructure needed to evaluate the effects of the irradiation on the material properties and microstructures, including hot cells for experiment disassembly, equipment to test highly radioactive specimens, and the shielded test equipment in the Low Activation Materials Development and Analysis Laboratory (LAMDA). Maintaining, upgrading, and replacing this state-of-the-art suite of instruments and test stands is an ongoing effort, shared with other reactor materials programs with similar needs.

Limited support of the FES System Studies team, "Materials Engineering in Support of the FNSF Program" provides materials expertise to that team and is a valuable link to the design community.

The fusion materials program includes several collaborations within the US and with international partners. The major continuing international collaborating partners are the Japan Agency for Quantum and Radiological Science and Technology (QST) collaboration, focused on structural materials, the Japanese National Institute for Fusion Sciences (the FRONTIER collaboration) and the Karlsruhe Institute of Technology in Germany, acting for EUROfusion (examining steel materials).

Productivity and recognition of the ORNL Fusion Materials Program is demonstrated in Chapter 15, "Awards, Honors and Recognition" and Chapter 16, "Publications and Presentations."

This research is funded by the Department of Energy, Office of Science, Office of Fusion Energy Sciences. We would like to acknowledge the active guidance of Daniel Clark in setting the direction and priorities of this work, and his help in the effective conduct of the program. 


\title{
2. ADVANCED STEELS
}

\subsection{CASTABLE NANOSTRUCTURED ALLOY DOWNSELECTION FOR SCALE-UP STUDIES BY PROPERTY COMPARISONS}

\author{
L.Tan (tanl@ornl.gov), T. Graening, X.Hu,W. Zhong, Y. Yang, S.J. Zinkle, Y. Katoh
}

\section{OBJECTIVE}

Castable nanostructure alloys (CNAs) have been developed at laboratory-scale at Oak Ridge National Laboratory to fill the performance gap between current reduced-activation ferritic-martensitic (RAFM) steels and oxide-dispersion-strengthened (ODS) alloys. Unlike ODS alloys fabricated by expensive powder metallurgy technology, CNAs use the mature steelmaking methods to develop high densities of carbonitrides or carbides in the tempered martensite matrix. The FY2020 effort focused on understanding the radiology of CNAs and the performance advantages of the carbonitride- and carbide-version CNAs, as the basis to advance further development of CNAs as a US-RAFM steel.

\section{SUMMARY}

Both carbide- and carbonitride-strengthened CNAs were developed and examined in the recent past, a nearly five-year effort. Systematic comparison of different aspects for the two types of CNAs are important to guide the further development, including scale-up of the CNAs. Radiological analysis indicated that the increased $\mathrm{N}$ in the carbonitride-CNAs leads to higher activity at $\geq 50$ years, and thus to disposal concerns under the current NRC regulations. However, the calculation using the Fetter's evaluation leads to a reduced waste disposal rating (WDR) of 0.25 from $\sim 0.05 \mathrm{wt} \% \mathrm{~N}$, depending on the irradiation dose and thus less concern for waste disposal. The other increased alloying elements, including $\mathrm{V}, \mathrm{Si}$, Ti, and $\mathrm{Mn}$, in CNAs, do not have significant effect on the specific activity, contact dose rate, or decay heat. By comparing the seven-aspect performance of precipitates, yield strength, creep resistance, Charpy impact toughness, helium management, deuterium retention, and phase transmutation resistance, carbide-CNAs showed some advantages over the carbonitride-CNAs. The advantages are manifest in the uniformly distributed higher density of carbide nanoprecipitates, greater Charpy impact upper shelf energies, lower deuterium retention and swelling, and potentially lower transmutation-induced composition changes and consequently thermodynamically more stable carbides. The carbide-CNAs showed the best-balanced performance, in contrast to the significantly varied performance of ODS alloys and the generally lower performance of current RAFM steels.

\section{PROGRESS AND STATUS}

Carbonitride precipitates are a common type of MX precipitate used in the current RAFM steels such as Eurofer97 and F82H. Other than carbonitride, carbide MX is also used in CNAs to study their effects in producing the desired microstructures and properties. Figure 1 shows the radiological analysis result of the carbonitride-CNA (CNA1) and carbide-CNA (CNA3), compared with Eurofer97-2 and F82H-BA12. It indicates comparable contact dose rates among the alloys, suitable for different waste recycling methods with different cooling times. The carbide-CNA tends to have slightly lower contact dose rates.

Following the developed scoring method based on seven-aspect performance, comparison of the carbideand carbonitride-CNAs with Eurofer97/F82H and ODS 14YWT is presented in Figure 2. The seven-aspect performance evaluates precipitate density and dispersion, yield strength at $600^{\circ} \mathrm{C}$, Larson-Miller creep parameter at $100 \mathrm{MPa}$, Charpy impact upper-shelf energy (USE), He-induced swelling, deuterium retention, and phase transmutation under neutron irradiation. For the first four aspects larger values give higher scores; 
for the latter three aspects lower values are favored for higher scores. Figure 2 indicates that the bestbalanced performance is for the carbide-CNAs, compared with the mostly varied performance of ODS 14YWT and the generally lower performance of the current RAFMs Eurofer97/F82H.

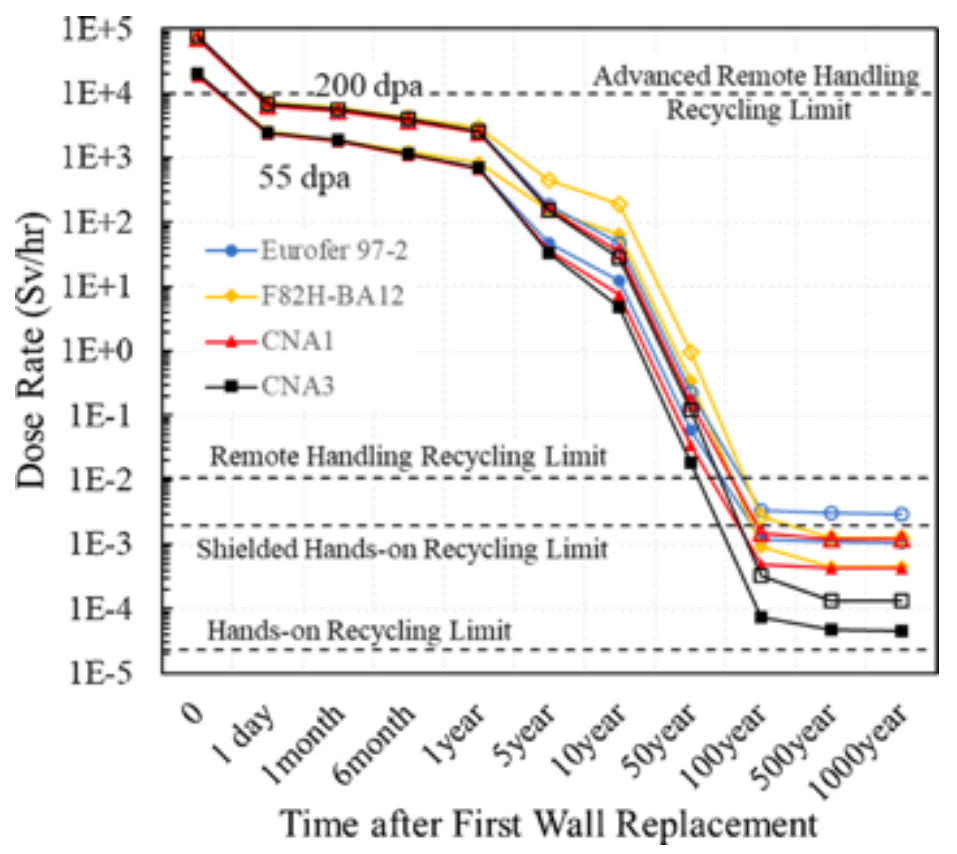

Figure 1. Contact dose rate of Eurofer 97-2, F82H-BA12, CNA1, and CNA3 after a five-year DEMO reactor service to a damage dose of 55 dpa (solid symbols) and 200 dpa (open symbols). [After W. Zhong, L. Tan, Radiological analysis, and transmutation calculation of representative castable nanostructured alloys, Fusion Engineering and Design 160 (2020) 111899.]

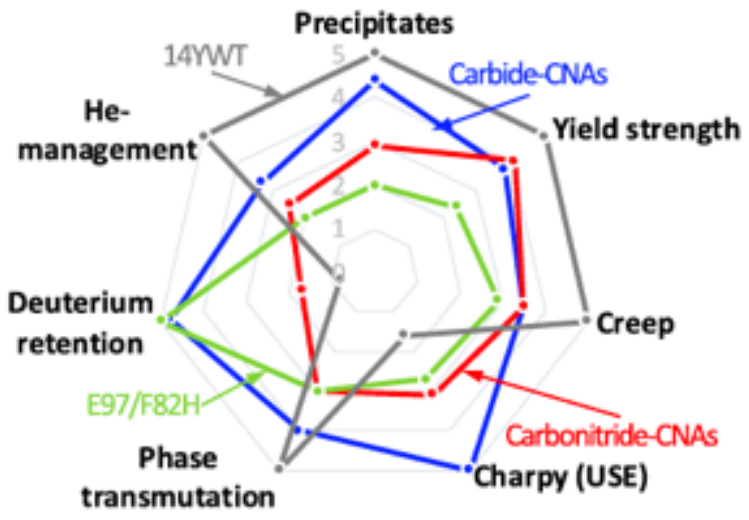

Figure 2. Seven-aspect performance comparison of carbide- and carbonitride-CNAs with Eurofer 97 (E97), F28H, and ODS 14YWT. [After L. Tan, T. Graening, X. Hu, W. Zhong, Y. Yang, S.J. Zinkle, Y. Katoh, Effects of carbonitrides and carbides on microstructure and properties of castable nanostructured alloys, Journal of Nuclear Materials 540 (2020) 152376.] 


\section{FUTURE PLANS}

The systematic survey has led us to select carbide-CNAs for the further developmental direction. One carbide-CNA composition has been selected for scale-up studies. Larger heats of this alloy will be produced by vacuum induction melting and electroslag remelting (VIM+ESR). 


\subsection{EFFECT OF CARBON CONTENT ON CARBIDE-VERSION CASTABLE NANOSTRUCTURED ALLOYS}

\section{L.Tan(tanl@,ornl.gov), Y. Yang}

\section{OBJECTIVE}

The preliminary systematic performance comparison showed the advantages of carbide-CNAs (Castable Nanostructured Alloys) over carbonitride-CNAs. To further improve carbide-CNAs, one direction is to refine the alloying composition. Carbon is a critical element in the alloy to stabilize the austenite phase over a larger temperature range and to determine the amount of carbides formed. This work focused on understanding the effects of carbon content on carbide-CNAs.

\section{SUMMARY}

Because of the high coarsening rate of Cr-rich $\mathrm{M}_{23} \mathrm{C}_{6}$, minimizing the $\mathrm{M}_{23} \mathrm{C}_{6}$ amount while maintaining a high density of $\mathrm{MC}(\mathrm{M}=\mathrm{Ti} / \mathrm{Ta} / \mathrm{W} / \mathrm{etc}$.) is hypothesized to provide better mechanical properties to ferriticmartensitic steels, including CNAs. Two heats of CNAs, called CNA8 and CNA9, were designed and fabricated to test the hypothesis. CNA8 has maximized $\mathrm{MC}$ amount with reduced $\mathrm{M}_{23} \mathrm{C}_{6}$ amount (only half compared to Eurofer97/F82H). In contrast, CNA9, with a lower content of carbon, has a comparable amount of $\mathrm{MC}$ but nearly two orders of magnitude lower content of $\mathrm{M}_{23} \mathrm{C}_{6}$ compared to CNA8. Tensile tests indicate that the low-C CNA9 may have slightly higher strength but noticeably lower elongation at higher temperatures than CNA8. Charpy impact tests showed higher upper-self energy (USE) with higher ductilebrittle transition temperature (DBTT) for the low-C CNA9 compared to CNA8.

\section{PROGRESS AND STATUS}

Following the previously designed carbide-CNAs with base composition Fe-9Cr-1W, CNA8 was designed to have a maximum mole fraction of $\mathrm{MC}$ at tempering temperature $750^{\circ} \mathrm{C}$ without forming this precipitate phase in $\delta$-ferrite. Figure 3 shows the calculated temperature-dependent phase mole fractions with the solid lines denoting the phases in CNA8. Other than $\mathrm{MC}$, the $\mathrm{M}_{23} \mathrm{C}_{6}$ amount is $\sim 50 \%$ reduced in CNA8 compared with that in Eurofer97/F82H. With CNA8 as a reference, the carbon content is further reduced in CNA9, denoted with dashed lines for the phases in Figure 3. The reduced carbon tried to keep the MC amount in CNA9 ( $\sim 0.45$ mole\%) comparable to that in CNA8 $\left(\sim 0.48\right.$ mole\%), but significantly lower $\mathrm{M}_{23} \mathrm{C}_{6}$ amount in CNA9 $(<0.1 \mathrm{~mole} \%)$ than in CNA8 $(\sim 1.05 \mathrm{~mole} \%)$. The reduced carbon also decreased the austenite temperature range in CNA9. Laboratory heats of CNA8 and CNA9 were arc melted into large buttons and then drop cast into $25.4 \times 25.4 \times 152 \mathrm{~mm}$. The CNA8 heat was annealed at $1150^{\circ} \mathrm{C}$ for $1 \mathrm{~h}$ and hot-rolled into a $6.3-\mathrm{mm}$ thick plate. The plate was finally normalized at $1150^{\circ} \mathrm{C}$ for $15 \mathrm{~min}$ with water quenching and tempered at $750^{\circ} \mathrm{C}$ for $30 \mathrm{~min}$ with air cooling. The processing and heat treatment of the CNA9 heat was much the same as the CNA8 heat, except for the use of $1100^{\circ} \mathrm{C}$ in CNA9 for the high temperature heat treatment.

Tensile tests using type SS-3 miniature specimens were conducted for the two heats, with the temperaturedependent strength and elongation shown in Figure 4a. The low-C CNA9 seems to have comparable or lower strength at lower temperatures but slightly higher strength at higher temperatures than CNA8. Unlike the small differences in strength, the low-C CNA9 tends to have lower elongation than CNA8, especially at higher temperatures. Half-size Charpy V-notch impact specimens in the T-L (transverse-longitudinal) orientation were tested to determine USE and DBTT of the two alloys. The data, together with the fitting curves in Figure $4 \boldsymbol{b}$, indicate that the low-C CNA9 has higher USE $(\sim 46.7 \mathrm{~J})$ but higher DBTT $\left(-35^{\circ} \mathrm{C}\right)$ than that of CNA8 $\left(\sim 42.1 \mathrm{~J}\right.$ and $\left.-73^{\circ} \mathrm{C}\right)$. 


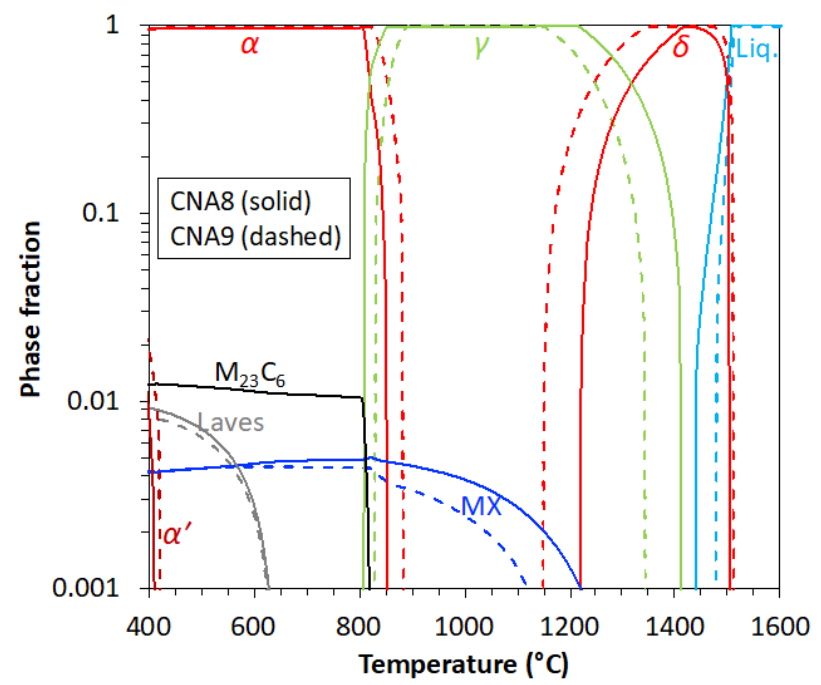

Figure 3. Calculated temperature-dependent phase mole fraction in CNA8 and CNA9.
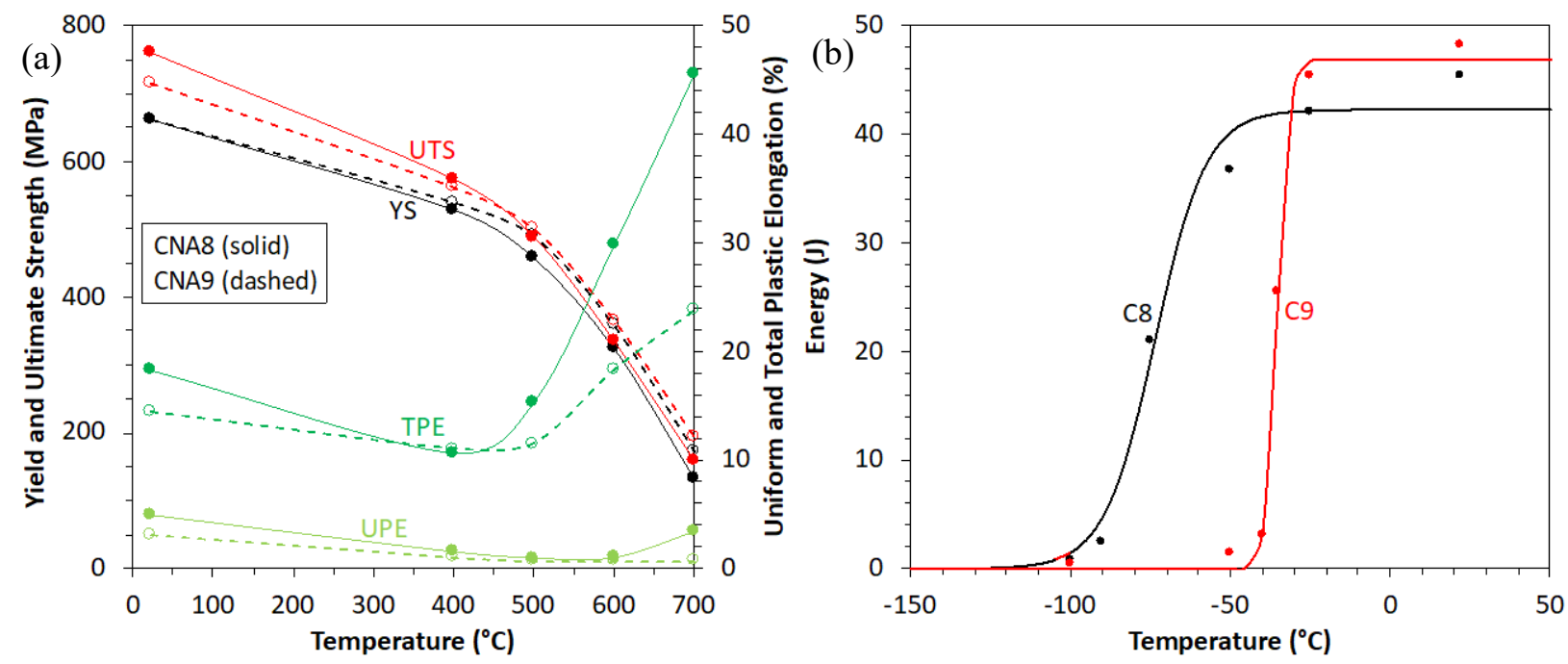

Figure 4. (a) Temperature-dependent yield and ultimate strength and uniform and total plastic elongation of CNA8 and CNA9. (b) Temperature-dependent Charpy impact absorbed energies of CNA8 (C8) and CNA9 (C9).

\section{FUTURE PLANS}

Microstructural characterization of the two alloys is in progress. Creep tests are scheduled for the two alloys. 


\subsection{EFFECTS OF NEUTRON IRRADIATION ON FRACTURE TOUGHNESS OF STANDARD AND Ni-DOPED F82H}

X. Chen (chenx2@ornl.gov), M. A. Sokolov, J. Robertson, J.W. Geringer, Y. Katoh (ORNL); M. Ando, H. Tanigawa (QST, Japan)

\section{OBJECTIVE}

This task aims to study the effects of irradiation temperature, dose, materials composition, Ni doping, and He production on fracture toughness of F82H irradiated in HFIR.

\section{SUMMARY}

Our results showed that irradiation embrittlement monotonically decreased with increasing irradiation temperature up to $400^{\circ} \mathrm{C}$ for $\mathrm{F} 82 \mathrm{H}$ IEA and $\mathrm{F} 82 \mathrm{H} \mathrm{Mod} 3$. F82H Mod3 showed better fracture toughness than F82H IEA both before and after neutron irradiation. We determined that $1.4 \% \mathrm{Ni}$ alloying can be used in $\mathrm{F} 82 \mathrm{H}$ for simulating the effects of $\mathrm{He}$ produced in a fusion reactor without jeopardizing the fracture toughness of the material. However, more studies are needed to fully understand the effects of high dose ( $>20 \mathrm{dpa}$ ) and high He production on F82H fracture toughness.

\section{PROGRESS AND STATUS}

F82H is the Japanese reference reduced-activation ferritic-martensitic (RAFM) steel for fusion blanket applications. The harsh environment of a fusion reactor, including neutron irradiation producing dpa, $\mathrm{He}$ and $\mathrm{H}$, can result in significant degradation of $\mathrm{F} 82 \mathrm{H}$ fracture toughness. Therefore, understanding the fracture toughness behavior of $\mathrm{F} 82 \mathrm{H}$ in the fusion environment is critical to ensuring the long-term safe operation of the fusion reactor. Recently, a paper has been published in the Journal of Nuclear Materials [1], summarizing seven irradiation campaigns (Figure 5) using the High Flux Isotope Reactor (HFIR) at ORNL containing five variants of F82H steels, including F82H IEA, F82H Mod3, F82H doped with 1.4\% natural $\mathrm{Ni}, \mathrm{F} 82 \mathrm{H}$ doped with $1.4 \%{ }^{58} \mathrm{Ni}$, and $\mathrm{F} 82 \mathrm{H}$ doped with $1.4 \%{ }^{60} \mathrm{Ni}$. The irradiation temperatures covered the range 220 to $530{ }^{\circ} \mathrm{C}$ and the neutron irradiation dose spanned 4 to $70 \mathrm{dpa}$. The effects of neutron irradiation temperature, dose, materials composition, $\mathrm{Ni}$ doping, and He production on $\mathrm{F} 82 \mathrm{H}$ fracture toughness are discussed. Figure 6 shows one example of the complicated effects of irradiation and material variables on irradiation embrittlement, seen in comparing the Master Curve reference temperatures $\mathrm{T}_{0 \mathrm{q}}$ for the several alloys in the HFIR JP 27, 28 and 29 capsules.

The main findings of this study are:

1) The irradiation temperature had a significant effect on irradiation embrittlement of F82H IEA and F82H Mod3. The irradiation embrittlement monotonically decreased with increasing irradiation temperature until the irradiation temperature reached $400{ }^{\circ} \mathrm{C}$.

2) Higher dose resulted in more embrittlement in F82H IEA, which did not saturate up to 20 dpa. More studies are needed to find if there is a saturation effect of the irradiation dose on F82 $\mathrm{H}$ embrittlement.

3) F82H Mod3 showed better fracture toughness than F82H IEA both before and after neutron irradiation.

4) $1.4 \% \mathrm{Ni}$ alloying can be used for $\mathrm{F} 82 \mathrm{H}$ irradiation in a fission reactor to simulate the He effects in a fusion reactor. We did not observe any detrimental effect of $1.4 \%{ }^{60} \mathrm{Ni}$ alloying on $\mathrm{F} 82 \mathrm{H}$ fracture toughness, either before or after neutron irradiation. 
5) Compared with F82H IEA, we observed significantly more embrittlement in F82H+1.4\% ${ }^{58} \mathrm{Ni}$ irradiated at $300{ }^{\circ} \mathrm{C}-342{ }^{\circ} \mathrm{C}$ to 70 dpa corresponding to $\sim 770 \mathrm{appm}$ He production. However, our current data are not sufficient to accurately define the threshold He content for additional embrittlement. In addition, we cannot exclude the possibility that irradiation temperatures also play a role in determining such threshold value.

RB11J and RB12J

$\begin{array}{llllllllll}1996 & 1998 & 2000 & 2002 & 2004 & 2006 & 2008 & 2010 & 2012 & 2014\end{array}$

JP25

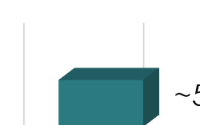

\section{-5 max dpa, 300 and $500^{\circ} \mathrm{C}$}

$\sim 20$ max dpa, 300 and $500^{\circ} \mathrm{C}$

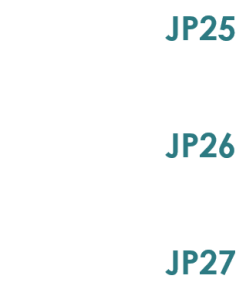

JP28 and JP29
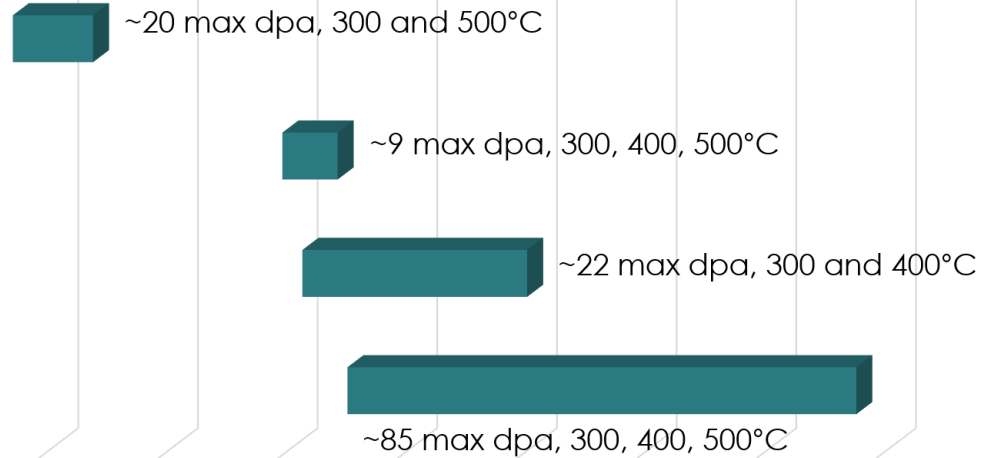

Figure 5. Timeline and target irradiation conditions for F82H irradiation experiments in HFIR [1]. 


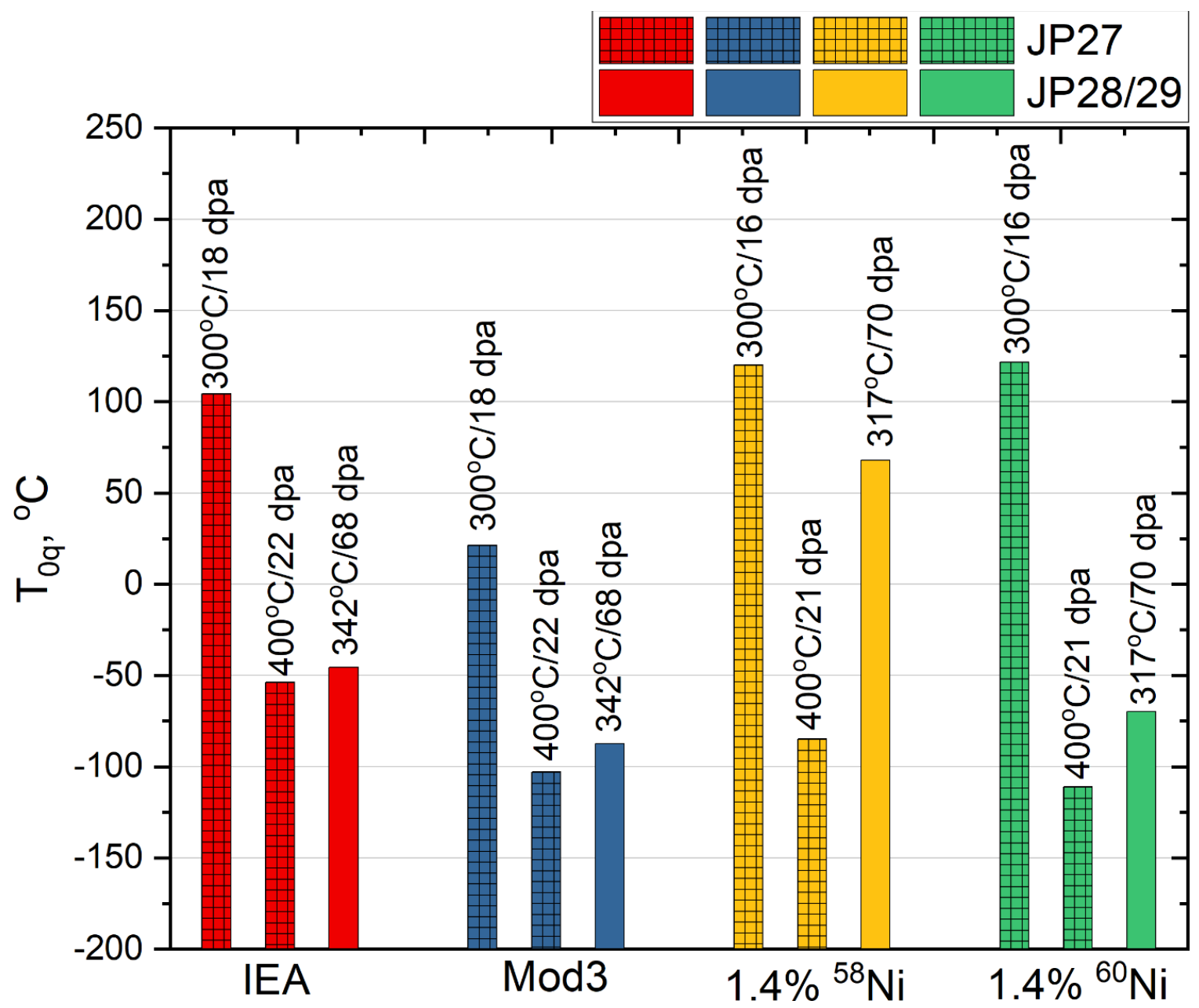

Figure 6. Comparison of the Master Curve reference temperature $\mathrm{T}_{0 \mathrm{q}}$ between JP27 and JP28/29 for F82H IEA, F82H Mod3, F82H+1.4\% ${ }^{58} \mathrm{Ni}$, and F82H+1.4\% ${ }^{60} \mathrm{Ni}$

\section{REFERENCES}

[1] X. Chen et al., "Effects of HFIR Neutron Irradiation on Fracture Toughness Properties of Standard and Ni-doped F82H”, Journal of Nuclear Materials, Volume 542, 15 December 2020, 152501. 


\subsection{TENSILE PROPERTIES OF HFIR IRRADIATED EUROFUSION PROJECT ALLOYS}

Arunodaya Bhattacharya (bhattacharya@ornl.gov), Xiang Chen, Jordan Reed, Tim Graening, Josina W. Geringer, Yutai Katoh (ORNL), Michael Rieth (KIT)

\section{OBJECTIVE}

Ten variants of Eurofer97 steels (denoted H, I, P, J, K, L, M, N, O, and reference E) were neutron irradiated in HFIR to ITER relevant conditions of $2.5 \mathrm{dpa}, 300^{\circ} \mathrm{C}$, for the EUROfusion program. These steels were produced using non-standard metallurgical heat treatments and minor alloying chemistry variations, targeting improvements in low-temperature hardening/embrittlement (LTHE) and high temperature strength of Eurofer97. We evaluated the neutron irradiation induced changes in the mechanical properties of the EUROfusion alloys.

\section{SUMMARY}

Vickers micro-hardness test data on the irradiated EUROfusion alloys were reported last year. Here, we report the results of uniaxial tensile tests performed at room temperature and irradiation temperature $\left(300^{\circ} \mathrm{C}\right)$, including the reduction of area (RA) estimated using SEM fracture surface analysis. All the steels showed hardening due to neutron irradiation, reflected in the increase in yield stress (YS) and ultimate tensile stress (UTS). The YS and UTS increase were accompanied by decrease in the elongation values and significant loss of local ductility reflected as a decrease of RA.

\section{PROGRESS AND STATUS}

A summary of the materials and their production routes are provided in Table 1. 
Table 1. Variants of Eurofer97 steels in these experiments

\begin{tabular}{|c|c|c|c|c|}
\hline M-Code & Material type & Heat & Condition & Provider \\
\hline $\mathrm{E}$ & EUROFER97/2 & 993391 & $980^{\circ} \mathrm{C} / 0.5 \mathrm{~h}+\mathrm{AQ}+760^{\circ} \mathrm{C}+\mathrm{AC}$ & KIT \\
\hline $\mathrm{H}$ & EUROFER-LT & J362A & $1000^{\circ} \mathrm{C} / 0.5 \mathrm{~h}+\mathrm{WQ}+820^{\circ} \mathrm{C}+\mathrm{AC}$ & KIT \\
\hline I & EUROFER-LT & J363A & $1000^{\circ} \mathrm{C} / 0.5 \mathrm{~h}+\mathrm{WQ}+820^{\circ} \mathrm{C}+\mathrm{AC}$ & KIT \\
\hline $\mathrm{P}$ & EUROFER-LT & J361A & $1000^{\circ} \mathrm{C} / 0.5 \mathrm{~h}+\mathrm{WQ}+820^{\circ} \mathrm{C}+\mathrm{AC}$ & KIT \\
\hline $\mathrm{L}$ & EUROFER97/2 & 994578 & $1150^{\circ} \mathrm{C} / 0.5 \mathrm{~h}+\mathrm{AQ}+700^{\circ} \mathrm{C}+\mathrm{AC}$ & CEA \\
\hline \multirow[t]{2}{*}{$\mathrm{J}$} & \multirow[t]{2}{*}{ EUROFER-LT } & \multirow[t]{2}{*}{ I196C } & $\begin{array}{l}\text { TMT: } 1250^{\circ} \mathrm{C} / 1 \mathrm{~h} \text { and then rolling to a } \\
\text { final rolling temperature of } 850^{\circ} \mathrm{C} \text { in } 6 \\
\text { rolling steps with a reduction of } 20-30 \% \\
\text { for each rolling pass, then } \mathrm{AC} \text {. }\end{array}$ & \multirow[t]{2}{*}{ SCK.CEN } \\
\hline & & & Q\&T: $880^{\circ} \mathrm{C} / 0.5 \mathrm{~h}+\mathrm{WQ}+750^{\circ} \mathrm{C} / 2 \mathrm{~h}+\mathrm{AC}$ & \\
\hline \multirow[t]{2}{*}{$\mathrm{K}$} & \multirow[t]{2}{*}{ EUROFER-HT } & \multirow[t]{2}{*}{ I427A } & $\begin{array}{l}\mathrm{TMT}: 1250^{\circ} \mathrm{C} / 1 \mathrm{~h} \text { and then rolling to a } \\
\text { final rolling temperature of } 850^{\circ} \mathrm{C} \text { in } 6 \\
\text { rolling steps with a reduction of } 20-30 \% \\
\text { for each rolling pass, then } \mathrm{AC} \text {. }\end{array}$ & \multirow[t]{2}{*}{ SCK.CEN } \\
\hline & & & $\begin{array}{l}\text { Q\&T: } 1050^{\circ} \mathrm{C} / 15 \min +\mathrm{WQ}+ \\
675^{\circ} \mathrm{C} / 1.5 \mathrm{~h}+\mathrm{AC}\end{array}$ & \\
\hline $\mathrm{M}$ & EUROFER97/2 & 993391 & $\begin{array}{l}1020^{\circ} \mathrm{C} / 0.5 \mathrm{~h}+\mathrm{AQ}+1020^{\circ} \mathrm{C} / 0.5 \mathrm{~h}+\mathrm{AQ} \\
+760^{\circ} \mathrm{C} / 1.5 \mathrm{~h}+\mathrm{AC} \quad \text { (double } \\
\text { austenitization) }\end{array}$ & ENEA \\
\hline \multirow[t]{2}{*}{$\mathrm{O}$} & \multirow[t]{2}{*}{ EUROFER-LT } & \multirow[t]{2}{*}{ VM2991 } & $\begin{array}{l}\text { TMT: } 1080^{\circ} \mathrm{C} / 1 \mathrm{~h} \text {, cooling to } 650^{\circ} \mathrm{C} \text { and } \\
\text { rolling, reduction } 40 \% \text { (from } 30 \mathrm{~mm} \text { to } \\
18 \mathrm{~mm} \text { ) }\end{array}$ & \multirow[t]{2}{*}{ ENEA } \\
\hline & & & Tempering: $760^{\circ} \mathrm{C} / 1 \mathrm{~h}+\mathrm{AC}$ & \\
\hline $\mathrm{N}$ & EUROFER-LT & VM2897 & $\begin{array}{l}920^{\circ} \mathrm{C} / 1.5 \mathrm{~h}+\mathrm{AQ}+920^{\circ} \mathrm{C} / 1.5 \mathrm{~h}+\mathrm{AQ}+ \\
760^{\circ} \mathrm{C} / 1 \mathrm{~h}+\mathrm{AC} \text { (double austenitization) }\end{array}$ & ENEA \\
\hline
\end{tabular}

Uniaxial tensile tests of the irradiated specimens were performed at room temperature and $300^{\circ} \mathrm{C}$ in the IMET hot cells. Following the tensile tests, the data were analyzed in detail, including accounting for effects of machine compliance in the stress-strain curves to determine the elongation values from the test machine crosshead motion due to the lack of an extensometer. All the steels showed irradiation hardening, reflected as an increase in the YS and UTS (Figure 7). This was accompanied by a reduction in uniform elongation (UE) and total elongation (TE), Figure 8. The increase in YS varied among the different steels, ranging from as low as $\sim 13 \%$ to values greater than $60 \%$. Highest increase in room temperature YS was shown by the P series steel from KIT, at nearly $66 \%$. The harder L series steel showed the least increase in YS, at $\sim 13.4 \%$. The reference E series steel showed $\sim 65 \%$ increase in the room temperature YS. Most of the steels 
showed lower tensile ductility for tests conducted at $300^{\circ} \mathrm{C}$ compared to tests at RT in both unirradiated and irradiated conditions, which is expected for 9\% Cr FM steels due to dynamic strain ageing.
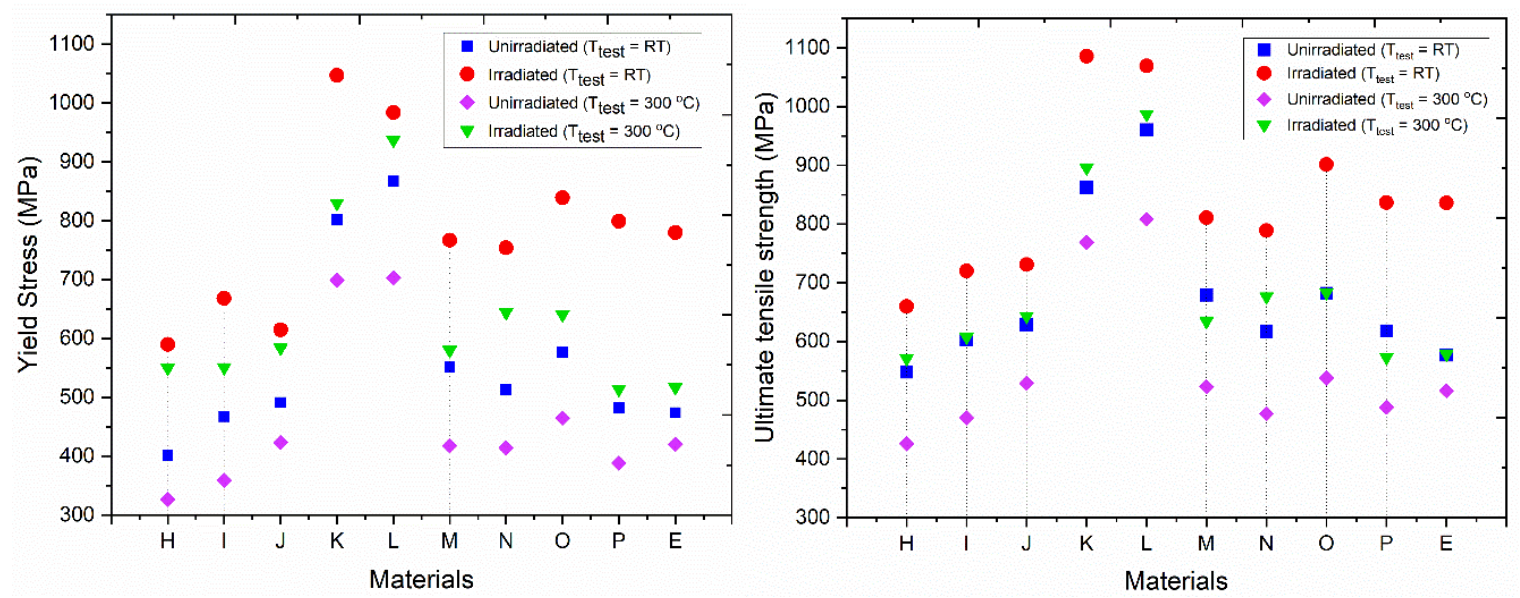

Figure 7. Comparison of the YS and UTS of irradiated Eurofusion steels. HFIR samples irradiated to $2.5 \mathrm{dpa}$ at a nominal $300^{\circ} \mathrm{C}$.
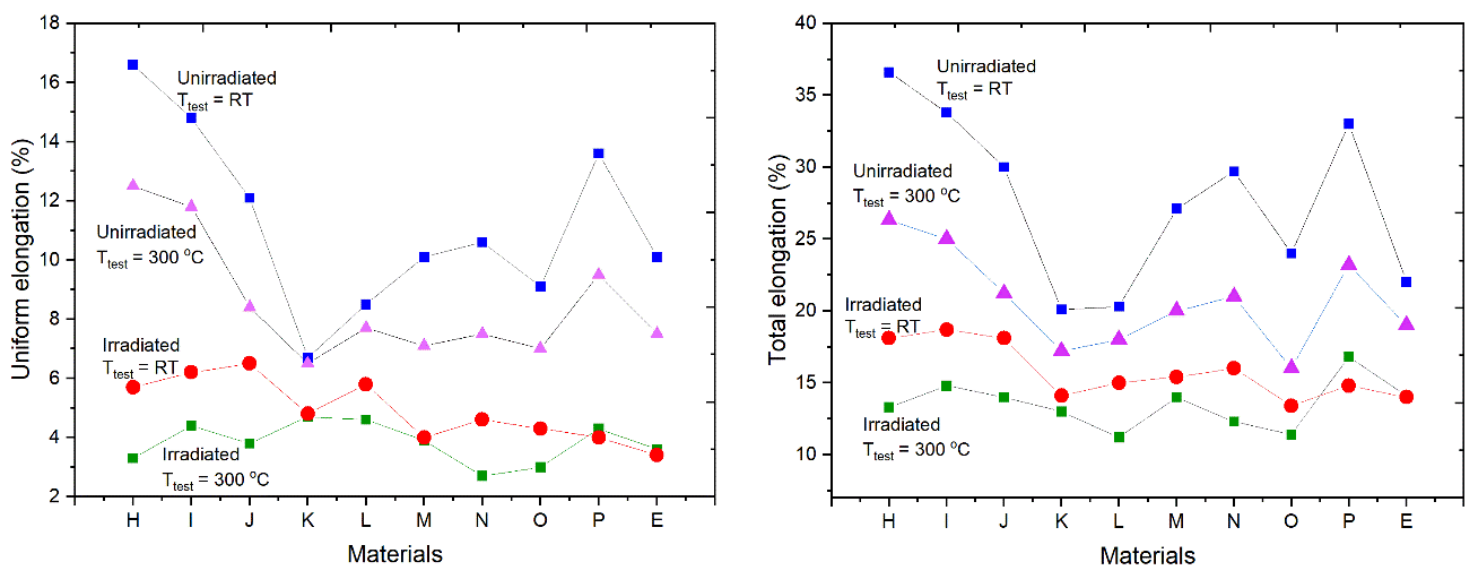

Figure 8. A comparison of the UE and TE of the ten Eurofusion steels. HFIR samples irradiated to 2.5 dpa at a nominal $300^{\circ} \mathrm{C}$.

Reduction in area (RA) after the room temperature tensile tests was calculated using SEM imaging of the fracture surface. Figure 9 compares RA for the ten steels in control and irradiated condition. All the steels showed reduced RA resulting from the neutron irradiation. The percentage change in RA due to the irradiation was highest for the harder L series steels. Least change in RA was measured for the reference E series steel. 


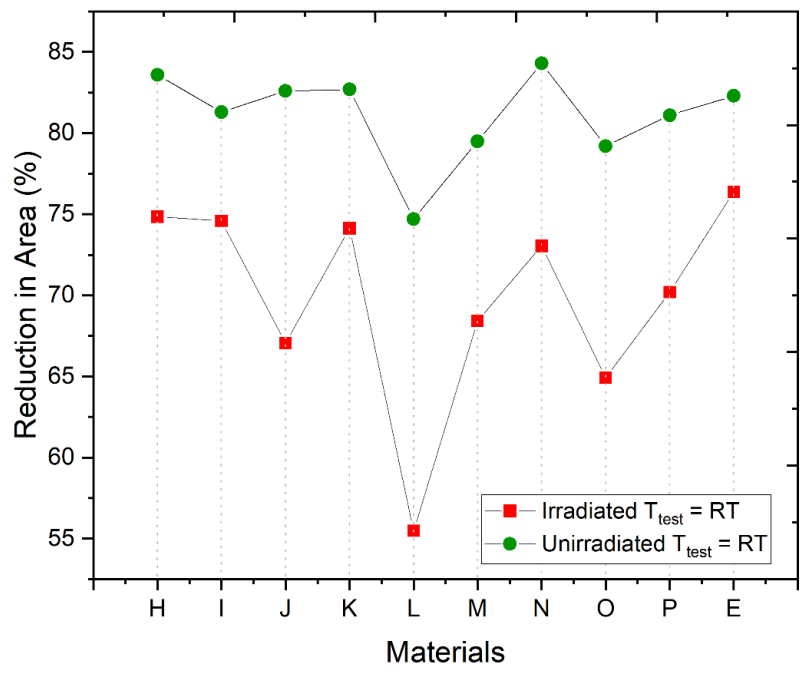

Figure 9. A comparison of RA for the ten EUROfusion steels in unirradiated and irradiated condition, after tensile tests at room temperature. 


\subsection{MICROSTRUCTURE CHARACTERIZATION OF EUROFUSION ALLOYS AND CORRELATION WITH IRRADIATION-INDUCED HARDENING}

Arunodaya Bhattacharya (bhattacharya@ornl.gov), Xiang Chen, Tim Graening, Josina W. Geringer, Yutai Katoh (ORNL), Michael Rieth (KIT)

\section{OBJECTIVE}

Ten variants of Eurofer97 steels (denoted H, I, P, J, K, L, M, N, O, and reference E) were neutron irradiated in HFIR to $2.5 \mathrm{dpa}, 300^{\circ} \mathrm{C}$, for the EUROfusion program. The objective here was to characterize the irradiation induced defect microstructures such as the dislocation loops of the ten Eurofusion steels and link the microstructure findings to irradiation induced hardening.

\section{SUMMARY}

The irradiation induced defect clusters, including dislocation loops, were characterized in the Eurofusion alloys. Most alloys showed a mixed population of $\mathrm{a}<100>$ and $\mathrm{a} / 2<111>$ type dislocation loops. No significant changes in the precipitates (mainly $\mathrm{M}_{23} \mathrm{C}_{6}$ carbides) due to irradiation were noted by TEM. By combining the dislocation loop data and measured tensile properties in a dispersed barrier hardening (DBH) model, we further confirm that the DBH models largely underpredict irradiation hardening in RAFM steels. The results necessitate atom probe tomography (APT) examination that may reveal solute nanoclustering features that might contribute to the extra hardening currently unaccounted for by the DBH model using the TEM data.

\section{PROGRESS AND STATUS.}

A summary of the materials and their production routes is given in Table 2 . 
Table 2. Variants of Eurofer97 steels in these experiments

\begin{tabular}{|c|c|c|c|c|}
\hline $\begin{array}{l}\text { M- } \\
\text { Code }\end{array}$ & Material type & Heat & Condition & Provider \\
\hline $\mathrm{E}$ & EUROFER97/2 & 993391 & $980^{\circ} \mathrm{C} / 0.5 \mathrm{~h}+\mathrm{AQ}+760^{\circ} \mathrm{C}+\mathrm{AC}$ & KIT \\
\hline $\mathrm{H}$ & EUROFER-LT & J362A & $1000^{\circ} \mathrm{C} / 0.5 \mathrm{~h}+\mathrm{WQ}+820^{\circ} \mathrm{C}+\mathrm{AC}$ & KIT \\
\hline I & EUROFER-LT & $\mathrm{J} 363 \mathrm{~A}$ & $1000^{\circ} \mathrm{C} / 0.5 \mathrm{~h}+\mathrm{WQ}+820^{\circ} \mathrm{C}+\mathrm{AC}$ & KIT \\
\hline $\mathrm{P}$ & EUROFER-LT & $\mathrm{J} 361 \mathrm{~A}$ & $1000^{\circ} \mathrm{C} / 0.5 \mathrm{~h}+\mathrm{WQ}+820^{\circ} \mathrm{C}+\mathrm{AC}$ & KIT \\
\hline $\mathrm{L}$ & EUROFER97/2 & 994578 & $1150^{\circ} \mathrm{C} / 0.5 \mathrm{~h}+\mathrm{AQ}+700^{\circ} \mathrm{C}+\mathrm{AC}$ & CEA \\
\hline \multirow[t]{2}{*}{$\mathrm{J}$} & \multirow[t]{2}{*}{ EUROFER-LT } & \multirow[t]{2}{*}{ I196C } & $\begin{array}{l}\mathrm{TMT}: 1250^{\circ} \mathrm{C} / 1 \mathrm{~h} \text { and then rolling to a } \\
\text { final rolling temperature of } 850^{\circ} \mathrm{C} \text { in } 6 \\
\text { rolling steps with a reduction of } 20- \\
30 \% \text { for each rolling pass, then } \mathrm{AC} \text {. }\end{array}$ & \multirow[t]{2}{*}{ SCK.CEN } \\
\hline & & & Q\&T: $880^{\circ} \mathrm{C} / 0.5 \mathrm{~h}+\mathrm{WQ}+750^{\circ} \mathrm{C} / 2 \mathrm{~h}+\mathrm{AC}$ & \\
\hline \multirow[t]{2}{*}{ K } & \multirow[t]{2}{*}{ EUROFER-HT } & \multirow[t]{2}{*}{ I427A } & $\begin{array}{l}\mathrm{TMT}: 1250^{\circ} \mathrm{C} / 1 \mathrm{~h} \text { and then rolling to a } \\
\text { final rolling temperature of } 850^{\circ} \mathrm{C} \text { in } 6 \\
\text { rolling steps with a reduction of } 20- \\
30 \% \text { for each rolling pass, then } \mathrm{AC} \text {. }\end{array}$ & \multirow[t]{2}{*}{ SCK.CEN } \\
\hline & & & $\begin{array}{c}\text { Q\&T: } 1050^{\circ} \mathrm{C} / 15 \min +\mathrm{WQ}+ \\
675^{\circ} \mathrm{C} / 1.5 \mathrm{~h}+\mathrm{AC}\end{array}$ & \\
\hline $\mathrm{M}$ & EUROFER97/2 & 993391 & $\begin{array}{c}1020^{\circ} \mathrm{C} / 0.5 \mathrm{~h}+\mathrm{AQ}+1020^{\circ} \mathrm{C} / 0.5 \mathrm{~h}+ \\
\mathrm{AQ}+760^{\circ} \mathrm{C} / 1.5 \mathrm{~h}+\mathrm{AC}(\text { double } \\
\text { austenitization) }\end{array}$ & ENEA \\
\hline \multirow[t]{2}{*}{$\mathrm{O}$} & \multirow[t]{2}{*}{ EUROFER-LT } & \multirow[t]{2}{*}{ VM2991 } & $\begin{array}{l}\text { TMT: } 1080^{\circ} \mathrm{C} / 1 \mathrm{~h} \text {, cooling to } 650^{\circ} \mathrm{C} \text { and } \\
\text { rolling, reduction } 40 \% \text { (from } 30 \mathrm{~mm} \text { to } \\
18 \mathrm{~mm} \text { ) }\end{array}$ & \multirow[t]{2}{*}{ ENEA } \\
\hline & & & Tempering: $760^{\circ} \mathrm{C} / 1 \mathrm{~h}+\mathrm{AC}$ & \\
\hline $\mathrm{N}$ & EUROFER-LT & VM2897 & $\begin{array}{l}920^{\circ} \mathrm{C} / 1.5 \mathrm{~h}+\mathrm{AQ}+920^{\circ} \mathrm{C} / 1.5 \mathrm{~h}+\mathrm{AQ}+ \\
760^{\circ} \mathrm{C} / 1 \mathrm{~h}+\mathrm{AC} \text { (double austenitization) }\end{array}$ & ENEA \\
\hline
\end{tabular}

Irradiation induced dislocation loops were detected by TEM examination of all the Eurofusion alloys. All the loops are expected to be interstitial type. The microstructure consisted of both types of loops typically seen in bcc Fe base alloys: loops with Burgers vector $a<100>$ and $a / 2<111>$. Figure 10 shows the typical loop microstructures observed in all Eurofusion alloys. Most loops were $>5 \mathrm{~nm}$, and up to $\sim 50 \mathrm{~nm}$ in diameter for all the materials. In Figure 10, the loops indicated by red arrows that are in edge-on configurations were the $a<100>$ type loops imaged along the [001] type zone axis. 

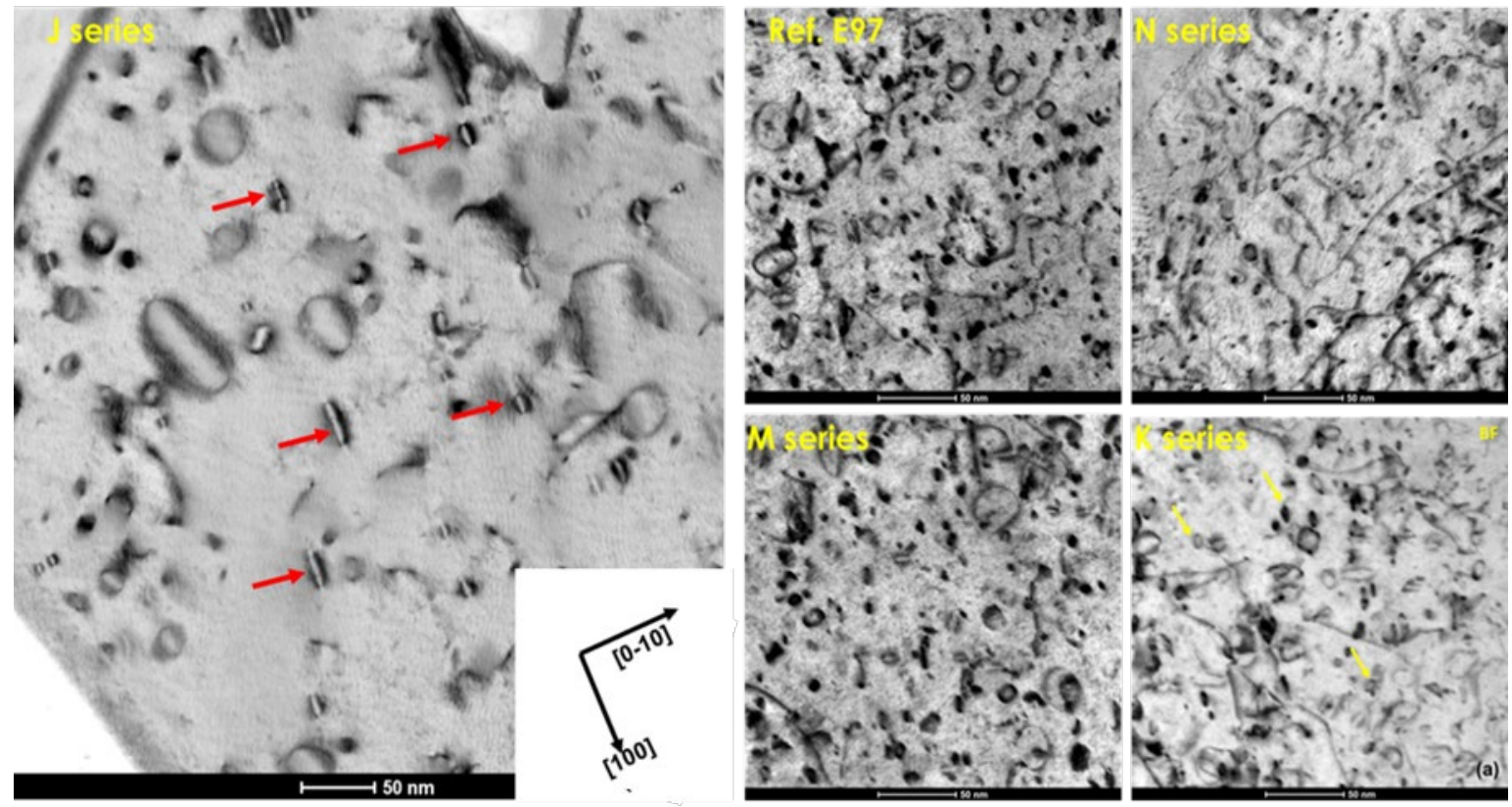

Figure 10. Dislocation loops in the Eurofusion alloys. Red arrows indicate the on-edge a $<100>$ type loops, imaged using $<110>$ type diffraction vector close to [001] zone axis.

The nanoprecipitates such as the $\mathrm{M}_{23} \mathrm{C}_{6}$ carbides remained largely unaffected by the irradiation, with no evidence of amorphization, size changes or agglomeration detectable by conventional TEM imaging (see Figure 11). This is expected for the modest neutron dose of $2.5 \mathrm{dpa}$.

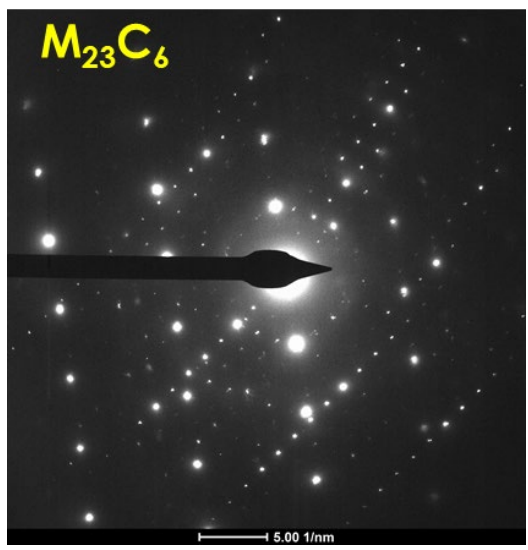

Figure 11. Selected area diffraction pattern from an $M_{23} C_{6}$ carbide in irradiated reference Eurofer97 steel, showing no evidence of amorphization during irradiation.

Following the dislocation loop analysis, the microstructure data was used as input to a dispersed barrier hardening model $(\mathrm{DBH})$. According to the $\mathrm{DBH}$ model proposed by Seeger, the change in strength is given by the relation

$$
\Delta \sigma=\operatorname{M\alpha \mu b}(\mathbf{N d})^{1 / 2}
$$

where, $\mathrm{M}$ is the Taylor factor, $\alpha$ is the defect cluster barrier strength, $\mu$ is the shear modulus, $\mathrm{b}$ is the Burgers vector, $\mathrm{N}$ is the defect number density and $\mathrm{d}$ is defect diameter. Using $\alpha$ value of $\sim 0.6$ for the dislocation loops and using the TEM data on defect number density and size, the increase in strength increase due to 
DBH was estimated. The strength increase predicted by DBH and the strength increase values obtained from the tensile tests for these seven different Eurofusion alloys are plotted in Figure 12. This shows that DBH generally underpredicts the experimentally observed irradiation hardening of these RAFM steels.

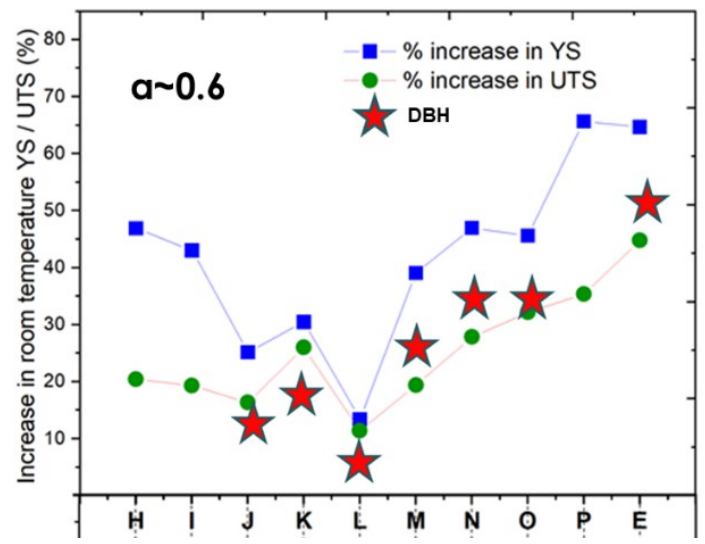

Figure 12. Comparison of experimentally observed strength change to hardening predicted by DBH for the different Eurofer 97 alloys irradiated to 2.5 dpa at $300{ }^{\circ} \mathrm{C}$.

\section{FUTURE RESEARCH:}

It is evident that DBH cannot explain the experimentally observed hardening measured in neutron irradiated Eurofer97 alloys. The next step will be atom probe tomography (APT) examination to search for potential solute nanoclustering features or other changes in the matrix resulting from the irradiation that might explain the additional hardening. 


\subsection{BAINITIC STEEL DEVELOPMENT FOR FUSION APPLICATIONS}

\section{Y.Yamamoto(yamamotoy@ornl.gov)}

\section{OBJECTIVE}

The aim of this work is to develop new bainitic steels, based on $3 \mathrm{Cr}-3 \mathrm{WV}(\mathrm{Ta})$ steels originally developed at ORNL. The goal is mechanical properties of both base metal and weldments superior to those of existing commercial bainitic steels or ferritic-martensitic (F-M) steels, together with no requirement for post-weld heat treatment (PWHT). The target applications of the alloys are high-temperature structural components in fusion reactors such as helium cooled vacuum vessels operating up to $450^{\circ} \mathrm{C}$ and blanket support structures operating up to $550^{\circ} \mathrm{C}$. Improvements of creep performance and room-temperature toughness are targeted via optimization of alloy composition and thermo-mechanical treatment.

\section{SUMMARY}

Property screening of a newly procured large-scale heat of modified 3Cr-3WVTa base bainitic steel (with high $\mathrm{Mn}$ and low $\mathrm{C}$ additions) was initiated. The new heat showed moderate performance in both the creeprupture testing and Charpy impact toughness testing with values comparable or slightly superior to the reference materials (original 3Cr-3WVTa steel or previously evaluated heat). Hardness analysis indicated a potential issue with the tempering process of the new heat plate from which the test specimens were machined; the tempering was accidentally conducted slightly above the Ae1 temperature. The microstructure consisted of over-tempered martensite and a small amount of untampered martensite, which might lead to lower creep resistance and smaller absorbed energies at given temperatures, respectively, than those of properly tempered materials. Optimization of the tempering process is currently in progress to avoid such unexpected property degradation.

\section{PROGRESS AND STATUS}

Evaluation of creep-rupture properties and Charpy impact toughness of a newly procured large-scale heat ( $\sim 80$ lbs., prepared by a commercial VIM) of MLC02T (a high Mn + low C containing steel, in Table 3) was initiated. The cross-weld creep properties of MSL02T at $550^{\circ} \mathrm{C}$ showed only a slight improvement compared to the original 3Cr-3WVTa steel, and unexpectedly lower creep strength than previously prepared MSLC2 heat with similar alloy composition (Figure 13a). The base-metal creep-rupture properties also showed similar trends to the cross-weld properties. The MLC02T heat achieved some improvements of the upper shelf absorbed energy in the Charpy impact testing (Figure 13b), which was possibly due to lower $\mathrm{Si} \mathrm{t}$ in the new heat. However, the ductile-brittle transition temperature did not change significantly compared to MSLC2.

Table 3. Nominal compositions of the steels

\begin{tabular}{llll}
\hline Name & Alloy composition, wt.\% (balanced Fe) & $* \mathrm{~A} 1,{ }^{\circ} \mathrm{C}$ & $* \mathrm{~A} 3,{ }^{\circ} \mathrm{C}$ \\
\hline MLC02T & 3Cr-3W-0.2V-0.16Si-2.0Mn-0.1Ta-0.05C & 737.7 & 854.9 \\
MSLC2 $\dagger$ & 3Cr-3W-0.2V-0.50Si-2.0Mn-0.1Ta-0.05C & 745.1 & 873.8 \\
Original $\dagger$ & 3Cr-3W-0.2V-0.16Si-0.4Mn-0.1Ta-0.1C & 790.6 & 899.7 \\
\hline
\end{tabular}

$\dagger$ reference materials, *calculated by JMatPro v. 9

It was found that an improper heat-treatment was used on the new heat plate from which the test specimens were machined. Figure 14 illustrates the effect of tempering temperature on the hardness of the new and original 3Cr-3WVTa steels. The plotted data were obtained from small-size specimens after tempering at given temperature for $1 \mathrm{~h}$. New MLC02T heat should show $\sim 290 \mathrm{HV}$ after tempering at $700^{\circ} \mathrm{C}$. The 
machined MLC02T specimens, on the other hand, exhibited lower hardness ( $245 \mathrm{HV})$ than the small-size specimen after tempering at "nominally" $700^{\circ} \mathrm{C}$. The results indicated that the tempering of the machined specimens was accidentally conducted at around $740-750^{\circ} \mathrm{C}$, based on the hardness comparison, which was slightly above Ael temperature. If this was the case, the microstructure consisted of a majority of overtempered martensite and a small amount of untempered martensite, which might lead to lower creep deformation resistance and smaller absorbed energies at given temperatures, respectively, compared to properly tempered materials. Optimization of the tempering process targeting lower tempering temperature is currently in progress to avoid the unexpected property degradation observed in the present results.
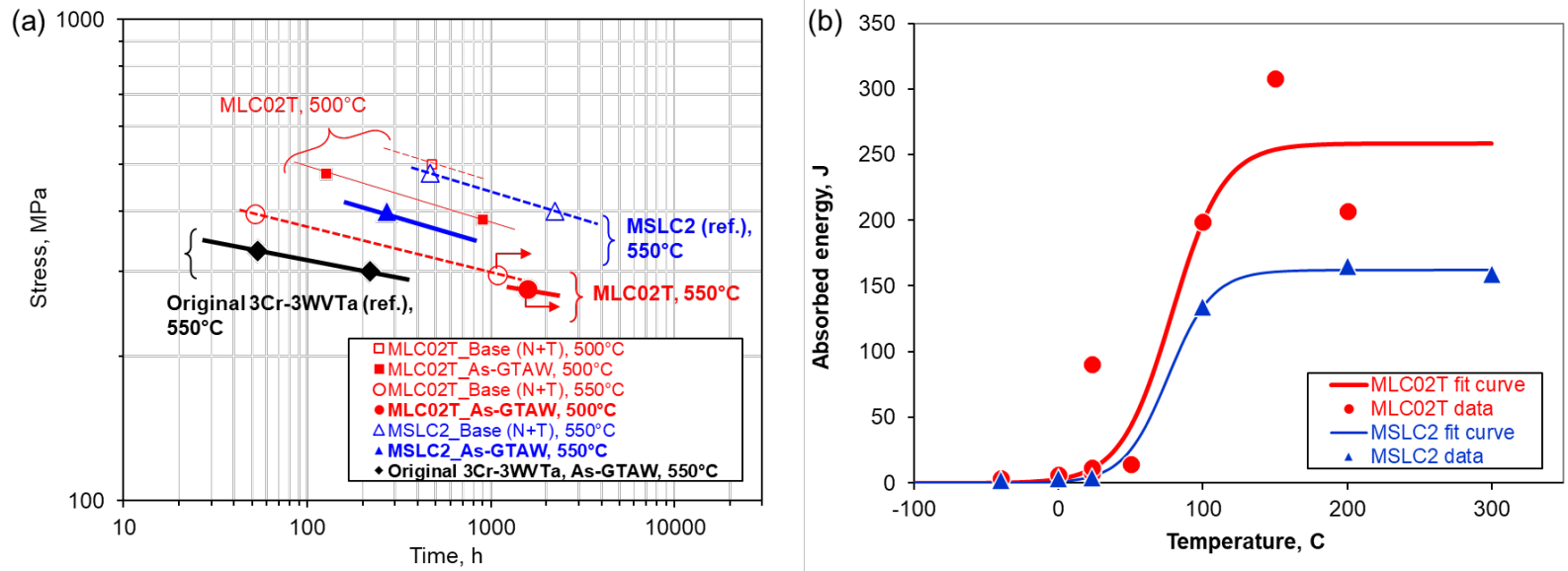

Figure 13. Property screening results of new heats compared to reference materials; (a) creeprupture life plotted as a function of stress, and (b) temperature dependence of Charpy impact absorbed energy.

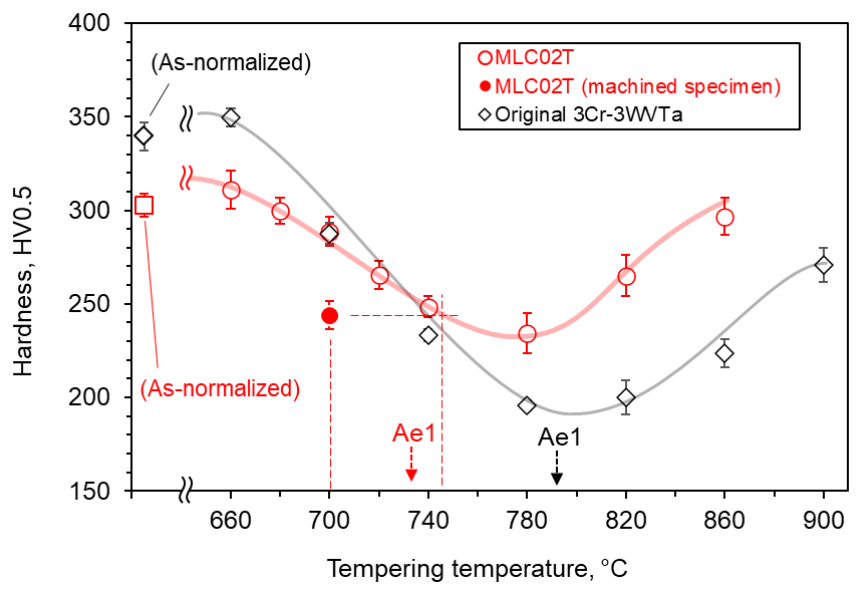

Figure 14. Vickers hardness of normalized-and-tempered original 3Cr-3WVTa and MLC02T plotted as a function of tempering temperature.

\section{FUTURE PLANS}

Tempering temperature effects will be evaluated by measuring DBTT of the new MLC02T heat, using the half-size Charpy specimens. The second iteration of the property evaluation of new MLC02T heat will be conducted using the optimized tempering conditions. 


\subsection{IRRADIATION INDUCED PHASE SEPARATION IN OXIDE DISPERSION STRENGTHENED ALLOYS}

Samara M. Levine, Arunodaya Bhattacharya (hattacharya@ornl.gov), David T. Hoelzer, Steven J. Zinkle, Yutai Katoh (ORNL)

\section{OBJECTIVE}

To understand the effect of neutron irradiation on oxide dispersion strengthened (ODS) alloys for fusion structural applications, Fe-14\% Cr base MA957 and Fe-20\% Cr-55 Al base PM2000 alloys were irradiated to $>60 \mathrm{dpa}$ at $300^{\circ} \mathrm{C}$ in the High Flux Isotope Reactor (HFIR), contained in the HFIR-JP28 and -29 irradiation capsules. The objective of this research is to characterize and understand irradiation induced phase separation and solute nanoclustering in the ODS alloys.

\section{SUMMARY}

High throughput energy dispersive X-ray (EDX) spectroscopy in scanning transmission electron microscopy (STEM) combined with advanced data analysis methods including multivariate statistical analysis (MVSA) revealed irradiation-enhanced phase separation and solute nanoclustering in the ODS alloys. For the PM2000 alloy, irradiation enhanced $\mathrm{Cr}$ rich $\alpha^{\prime}$ phase separation was detected, with precipitates distributed homogeneously throughout the matrix. Further, evidence of (Al, Ti) rich phase was also seen in the PM2000 alloy using MVSA, which is believed to be a $\beta$ ' phase. Extensive Cr rich $\alpha$ ' phase separation was also found in the MA957 alloy, with precipitate sizes $>5 \mathrm{~nm}$ seen in the microstructure. In addition, evidence of a (Ni, Ti) rich phase was also found in MA957. Collectively, the extensive phase separation into $\alpha$ ' phase in both the steels and with the added complexity of other solute clustering induced by irradiation is expected to significantly degrade the steel performance.

\section{PROGRESS AND STATUS}

Fe-Cr base ODS alloys are a promising class of fusion first wall/plasma facing/blanket structural material candidates. In fusion reactor service, ODS alloys will suffer unprecedented neutron irradiation damage ( 150-200 dpa) over a wide irradiation temperature range $\left(\sim 300-700^{\circ} \mathrm{C}\right)$. Stability of the alloy, including resistance of the nanoparticles to neutron damage, irradiation-induced/enhanced phase separation and solute nanoclustering, are critical to maintaining the steel properties. Various ODS alloys were irradiated to high neutron doses in HFIR in the HFIR-JP28 and -29capsules. Alloys PM2000, MA957 and 12YWT were included and reached doses greater than $60 \mathrm{dpa}$ at $\sim 300{ }^{\circ} \mathrm{C}$. We have studied the evolution of the matrix chemistry in an Fe-20\%Cr-5\%A1 PM2000 and Fe-14\% Cr base MA957 alloy using STEM-EDX analysis combined with MVSA.

Figure 15 shows principal component analysis (PCA) end-member analysis of the STEM-EDX data. This treatment shows extensive $\mathrm{Cr}$ rich $\alpha^{\prime}$ phase formation in the $\mathrm{Fe}-\mathrm{Cr}$-Al rich matrix of the PM2000 alloy. The precipitates were developed to an extent that they appeared interconnected. The X-ray spectrum decomposed as a variance fraction plot from the PCA data is shown in Figure 15, where positive peaks contribute to the red regions of the map while negative peaks contribute to the blue areas. Two principal components contributing to the map were $\mathrm{Fe}$ and $\mathrm{Cr}$, with more red regions being represented by $\mathrm{Cr}$ enriched areas and blue represented by Fe rich areas. Given the high $\mathrm{Cr}$ level of this alloy, $\alpha$ ' phase formation was expected. In the same material, MVSA was also performed to reveal other solute nanoclustering features forming under irradiation. PCA end member analysis identified a homogeneous distribution of (Al, Ti) rich phase in the PM2000 alloy. The results are shown in Figure 16 where the positive Al, Ti peaks of the EDX spectra contribute to the endmember maps as red regions. This phase 
appeared to be locally depleted around the large oxide nanoparticles in the alloy. While a final identify of this phase is difficult to obtain without atom probe analysis, it is likely that the phase is $(\mathrm{Fe}, \mathrm{Al}, \mathrm{Ti})$ rich $\beta$ ' phase [1].

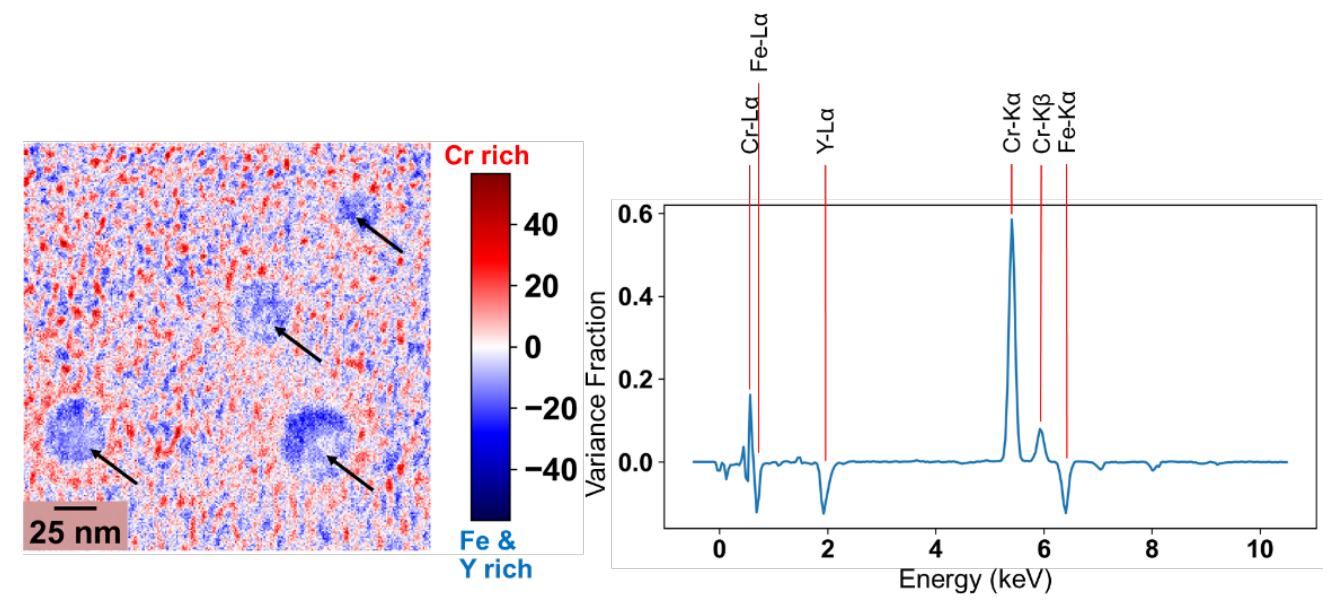

Figure 15. PCA of STEM-EDX data identifying Cr rich $\alpha$ ' phase formation in PM2000 alloy. Arrows point to the large ODS particles in the alloy that appear as $Y$ rich. $Y$ plus Fe rich regions are collectively shown in blue.
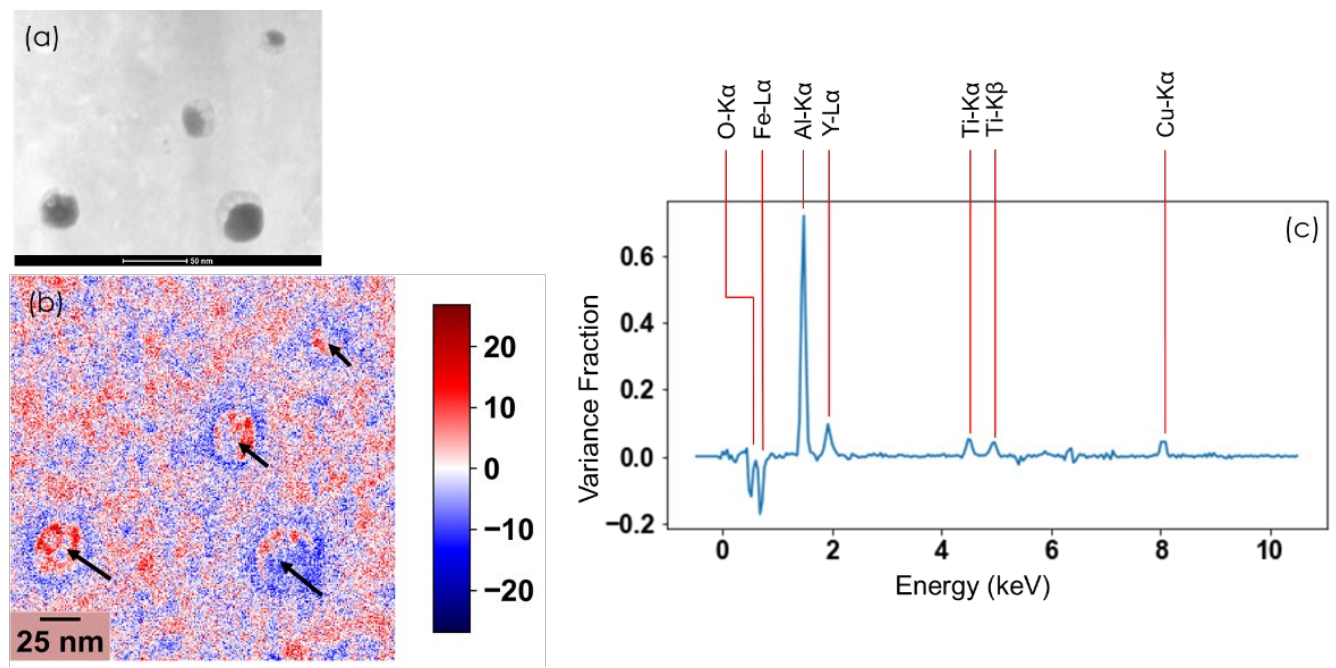

Figure 16. PCA end member analysis revealing (Al, Ti) clustering in PM2000 alloy. (a) HAADF image (b) PCA map showing the Al, Ti rich regions in red. (c) EDX spectrum corresponding to the map where positive peaks contribute to the enriched regions in red. Yttrium peak originates from the large oxide particle. $\mathrm{Cu}$ peak arises from the TEM specimen holder. Arrows point to the large ODS particles.

In the neutron irradiated MA957, similar to the PM2000, extensive $\mathrm{Cr}$ rich embrittling $\alpha$ ' phase formation occurred (Figure 17a). PCA end member analysis was performed to verify that mainly $\mathrm{Cr}$ and $\mathrm{Fe}$ were contained in the $\alpha$ ' phase, with no evidence of other alloying species detected in these precipitates, Figure 18. In addition to $\alpha$ ' phase separation, evidence of $\mathrm{Ni}$ and $\mathrm{Ti}$ rich clusters was detected by STEM-EDX (Figure $17 \boldsymbol{b}$ and $\boldsymbol{c}$ ). PCA analysis revealed that $\mathrm{Ni}$ and $\mathrm{Ti}$ contributed jointly to the same regions/clusters of the EDX maps, suggesting that the phase formed is (Ni,Ti) rich (Figure 19). 

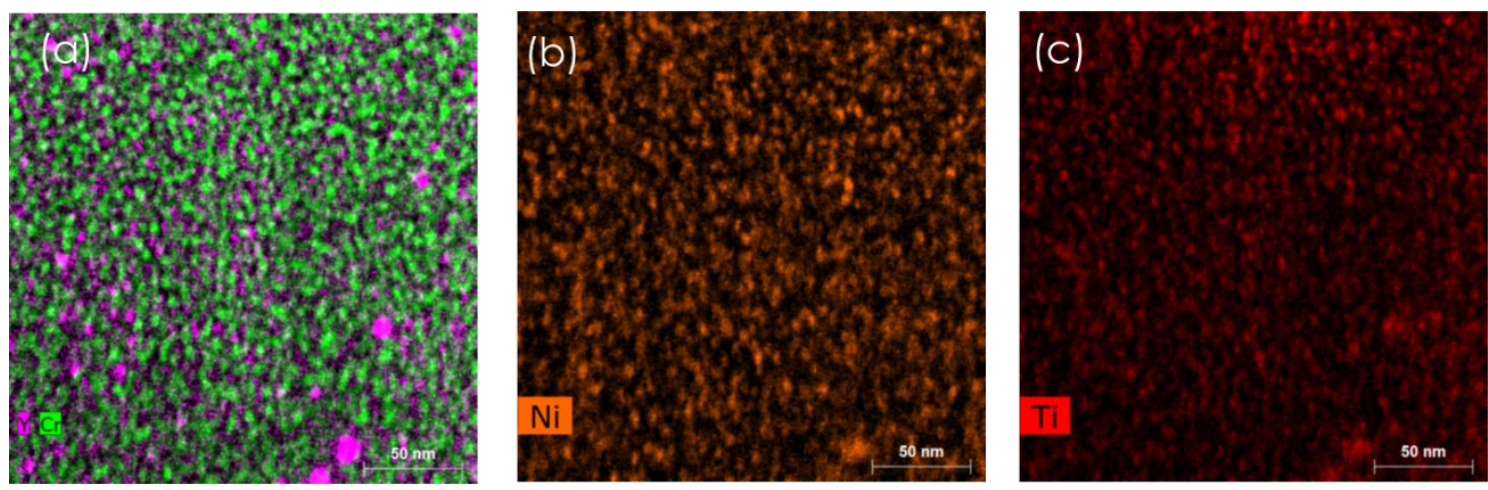

Figure 17. STEM-EDX raw count maps of neutron irradiated MA957. (a) Y and Cr map showing the $\mathrm{Cr}$ rich precipitates and the nano-oxides, (b) $\mathrm{Ni}$ and (c) $\mathrm{Ti}$.

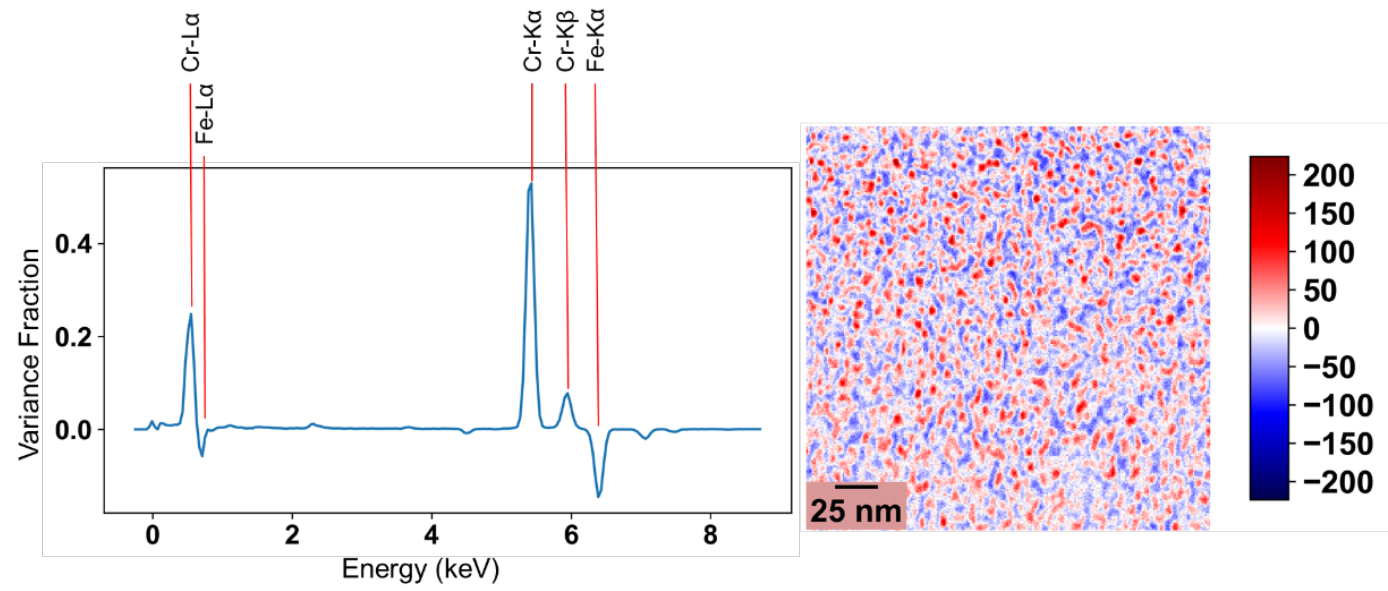

Figure 18. PCA end member analysis of STEM-EDX data identifying Cr rich $\alpha$ ' phase in MA957 alloy.

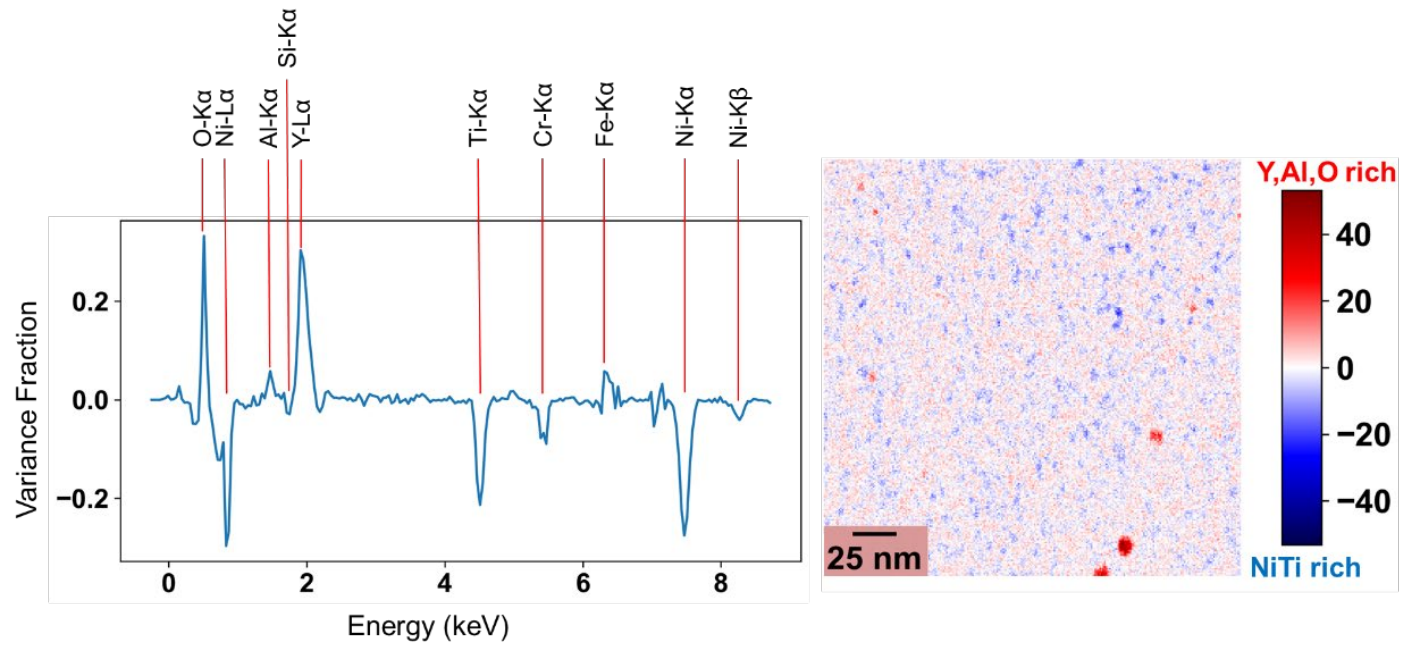

Figure 19. Evidence of Ni,Ti rich phase formation in irradiated MA957. 


\section{FUTURE RESEARCH:}

Atom probe tomography (APT) experiments in conjunction with high-resolution analytical electron microscopy experiments are planned to identify the number density, size and exact compositions of the irradiation induced phases in the ODS alloys.

\section{REFERENCES}

[1] Capdevilla et al. Strengthening by intermetallic nanoprecipitation in Fe-Cr-Al-Ti alloy, Acta Materialia 107 (2016) 27-37. 


\subsection{DEVELOPMENT OF TRANSFORMATION ENHANCED ODS Fe-Cr ALLOYS}

\section{D.T. Hoelzer (hoelzerd@ornl.gov)}

\section{OBJECTIVE}

Two transformation enhanced oxide dispersion strengthened (ODS) $\mathrm{Fe}-10 \mathrm{Cr}$ alloys were developed for fusion reactor applications requiring high-temperature strength and toughness properties and microstructural stability during exposure to energetic neutrons and transmutated He concentrations. The objective of this task is to select one of the ODS Fe-10Cr alloys for further development, based on the microstructure and mechanical properties.

\section{SUMMARY}

Two transformation enhanced ODS Fe-10Cr alloys, one with $1 \% \mathrm{~W}$ (wt.\%) and the other with no W, were developed to investigate if $1 \% \mathrm{~W}$ had a beneficial effect on the microstructure and mechanical properties. In this study, transmission electron microscopy (TEM) and energy filtered transmission electron microscopy (EFTEM) revealed both alloys contained ultra-small grains and oxide particle dispersions consisting of high number densities $\left(4.5-5.0 \times 10^{23} \mathrm{~m}^{-3}\right)$ and nano-sizes $(2.2-2.3 \mathrm{~nm})$. Although the TEM/EFTEM results were inconclusive on any benefit of $1 \% \mathrm{~W}$, previously reported results showed this addition improved the tensile and creep properties. Based on these results further alloy development will focus only on the ODS Fe-10Cr alloy containing $1 \% \mathrm{~W}$.

\section{PROGRESS AND STATUS}

The nominal compositions of the two ODS Fe-10Cr alloys are Fe-10Cr-1W-0.3 Ti-0.2V (M4) and Fe-10Cr$0.3 \mathrm{Ti}-0.2 \mathrm{~V}$ (M5). Both alloys were produced by mechanical alloying with the addition of $0.3 \mathrm{Y}_{2} \mathrm{O}_{3}$ (wt. \%). No W was added to M5 to determine if it has any benefit on the important microstructural features and/or on mechanical properties compared to M4 containing $1 \% \mathrm{~W}$. In previous reports, scanning electron microscopy showed that the two ODS Fe-10Cr alloys exhibited similar microstructures consisting of ultrasmall $(<0.5 \mu \mathrm{m})$ grains. The tensile properties indicated M4 containing $1 \% \mathrm{~W}$ showed a better balance of strength and ductility from room temperature to $800^{\circ} \mathrm{C}$ compared to the $\mathrm{W}$ free $\mathrm{M} 5$. The high temperature creep properties obtained by strain rate jump tests also indicated that M4 was superior to the M5.

Bright-field TEM micrographs revealing the ultra-small grains of M4 containing 1\%W and M5 that is $\mathrm{W}$ free are shown in Figure 20. The grains are elongated along the extrusion axis with grain aspect ratios of $<2$ in length-to-width. Energy filtered TEM resolved the Y-Ti-oxide particles present in the two ODS Fe$10 \mathrm{Cr}$ alloys. Figure 21 shows EFTEM Fe-M jump ratio maps of the oxide particle dispersions in M4 and M5. The dark contrast of the oxide particles in the Fe-M jump ratio maps is due to local depletion of iron by the Y-Ti-oxide particles. The average size and number density of the Y-Ti-oxide particles observed in M4 and M5 were quantified using EFTEM Fe-M jump ratio and thickness maps and Image $\mathrm{J}$ software. Table 4 provides the values of the average size and number density that was determined for the oxide particles in M4 and M5. Figure 22 shows the size distribution of the oxide particle dispersions obtained from Image $J$ analysis. These results show that a majority of the oxide particles in both alloys possess sizes less $\sim 3 \mathrm{~nm}$ diameter and high number densities of $4.5-5.0 \times 10^{23} \mathrm{~m}^{-3}$ suggesting no effective benefit of $1 \% \mathrm{~W}$. 
(a)

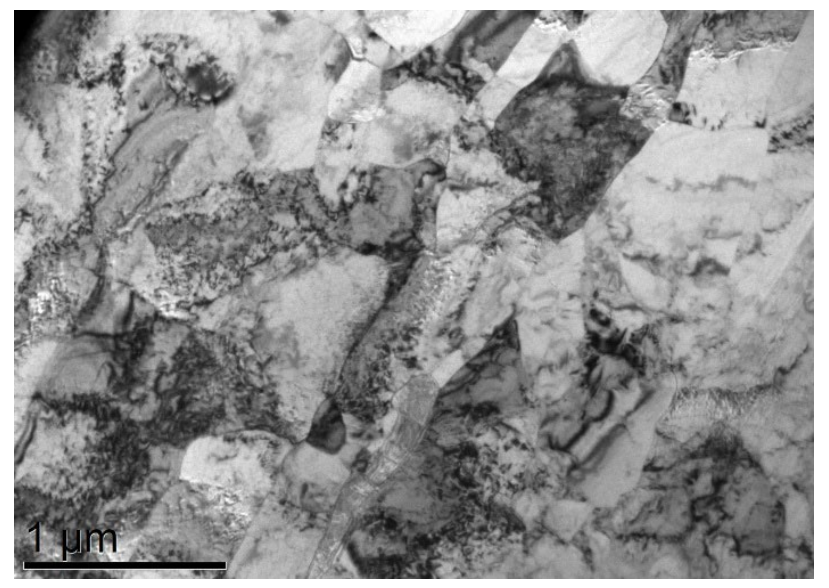

(b)

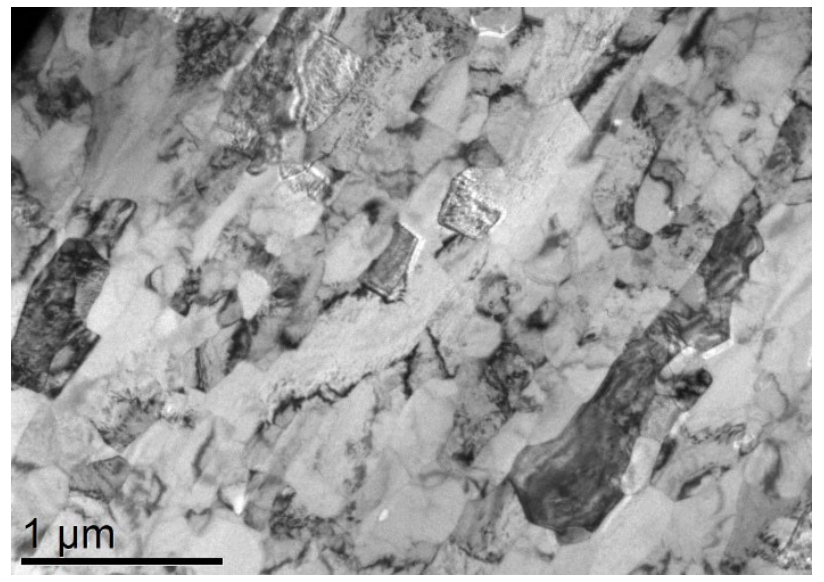

Figure 20. Bright-field TEM micrographs showing the ultra-small grains present in (a) M4 containing $1 \% \mathrm{~W}$ and (b) M5 that is W-free.

(a)

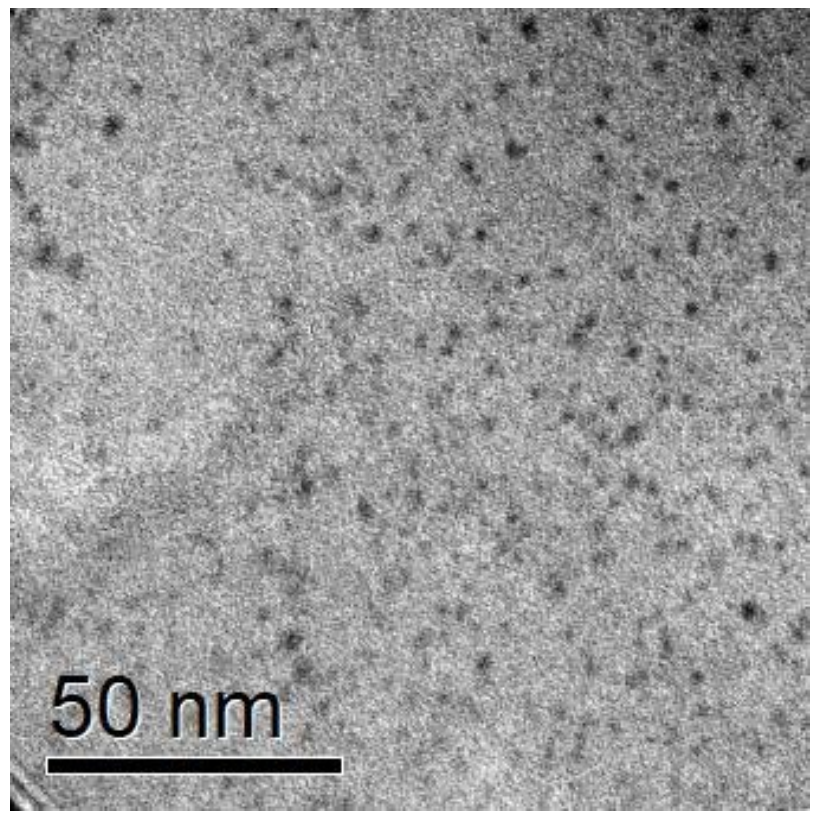

(b)

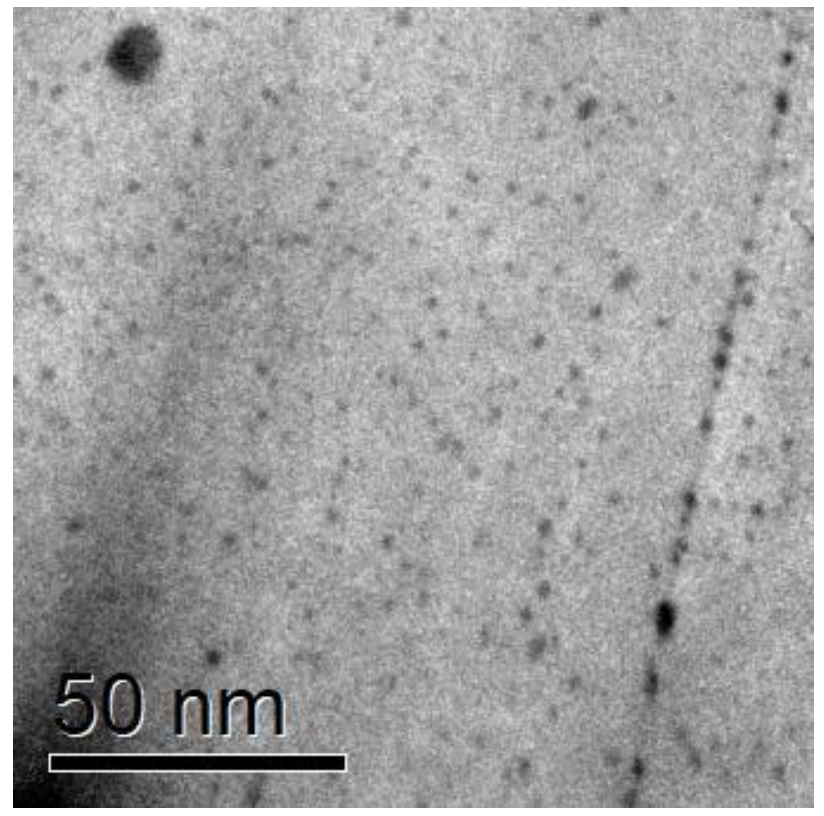

Figure 21. EFTEM Fe-M jump ratio maps showing the dispersion of nano-size oxide particles present in (a) M4 containing $1 \% \mathrm{~W}$ and (b) $\mathrm{M} 5$ that is $\mathrm{W}$-free. 
Table 4. Average size and number density measured for oxide particle dispersions in M4 and M5

\begin{tabular}{|c|c|c|}
\hline Temperature & $\begin{array}{c}\text { Diameter } \\
(\mathrm{nm})\end{array}$ & $\begin{array}{c}\text { Number Density } \\
\left(10^{23} \mathrm{~m}^{-3}\right)\end{array}$ \\
\hline M4 (1\%W) & $2.29+/-0.83$ & $4.50+/-0.84$ \\
\hline M5 (no W) & $2.17+/-0.74$ & $5.00+/-0.63$ \\
\hline
\end{tabular}

(a)

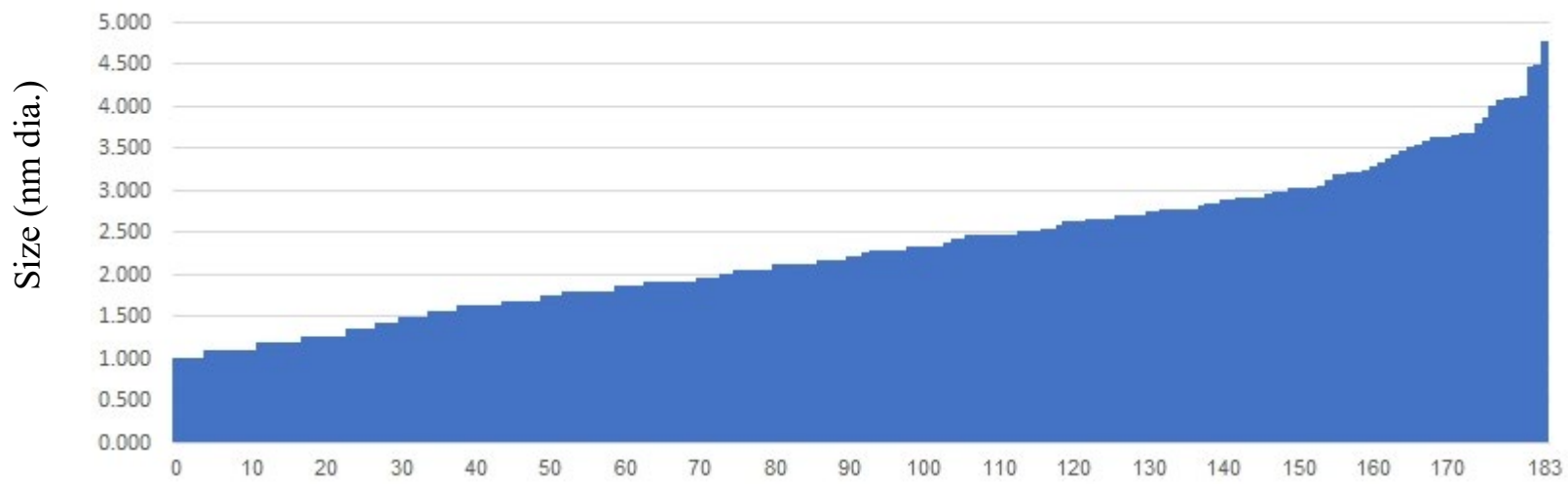

(b)

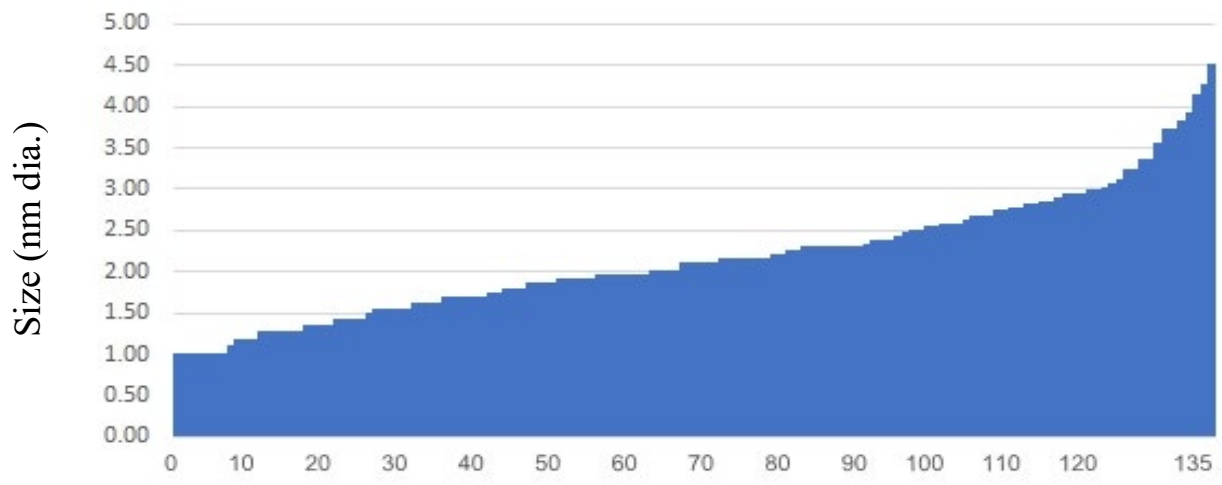

Figure 22. Size distribution of the oxide particle dispersions obtained from Image $J$ analysis of (a) M4 containing $1 \% \mathrm{~W}$ and (b) M5 that is $\mathrm{W}$-free. The $\mathrm{x}$-axis of the number associated with the analyzed oxide particle arranged from smallest to largest.

The TEM and EFTEM results show no apparent differences between the size and number density of the oxide particles between the two ODS Fe-10Cr alloys, which indicates that the $1 \% \mathrm{~W}$ contained in M4 has no effect on the nucleation and growth of the Y-Ti-oxide particles. However, the tensile and creep properties indicated that the $1 \% \mathrm{~W}$ contained in M4 provided an overall improvement in the balance of strength and ductility and high temperature creep performance compared to the W free M5. Thus, further future alloy development efforts will concentrate on M4 containing $1 \% \mathrm{~W}$. 


\section{FUTURE PLANS}

A larger heat of M4 will be produced for continuing development of this alloy. We will study the effects of thermal mechanical treatments (TMT) on the transformation kinetics and volume fraction of the face centered cubic iron phase from the body centered cubic iron phase that occurs above the $\sim 910^{\circ} \mathrm{C}$ transition temperature. The goal is to improve the strength, ductility, creep, and fracture toughness of M4 without degrading the ultra-fine grain structure and the dispersion of a high number density of nano-size Y-Ti-oxide particles that provide the high point defect sink strength required for radiation tolerance. 


\subsection{Fe-Cr-AI ODS ALLOYS FOR FUSION REACTOR APPLICATIONS}

Sebastien Dryepondt (dryepondtsn@ornl.gov), Caleb Massey, Phil Edmondson, K.A. Unocic, Ying Yang (ORNL)

\section{OBJECTIVES}

This project aims to develop and characterize advanced oxide dispersion strengthened (ODS) Fe-10/12Cr$5 / 6 \mathrm{Al}-0.3 \mathrm{Zr}+\mathrm{Y}_{2} \mathrm{O}_{3}$ alloys with a high number density of nano oxide precipitates to improve the alloy irradiation resistance and creep performance. The high Al-content will ensure the formation of an Al-rich scale to provide adequate compatibility with $\mathrm{Pb}-\mathrm{Li}$ at $600-800^{\circ} \mathrm{C}$.

\section{BACKGROUND}

The dual coolant lead-lithium (DCLL) blanket is the leading concept in the United States for DEMO-type fusion reactors and a key material requirement is alloys with acceptable $\mathrm{Pb}-\mathrm{Li}$ compatibility. Aluminaforming alloys are great candidates at temperature above $\sim 550^{\circ} \mathrm{C}$ due to the formation of a "semi-protective" $\mathrm{LiAlO}_{2}$ oxide layer [1,2]. Al-containing oxide dispersion strengthened (ODS) alloys are, therefore, prime candidate materials for advanced fusion reactors operating at temperatures $>650^{\circ} \mathrm{C}$ due to their superior irradiation and creep resistance compared to RAFM steels at $650^{\circ} \mathrm{C}-800^{\circ} \mathrm{C}$, and because of their superior $\mathrm{Pb}$-Li compatibility compared to 9Cr or 14YWT ODS alloys. ORNL has developed and extensively characterized at $700-800^{\circ} \mathrm{C}$ several ODS Fe-10/12-Cr-5/6Al- $0.3 \mathrm{Zr}+0.25 \mathrm{Y}_{2} \mathrm{O}_{3}$ alloys to demonstrate their potential for fusion applications [1-6]. In FY20, research focused on the in-depth analysis of the impact of the processing route on ODS FeCrAl microstructure and on the comparison of the ODS FeCrAl alloy longterm creep properties with the creep properties of other ODS alloys. The potential of additive manufacturing for the fabrication of ODS FeCrAl fusion components was also evaluated.

\section{EXPERIMENTS}

Gas atomized Fe-10Cr-6.1Al-0.3Zr (wt.\%) powder was ball milled in a CM01 Simoloyer for $40 \mathrm{~h}$ under Ar with nanocrystalline yttria, $17-31 \mathrm{~nm}$ in diameter. About $600 \mathrm{~g}$ of the powder was annealed for $1 \mathrm{~h}$ and then extruded at $900^{\circ} \mathrm{C}(4 \mathrm{H} 9 \mathrm{C})$ or $1000^{\circ} \mathrm{C}(4 \mathrm{H} 10 \mathrm{C})$ using a 2-in. OD mild steel extrusion can. Larger quantities of the same ball milled powder were produced using a CM08 Zoz Simoloyer. A two-step extrusion process was tried using a larger 4-in. OD extrusion can and a $2 \times 1.5 \mathrm{in}$. rectangular die. $1.5 \mathrm{~kg}$ of powder was annealed at $750^{\circ} \mathrm{C}$ for two hours before annealing for $30 \mathrm{~min}$ and extrusion at $950^{\circ} \mathrm{C}$. For the $125 \mathrm{YZ}$ reference ODS FeCrAl alloy i.e. the first ODS FeCrAl produced at ORNL, an Fe-12Cr-5Al powder was ball milled with a mixture of nanocrystalline yttria and zirconia powders before annealing for $1 \mathrm{~h}$ and extrusion at $950^{\circ} \mathrm{C}$ using the large extrusion can and rectangular die. The composition of the extruded alloys is given in Table 5.

Table 5. Chemical compositions of alloys (wt\%) provided by DIRATS using ICP-OES

\begin{tabular}{lllllllllll}
\hline Sample & $\boldsymbol{F o r m}$ & $\boldsymbol{M i l l}$ & $\boldsymbol{F e}$ & $\boldsymbol{C r}$ & $\boldsymbol{A l}$ & $\boldsymbol{Z r}$ & $\boldsymbol{Y}$ & $\boldsymbol{O}$ & $\boldsymbol{C}$ & $\boldsymbol{N}$ \\
\hline $\mathbf{1 2 5 Y Z}$ & Extruded alloy & CM08 & 82.8 & 11.51 & 4.86 & 0.3 & 0.18 & 0.19 & 0.025 & 0.016 \\
$\boldsymbol{Z Y 1 0 C}$ & Extruded Alloy & CM01 & 83.4 & 9.74 & 6.02 & 0.28 & 0.22 & 0.129 & 0.019 & 0.058 \\
$\boldsymbol{Z Y 9 C}$ & Extruded Alloy & CM01 & 83.34 & 9.73 & 6.07 & 0.28 & 0.21 & 0.13 & 0.017 & 0.092 \\
$\boldsymbol{Z Y 7 9 5 C}$ & Extruded Alloy & CM08 & 83.49 & 9.76 & 5.97 & 0.28 & 0.22 & 0.099 & 0.059 & 0.043 \\
\hline
\end{tabular}


Characterization of the alloys was mainly by atom probe tomography (APT) and scanning or transmission electron microscopy (S/TEM) methods [4-7]. Creep tests at $700^{\circ} \mathrm{C}$ and $800^{\circ} \mathrm{C}$ used sub size SS3-type dog bone specimens with a gage length of $7.62 \mathrm{~mm}$ and a gage section of $2 \mathrm{~mm} \times 2 \mathrm{~mm}$.

\section{RESULTS}

\section{Microstructure characterization}

Previous papers and reports have highlighted the presence of high number density of fine $(\mathrm{Y}, \mathrm{Al}, \mathrm{O})$ nano precipitates as well as larger $\mathrm{ZrC}, \mathrm{Zr}(\mathrm{N}, \mathrm{C})$ and $(\mathrm{Fe}, \mathrm{Cr})_{23} \mathrm{C}_{6}$ precipitates in ORNL FeCrAl steels [4-6]. Thermodynamic calculations using the CALPHAD approach revealed that the absence of trigonal $\delta$-phase $\mathrm{Zr}_{3} \mathrm{Y}_{4} \mathrm{O}_{12}$ nano precipitates, reported in several $\mathrm{Fe}-10-15 \mathrm{Cr}-4-7 \mathrm{Al}-0.2-0.6 \mathrm{Zr}-0.35 \mathrm{Y}_{2} \mathrm{O}_{3}$ ODS alloys [8-9], was most likely due to a difference in $\mathrm{N}$ concentration. Low $\mathrm{C}$ and $\mathrm{N}$ concentrations favor the formation of $\mathrm{Zr}_{2} \mathrm{Y}_{4} \mathrm{O}_{12}$ over $\mathrm{Zr}(\mathrm{N}, \mathrm{C})$ carbides [7] and Ukai et al. reported $\mathrm{C}$ and $\mathrm{N}$ concentrations of $\sim 0.03 \mathrm{wt} \%$ and $\sim 0.005 \mathrm{wt} \%$, respectively, while our ODS FeCrAl alloys have concentrations varying from $0.017 \mathrm{wt} \%$ to $0.059 \mathrm{wt} \%$ for $\mathrm{C}$ and from $0.016 \mathrm{wt} \%$ to $0.092 \mathrm{wt} \%$ for $\mathrm{N}$ (Table 5).

Additional APT and STEM characterization was conducted to identify the $(\mathrm{Y}, \mathrm{Al}, \mathrm{O})$ nano precipitates in the 4H10C alloy, and Figure 23 shows STEM images of a) YAM $\left(\mathrm{Y}_{4} \mathrm{Al}_{2} \mathrm{O}_{9}\right)$ and b) YAG $\left(\mathrm{Y}_{3} \mathrm{Al}_{5} \mathrm{O}_{12}\right)$ precipitates. After ball milling, Y may be either in solid solution or form (Y,O)-rich nano cluster [10]. High temperature annealing during the powder consolidation will therefore lead to YAG precipitate nucleation from Y in solution while Y-rich YAM precipitates will form from Y-rich clusters. All these results have been summarized in a paper published in the Journal of Nuclear Materials [7].
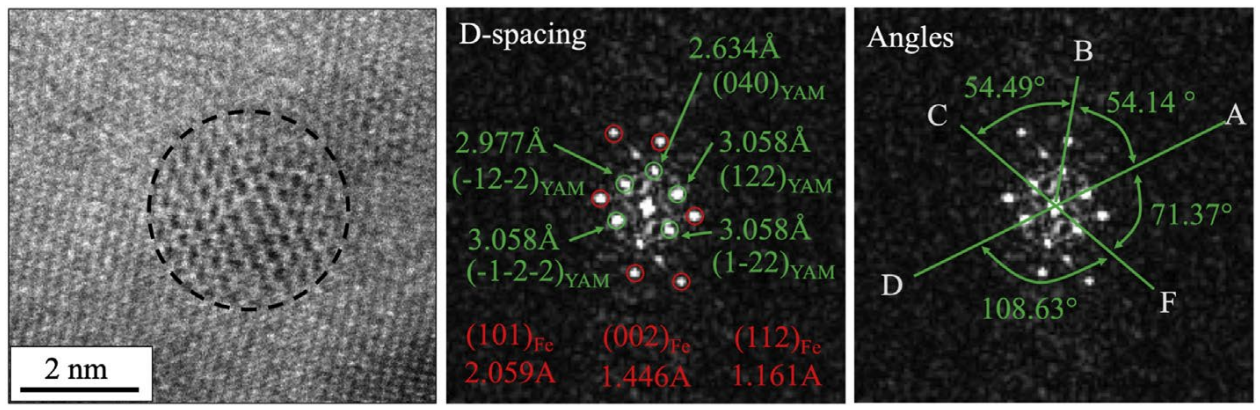

(a) Identified precipitate consistent with YAM
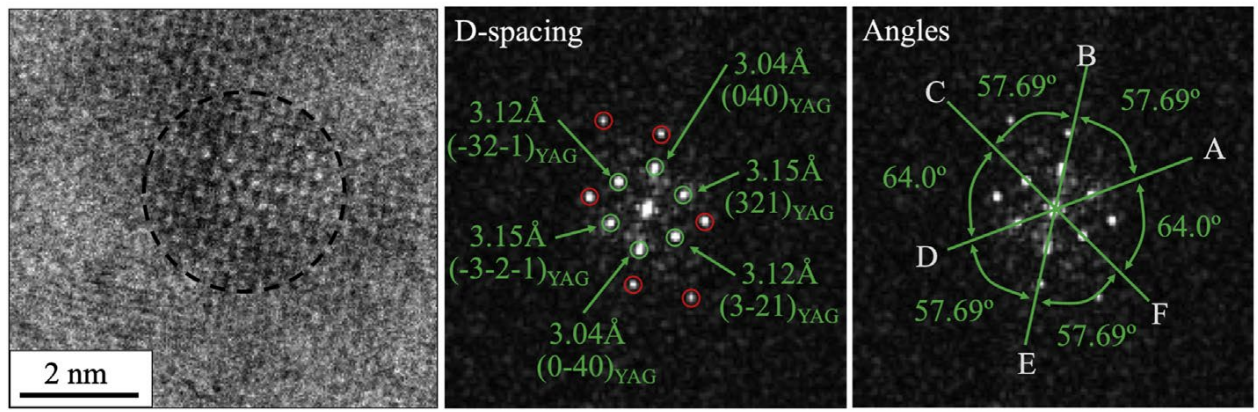

(b) Identified precipitate consistent with YAG

Figure 23. High-resolution S/TEM images of select nanoscale precipitates in the $4 \mathrm{H10C}$ alloy showing examples of precipitates matching the structure of (a) YAM and (b) YAG [7]. 


\section{Long-term creep tests}

Figure 24a compares long-term creep data for the 125YZ and ZY9C ODS FeCrAl alloys with results from Kimura et al. generated on Fe-16Cr-4Al-2W ODS FeCrAl [11]. Even if the ORNL specimens were tested at a higher $140 \mathrm{MPa}$ stress and have not reached failure, the $125 \mathrm{YZ}$ and $\mathrm{ZY} 9 \mathrm{C}$ creep lifetimes at $700^{\circ} \mathrm{C}$ were superior to the estimated lifetimes for the ODS Fe-16Cr-4Al-2W-Zr/Hf alloys. The newest ODS FeCrAl alloys, developed by the same Japanese research group, have been creep tested at higher temperatures or as thin claddings with large elongated grains rendering direct comparison difficult [9,12-14]. They identified grain boundary sliding (GBS) associated with the formation of voids as key damage mechanisms, and Figure 24b-2d highlight the presence of voids in the $125 \mathrm{YZ}$ and ZY9C specimens creep tested for $\sim 25,000$ $\mathrm{h}$ at $700^{\circ} \mathrm{C}$ with an applied stress of $140 \mathrm{MPa}$. For both alloys, many of these voids were related to the presence of $\mathrm{Al}_{2} \mathrm{O}_{3}$ stringers at grain boundaries. In addition, the presence of large AlN clusters in the high $\mathrm{N}$ ZY9C steel resulted in the formation of a few large voids, while large grains were sometimes observed in the vicinity of voids in the $125 \mathrm{YZ}$ specimen. Stress relaxation through dislocation motion is required for GBS to take place [12-14], and nano precipitates are key to pin dislocations and hinder creep cavitation. The TEM micrograph and corresponding elemental maps shown in Figure 25 highlight the presence of (Y,Al)-rich oxides and a few coarser $\mathrm{Zr}(\mathrm{C}, \mathrm{N})$ precipitates in the $125 \mathrm{YZ}$ specimen tested for $26,700 \mathrm{~h}$ at $700^{\circ} \mathrm{C}, 140 \mathrm{MPa}$. The stability of the nano oxides explains the superior creep resistance of the ODS FeCrAl alloys at $700-800^{\circ} \mathrm{C}$.

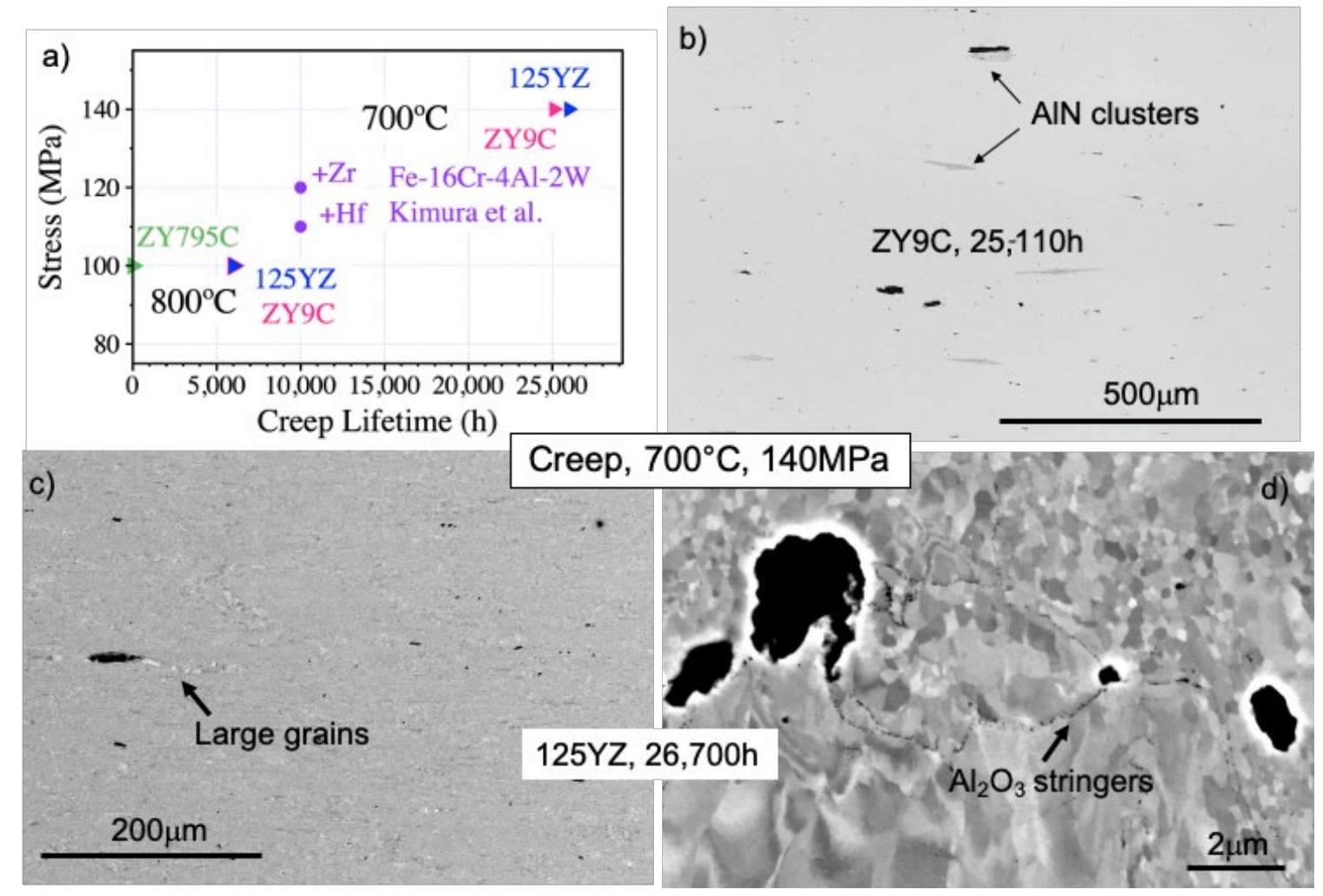

Figure 24. a) Comparison of creep lifetimes for ODS FeCrAl tested at $700^{\circ} \mathrm{C}$ or $800^{\circ} \mathrm{C}$, b) Optical image of the $\mathrm{ZY9C}$ specimen creep tested for $25,110 \mathrm{~h}$ at $700^{\circ} \mathrm{C}$ highlighting voids and AlN clusters, c) Scanning electron microscopy (SEM) images of the $125 \mathrm{YZ}$ specimen creep tested at $700^{\circ} \mathrm{C}$, $140 \mathrm{MPa}$ for $26,700 \mathrm{~h}$ showing voids related to large grains or alumina stringers. 

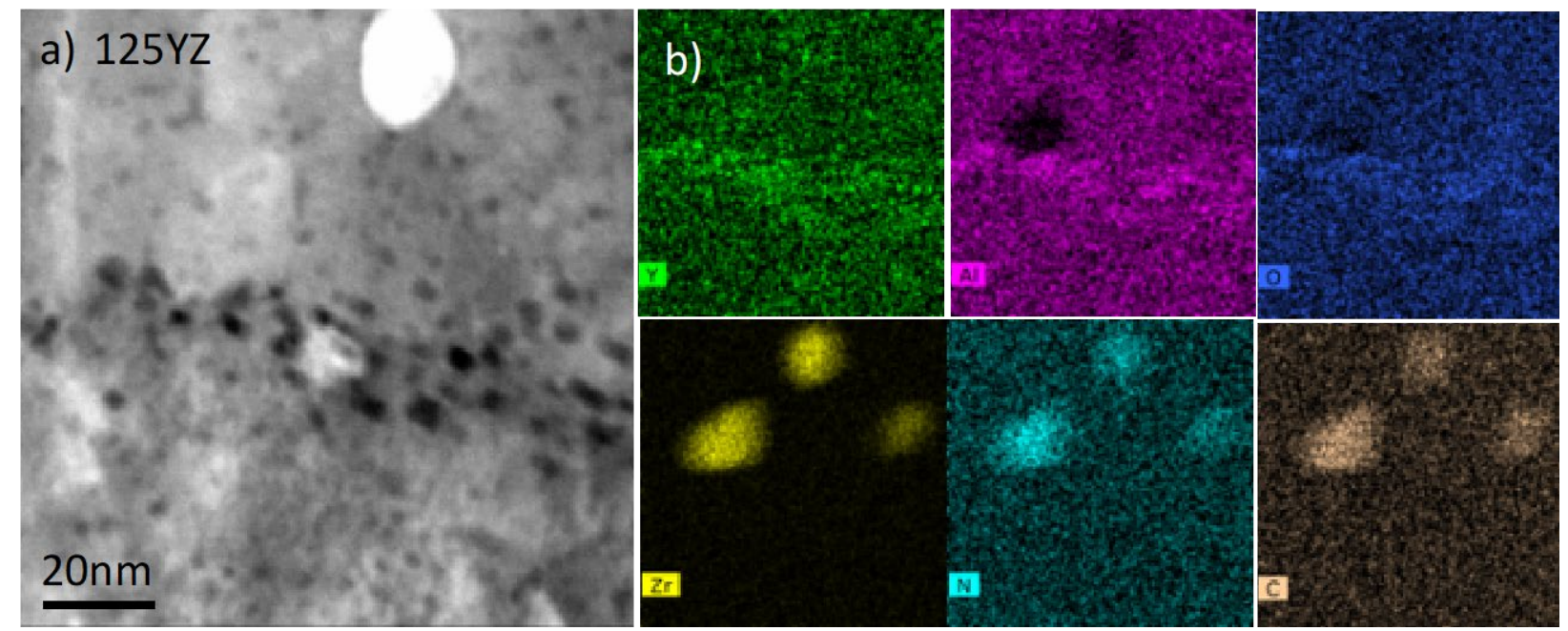

Figure 25. $125 \mathrm{YZ}$ specimen creep tested at $700^{\circ} \mathrm{C}, 140 \mathrm{MPa}$ for $26,700 \mathrm{~h}$, a) TEM micrograph, b) Corresponding chemical maps.

To compare the ODS FeCrAl creep performance with the performance of other ODS alloys, Figure 26 shows ORNL's data added to a Larson Miller parameter (LMP) versus applied stress plot published by Jaumier et al.[15]. In the $700-800^{\circ} \mathrm{C}$ and $100-140 \mathrm{MPa}$ ranges, the resulting high LMP values obtained for the ODS FeCrAl alloys are consistent with data from other ODS FeCr steels. Klueh et al. came to the same conclusion when comparing ODS MA956 (Fe-22Cr-6Al-0.4Y) and ODS MA957 (Fe-14Cr-1Ti-0.28Y) [16]. At low LMP values and high stresses, ODS MA956 exhibited lower creep performance compared to MA957 but the two alloys showed similar creep strength at high LMP values, low stresses.

Finally, for alloy ZY795C, annealing the ball milled powder for $2 \mathrm{~h}$ at $750^{\circ} \mathrm{C}$ aimed at the formation of very fine nano precipitates, while extrusion at $950^{\circ} \mathrm{C}$ would increase the alloy ductility without precipitate coarsening. Creep testing was conducted at $800^{\circ} \mathrm{C}$ on $4 \mathrm{H} 795 \mathrm{C}$ specimens, but premature failure was observed at both 120 and $100 \mathrm{MPa}$ (Figure 24a). Cross-section micrographs revealed again the presence of many voids related to both alumina stringers and AlN clusters. Unfortunately, the rapid creep degradation of the $4 \mathrm{H} 795 \mathrm{C}$ alloy at $800^{\circ} \mathrm{C}$ is likely related to a non-optimum nano precipitate distribution. These results highlight the difficulty in producing high-quality ODS alloys due to the complex fabrication procedure. 


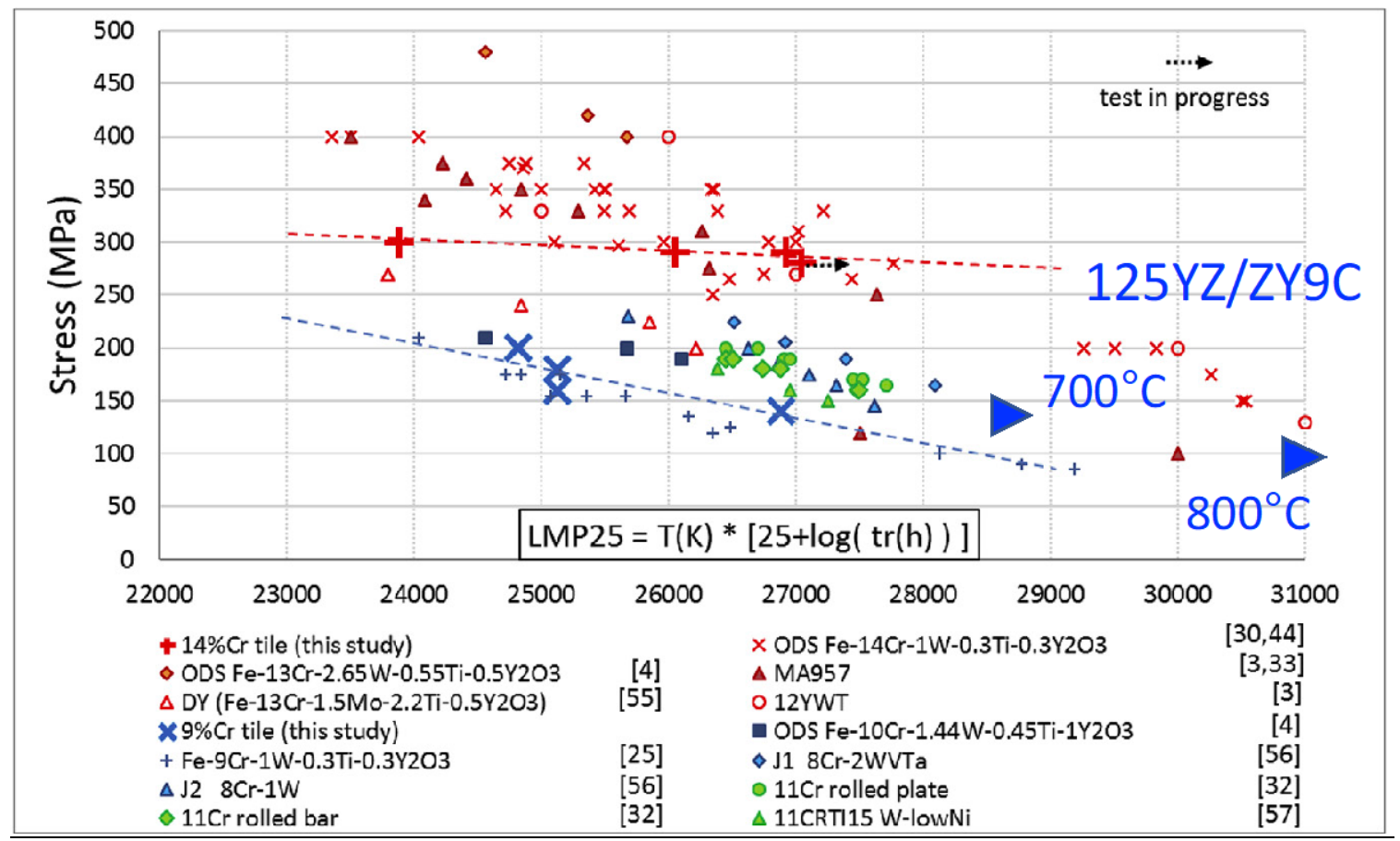

Figure 26. LMP plot comparing various ODS FeCr steels with the added 125YZ and106ZY9C ODS FeCrAl alloys shown in blue [15].

\section{CONCLUSION AND FUTURE WORK}

The high number density of YAP and YAG nano precipitates identified in ORNL's ODS FeCrAl alloys resulted in creep lifetimes, at $700^{\circ} \mathrm{C}$ and $800^{\circ} \mathrm{C}$ and with applied stresses of $140 \mathrm{MPa}$ and $100 \mathrm{MPa}$, respectively, similar to what has been reported for other ODS alloys. Significant improvement has been made in understanding the nano precipitate formation, but careful control of each step of the fabrication process is required to obtain the desired ODS FeCrAl microstructure. Additive manufacturing of ODS alloys is attracting lots of attention for the potential fabrication of complex ODS components. In situ reaction to fabricate oxide precipitates during melting of conventional FeCrAlY gas atomized powder would be a very cost-effective solution [17], but the nucleation of high number density of nano oxides will certainly be a challenge as observed in the fabrication of ODS alloys via reactive gas atomization processing [18]. Another interesting option is to mix metallic powder with ceramic powder before printing as in experiments by Zhong et al. with 316L powder and yttria, $800 \mathrm{~nm}$ in size [19]. They observed mainly (Y,Si,O)-rich precipitates, $\sim 40 \mathrm{~nm}$ in size and further improvement might be achieved with the use of finer yttria powder. The most promising method is to use ball milled powder and several research groups, including ORNL, have demonstrated that very fine nano precipitates can be achieved in laser powder bed fusion $\mathrm{FeCr}$ and $\mathrm{FeCrAl}$ ODS alloys [20-22]. Optimization of the fabrication parameters and powder chemistries are still required to improve the alloy mechanical properties.

\section{REFERENCES}

[1.] K. A. Unocic, and D. T. Hoelzer, Journal of Nuclear Materials, 479, 357-364 (2016).

[2.] J. Jun, K. A. Unocic, M. J. Lance, H. M. Meyer, III, B. A. Pint, Journal of Nuclear Materials, 528, 151847 (2020).

[3.] B.A. Pint, S. Dryepondt, K.A. Unocic, D.T. Hoelzer, JOM 66(12), 2458-2466 (2014).

[4.] K. A. Unocic, B. A. Pint, and D. T. Hoelzer, Journal of Materials Science, 51, 9190-9206 (2016). 
[5.] C.P. Massey, S.N. Dryepondt, P.D. Edmondson, K.A. Terrani and S.J. Zinkle, Journal of Nuclear Materials, 15, 227-238 (2018).

[6.] C.P. Massey, S. N. Dryepondt, P.D. Edmondson, M.G. Frith, K C. Littrell, A. Kini, B. Gault, K.A. Terrani, and S.J. Zinkle, Acta Materialia, 166, 1-17 (2019).

[7.] C.P. Massey, P.D. Edmondson, K.A. Unocic, Y. Yang, S. N. Dryepondt, A. Kini, B. Gault, K.A. Terrani, and S.J. Zinkle, Journal of Nuclear Materials, 533, 152105 (2020).

[8.] P. Dou, A. Kimura, R. Kasada, T. Okuda, M. Inoue, S. Ukai, S. Ohnuki, T. Fujisawa, F. Abe, Journal of nuclear materials, 444, 441-453 (2014).

[9.] S. Ukai, S. Kato, T. Furukawa and S. Ohtsuka, Materials Science \& Engineering A, 794, 139863 (2020).

[10.]C. A. Williams, P. Unifantowicz, N. Baluc, G.D.W. Smit and E.A. Marquis, Acta Materialia, 61, 2219-2235 (2019).

[11.]A. Kimura, R. Kasada, N. Iwata, H. Kishimoto, C.H. Zhang, J. Isselin, P. Dou, J.H. Lee,

[12.] N. Muthukumar, T. Okuda, M. Inoue, S. Ukai, S. Ohnuki, T. Fujisawa, T.F. Abe, Journal of Nuclear Materials, 417, 176-179 (2011).

[13.] H. Masuda, H. Tobe, E. Sato , Y. Sugino, S. Ukai, , Acta Materialia, 120, 205-215 (2016).

[14.] H. Masuda, H. Tobe, E. Sato , Y. Sugino, S. Ukai, Acta Materialia, 132, 245-254 (2017).

[15.] R. Kamikawa, S. Ukai, S. Kasai, N. Oono, S. Zhang, Y. Sugino, H. Masuda, E. Sato, Journal of Nuclear Materials 511, 591-597 (2018).

[16.] T. Jaumier, S. Vincent, L. Vincent, R. Desmorat, Journal of Nuclear Materials, 518, 274-286 (2019).

[17.] R.L. Klueh, J.P. Shingledecker, R.W. Swindeman and D.T. Hoelzer, Journal of Nuclear Materials, 341, 103-114 (2005).

[18.] H. Springer, C. Baron, A. Szczepaniak, E.A. Jägle, M.B.Wilms, A.Weisheit and D. Raabe, Materials and Design, 111, 60-69 (2016).

[19.] NJ.R. Rieken, I.E. Anderson, M.J. Kramer, G.R. Odette, E. Stergar and E. Haney, Journal of Nuclear Materials, 428, 65-75 (2012).

[20.] Y. Zhong, L. Liu, J. Zou, X. Li, D. Cui and Z. Shen, Journal of Materials Science \& Technology, 42, 97-105 (2020).

[21.] T. Boegelein, S.N. Dryepondt, A. Pandey, K. Dawson, G.J. Tatlock, Acta Materialia, 87, 201-215 (2015).

[22.] E. Vasquez, P.F. Giroux, F. Lomello, A. Chniouel, H. Maskrot, F. Schuster and P. Castany, Journal of processing tech., 267, 403-413 (2019).

[23.] Y. Shi, Z. Lu, L. Yu, R. Xie, Y Ren and G. Yang, Materials Science and Engineering A, 774, 138937 (2020). 


\section{CERAMIC AND COMPOSITE MATERIALS}

\subsection{DESIGN AND STRATEGY FOR NEXT-GENERATION SILICON CARBIDE COMPOSITES FOR NUCLEAR ENERGY}

T. Koyanagi (koyangit@ornl.gov), Y. Katoh (ORNL), T. Nozawa (National Institutes for Quantum and Radiological Science and Technology)

\section{OBJECTIVE}

The goal of this task is to develop next-generation nuclear grade $\mathrm{SiC}$ composite with enhanced radiation resistance for fusion structural applications.

\section{SUMMARY}

As performance data accumulates, the limitations of the current generation of nuclear-grade $\mathrm{SiC} / \mathrm{SiC}$ composites are becoming more apparent. These limitations mainly involve strength degradation during high-dose neutron irradiation. This report discusses several options for improving the performance of the next generation of $\mathrm{SiC}$ composites to enhance the radiation resistance. The main emphasis is on the selection of the fibers and the design and development of alternative interphase layers for advanced composites. The technical details are fully described in the publication in Journal of Nuclear Materials 540 (2020) 152375.

\section{PROGRESS AND STATUS}

The limitations of the current generation of nuclear-grade $\mathrm{SiC} / \mathrm{SiC}$ composites result mainly from strength degradation due to high-dose neutron irradiation at low to intermediate temperatures $\left(300-600^{\circ} \mathrm{C}\right)$. To overcome these limitations, this task identified options for improving the performance of the next generation of $\mathrm{SiC} / \mathrm{SiC}$ composites with enhanced radiation resistance, as described below.

- The dimensional stability and strength of Hi-Nicalon Type S SiC fibers under irradiation need to be improved. Tyranno SA3 SiC fiber has demonstrated greater dimensional stability, but the effect of neutron irradiation on its strength remains unclear and needs to be addressed. High-purity chemical vapor deposited (CVD) SiC fiber without a carbon core is another option as a reinforcement because no significant degradation of the strength of high-purity $\mathrm{SiC}$ in other forms has been reported following high-dose irradiation.

- Debonding at the fiber/matrix interface due to the dimensional instability of the carbon interphase (Figure 27) limits the mechanical properties of irradiated $\mathrm{SiC} / \mathrm{SiC}$ composites and warrants the development of new interphase materials. In addition to dimensional stability, the performance and processing requirements of the interphase include crack deflection at the interface, fiber-pullout capability, chemical compatibility among the composite constituents during processing and reactor operation, chemical stability with reactor coolants, and effectiveness as a thin layer (Figure 28). Although available composite theory and processing technologies are able to satisfy some of the requirements, limited knowledge of the high-dose radiation resistance of materials makes selection of the interphase material challenging. 
- The development of a constitutive model for the stress state in irradiated $\mathrm{SiC} / \mathrm{SiC}$ composites would be useful for assessing new fiber/interphase systems and for identify promising composite microstructures. The challenges include experimental validation of the calculated stress state in irradiated materials and investigation of the dimensional stability and mechanical properties of the interphase. In addition, an understanding of the role of the interfaces between composite constituents in radiation defect evolution is needed for improvement of the model.

\section{FUTURE PLANS}

Future work will include selection of the interface material and the processing route. CVD method will be employed for the interface coating. This will be an initial step in the development of advanced $\mathrm{SiC} / \mathrm{SiC}$ composites.
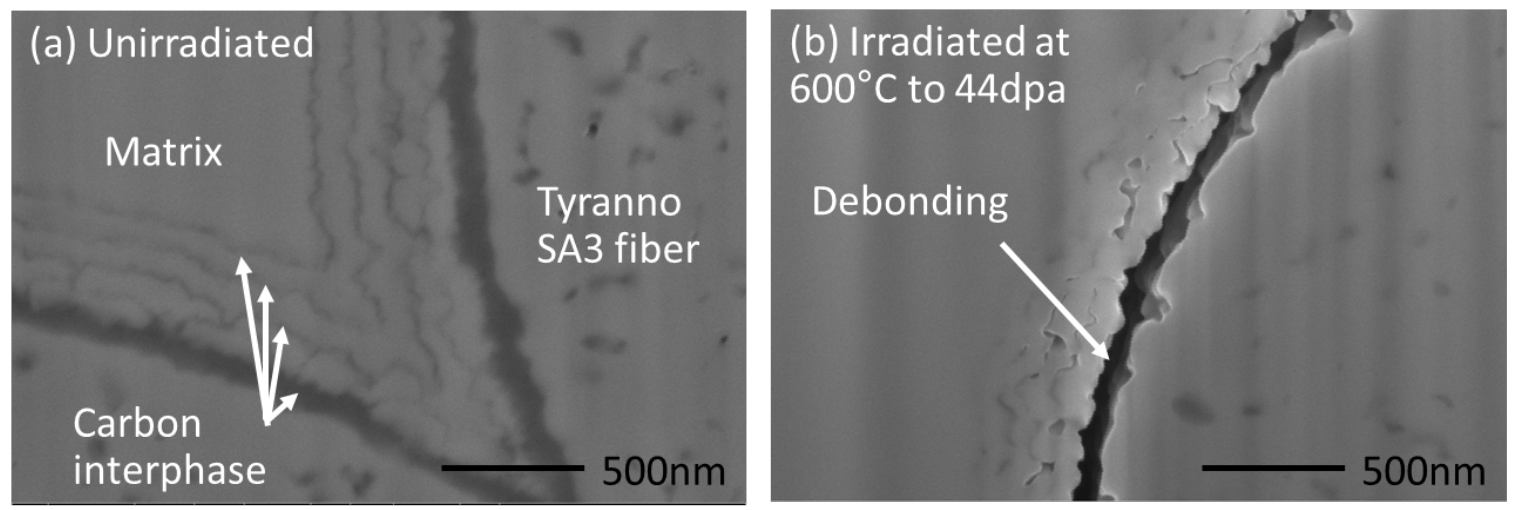

Figure 27. SEM images of pyrolytic carbon interphase in Tyranno SA3 SiC fiber reinforced CVI $\mathrm{SiC} / \mathrm{SiC}$ composite: (a) unirradiated and (b) neutron irradiated at $600^{\circ} \mathrm{C}$ to $44 \mathrm{dpa}$. Irradiationinduced interfacial debonding was observed.

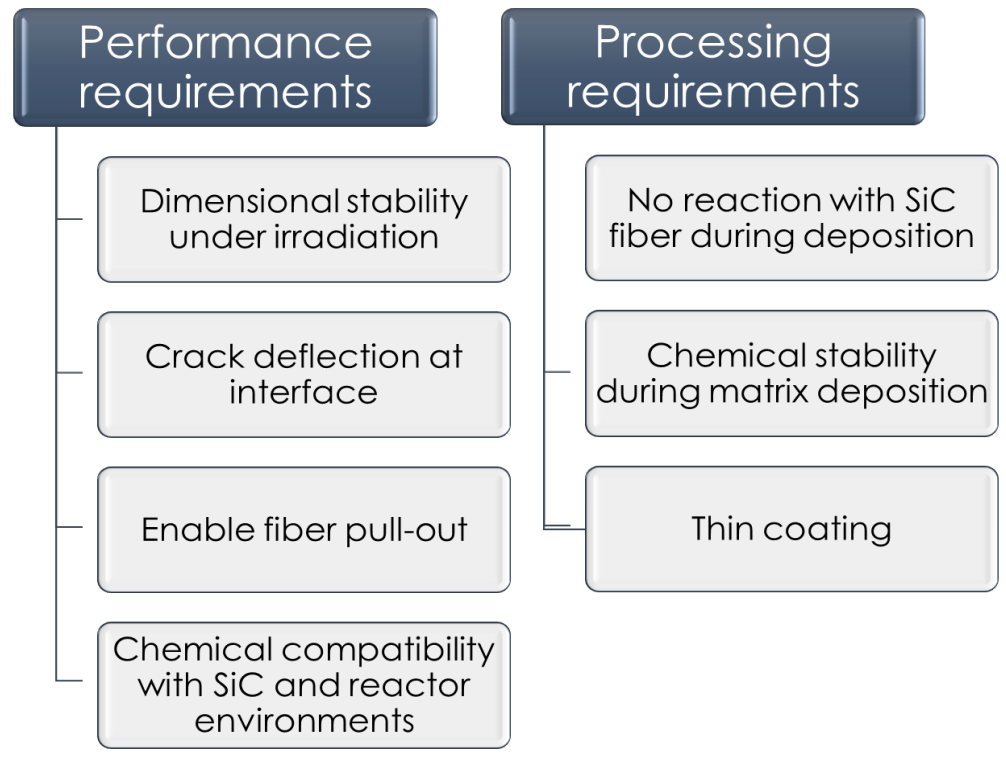

Figure 28. Performance and processing requirements for development of the interphase between fiber and matrix in $\mathrm{SiC} / \mathrm{SiC}$ composites for use in high-dose radiation environments. Reprinted from Journal of Nuclear Materials 540 (2020) 152375. 


\subsection{SiC JOINING TECHNOLOGY FOR FUSION REACTORS}

T. Koyanagi (koyangit@ornl.gov), Y. Katoh (ORNL), T. Hinoki (Kyoto University), C. Henager (Pacific Northwest National Laboratory), Monica Ferraris (Politecnico di Torino), Salvatore Grasso (Southwest Jiaotong University), Huaxin Li (Hefei University of Technology, China)

\section{OBJECTIVE}

The objective of this work is to develop technologies to join silicon carbide to other materials for fusion applications. The task had two themes in this fiscal year: (1) the effects of neutron irradiation on the joint strength and (2) the development of an advanced direct joining method for SiC.

\section{SUMMARY}

This study filled a knowledge gap on neutron-irradiation resistance of SiC joints for nuclear applications. It included an investigation of high-dose neutron irradiation effects on the strength of selected joints and low-dose neutron irradiation effects on recently developed joints fabricated by state-of-the-art processing methods. There was no notable degradation of torsional strengths of the joints following the high dose irradiation. The irradiation-induced degradation of $\mathrm{SiC}$ joints at low neutron dose was highly dependent on joint type. This work has been published in the Journal of the European Ceramic Society 40 (2020) 10231034.

Direct joining of low-resistivity grade, nitrogen doped $\beta$-SiC was demonstrated at a relatively low nominal temperature by passing an electric current through the material. This result indicates that rapid electron current assisted joining is a practical and appropriate method for joining SiC-based materials. A research article describing this work has been accepted by the Journal of the European Ceramic Society (https://doi.org/10.1016/j.jeurceramsoc.2020.05.072).

\section{PROGRESS AND STATUS}

\section{The effects of neutron irradiation on SiC joint strength}

The joining methods used for $\mathrm{SiC}$ in the high-dose radiation study included pressure-assisted liquid-phase sintering (LPS) of $\mathrm{SiC}$ nano powder, pressureless calcia-alumina glass ceramics joining (CA), and reaction sintering of Ti-Si-C (MAX phase) powders with hot-pressing. The joints were neutron-irradiated at $530^{\circ} \mathrm{C}$ to $20 \mathrm{dpa}$ in HFIR. SiC joints produced by other methods - included low-pressure LPS of cold-pressed SiC green body, pressureless reaction sintered Ti-Si-C powder joint, spark plasma-sintered Ti diffusion bond, and hot-pressed Ti diffusion bond - were irradiated at $\sim 500^{\circ} \mathrm{C}$ to $\sim 2 \mathrm{dpa}$. The findings are summarized as follows.

- The pressure-assisted LPS-SiC-based joints, hot-pressed MAX-phase joints, and pressureless CA glass ceramic joint retained their strength after exposure to neutron irradiation for $\sim 350$ days $(20 \mathrm{dpa})$ at $530^{\circ} \mathrm{C}$ (Figure 29). This demonstration encourages further development of $\mathrm{SiC}$ for nuclear applications.

- The strength of the as-fabricated LPS-SiC-based joints were highly dependent on processing and microstructure. In addition, the results indicated that nonuniform microstructures resulted in the joint failures observed after irradiation for both types of pressure-assisted LPS-SiC joints. The joint produced by low-pressure LPS of cold-pressed $\mathrm{SiC}$ green body retained its strength following irradiation at $480^{\circ} \mathrm{C}$ to 2.9 dpa and at $730^{\circ} \mathrm{C}$ to $2.3 \mathrm{dpa}$. 
- MAX-phase-based joints - including Ti diffusion bond, pressureless MAX-phase bond, and SPS MAXphase bond-retained their strength following neutron irradiation at $\sim 500^{\circ} \mathrm{C}$ to $2.9 \mathrm{dpa}$ and at $\sim 700^{\circ} \mathrm{C}$ to $2.3 \mathrm{dpa}$, regardless of the differences in the joint microstructures. Irradiation-induced cracking was a common damage process, likely caused by differential swelling between the $\mathrm{SiC}$ substrate and the joint phases.

\section{Direct joining of $\mathrm{SiC}$}

Direct joining of nitrogen doped $\mathrm{SiC}$ was achieved by an electric current-assisted method with and without a graphite die (Figure 30). It is feasible to reduce the nominal joining temperature of direct-bonded $\mathrm{SiC}$ ceramics by increasing the electric current through the material. A direct-bonded nitrogen doped-SiC joint was achieved using the joining conditions of $1750^{\circ} \mathrm{C}$ for 10 min under a pressure of $20 \mathrm{MPa}$ with a $\sim 270$ $\mathrm{A} / \mathrm{cm}^{2}$ current density passing through the specimen. This is the most promising condition among those used in this study. The joining temperature was lower than the reported value $\left(1900^{\circ} \mathrm{C}\right)$ required for undoped $\mathrm{SiC}$.

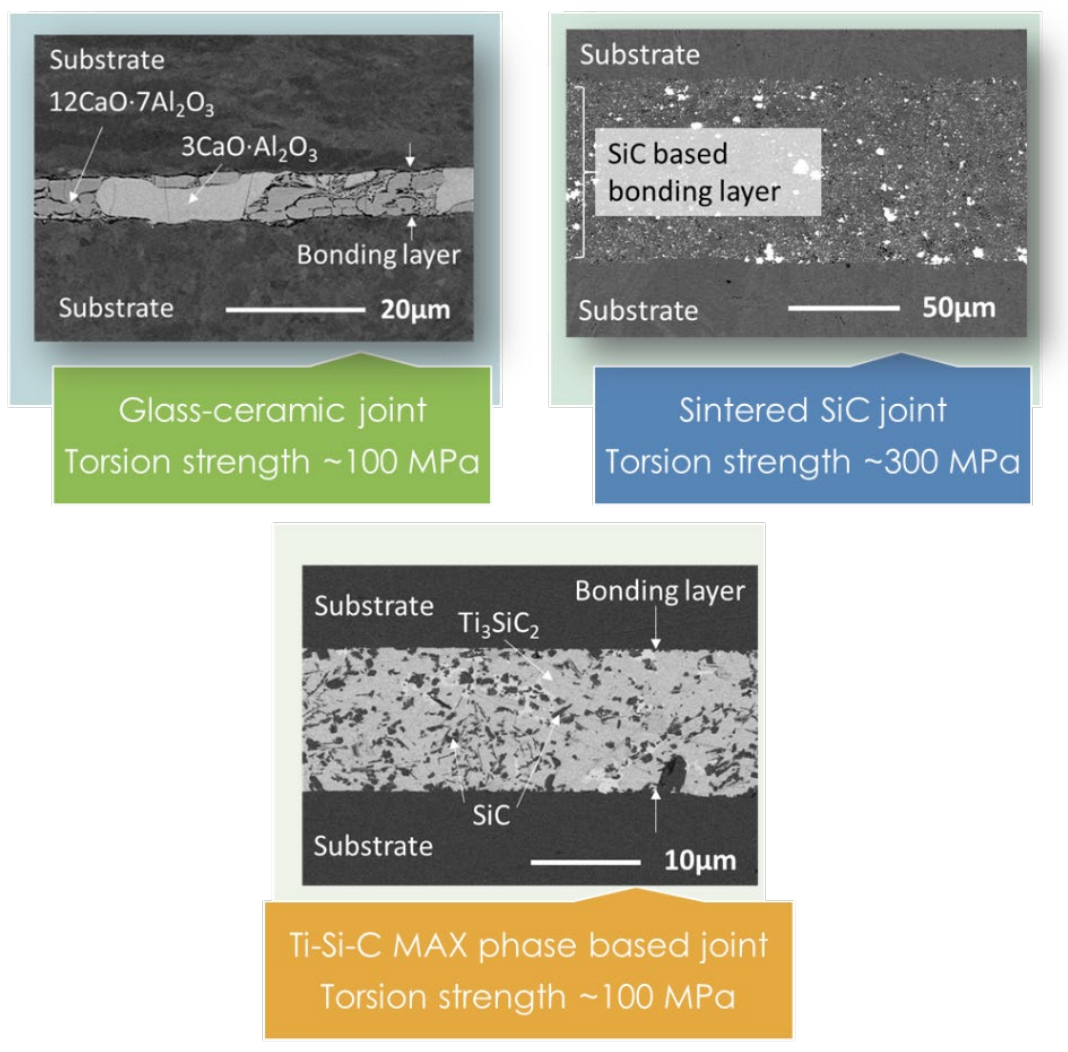

Figure 29. SiC joints tested in study of the effects of high dose neutron irradiation. 


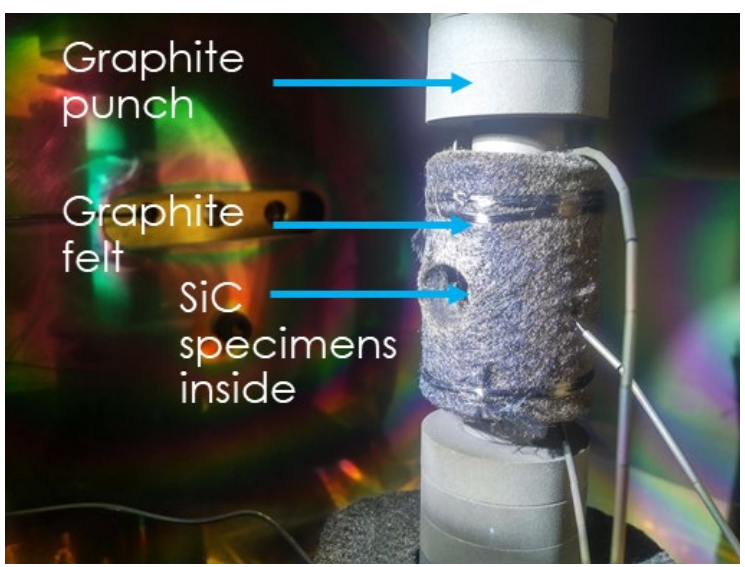

Figure 30. Experimental setup for electric current assisted joining of SiC. Shows absence of graphite die surrounding the specimen and carbon felt used only around the punches. 


\subsection{ADVANCED CHARACTERIZATION OF IRRADIATED SILICON CARBIDE: DETERMINATION OF NEUTRON IRRADIATION TEMPERATURES USING ELECTRICAL RESISTIVITY}

\section{T.Koyanagi (koyangit@ornl.gov), H.Wang, Y. Katoh (ORNL)}

\section{OBJECTIVE}

The goal of this task is to develop an advanced characterization technique for determination of irradiation temperature using an irradiated passive $\mathrm{SiC}$ temperature monitor. The experimental determination of irradiation temperature is a key requirement of all irradiation studies.

\section{SUMMARY}

The irradiation temperature of $\mathrm{SiC}$ was determined by post-irradiation measurement of the recovery of the electrical resistivity due to thermal annealing in a rapid heating/cooling optical furnace. We have demonstrated that this electrical resistivity measurement is effective for determining the irradiation temperature of SiC. A manuscript based on this study has been published in Journal of Nuclear Materials $540(2020) 152370$.

\section{PROGRESS AND STATUS}

High-purity, high resistivity grade CVD SiC temperature monitors irradiated in HFIR were subjected to isochronal annealing cycles during which electrical resistivity was measured using the setup shown in Figure 31. Neutron collisions in the $\mathrm{SiC}$ result in displaced lattice atoms (interstitials) that act as electron donors yielding a significant decrease in electrical resistivity. The irradiation defects become thermodynamically unstable and start to recombine when heated above the irradiation temperature, resulting in a recovery of the electrical resistivity. The resistivity was measured at a fixed elevated temperature, chosen to be above the ambient but below the nominal irradiation temperature. When the resistivity was plotted as a function of annealing temperatures, a clear increase was observed when annealed above the irradiation temperature due to the recovery of irradiation defects (Figure 32). Based on this result, we could experimentally investigate irradiation temperature of $\mathrm{SiC}$ material.

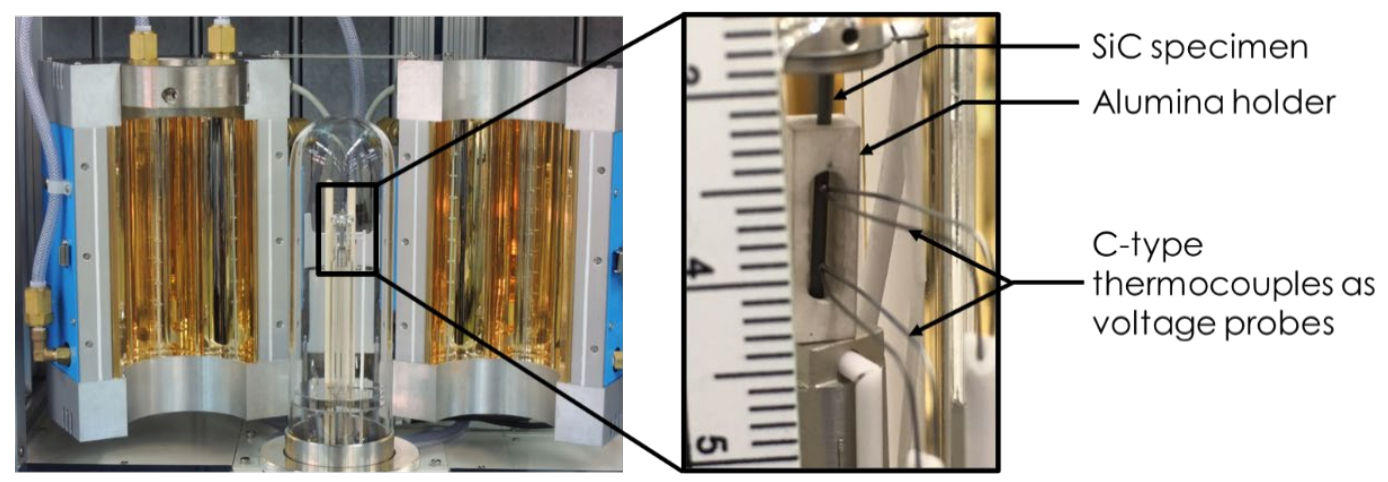

Figure 31. ULVAC-Riko ZEM-5 electrical resistivity/Seebeck coefficient measurement system. The open optical furnace shows the quartz tube heating elements and the enlargement shows details of the sample and electrical measurement leads centered in the chamber. Scale marks are in inches. 


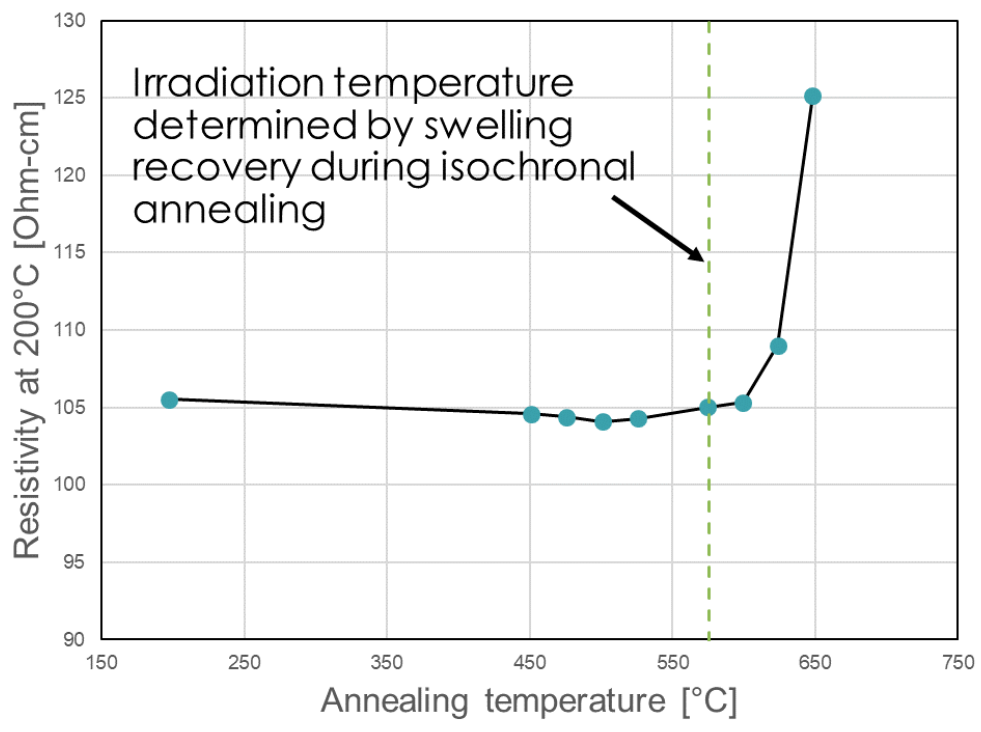

Figure 32. Electrical resistivity of $\mathrm{SiC}$ as a function of peak annealing temperature following neutron irradiation at $\sim 550^{\circ} \mathrm{C}$. The resistivity was measured at $200^{\circ} \mathrm{C}$ after each isochronal annealing step.

\section{FUTURE PLANS}

This newly developed technique is now an option for determination of irradiation temperature for future irradiation experiments. 


\subsection{DEFECT CHARACTERIZATION IN IRRADIATED TiB 2 BY ELECTRON MICROSCOPY AND ADVANCED ANALYSIS}

Arunodaya Bhattacharya (bhattacharya@ornl.gov), Rama Vasudevan, Andrew Lupini, Yutai Katoh (ORNL), Steve Zinkle (UT-Knoxville)

\section{OBJECTIVE}

Ultra-high temperature ceramics (UHTC) such as isotopically modified $\mathrm{TiB}_{2}$ may offer game changing impact on first-wall/plasma facing fusion structural design space owing to their excellent high temperature properties. But the irradiation effects on properties of such ceramics are largely unexplored. Our objective is to understand the atomic level defect formation and configuration in $\mathrm{TiB}_{2}$ after fusion relevant irradiation conditions by combining advanced characterization with advanced data science methods.

\section{SUMMARY}

By combining high-resolution scanning transmission electron microscopy (HR-STEM) with machine learning (ML) and advanced statistical analysis, we show atomic scale defect clusters and identified atomiclevel displacements in the atom columns in irradiated $\mathrm{TiB}_{2}$. We provide example results from ion irradiated $\mathrm{TiB}_{2}$ where defects clusters, strain buildup and strain direction were identified at the atomic level. The results open new avenues of research for studying irradiation effects in UHTCs and highlight the role of advanced data science in characterizing nuclear irradiation effects.

\section{PROGRESS AND STATUS}

We studied hexagonal $\mathrm{TiB}_{2}$ using $8 \mathrm{MeV}$ Ti ion irradiation at $200^{\circ} \mathrm{C}$ to 15 dpa mid-range dose. Figure 33 shows the atomic scale high-angle annular dark field (HAADF) image of $\mathrm{TiB}_{2}$ in unirradiated and irradiated conditions. The unirradiated state shows a near-perfect arrangement of the atomic columns. After irradiations, the atomic columns were imperfect and show some warping. The encircled area in Figure 33 in the irradiated sample revealed features representing irradiation induced kink formation in the atomic planes. These defects appeared different than typical loop type defects expected in most materials. Most defects were contained along the prismatic planes of the hexagonal crystal structure.

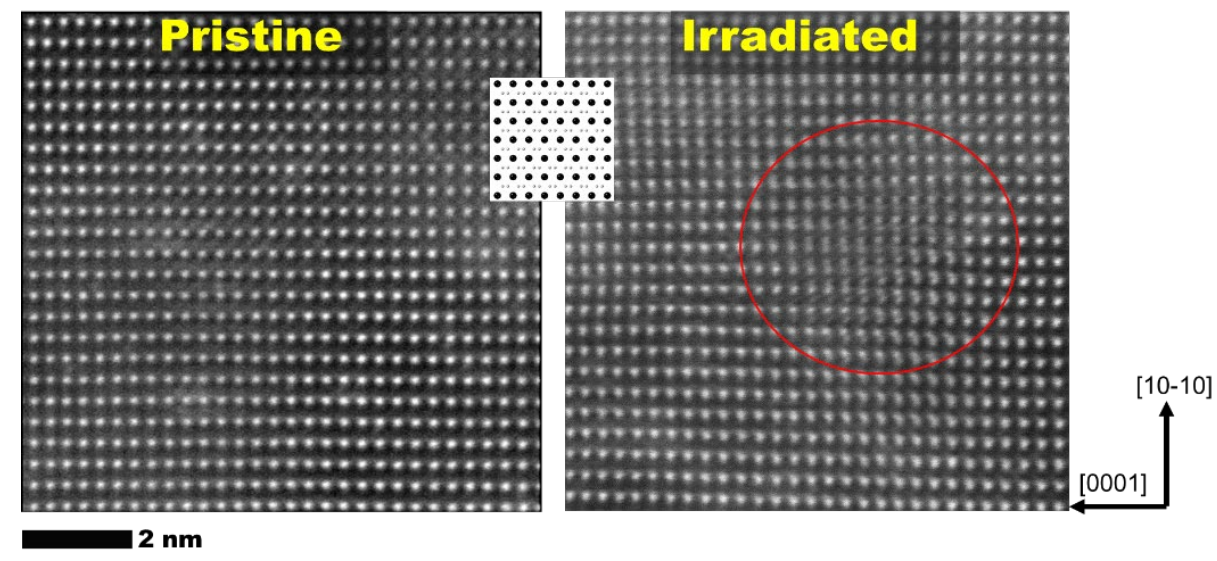

Figure 33. Atomic-scale HAADF images showing the arrangement of atomic columns when imaged along [11-20] zone axis in unirradiated and irradiated $\mathbf{T i B}_{2}$. The encircled region shows irradiation induced defects that look like kinks. 
To better understand the defects in $\mathrm{TiB}_{2}$, a combination of machine learning and advanced statistical data analysis methods were used. A machine learning module developed for hexagonal materials was used to identify the atoms in the HAADF image. Figure 34a shows the raw HAADF image of the irradiated sample and Figure $34 \boldsymbol{b}$ shows that the machine learning module successfully matched the atoms in the HAADF image. The atomic position data was then used to perform Local Crystallography Analysis, where the configurations of 8 nearest neighbor atoms was evaluated (Figure 34c). Using this method, a data set representing the atom locations with respect to their original positions with their local neighborhood, known as nearest neighbor point clouds, was generated (Figure 34d). A comparison of the atom distributions using the point clouds for the irradiated and initial samples is given in Figure 35 where the difference between the two cases is shown. In the irradiated case, numerous atoms/atomic columns were displaced from the original positions, giving rise to vertical lines/streaks. Without ML plus statistical analysis, the slightly displaced atoms/columns giving rise to the vertical lines in the point clouds were nearly invisible to the human eye.

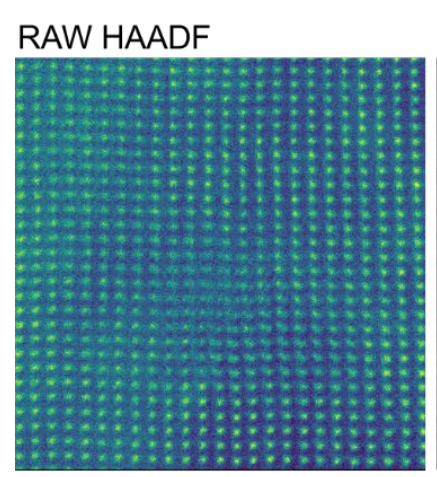

(a)

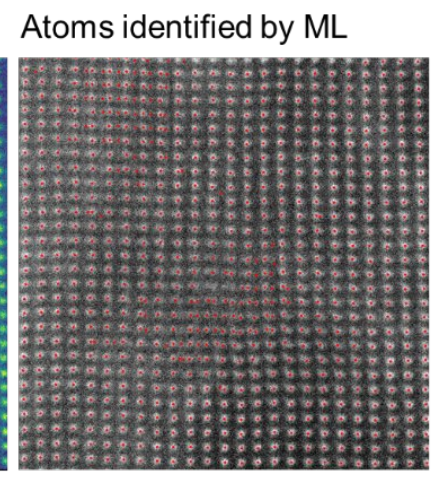

(b)

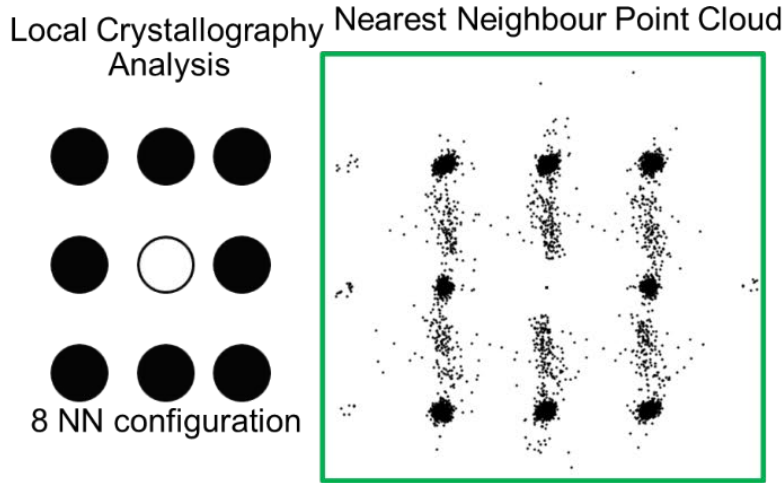

(c)

(d)

Figure 34. Machine learning and local crystallography analysis of irradiated $\mathrm{TiB}_{2}$ data. (a) HAADF image (b) atoms identified in the HAADF image by machine learning, (c) a schematic showing 8 nearest neighbour configurations used for local crystallography analysis and (d) point cloud of atoms from local crystallography analysis.
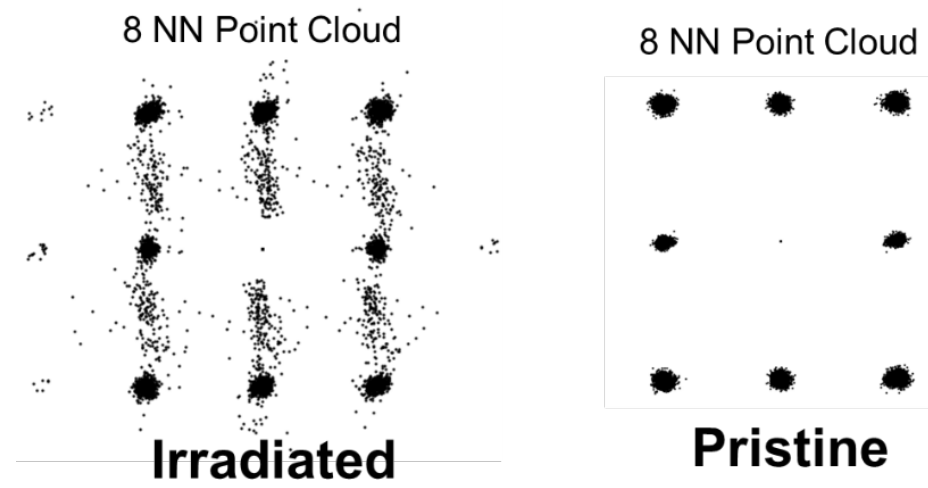

Figure 35. Atom distributions represented by point clouds compared for the irradiated and unirradiated $\mathrm{TiB}_{2}$. The vertical lines are constituted by the atoms/columns that are slightly displaced from their regular lattice sites. 
Using the local crystallography data (point clouds) as input to statistical methods, namely Principal Component Analysis (PCA), the revealed defected regions in the irradiated $\mathrm{TiB}_{2}$ samples. This is shown in the examples of the two major PCA components in Figure 36. The extent and the direction of lattice displacements from the irradiation induced defects in $\mathrm{TiB}_{2}$ identified in the two PCA components are also shown in Figure 36 (as dot-arrow diagrams). For component 1, which is somewhat representative of the overall matrix (mostly blue and red atoms), one can see that the net effect of the irradiation is the diagonal atoms are slightly pushed outwards while the centre atoms are pushed inwards, but the displacements are small. However, in the locally defected regions, significant displacement of a diagonal atom outwards and a centre atom inwards from the regular sites was identified.

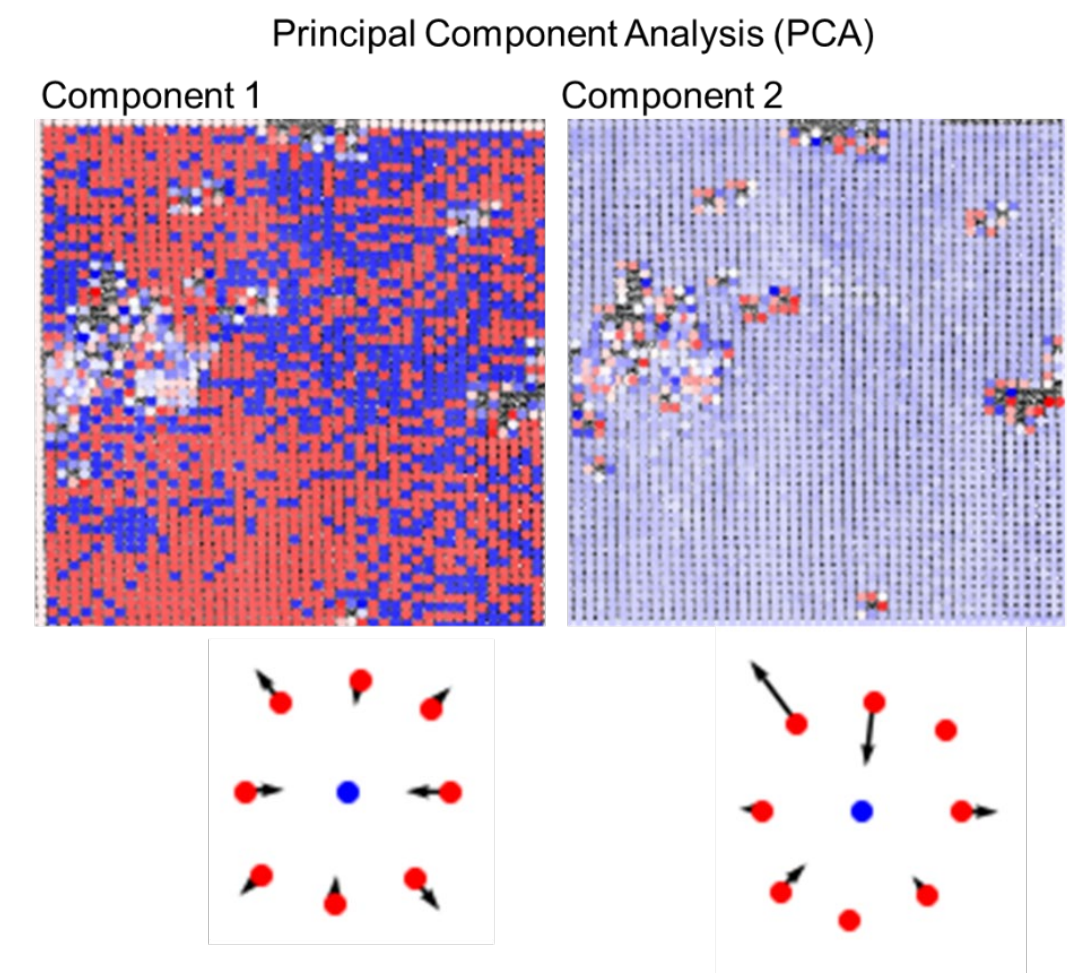

Figure 36. PCA of irradiated point cloud data, identifying two major components in the HAADF images. Component 2, which is also visible in Component 1 identified a locally defected structure generating strong displacement of lattice atoms from their regular sites.

\section{FUTURE RESEARCH DIRECTION}

These results show that atomic scale HAADF, when analyzed using advanced data science methods, provide substantial insight into atomic displacements in and around defects. In future, we will convert the qualitative estimation of atom displacements into quantitative results of changes in the lattice parameters, which can be directly used in defect modeling such as Density Functional Theory (DFT) calculations. 


\section{HIGH HEAT FLUX AND PLASMA FACING MATERIALS}

\subsection{IRRADIATION EFFECTS ON THERMAL AND MECHANICAL PROPERTIES OF TUNGSTEN - PHENIX COLLABORATION}

\section{M. Garrison (garrisonlm@ornl.gov), J. Echols, N. Reid, T. Miyazawa, M. Akiyoshi, Y. Katoh}

\section{OBJECTIVE}

The PHENIX collaboration will expand the database on neutron irradiation effects on tungsten materials.

\section{SUMMARY}

The RB*19J capsule irradiated over 20 varieties of tungsten in HFIR in three temperature zones, nominally 500,800 , and $1200^{\circ} \mathrm{C}$. Tensile tests of all materials at the irradiation temperatures have been completed. Most materials were brittle when tested at $700^{\circ} \mathrm{C}$ after irradiation to $\sim 0.7 \mathrm{dpa}$ at $\sim 800^{\circ} \mathrm{C}$. Fracture surface imaging in the scanning electron microscope (SEM), hardness tests on all materials and thermal diffusivity tests on select materials have been completed. The alloys containing Re have significantly lower thermal diffusivity than the unalloyed tungsten, while the unalloyed and irradiated tungsten have higher thermal diffusivity than the unirradiated $\mathrm{W}-3 \%$ Re. The results indicate that transmutation of $\mathrm{W}$ to Re and Os is less than $3 \%$ in the thermal neutron shielded capsule.

\section{PROGRESS AND STATUS}

The results for one example material, ALMT produced polycrystalline tungsten, is shown in Figure 37. For all conditions, the irradiated material is stronger and less ductile than the unirradiated sample tested at the same temperature. The polycrystalline $\mathrm{W}$ was brittle after irradiation to the middle dose and temperature, $776^{\circ} \mathrm{C}$ and $0.69 \mathrm{dpa}$. The same trend was observed for the single crystal tungsten irradiated in this campaign.

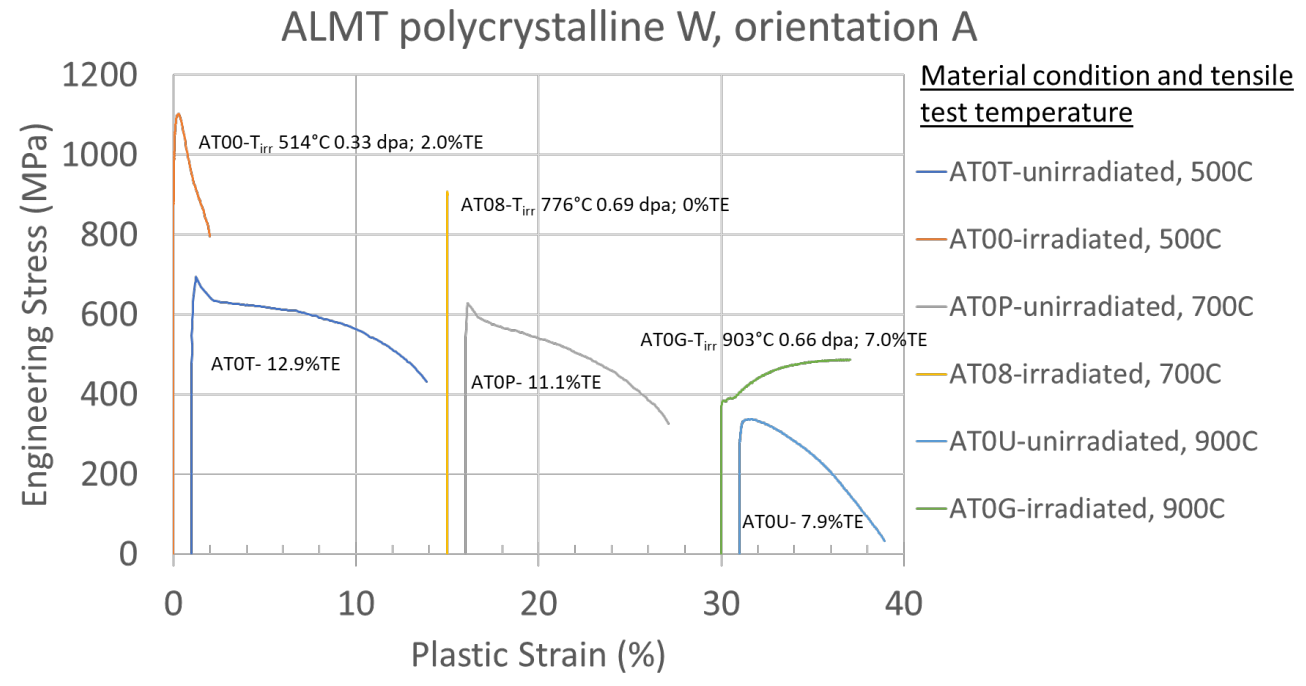

Figure 37. Tensile properties of polycrystalline tungsten machined in the " $A$ " orientation and tensile tested before and after irradiation at test temperatures of 500,700 , and $900^{\circ} \mathrm{C}$. 
Thermal diffusivity of select materials was measured with the NETZSCH LFA-467HT hyper flash analyzer operating in vacuum, with the results shown in Figure 38. For unalloyed tungsten and K-doped W-3\%Re the samples were prepared with the grains elongated either perpendicular or parallel to the surface. The grain orientation has a much smaller effect on the thermal diffusivity than the Re alloying. The unalloyed tungsten had an approximately $20 \%$ drop in thermal diffusivity at room temperature after irradiation. The difference between the unirradiated and irradiated thermal diffusivity values decreases with increasing temperature. The irradiated unalloyed tungsten has a higher thermal diffusivity than the unirradiated Kdoped W-3\% Re material, which indicates that the transmutation in the unalloyed tungsten was less than $3 \%$. The K-doped W-3\% Re material had an approximately 10\% drop in thermal diffusivity at room temperature due to neutron irradiation.

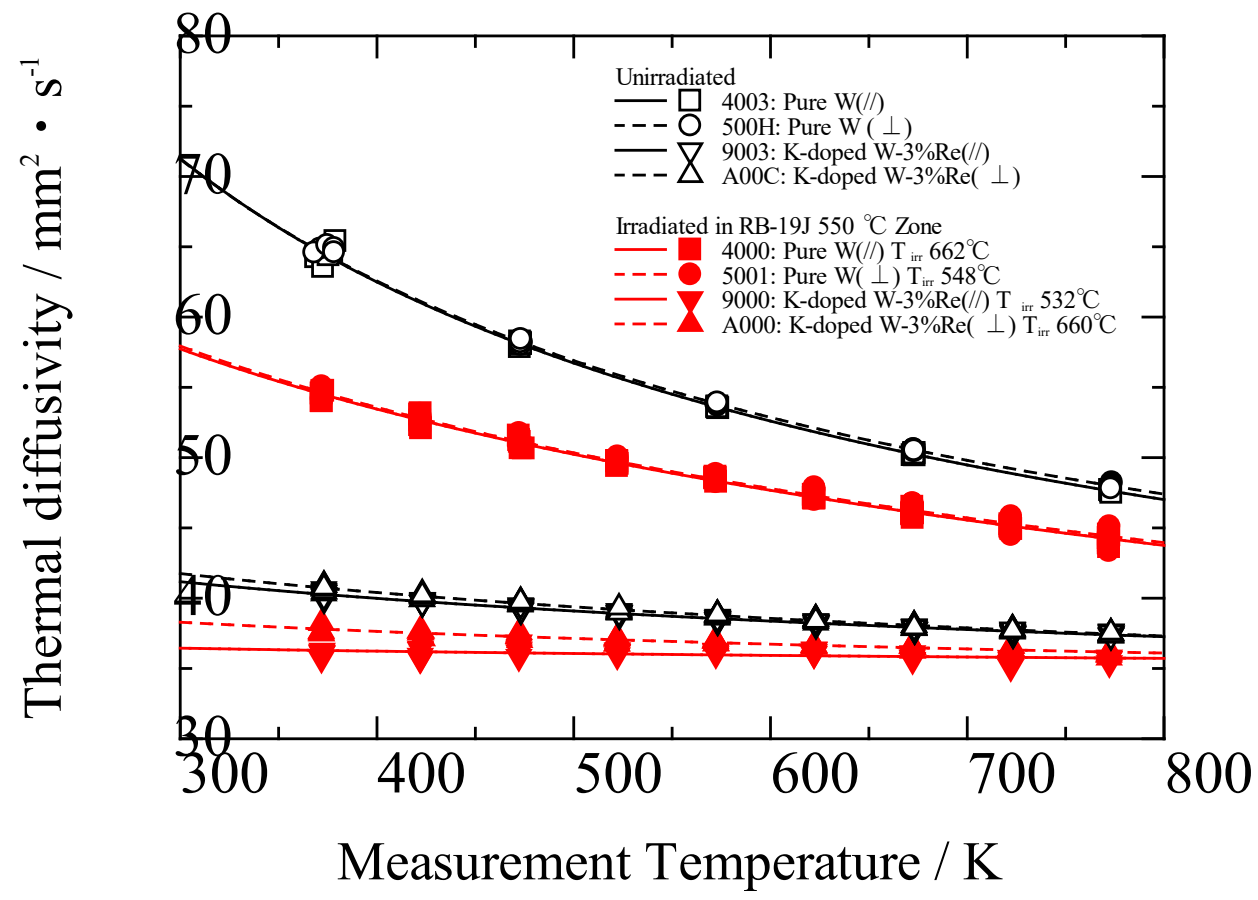

Figure 38. Thermal diffusivity of as-irradiated and unirradiated tungsten materials. The open and black symbols represent unirradiated specimens and the filled and red symbols the irradiated specimens. Reproduced from Masafumi Akiyoshi, Lauren M. Garrison, Josina W. Geringer, Hsin Wang, Akira Hasegawa, Shuhei Nogami, and Yutai Katoh. "Thermal diffusivity of irradiated tungsten and tungsten-rhenium alloys." Accepted by Journal of Nuclear Materials. September 2020. 


\subsection{TENSILE PROPERTIES OF TUNGSTEN FIBERS FOR APPLICATION IN COMPOSITE MATERIALS}

\section{L.M. Garrison (garrisonlm@ornl.gov), J.R. Echols, M. Gussev (ORNL)}

\section{OBJECTIVE}

The goal of this project is to develop a method for tensile testing of tungsten fibers and to determine the mechanical properties of the fibers for use in fiber strengthened composites.

\section{SUMMARY}

A new method and fixture were developed for tensile testing fibers at room temperature. Tungsten fibers were irradiated as part of the PHENIX collaboration in the HFIR RB*19J capsule. Initial tests of the irradiated tungsten fibers have been completed, and the fibers retain some ductility at room temperature after irradiation. The next tests will compare unalloyed $\mathrm{W}$ and $\mathrm{K}$-doped tungsten fibers and heat treated versus as-produced tungsten fibers.

\section{PROGRESS AND STATUS}

Tungsten fiber reinforced tungsten composites are a promising material for plasma-facing components. The fibers provide the strength and toughness for the brittle matrix. Because the fibers dominate the properties of the composite, it is important to understand their properties before and after irradiation. Three types of tungsten fibers with $150 \mu \mathrm{m}$ diameter and 37 to $40 \mathrm{~mm}$ length were irradiated in HFIR in the

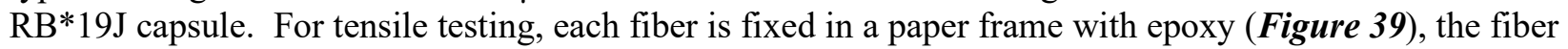
coated with white spray paint, then a speckle pattern created with a fine mist of black spray paint. The mounted specimen is loaded into the test machine grips, with grip s contacting only the paper frame beyond the ends of the fiber. Test load is thus transferred to the specimen while strain can be measured by noncontact camera viewing of the speckle pattern on the gage section of the fiber. (Figure 40).

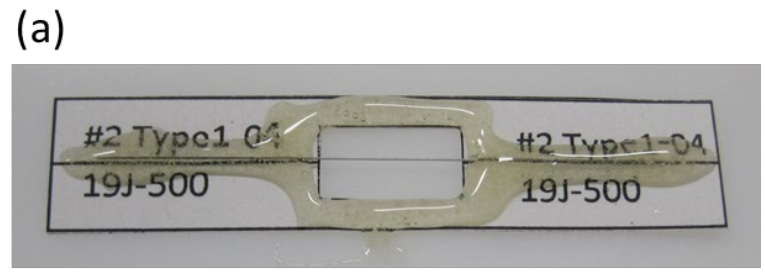

(b)

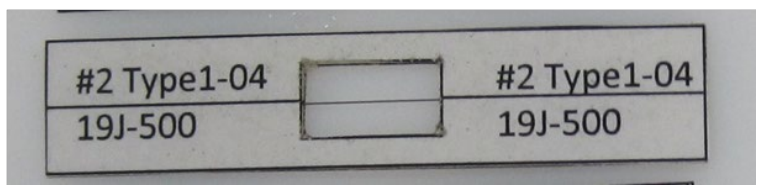

Figure 39. (a) One neutron irradiated fiber was placed in the epoxy on the bottom half of the paper frame. (b) A second layer of paper was placed on top of the fiber and epoxy. The paper frame provides support when loading the fiber in the test frame. The sides of the frame are cut before the tensile test. 
(a)

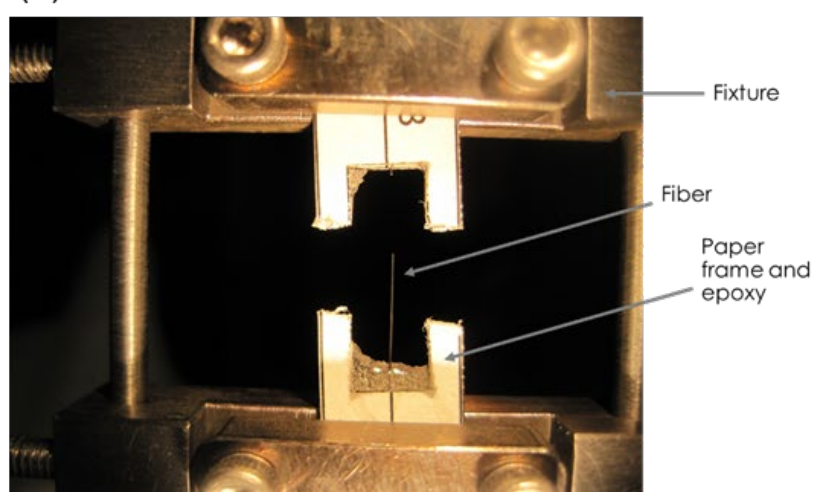

(b)

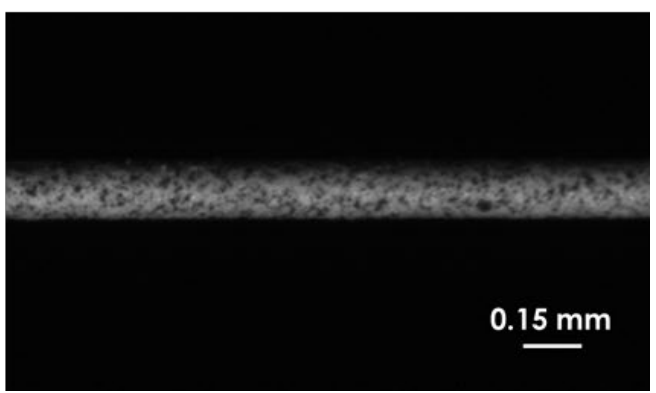

Figure 40. (a) Close up view of a fiber after a successful tensile test. Epoxy fixes the fiber ends inside the paper frame, and the paper plus epoxy ensure that the metal clamp of the fixture does not have any direct contact with the delicate fibers. (b) Camera image of the speckle paint pattern on the fiber surface.

The fibers for this experiment were irradiated at three conditions, approximately $0.2 \mathrm{dpa}$ at $500^{\circ} \mathrm{C}, 0.7 \mathrm{dpa}$ at $800^{\circ} \mathrm{C}$, and $0.7 \mathrm{dpa}$ at $1000^{\circ} \mathrm{C}$. The results of room temperature tensile tests of unalloyed tungsten (Type 3 fiber) specimens from the lower two temperatures are shown in Figure 41. The fiber had minimal change in tensile properties after $0.2 \mathrm{dpa}$ irradiation, but after $0.7 \mathrm{dpa}$ irradiation the fiber has lost significant ductility and the fracture surface shows a distinct difference. Despite this, the fibers are promising because they show some ductility at room temperature and some of that ductility remains after irradiation, whereas plate produced tungsten retained room temperature ductility only for elevated temperature irradiations.

\section{FUTURE WORK}

Some tests of unalloyed W (Type 3) and K-doped and heat treated (Type 2) fibers after irradiation at 500 and $800^{\circ} \mathrm{C}$ have been completed. The tests for all fibers from the $1000^{\circ} \mathrm{C}$ irradiation temperature zone and the remaining K-doped fibers (Type 1) will be completed. The digital image correlation data will be analyzed to give more information about the deformation and fracture of the fibers. 


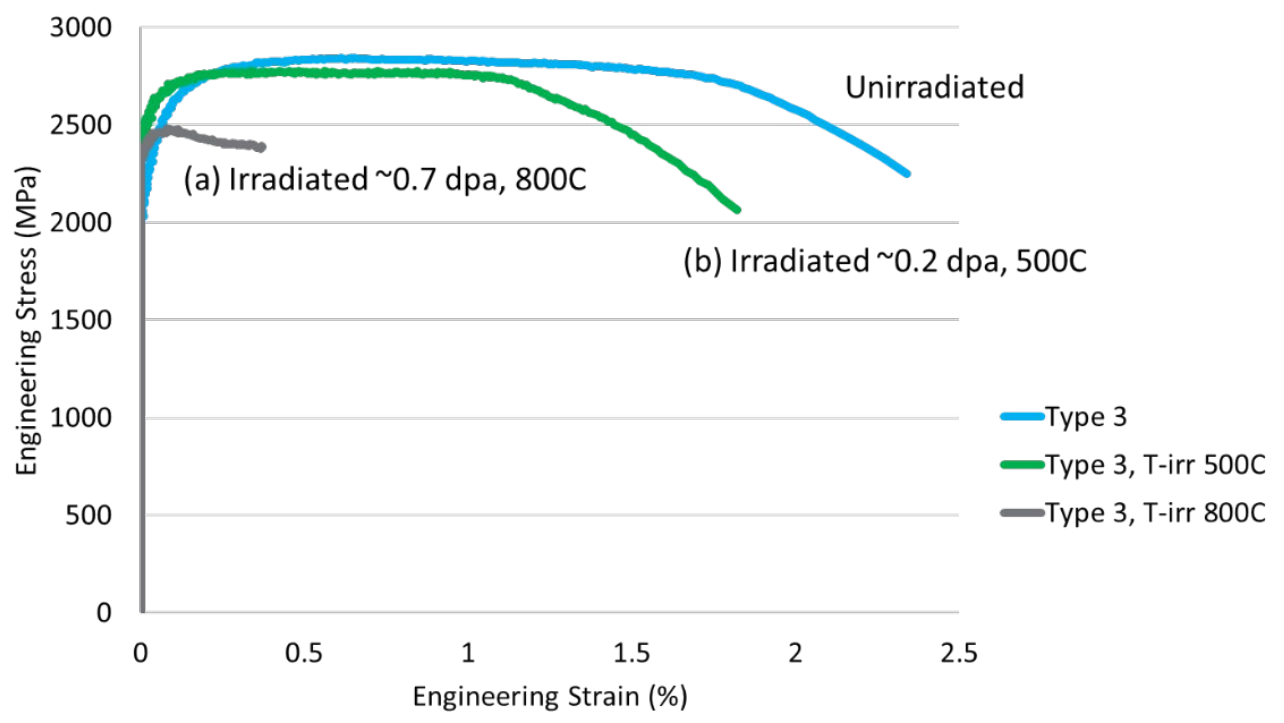

(a)

(b)
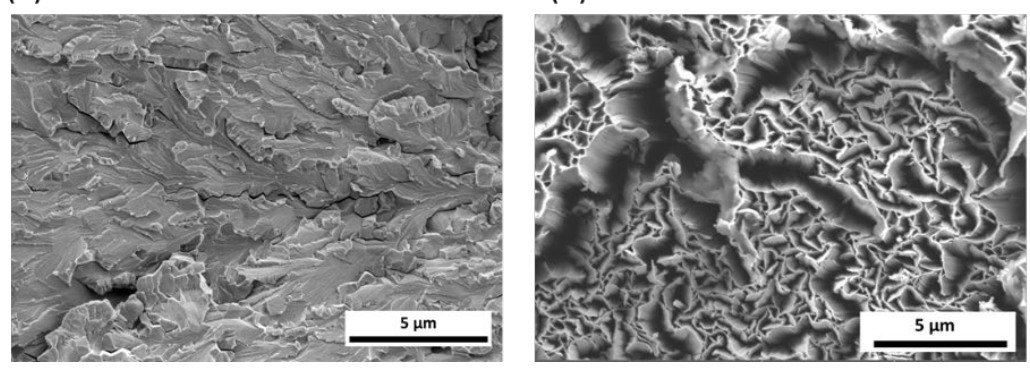

Figure 41. Unalloyed tungsten fiber (Type 3) tensile tested at room temperature. (a) Fracture surface after irradiation to $0.7 \mathrm{dpa}$ at $800^{\circ} \mathrm{C}$ shows brittle cleavage. (b) Fracture surface after $0.2 \mathrm{dpa}$ at $500^{\circ} \mathrm{C}$ shows each grain elongated to a ductile knife edge failure. 


\subsection{EFFECT OF IRRADIATION ON THE ELECTRICAL RESISTIVITY OF TUNGSTEN MATERIALS - PHENIX COLLABORATION}

\section{J.R.Echols (echolsjr@ornl.gov),L.M. Garrison(ORNL)}

\section{OBJECTIVE}

The PHENIX collaboration is directed at expanding the database on neutron irradiation effects in tungsten materials. This task is evaluating the effects of irradiation on the electrical resistivity.

\section{SUMMARY}

Electrical resistivity of single and polycrystalline tungsten samples exposed to neutron radiation between 0.2 and $0.7 \mathrm{dpa}$ is shown to increase but does not show a clear trend on the basis of dpa alone. Polycrystalline samples with elongated grains exhibit measurable changes in resistivity for different sample orientations and this effect is exaggerated following irradiation - indicating that grain boundaries play a role in changes of resistivity during irradiation.

\section{PROGRESS AND STATUS}

The US-Japan collaboration, PHENIX, has a goal of investigating tungsten and tungsten-based materials' response to neutron irradiation for use in future fusion reactors. To this end, the PHENIX collaboration exposed over 1500 single crystal, polycrystalline, and W-Re alloy samples in the RB*19J irradiation capsule in the High Flux Isotope Reactor (HFIR) to doses of $\sim 0.2-0.7$ dpa. The nominal irradiation temperatures for three different capsules were 430-670, 740-960, and $880-1080^{\circ} \mathrm{C}$. A gadolinium shield was included in the capsule to reduce the thermal neutron flux (and therefore the rate of $\mathrm{W}$ to $\mathrm{Re}$ and Os transmutations) to more fusion relevant values.

Tungsten's high thermal conductivity, in particular, is critical for its use as a component material in fusion reactors and one of the reasons for the material's popularity. Neutron irradiation, however, will degrade the thermal conductivity of tungsten components. To understand the separate effects of electronic and phononic heat transfer, electrical conductivity must be measured and compared against thermal conductivity measurements. New electrical resistivity measurement systems have been designed and optimized for small sample geometries required by many HFIR irradiation campaigns and utilized by the PHENIX collaboration. These fixtures are shown in Figure 42. 

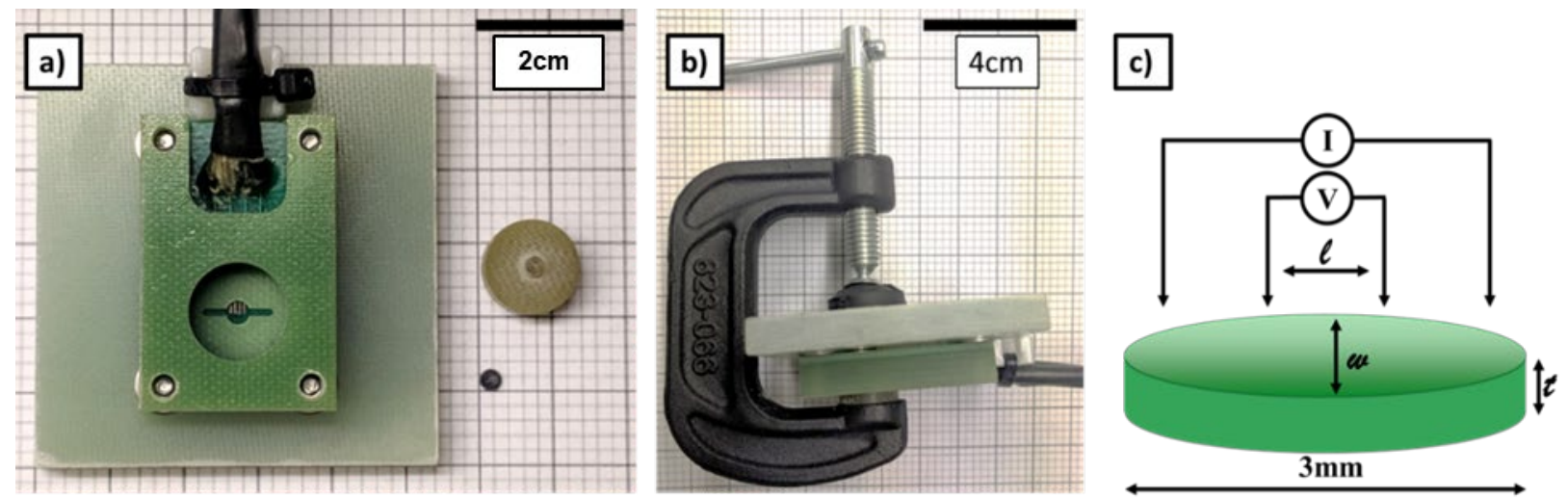

Figure 42. Electrical resistivity measuring apparatus. For each image, major gridlines are $1 \mathrm{~cm}$ apart. a) Disassembled $3 \mathrm{~mm}$ disk holder. Apparatus on left, example $3 \mathrm{~mm}$ disk and plug on right. b) Assembled $3 \mathrm{~mm}$ disk fixture. The plug is clamped in the apparatus to ensure good contact with the pins. c) Simplified $3 \mathrm{~mm}$ disk circuit schematic.

Electrical resistivity was measured for thick plate ALMT produced polycrystalline tungsten with elongated grains (material codes AT and BT) and single-crystal tungsten (material code UE). For the polycrystalline material, samples were cut in different orientations with respect to the elongated grains. AT series samples were cut at 90 degrees relative to BT series samples. Examples of the microstructure when viewing the sample face are given in the top half of Figure 43. Grain size calculations on these images utilizing the linear intercept method indicate an average grain length of 2.1 microns for the AT series, and 1.4 microns or 2.3 microns for the BT series in the horizontal and vertical directions, respectively.

BT series polycrystalline samples, when rotated in the resistivity fixture between measurements, exhibit a periodicity in resistivity. The bottom half of Figure 43 shows the angular-to-resistivity relationship for selected BT samples, along with a comparison for the equiaxed AT series samples. The equiaxed AT series sample does not show any apparent periodicity. For the irradiated BT specimen, there is an approximately $5 \%$ change in resistivity depending on the sample orientation. There is also an apparent difference in amplitude in the BT series samples. The unirradiated amplitude is $\sim 10^{9}$ while the irradiated sample BT02 is approximately double that. It is likely that either radiation defects and/or transmutant element segregation to the grain boundaries is responsible for this amplitude increase. 
AT Orientation - No Irradiation

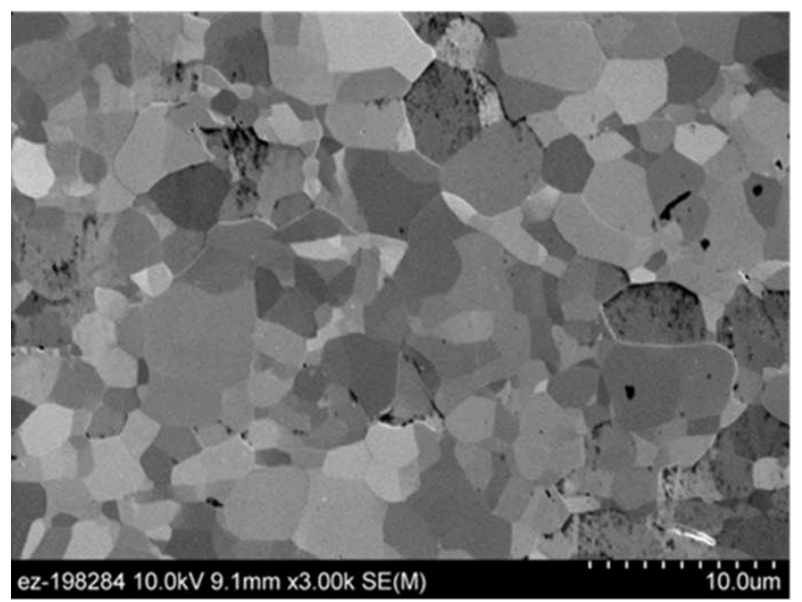

AT01

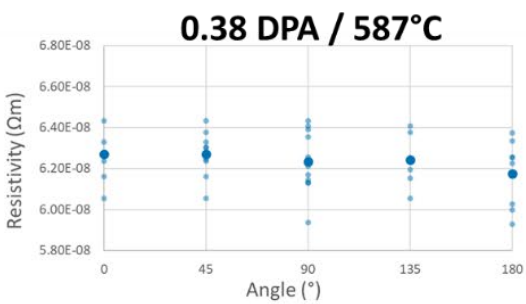

10.0um

\section{BT02}

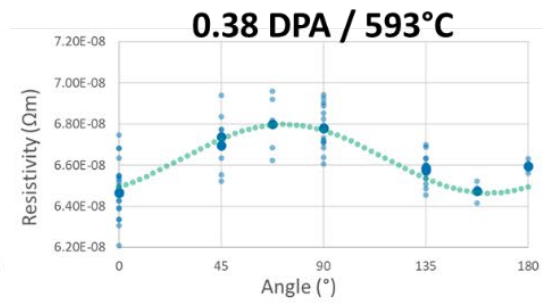

BT Orientation - No Irradiation

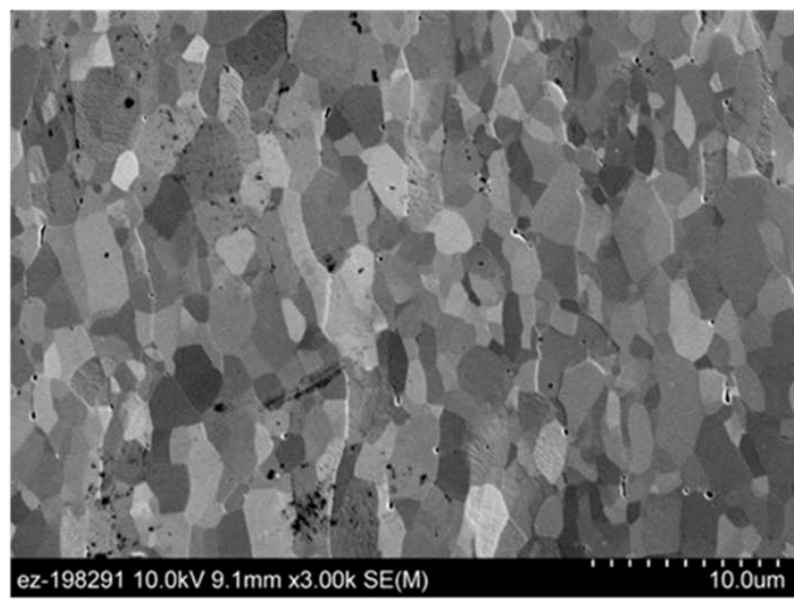

BT Series

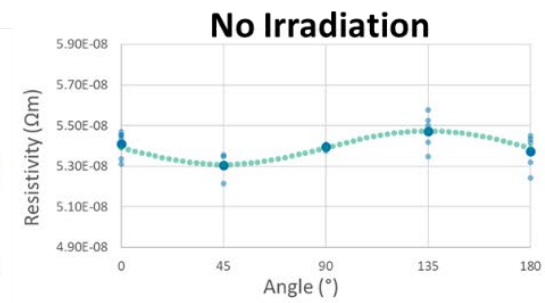

Figure 43. (top) Unirradiated grain structure for AT (isotropic grains) and BT (elongated grains) series materials. (bottom) Electrical resistivity as a function of sample rotational orientation relative to the probes for selected polycrystalline samples. Average values are shown with larger, darker icons and individual measurements are given with smaller, lighter icons. Sine waves fit to the BT series samples are shown in aqua alongside the data. The 0 -degree angle is arbitrary for individual samples because the grains are too small to see with the eye when inserting samples in the fixture. Resistivity values are tentative and may change slightly in future reports.

Electrical resistivity measurements for a subset of the investigated samples are shown in Figure 44. Unirradiated tungsten from the BT series exhibits resistivity near $0.54 \mathrm{n} \Omega \mathrm{m}$, while the UE series has a slightly lower value around $0.52 \mathrm{n} \Omega \mathrm{m}$. All polycrystalline samples exhibit resistivity in excess of 0.59 $\mathrm{n} \Omega \mathrm{m}$ following irradiation. There does not appear to be a simple relationship between resistivity and either irradiation temperature or dose - with samples irradiated to higher doses and temperatures. This effect is likely a result of higher temperatures enabling lower concentrations of radiation-induced defect clusters that inhibit electron transfer but may also be a result of recrystallization.

One sample of single crystal tungsten, UE02, exhibits low resistivity, near $0.57 \mathrm{n} \Omega \mathrm{m}$, following irradiation. UE06, however, which was irradiated at higher temperature and approximately double the dose, has resistivity more similar to the polycrystalline samples. 


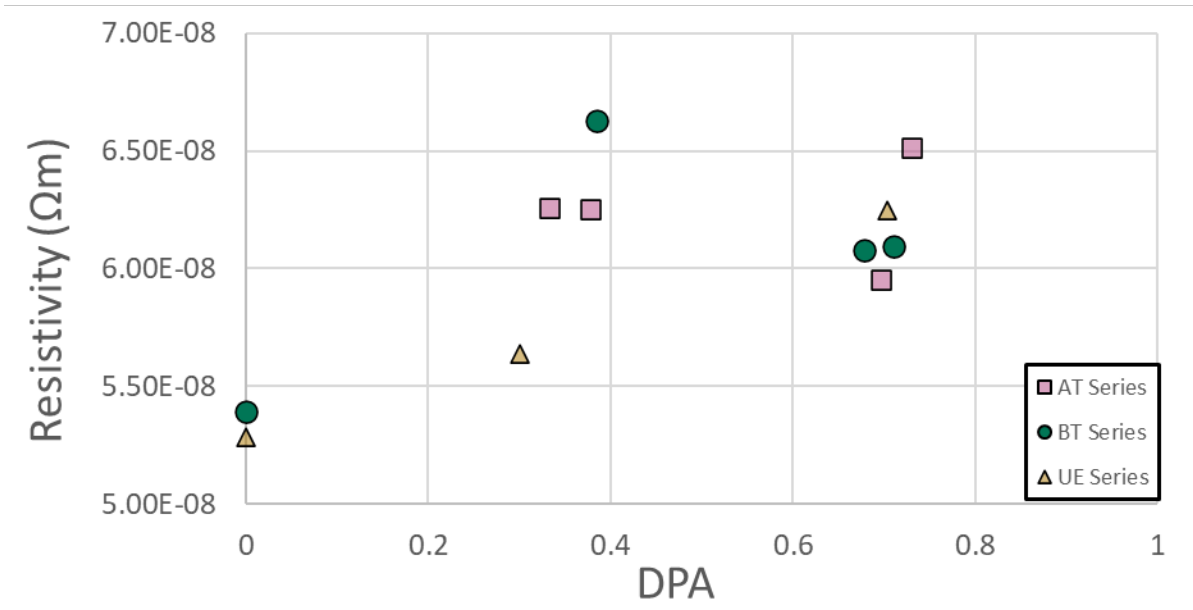

Figure 44. Tentative electrical resistivity of irradiated, AT, BT, and UE series tungsten materials as a function of dpa. Approximate irradiation temperature for each sample is given in the legend. Measurements were taken between $20^{\circ} \mathrm{C}$ and $24^{\circ} \mathrm{C}$ and normalized to $20^{\circ} \mathrm{C}$

\section{FUTURE PLANS}

Data analysis is currently underway to quantify the apparent grain boundary resistivity upon irradiation for all three irradiation conditions as well as to investigate recrystallization behavior. This work, when considered together with raw resistivity change and thermal conductivity measurements, will provide the basis for the mechanistic understanding of tungsten conductivity changes under fusion-relevant neutron irradiation. 


\title{
4.4 MICROSTRUCTURES OF IRRADIATED TUNGSTEN
}

\author{
C.M.Parish (parishcm@ornl.gov),D.G.Morrall (ORNL)
}

\section{OBJECTIVE}

The overarching objective of this work is to bridge the gap between the atomistic knowledge and models and the phenomenological materials science underlying the design, fabrication, and service of divertor and other plasma-facing materials for magnetic confinement fusion. Specifically, the influence of intrinsic defects (dislocations, grain boundaries) and extrinsic defects (ion- and neutron-irradiation damage, impurities) interactions with $\mathrm{He}$ and bubbles, in terms of nucleation sites, growth, trapping, and surface degradation, will be measured.

\section{SUMMARY}

This year we have explored both radiation damage microstructures in continued analysis of the HFIRRB*19J capsule neutron-irradiated tungsten.

\section{PROGRESS AND STATUS}

Neutron-irradiated tungsten specimens from the HFIR-RB*19J gadolinium-shielded capsule were examined. Electron backscatter diffraction (EBSD) was used to examine the grain sizes of the polycrystalline specimens. In particular, high-temperature irradiations in the $19 \mathrm{~J}$ experiment were found to cause complete recrystallization despite low $\left(\sim 1000^{\circ} \mathrm{C}\right)$ temperature, a surprising and important result. Figure 45 shows $500^{\circ} \mathrm{C}, 800^{\circ} \mathrm{C}$, and $1000^{\circ} \mathrm{C}$ irradiated samples of thick-plate tungsten. Clearly, the $1000^{\circ} \mathrm{C}$ samples showed complete recrystallization, whereas the others retained their as-hot-worked structure. Recrystallization is well known to catastrophically degrade the mechanical properties of tungsten, so this will have important implications on the plasma-facing service characteristics of tungsten in a fusion nuclear environment.

The 500 and $800^{\circ} \mathrm{C}$ samples show average grain sizes of $\approx 2.3 \mu \mathrm{m}$, with ranges from 0.6 to $22 \mu \mathrm{m}$. The $1000^{\circ} \mathrm{C}$, on the other hand, shows an average of $\approx 22.1 \mu \mathrm{m}$ grain size with a range of 2.5 to $87.6 \mu \mathrm{m}$; that is, roughly ten times the grain diameter $(\sim 100 \times$ the area). Although "recrystallization temperature" is not a thermodynamic parameter but rather varies widely depending on many factors (such as time at temperature, dislocation density, etc.), recrystallization of wrought tungsten is generally in the $1300+{ }^{\circ} \mathrm{C}$ range, so recrystallization here at $\approx 1000^{\circ} \mathrm{C}$ is indicative of a radiation-accelerated processes. 


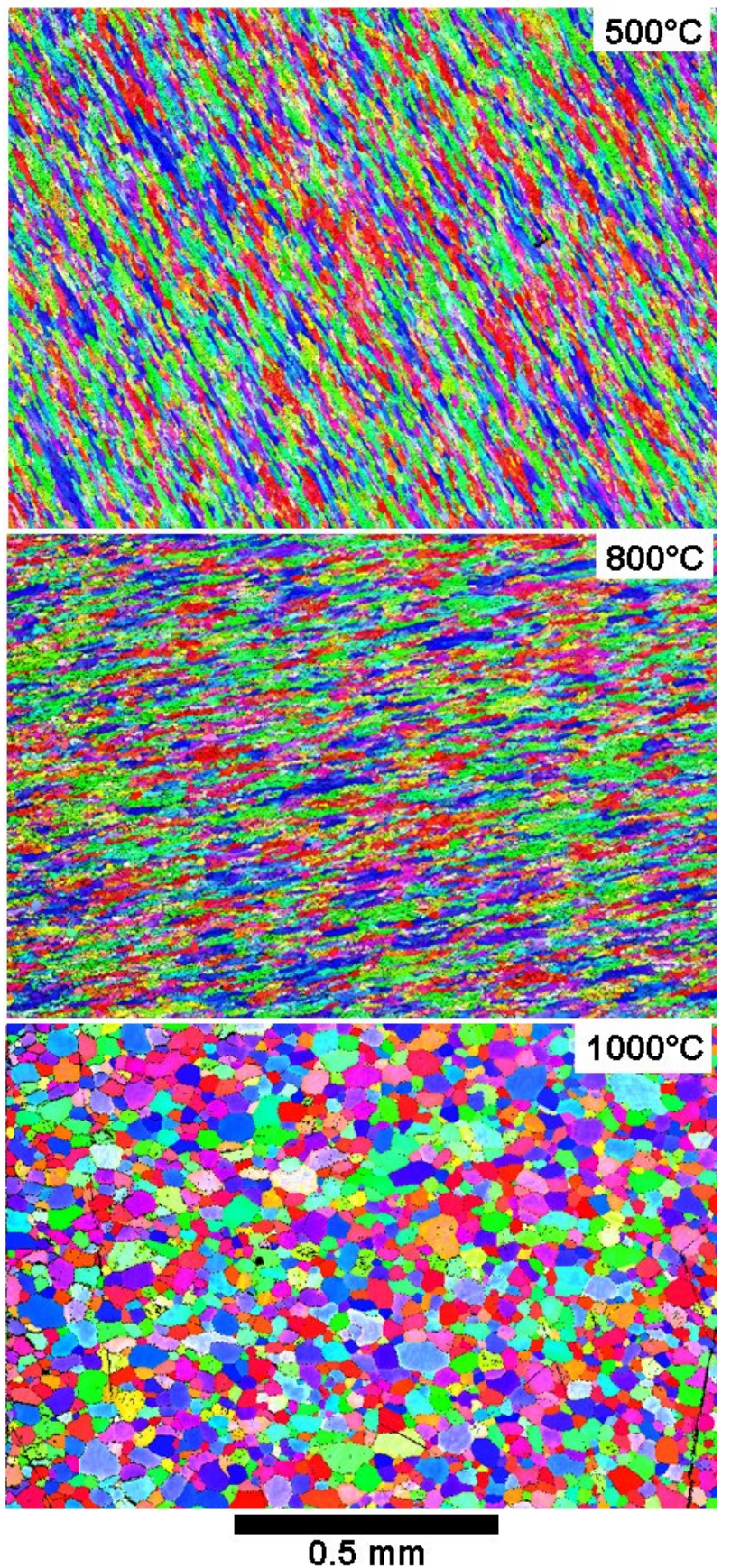

Figure 45. EBSD images of three cycle ( $\sim .5$ dpa) HFIR-irradiated, gadolinium-shielded tungsten at $\sim 500, \sim 800$, and $\sim 1000^{\circ} \mathrm{C}$. The $1000^{\circ} \mathrm{C}$ material is fully recrystallized.

We also examined the transmutation and precipitation in greater detail in the 19J capsule gadoliniumshielded specimens. In summary, transmutation and resulting precipitation is much less than observed in the non-shielded specimens from other experiments. Surprising results were found and are still under analysis and interpretation. However, interesting examples are shown in Figure 46. First, in the W- $0.4 \% \mathrm{Re}$ alloy (top row), Os-rich regions are seen both sitting in the matrix and associated with voids. Second, Rerich regions are seen to both occur on voids and, with lower frequency, in the matrix (circled). 

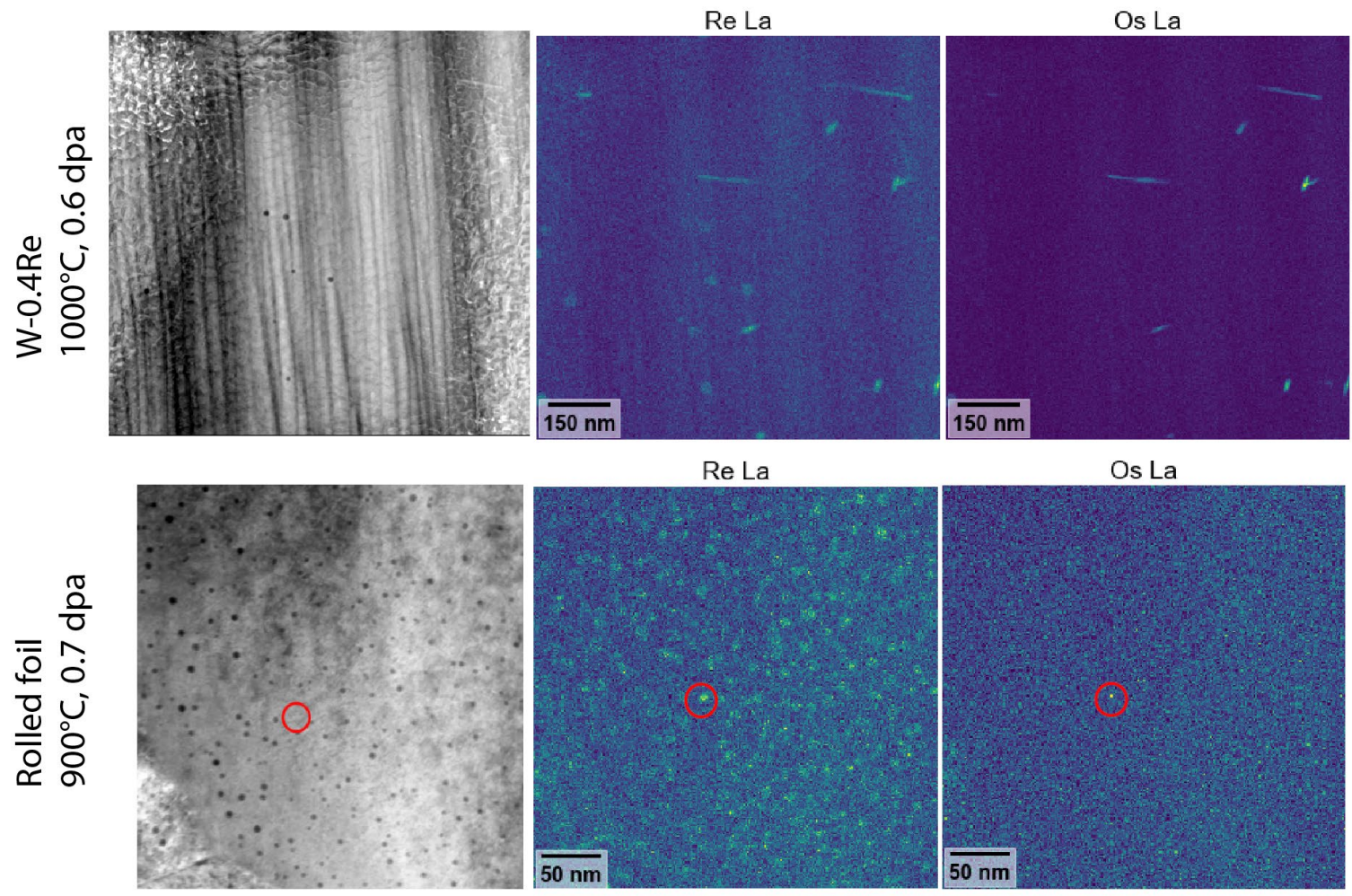

Figure 46. STEM images and $\mathrm{X}$-ray maps from two samples, $\mathrm{W}-0.4 \mathrm{Re} / 1000^{\circ} \mathrm{C} 0.6 \mathrm{dpa}$ and rolled foil, $9^{\circ 0}{ }^{\circ} \mathrm{C}, 0.7 \mathrm{dpa}$. Re and $\mathrm{Os}$ transmutant clusters and precipitates are visible.

The influence of these precipitates on plasma-materials interactions is still unclear, but the ongoing efforts and results will be important for the future understanding of how helium, tritium, etc., interact with the materials structures formed during service in the fusion environment. 


\subsection{TUNGSTEN BASE COMPOSITES}

\section{H. Gietl (gietlha@ornl.gov),.T.Koyanagi, Y.Katoh (ORNL)}

\section{OBJECTIVE}

The goal of this task is to define and develop tungsten-based composites suitable for fusion applications. Tungsten fiber reinforced tungsten $\left(\mathrm{W}_{f} / \mathrm{W}\right)$ and silicon carbide fiber reinforced tungsten $\left(\mathrm{SiC}_{f} / \mathrm{W}\right)$ composites are studied.

\section{SUMMARY}

Theoretical assessments of $\mathrm{W}_{\mathrm{f}} / \mathrm{W}$ and $\mathrm{SiC}_{\mathrm{f}} / \mathrm{W}$ composites for fusion PFCs were conducted. The fiber reinforcement is proposed to overcome brittleness of $\mathrm{W}$ matrix at temperatures below the DBTT. $\mathrm{SiC}_{\mathrm{f}}$ reinforcement is suggested because of the $\mathrm{SiC}$ resistance to radiation degradation and its high temperature stability.

\section{PROGRESS AND STATUS}

Trade-off between thermal conductivity and ultimate strength achieved by changing the fiber volume fraction is an important consideration for $\mathrm{SiC}_{\mathrm{f}}$ reinforcement. Increasing the fiber volume fraction leads to increased ultimate strength but decreased thermal conductivity. The fiber volume fraction required for the quasi-ductile failure is strongly affected by radiation induced hardening of the $\mathrm{W}$ matrix and degradation of the fibers due to high temperature annealing. Once those phenomena occur, a higher fiber volume fraction is required to maintain the quasi-ductile fracture. Analysis showed that high strength and/or ductility of the $\mathrm{W}$ fibers after irradiation and annealing is essential to retaining the quasi-ductile failure of $\mathrm{W}_{\mathrm{f}} / \mathrm{W}$ composites. The calculations of stress state under steady state heat flux and thermal shock conditions suggest selecting a $\mathrm{SiC}$ fiber volume fraction of $>30 \%$ to increase the probability of withstanding those stresses without complete failure.

In addition to the theoretical assessment, the capability of in situ tensile testing of composites was demonstrated. Figure 47 shows a room temperature in situ tensile test of a $\mathrm{W}_{\mathrm{f}} / \mathrm{W}$ composite specimen fabricated with a $\mathrm{Y}_{2} \mathrm{O}_{3}$ interphase layer on the fibers.

\section{FUTURE PLANS}

Future research for optimization of the thermo-mechanical properties will include exploring the processing technology for dense matrix infiltration and microstructural optimization of the fiber/matrix interphases to enable matrix crack deflection under a reactor operating environment. Development of these W base composites is continuing. 

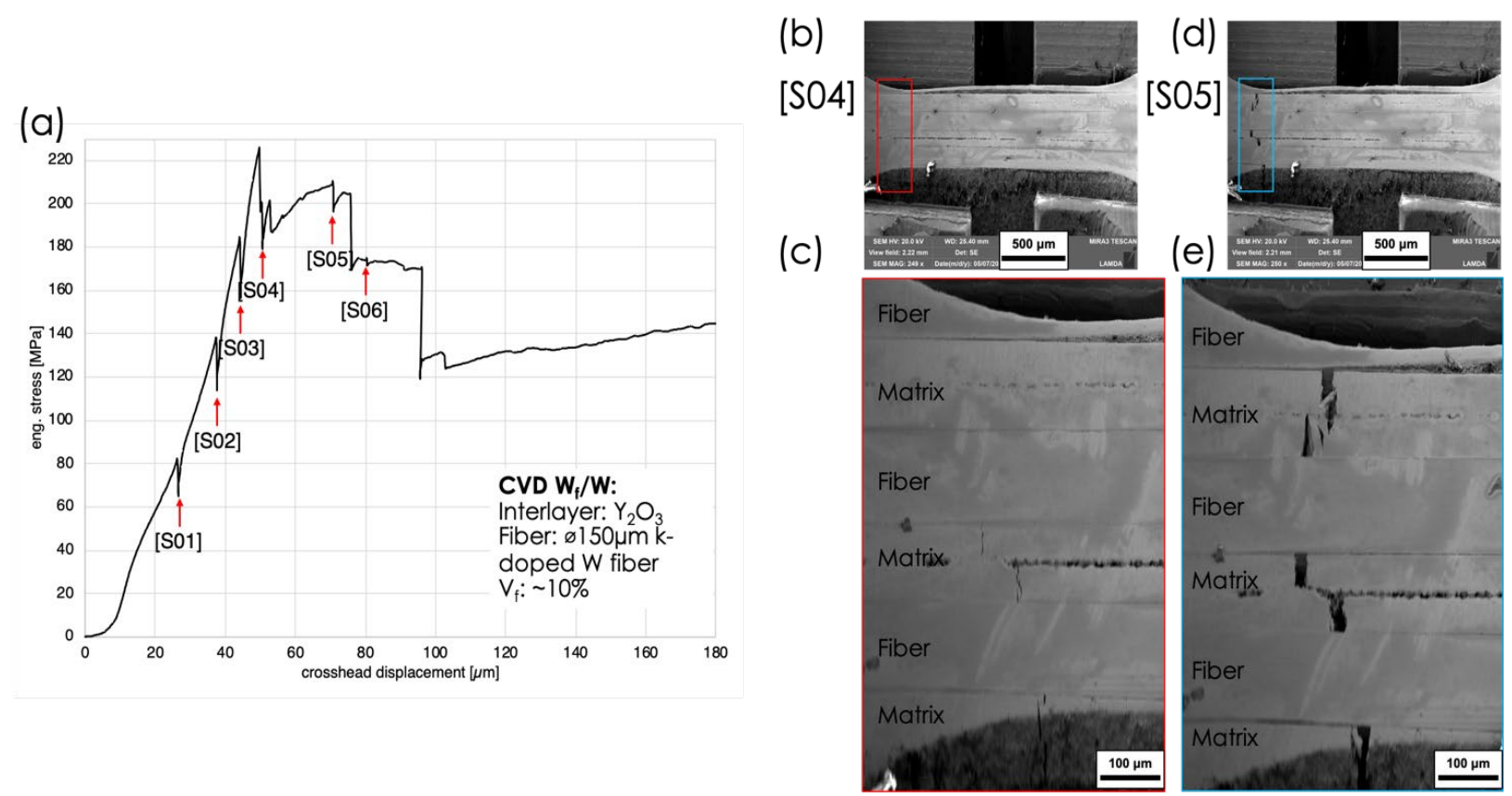

Figure 47. Initial tensile test of a $W_{f} / W$ composite sample. (a) Engineering stress vs crosshead displacement. (b) SEM image of sample at the load step [S04]. (c) higher magnification showing detail at load step [S04] where some cracks near the end of the specimen gage section are seen. (d) SEM image at step [S05]. (c) detailed view at load step [S05] when the matrix crack reached the surface, but the specimen is still able to support nearly $\sim 90 \%$ of the maximum load. 


\subsection{FABRICATION OF FUNCTIONALLY GRADED TUNGSTEN STEEL LAMINATES}

\section{L.M. Garrison (garrisonlm@ornl.gov), S.Wonner, Y. Katoh (ORNL)}

\section{OBJECTIVE}

The objective of this project is to create a functionally graded tungsten to steel laminate composite for use in plasma facing components in fusion reactors.

\section{SUMMARY}

Four tungsten steel laminate composites have been fabricated, with two different fabrication conditions and four different foil stacking patterns. The general trend observed from the tensile tests is that the UTS of the composites increase with the percentage of tungsten but stayed below the UTS of the individual tungsten foils. In addition to the percentage of tungsten, the UTS also depends on the shape of the tungsten foils component of the composites. The ones with segmented tungsten foils had a lower UTS than would have been predicted based only on the percentage of tungsten.

\section{PROGRESS AND STATUS}

Tungsten foils are ductile at room temperature, so are a candidate for tungsten-based composites for plasmafacing components. For divertors that will operate at high temperatures, steel is the material of choice for the structural part of the component. Thus, tungsten-steel composites would be useful as the transition to bridge the difference in thermal expansion of tungsten and steel. Four unalloyed tungsten-grade 92 steel composites with different foil thicknesses and stacking patterns were fabricated by hot pressing and rolling (Table 6). (The Grade 92 was selected as a surrogate for an RAFM alloy.) Composite 1 had a graded composition from mostly steel to mostly tungsten (Figure 48a), while the other composites had uniform composition of alternating layers across the thickness. An intermetallic layer formed between the tungsten and steel layers during the processing at $1000^{\circ} \mathrm{C}$.

Table 6. Parameters of the tungsten-steel laminate composites

\begin{tabular}{|c|c|c|c|c|c|c|}
\hline & & \multicolumn{2}{|c|}{ Foil Thickness $(\mu \mathrm{m})$} & \multicolumn{2}{|c|}{ Number of Foils } & \multirow[b]{2}{*}{ Processing Conditions } \\
\hline \multicolumn{2}{|c|}{ Composite } & Tungsten & Steel & Tungsten & Steel & \\
\hline \multirow{3}{*}{1} & Section 1 & 250 & 76 & 10 & 10 & \multirow{3}{*}{$\begin{array}{c}\text { Hot Pressing / Rolling } \\
\text { at } 1000^{\circ} \mathrm{C} \\
80 \% \text { height reduction }\end{array}$} \\
\hline & Section 2 & 100 & 100 & 10 & 10 & \\
\hline & Section 3 & 25 & 250 & 10 & 10 & \\
\hline \multirow{2}{*}{\multicolumn{2}{|c|}{2}} & 25 & 250 & 10 & 10 & \multirow{4}{*}{$\begin{array}{l}\text { Hot Pressed at } 1000^{\circ} \mathrm{C} \\
20 \% \text { height reduction }\end{array}$} \\
\hline & & & & & & \\
\hline & 3 & 25 & 100 & 38 & 37 & \\
\hline & 4 & 100 & 100 & 40 & 39 & \\
\hline
\end{tabular}



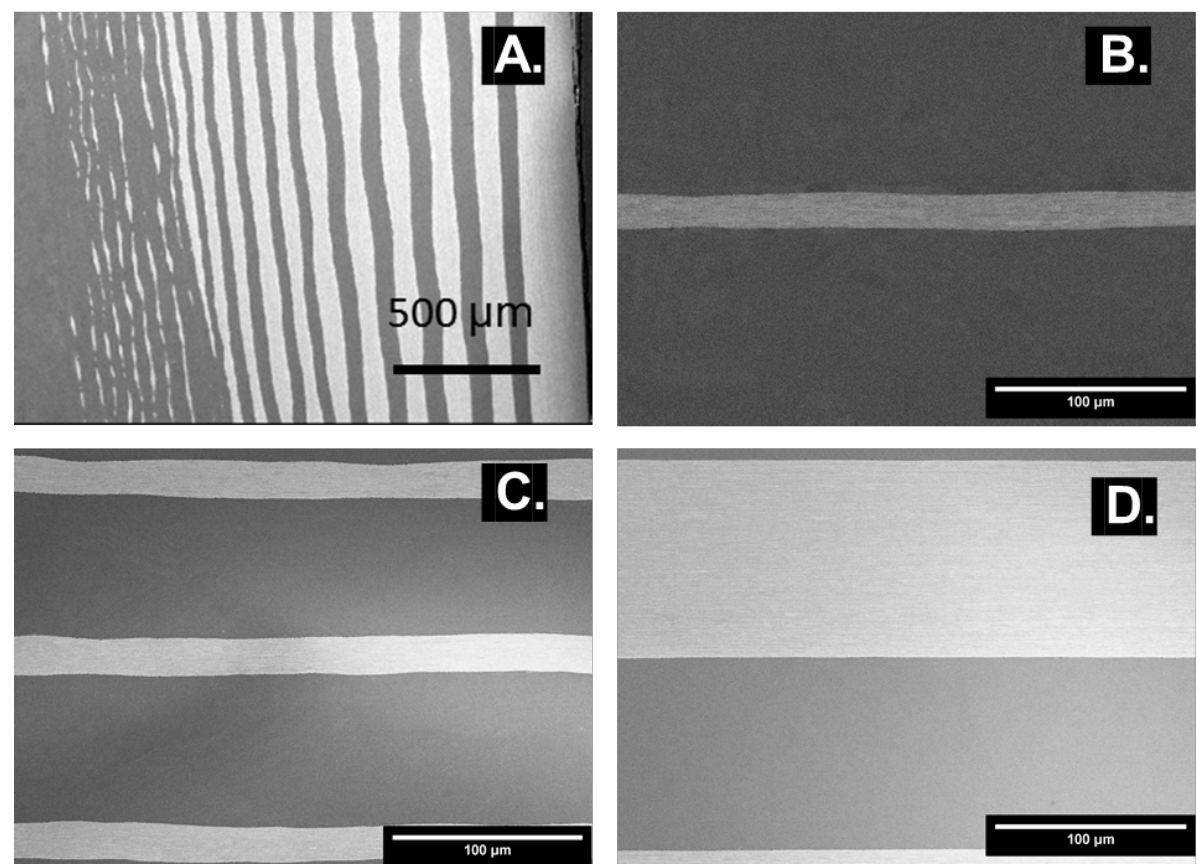

Figure 48. SEM Micrographs of polished cross sections of: (A) Composite 1, (B) Composite 2, (C) Composite 3, and (D) Composite 4. In all the images the $W$ layers appear brighter and the steel layers appear darker. Note that $(A)$ is at a different magnification than the others three.

SSJ2 tensile samples were cut from each composite so that the rolling direction and the long direction of the stacked foils coupons was parallel to the tensile direction. Since the composites have different layer thicknesses, there were varying amounts of tungsten and steel in each $0.5 \mathrm{~mm}$ thick tensile bar. There is a trend of increasing ultimate tensile strength (UTS) with increasing percentage of tungsten in the tensile bar (Figure 49). The lowest UTS for room temperature tensile tests was in the section of Composite 1 that had the thinnest tungsten layers; those layers did not remain continuous during fabrication, resulting in the low UTS.

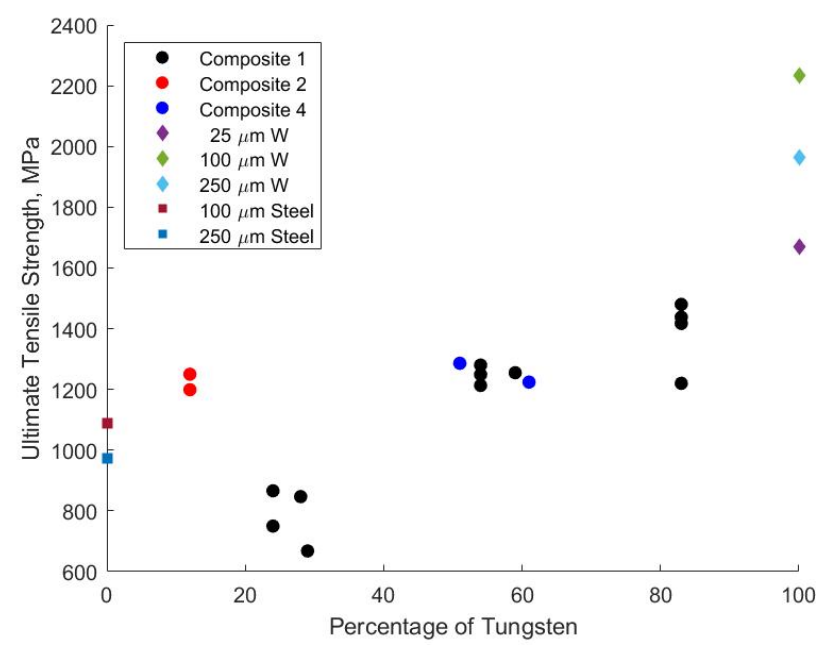

Figure 49. Ultimate tensile strength versus percentage of tungsten for room temperature tensile tests. Tungsten foils are shown as diamond markers, and the steel foils are shown in square markers. 
The fracture surfaces of the three different regions of Composite 1 after room temperature tensile tests are shown in Figure 50. In Sections 1 and 2 the tungsten foils have flat and jagged fracture surfaces. Figure $50 b$ highlights the flat horizontal grain structure within the tungsten foil. In contrast, the thin tungsten layers in Section 3 have partially pulled out of the composite at the center of the composite and appear as ribbons (Figure 50e-f). The three thicknesses of tungsten foils used in the composites each had slightly different starting microstructure and tensile properties, and that leads to some of the difference observed in the final tungsten-steel composites.
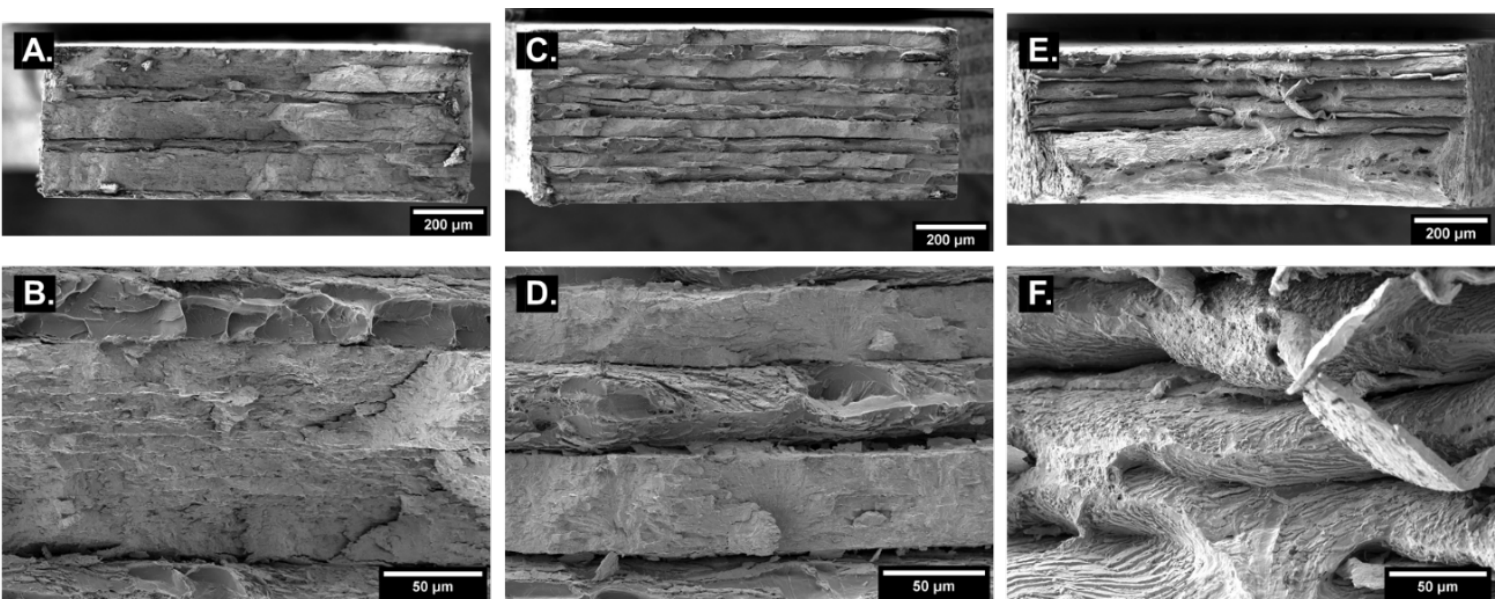

Figure 50. Fracture surfaces of composite 1 tensile samples. Section 1 (A-B), Section 2 (C-D), Section 3 (E-F). 


\section{PLASMA MATERIALS INTERACTIONS}

\subsection{HELIUM EFFECTS ON THE SURFACE AND SUBSURFACE EVOLUTION IN SINGLE- CRYSTAL TUNGSTEN}

Cuncai Fan, Chad M Parish, Yutai Katoh, Xunxiang Hu (hux1@ornl.gov), (ORNL)

\section{OBJECTIVE}

Tungsten (W) is one of the most promising plasma facing materials (PFMs) for future fusion reactors. In the past decade, its behavior under irradiation and helium (He) plasma interaction has been extensively studied. However, some key knowledge gaps still exist, such as the influence of crystallographic orientation on the surface and subsurface evolution. The objective of this work is to explore the He ion-beam irradiation damage effects in single-crystal W samples with three different surface planes: $\{100\},\{110\}$ and $\{111\}$.

\section{SUMMARY}

$\mathrm{W}\{100\},\{110\}$ and $\{111\}$ were all irradiated at room temperature (RT) by $40 \mathrm{keV} \mathrm{He}$ to a fluence of $1 \times 10^{16} / \mathrm{cm}^{2}$, followed by thermal desorption spectroscopy (TDS) up to $\sim 1920 \mathrm{~K}$. The microstructures of He-irradiated $\mathrm{W}$ before and after TDS heat treatment were characterized by scanning and transmission electron microscopy (SEM and TEM). Subsurface He bubbles were imaged in all irradiated samples, but newly formed $<111>$-oriented surface grains and surface blisters were only observed in single crystal W with orientations of $\{100\}$ and $\{110\}$. These results reveal that radiation damage, He thermal desorption, and surface/subsurface evolution are all strongly dependent on crystallographic orientation.

\section{PROGRESS AND STATUS}

Figure 51 compiles the SEM-EBSD results of as-polished and He-irradiated W discs. Evidently, the inverse pole figure (IPF) orientation maps reveal small new grains that are only formed in $\mathrm{W}\{100\}$ and $\{110\}$ after He irradiation. In particular, the normal direction-projected (IPF-Z) orientation maps in Figure 51(a3) and (b3) indicate that the irradiation-induced new grains are primarily $<111>$-oriented in both cases, as well indexed by their corresponding IPFs in Figure 51(a4) and (b4). Compared with He-irradiated W $\{111\}$, the He-irradiated W $\{100\}$ and $\{110\}$ also manifested different He thermal desorption behavior with distinct desorption peak temperatures and He desorption percentages, which is determined by their different microstructures caused by the He ion irradiation. After TDS, although subsurface He bubbles were formed in all irradiated samples (see Figure 52), their size and density were different for different original surface orientations, presumably because of the different interactions between implanted $\mathrm{He}$ and irradiationinduced grain boundaries. In addition, Figure 53 shows that the micrometer-sized blisters were only formed on the surfaces of $\mathrm{W}\{100\}$ and $\{110\}$ after TDS, indicating the important role of orientation change in the surface modifications of $\mathrm{W}$.

\section{FUTURE PLANS}

Future work will be focused on the mechanistic understanding of the helium effects on surface evolution identified in the current study through performing large scale molecular dynamics modeling. In addition, 
similar studies will also be performed on polycrystalline tungsten to compare with the results of single crystalline tungsten.
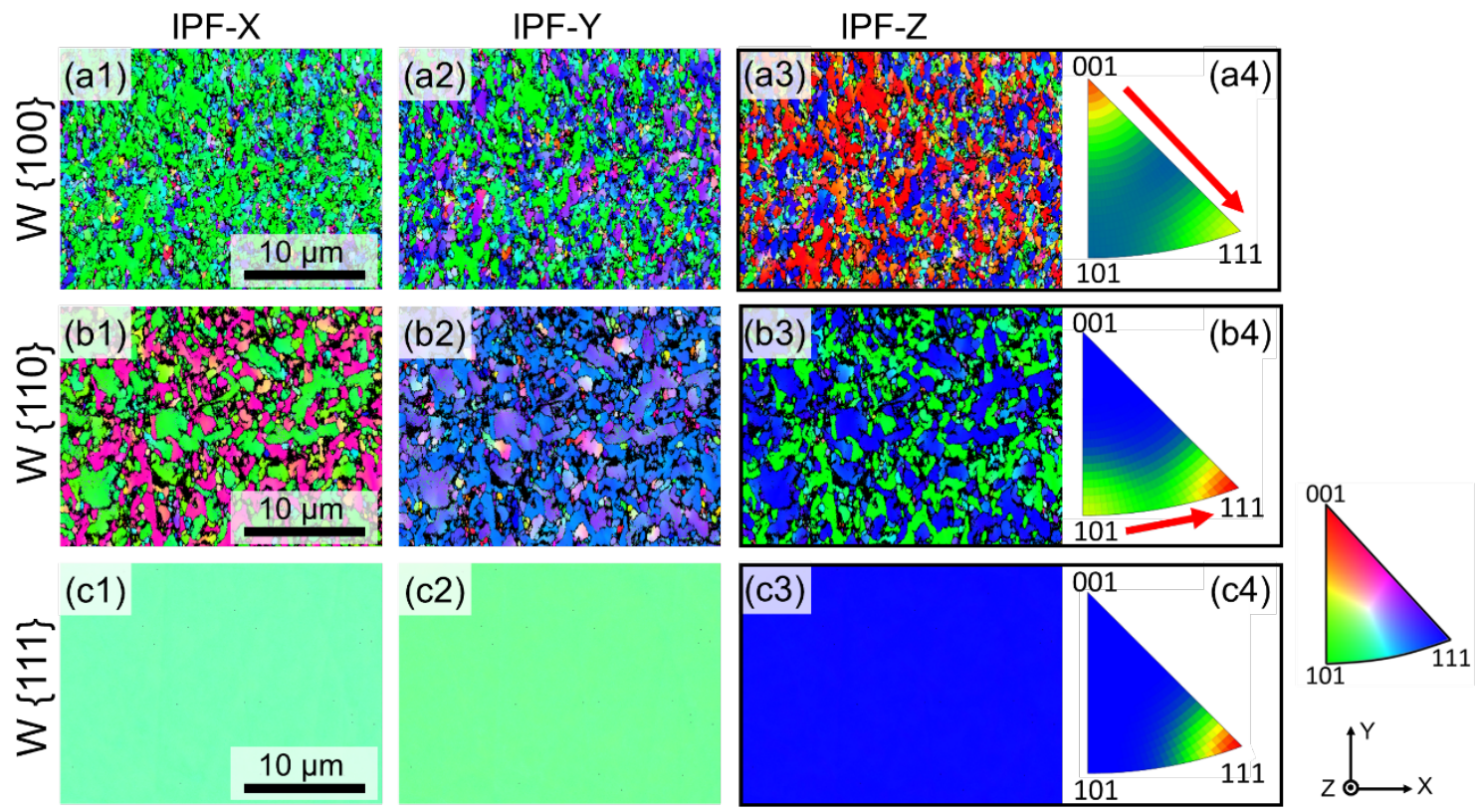

Figure 51. New $<111>$ grains only formed in He-irradiated $W\{100\}$ and $W\{111\}$ at RT. Left three column images: the in-plane (IPF-X and IPF-Y) and normal direction-projected (IPF-Z) orientation maps. Right column images: the corresponding IPFs of orientation maps IPF-Z.
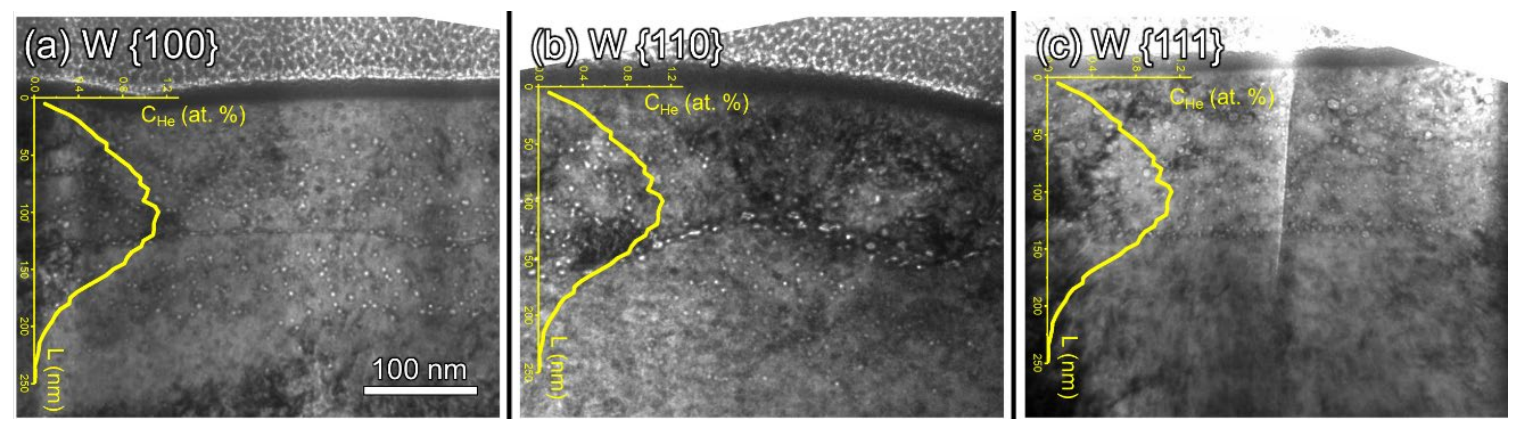

Figure 52. Bright-field TEM images showing the subsurface He bubbles formed in all He-irradiated W samples after TDS. The superimposed plot is the calculated He concentration profile $\mathrm{C}_{\mathrm{He}}$ versus ion penetration depth $L$. 

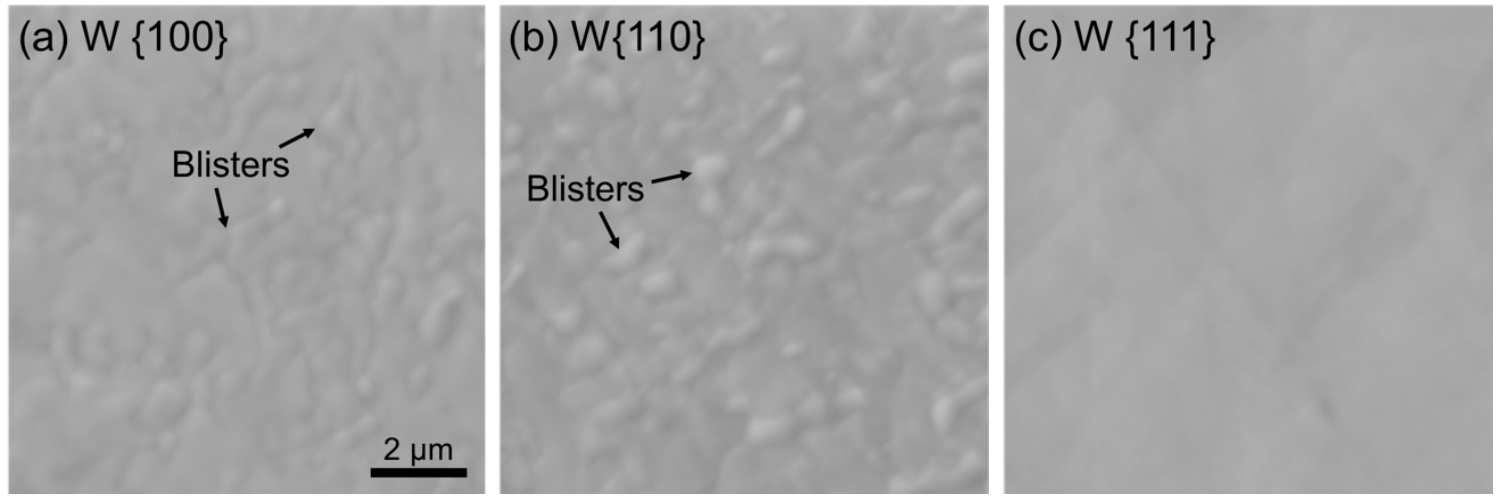

Figure 53. SEM images showing the surface blisters formed only in He implanted (a) $W\{100\}$ and (b) $\mathrm{W}\{110\}$ after TDS. 


\subsection{IMPACT OF HELIUM IMPLANTATION ON THE CRYSTALLOGRAPHIC ORIENTATION CHANGES IN SINGLE-CRYSTALLINE TUNGSTEN}

Cuncai Fan, Yutai Katoh, Xunxiang Hu (hux1@ornl.gov), (ORNL)

\section{OBJECTIVE}

Our recent studies revealed that He ion irradiation at room temperature (RT) produces $<111>$-oriented surface grains in single-crystalline $\mathrm{W}\{100\}$ and $\{110\}$, which may play an important role in the surface and subsurface modifications of W subjected to fusion-relevant service environments. Although the driving force for the formation of surface grains is well rationalized by ion channeling effects, the underlying formation mechanism remains unclear. The objective of this work is to explore the orientation relationship between irradiation-induced surface grains and the single-crystal W matrix.

\section{SUMMARY}

The experimental results of electron backscatter diffraction (EBSD) demonstrated that the formation of $<111>$-oriented surface grains in both He-irradiated $\mathrm{W}\{100\}$ and $\mathrm{W}\{110\}$ can be explained as the grain rotation of matrix around its in-plane $<110>$ axis.

\section{PROGRESS AND STATUS}

Conventional electron backscatter diffraction (EBSD) was first performed on He-irradiated W $\{100\}$ and $\{110\}$ specimens. The normal direction-projected orientation maps and corresponding selected Backscatter Kikuchi patterns (BKPs) in Figure 54, from the regions of matrix (marked by M) and new surface grains (marked by S), imply both the surface grains and matrix have one of their $\{110\}$ planes (marked by yellow lines) aligned in the same direction. Such crystallographic information can be better visualized and summarized by their pole figures (PFs), as shown in Figure 55. After comparing with the standard cubic stereographic projections, it is concluded that both Figure 55(a) and (b) contain two separate diffraction signals arising from matrix and irradiation-induced surface grains, as denoted by the black and white symbols, respectively. In addition, these two diffraction patterns obviously rotate around one in-plane axis (the black line) that is along the $<110>$ crystallographic direction.

\section{FUTURE PLANS}

Future work will be focused on understanding the mechanism of irradiation-induced grain rotation via simulation or high-resolution TEM experiment. 

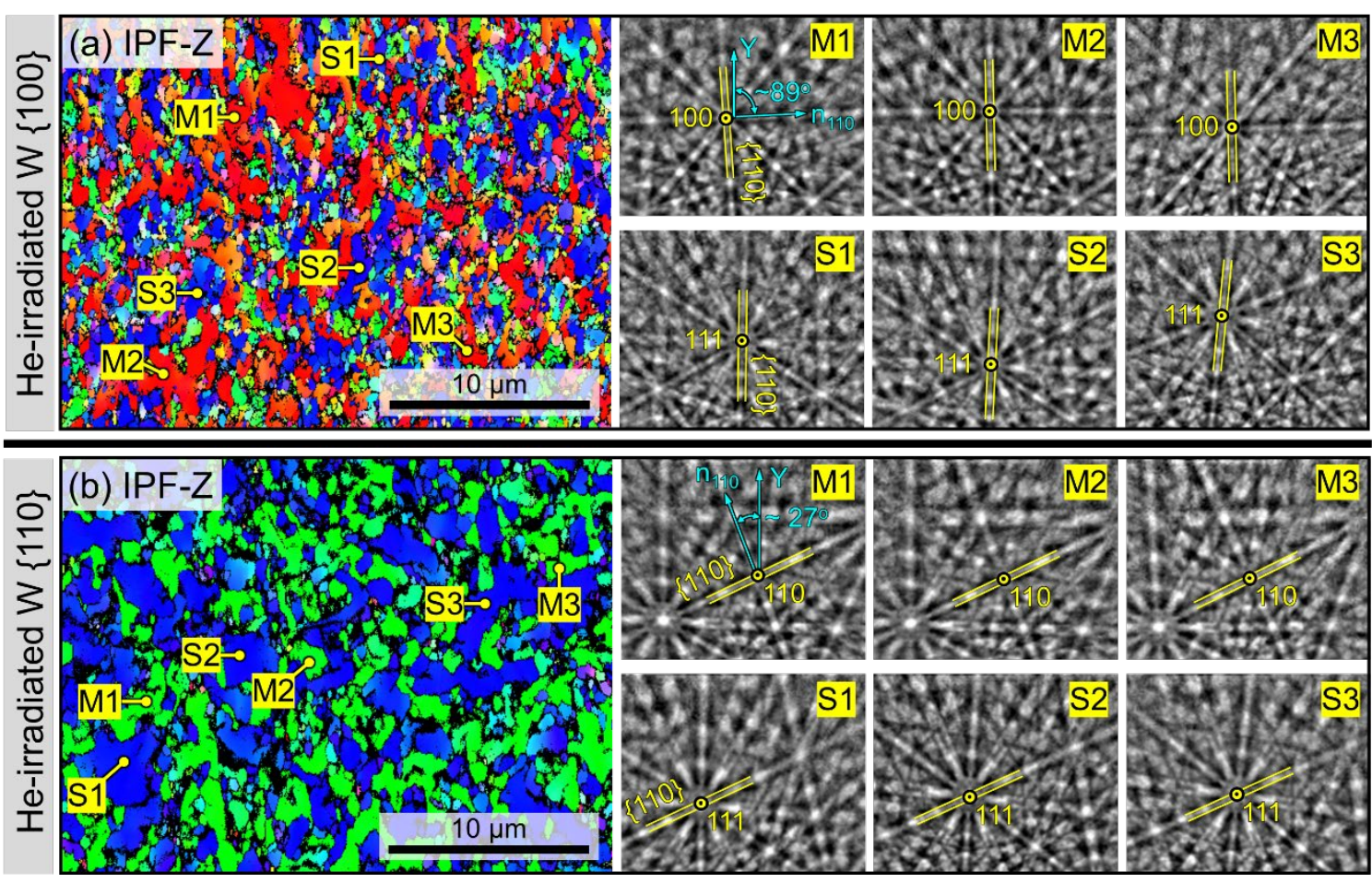

Figure 54. Orientation maps of (a) He-irradiated $W\{100\}$ and (b) He-irradiated $W\{110\}$, in conjunction with selected BKPs patterns from matrix and new grain regions.
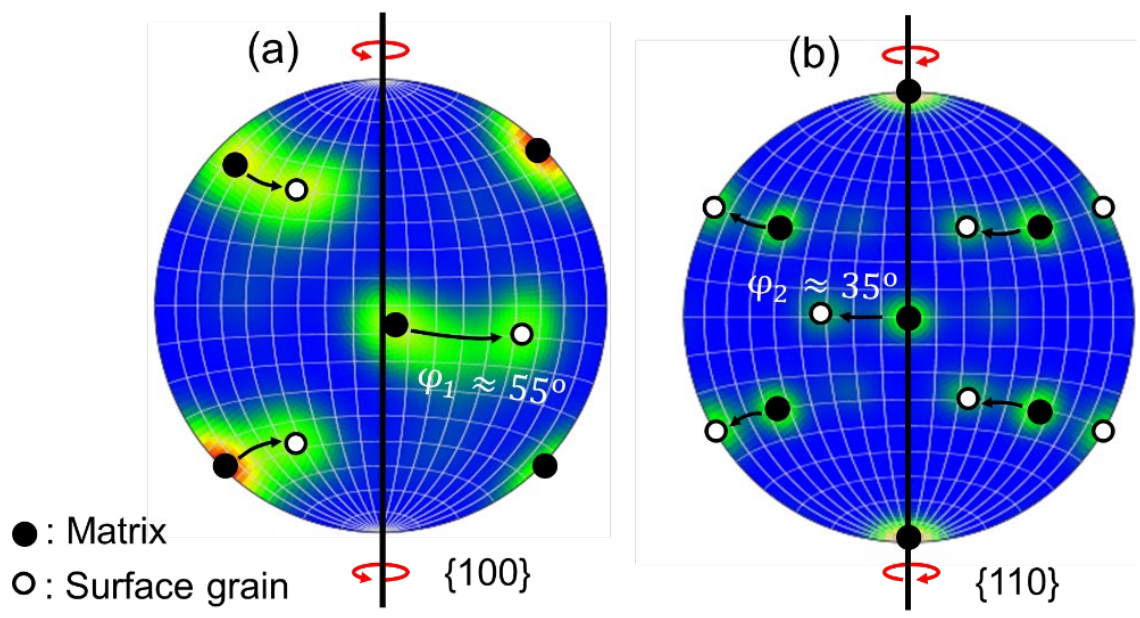

Figure 55. Pole figures for He-irradiated (a) $W\{100\}$ and (b) $W\{110\}$, indicating the formation of surface grains via the grain rotation of matrix around an in-plane $<110>$ axis. 


\title{
5.3 DAMAGE-MECHANISM INTERACTIONS AT THE PLASMA-MATERIALS INTERFACE
}

\author{
C.M.Parish (parishcm@ornl.gov),D.G.Morrall (ORNL)
}

\section{OBJECTIVE}

The overarching objective of this work is to bridge the gap between the atomistic knowledge and models and the phenomenological materials science underlying the design, fabrication, and service of divertor and other plasma-facing materials for magnetic confinement fusion. Specifically, the influence of intrinsic defects (dislocations, grain boundaries) and extrinsic defects (ion- and neutron-irradiation damage, impurities) interactions with $\mathrm{He}$ and bubbles, in terms of nucleation sites, growth, trapping, and surface degradation, will be measured.

\section{SUMMARY}

This year we have explored plasma effects including analysis of the flux and fluence effects on the nearsurface region of tungsten, and exploration of helium effects on the near-surface microstructure.

\section{PROGRESS AND STATUS}

In order to understand He bubble formation due to exposure to He plasma, several tungsten samples were exposed to He plasma at constant substrate temperature with varying plasma fluences (isothermal experiment); or, exposed to a constant plasma fluence at a variety of temperatures (isofluence experiment).

Two experiments were performed: a temperature scan and a fluence scan. The fluence scan used single crystal tungsten (SCW) and the temperature scan used polycrystalline tungsten (PCW). These samples were exposed to $\mathrm{He}^{+}$plasma at the PISCES-A device at UC-San Diego. PCW samples were exposed to a constant fluence $\left(1 \times 10^{25} \mathrm{He} / \mathrm{m}^{2}\right)$ at a flux of $2 \times 10^{21} \mathrm{He} / \mathrm{m}^{2} \mathrm{~s}^{1}$ of $\mathrm{He}$ plasma at several surface temperature conditions: $310 \mathrm{~K}, 400 \mathrm{~K}, 500 \mathrm{~K}$, and $600 \mathrm{~K}$. The SCW samples consisted of $<001>$ oriented grains in-plane, with very small $\left(\sim 1^{\circ}\right)$ subgrains. They were kept at a near-constant surface temperature $(\sim 873 \mathrm{~K})$ and flux (of $1 \times 10^{22}$ $\left.\mathrm{He} / \mathrm{m}^{2} \mathrm{~s}^{1}\right)$ with varying fluences: $2.5 \times 10^{24}, 2 \times 10^{25}$, and $1.25 \times 10^{26} \mathrm{He} / \mathrm{m}^{2}$. These temperatures and fluence values were chosen as they are near, but below, the critical range wherein nanofuzz has been seen to form in previous studies.

The temperature scan (PCW, $10^{25} \mathrm{He} / \mathrm{m}^{2}$ ) was intended to measure the changes in the helium bubble diameter and density in the tungsten, because it is hypothesized the high-density bubbles may prevent fuel (tritium) penetration into the underlying substrate. The bubbles at these low temperatures were too small $(<2 \mathrm{~nm})$ to quantify reliably, Figure 56, but interestingly a thick region of oxide was observed on the surface (further complicating bubble-size analysis due to amorphous contrast in TEM). This oxide is inferred to have grown, possibly in an accelerated fashion, after plasma exposure, perhaps due to the highly nanostructured surface region. 

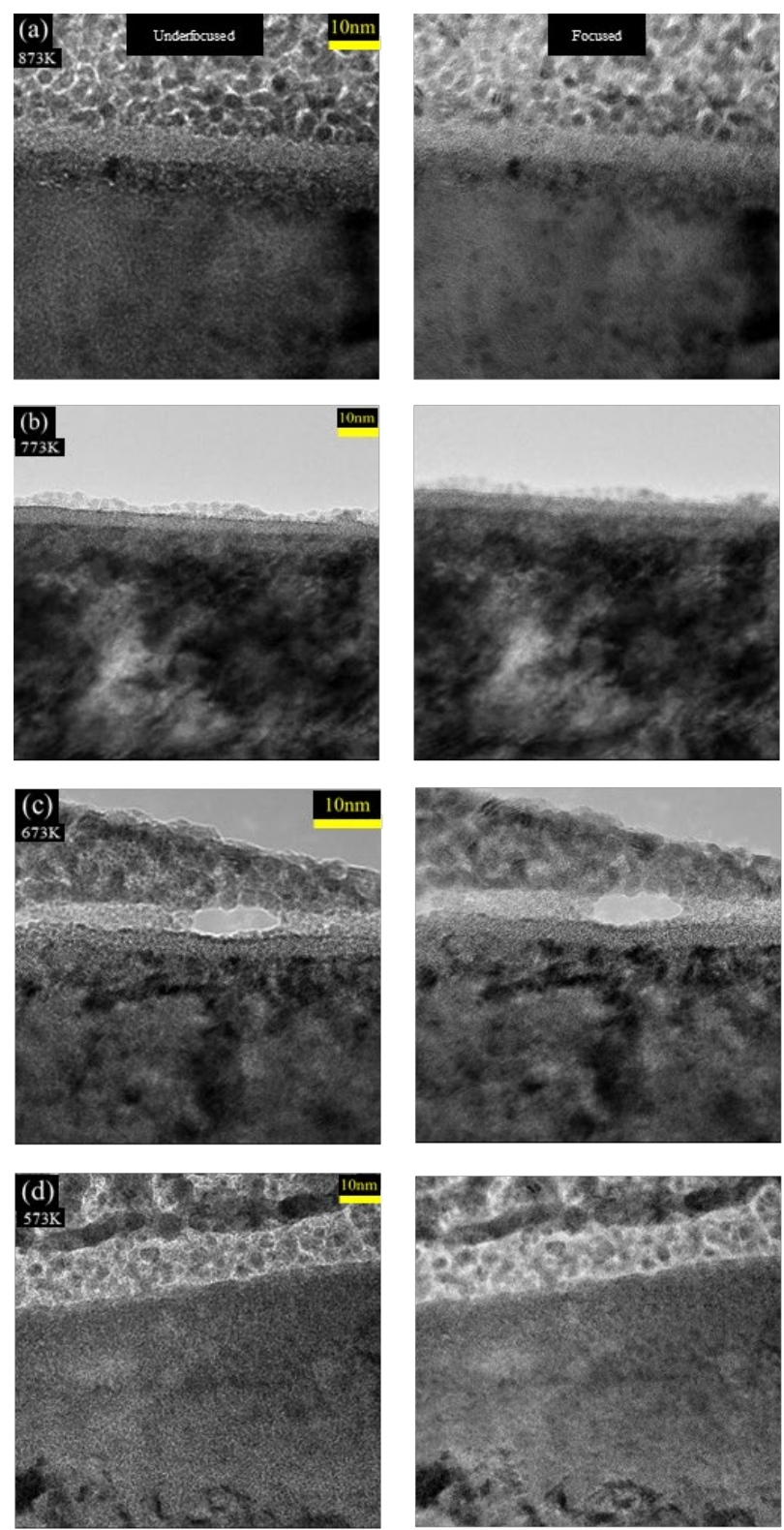
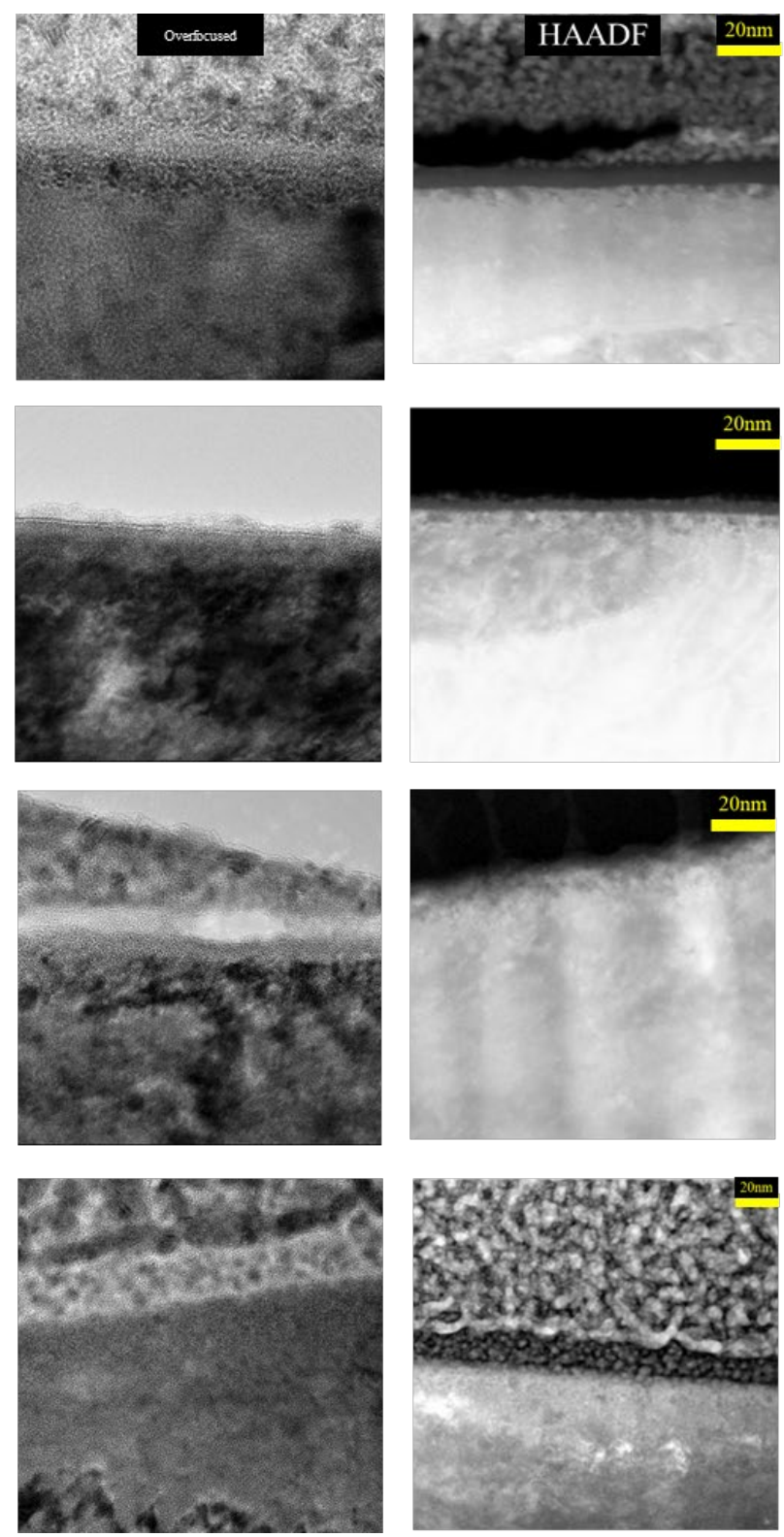

Figure 56. Fresnel contrast (left under-focused $\sim 150 \mathrm{~nm}$, center focused, right overfocused $\sim 150 \mathrm{~nm}$ ) and high angle annular dark field (HAADF, far right) of PCW at (a) $600 \mathrm{~K}$, (b) $500 \mathrm{~K}$, (c) $400 \mathrm{~K}$, and (d) $310 \mathrm{~K}$.

The fluence scan (SCW, $873 \mathrm{~K}, 10^{24}$ to $10^{26} \mathrm{He} / \mathrm{m}^{2}$ ) showed the expected increasing density and diameter of the helium bubbles with fluence, Figure 57 and Figure 58. The experiment showed the effect of increasing fluence on the bubble population. Specifically, a slight reduction in density but large increase in bubble size and polydispersity as fluence increases.

Work continues on these plasma-materials interaction effects. 

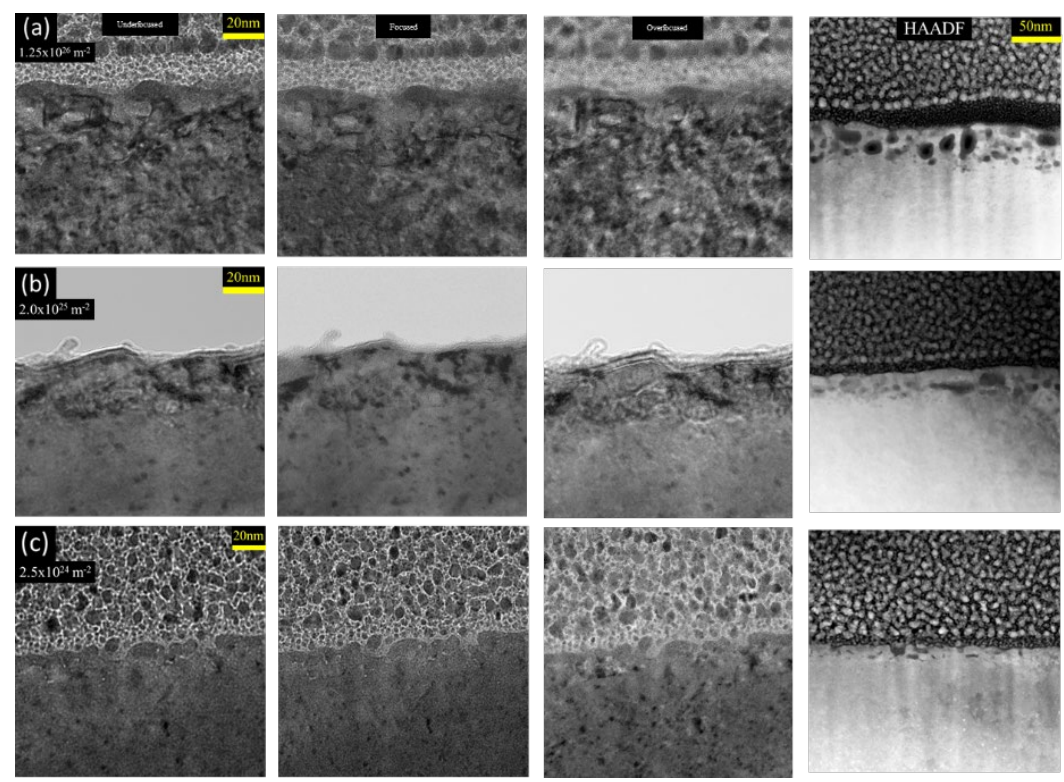

Figure 57. Fresnel contrast (defocus $\sim 150 \mathrm{~nm}$ ) and high angle annular dark field (HAADF) of SCW at (a) $1.25 \times 10^{26}$ (b) $2.0 \times 10^{25}$ (c) $2.5 \times 10^{24} \mathrm{~m}^{-2}$.
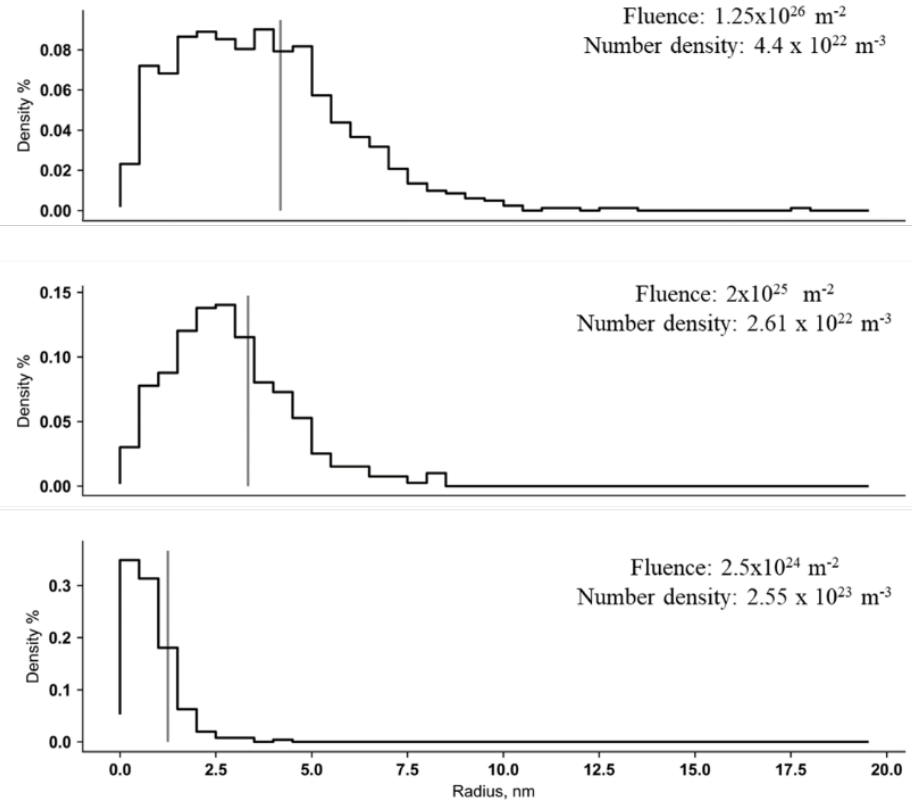

Figure 58. He bubble relative density distribution and number density in SCW samples. 


\title{
6. LIQUID METAL COMPATIBILITY
}

\subsection{LIQUID METAL COMPATIBILITY IN FLOWING SYSTEMS}

\author{
B. A. Pint (pintba@ornl.gov), J.Jun (ORNL)
}

\section{OBJECTIVE}

This task investigates the possibility of increasing the $\mathrm{Pb}$-Li temperature in the dual coolant lead-lithium (DCLL) blanket concept to improve the overall system efficiency. A series of monometallic FeCrAlMo thermal convection loops have been completed with flowing $\mathrm{Pb}-\mathrm{Li}$ up to $700^{\circ} \mathrm{C}$ to provide baseline compatibility data. A next step will be to expose more fusion relevant materials such as $\mathrm{SiC}$ and ODS $\mathrm{FeCrAl}$ to flowing $\mathrm{Pb}-\mathrm{Li}$.

\section{SUMMARY}

Characterization of a fourth monometallic thermal convection loop (TCL) fabricated from dispersion strengthened FeCrAl (Kanthal alloy APMT, Fe-21Cr-5Al-3Mo) tubing was completed. The fifth TCL experiment also completed $1000 \mathrm{~h}$ of operation with the same peak temperature of $700^{\circ} \mathrm{C}$. The loop was fabricated from APMT, but specimens included CVD SiC and ODS FeCrAl. A dissimilar materials interaction was observed where a very large dissolution of ODS FeCrAl occurred and $\mathrm{Fe}$ and $\mathrm{Cr}$ in the $\mathrm{Pb}$ $\mathrm{Li}$ reacted with $\mathrm{SiC}$ to form a thick $\mathrm{Fe}$ - and $\mathrm{Cr}$-rich carbide layer suggesting that these three materials are not a compatible system at these elevated temperatures.

\section{PROGRESS AND STATUS}

Starting in 2014, a series of monometallic thermal convection loops (TCLs) have been fabricated from Kanthal alloy APMT (Fe-21Cr-5Al-3Mo) with peak operating temperatures of 550, 600, 650 and $700^{\circ} \mathrm{C}$ to assess $\mathrm{Pb}$-Li compatibility and establish the maximum operating temperature for an alumina-forming alloy or coating. Each loop operated for $1000 \mathrm{~h}$ and the fourth loop was completed in late 2019 and the fifth loop, which included oxide dispersion strengthened (ODS) Fe-10Cr-6Al and chemical vapor deposition (CVD) $\mathrm{SiC}$ as a surrogate for $\mathrm{SiC} / \mathrm{SiC}$ composites, was completed in 2020. The key finding from these two experiments is that $700^{\circ} \mathrm{C}$ is likely too high a temperature for acceptable $\mathrm{Pb}-\mathrm{Li}$ compatibility. Figure 59 shows the specimen mass change from both experiments. In general, the mass losses for APMT specimens in the $4^{\text {th }}$ TCL experiment were low except for those that were not pre-oxidized for $2 \mathrm{~h}$ at $1000^{\circ} \mathrm{C}$ in laboratory air. However, several specimens at the top of the hot leg (HL) were not recovered and may have experienced significant dissolution. In the $5^{\text {th }}$ multi-material TCL, the mass losses and mass gains were much higher. The mass losses were mainly the ODS FeCrAl specimens both with and without preoxidation. The mass gains, especially in the cold leg (CL) were for the CVD SiC specimens. Four APMT specimens were exposed in the $5^{\text {th }}$ TCL and in each case experienced higher mass loss than comparably located APMT specimens from the $4^{\text {th }}$ TCL. Overall, the results suggest that a dissimilar material interaction occurred in the $5^{\text {th }}$ TCL whereby Fe and $\mathrm{Cr}$ dissolved from the ODS FeCrAl specimens into the liquid, then reacted with the $\mathrm{CVD} \mathrm{SiC}$ to form a $\mathrm{Fe}$ - and $\mathrm{Cr}$-rich carbide reaction layer. An example is shown in Figure 60. By removing $\mathrm{Fe}$ and $\mathrm{Cr}$ from the liquid to form a carbide, this accelerated dissolution of the FeCrAl specimens to much higher levels than observed in the prior TCL. In general, the ODS FeCrAl specimens appeared to be less protective than APMT, presumably because the higher Cr content in APMT helped to form a protective Al-rich oxide. 


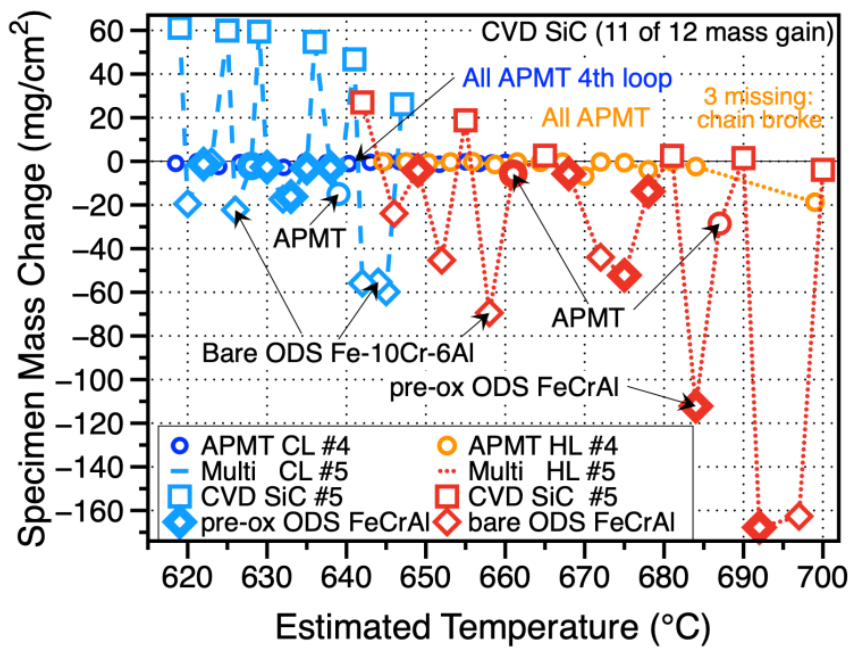

Figure 59. Specimen mass change of specimens in PbLi of the thermal convection loops as a function of estimated temperature in the hot leg (HL) and cold leg (CL) of the $4^{\text {th }}$ (APMT only) and $5^{\text {th }}$ (multimaterial) TCL experiments.
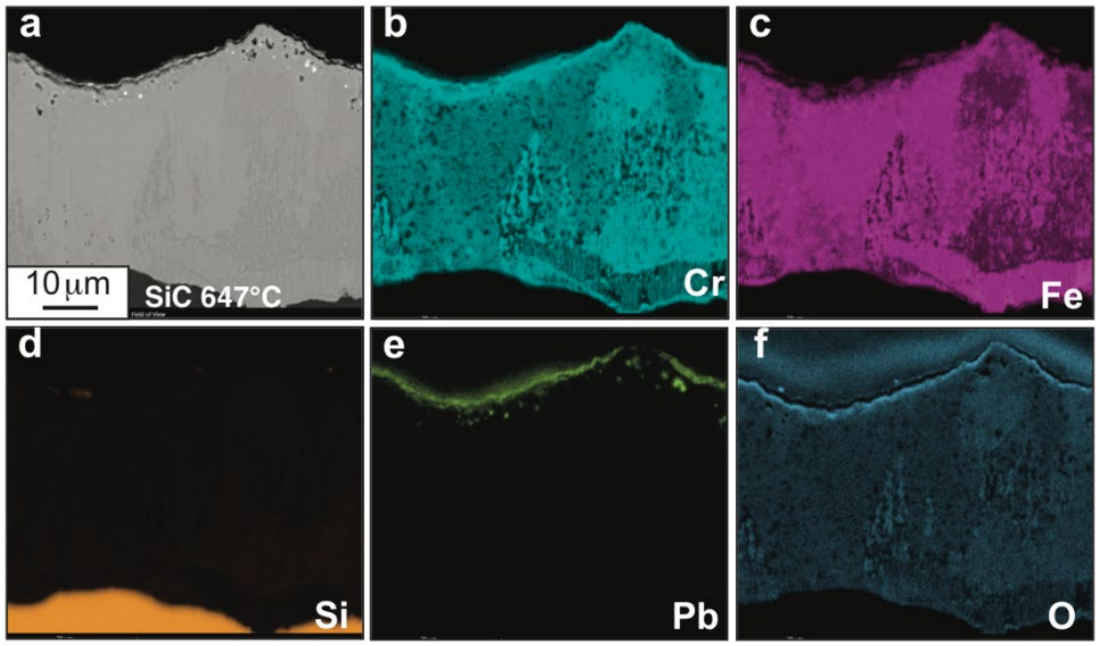

Figure 60. (a) SEM backscattered electron image of the reaction product formed on CVD SiC after $1000 \mathrm{~h}$ at $647^{\circ} \mathrm{C}$ in the $5^{\text {th }}$ TLC cold leg. EDX maps were collected from the same region of (b) $\mathrm{Cr}$, (c) $\mathrm{Fe}$, (d) $\mathrm{Si}$, (e) $\mathrm{Pb}$ and (f) $\mathrm{O}$.

\section{FUTURE PLANS}

In FY21, the FESS Blanket program plans to operate a sixth TCL experiment with a peak temperature of $650^{\circ} \mathrm{C}$ and include CVD SiC and aluminized F82H specimens. To support the FRONTIER collaboration, a liquid Sn TCL experiment is being assembled that will include APMT and specimens of several ODS FeCrAl specimens. The Sn TCL is planned to operate with a peak temperature of $400^{\circ} \mathrm{C}$ to verify that preoxidized FeCrAl is compatible with $\mathrm{Sn}$ in a temperature gradient. 


\section{EXPLORATORY, UNIQUE AND INNOVATIVE MATERIALS}

\subsection{TRITIUM BREEDING MATERIAL - EXPERIMENTAL}

PhilEdmondson,edmondsonpd@ornl.gov (ORNL)

\section{OBJECTIVE}

The overarching objective of this task is to investigate the radiation response of candidate ceramic tritium breeding materials, and to explore the possibility of using additive manufacturing techniques to produce tritium breeding modules based on Li ceramics.

\section{SUMMARY}

For a commercial, power producing nuclear fusion reactor to become viable, a self-sustaining tritium source must be available at the power plant site. This will require tritium to be generated - bred - on site. Current designs have centered on the production of tritium using $\mathrm{Li}$ in either a solid or liquid form in which the energetic neutrons from the D-T plasma are captured in the Li atoms with tritium as one of the reaction products. While significant research has focused on the production of material for solid-state breeder applications, these have centered on the fabrication of pebbles. In this research task, the potential of additive manufacturing techniques to be used to produce $\mathrm{Li}_{2} \mathrm{TiO}_{3}$ ceramic modules for breeder applications, and the radiation response of $\mathrm{Li}_{2} \mathrm{TiO}_{3}$ produced through solid-state synthesis and additively manufactured routes are to be studied.

\section{PROGRESS AND STATUS}

To achieve the desired task, $\mathrm{Li}_{2} \mathrm{TiO}_{3}$ (LTO) materials needed to be procured. Praxair was identified as a potential supplier and orders were placed for powdered LTO for use in the additive manufacturing (AM) portion of the task, and a bulk wafer of LTO to be used as a baseline comparison and for the radiation response study.

\section{$\underline{\text { Powdered LTO }}$}

The AM technique to be used in this task has been down-selected to be binder jet printing, a method that requires powder with a specific average size of 20-50 $\mu \mathrm{m}$. An order was placed with Praxair to develop and provide this size of powdered LTO using a spray granulation and sintering approach.

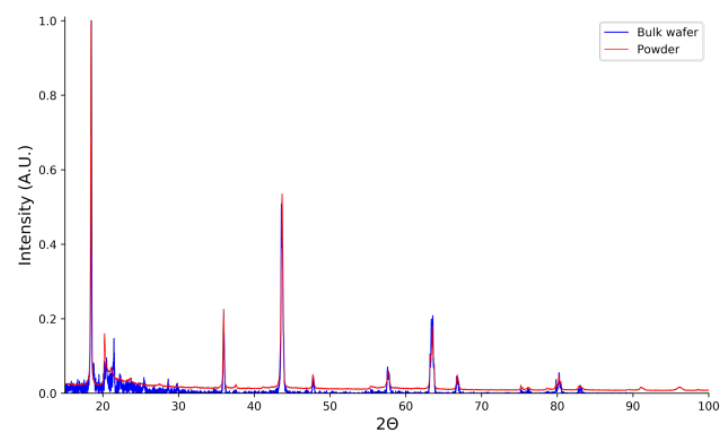

Figure 61. XRD results of the powdered and bulk LTO materials. 
XRD phase analysis of the powdered material (Figure 61) confirmed that the material was phase-pure LTO with monoclinic phase $(\mathrm{C} 2 / \mathrm{c})$. Scanning electron microscopy was also used to image the powder particles and measure the size distributions, as shown in Figure 62. The mean particle size was determined to be $25.04 \mu \mathrm{m}$, with a median size of $22.80 \mu \mathrm{m}$, suitable for use in AM.
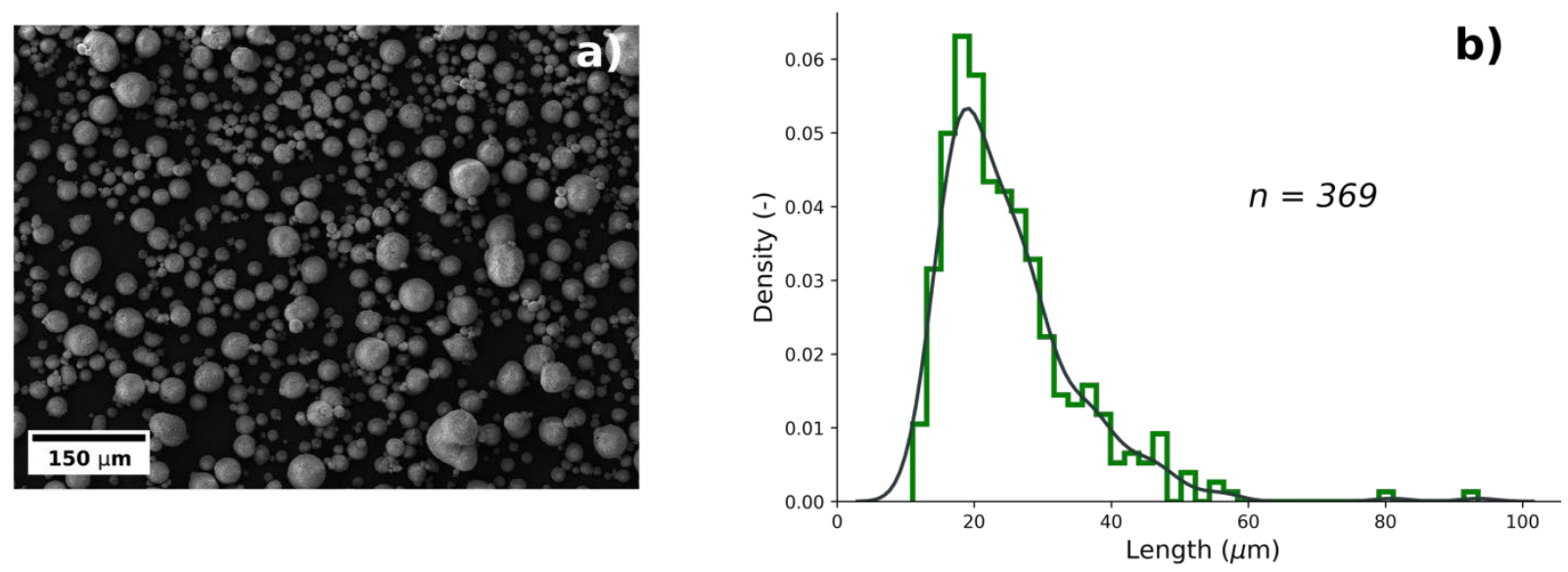

Figure 62. SEM micrograph showing distribution of LTO powder particles a), and the size distribution histogram b). The total number of particles measured to obtain the size distribution was 369.

The ability to conduct the AM portion of the task has been impacted by COVID-19 because the machine required has not been installed due to difficulties in the field service engineer getting site access.

\section{Bulk LTO}

The bulk wafer to be used in this task was procured from Praxair at the same time as the powder and was delivered in a vacuum sealed bag. XRD analysis (Figure 61) confirmed that it was the expected monoclinic $(\mathrm{C} 2 / \mathrm{c})$ phase.

\section{FUTURE PLANS}

Continued baseline analysis of the LTO materials will be conducted, including Raman spectroscopy. Some of the material has been sent to Brookhaven National Laboratory for further XRD analysis using the NSLSII. Specifically, this will focus on the generation of the phase diagram at room pressure, but at temperatures up to and above expected operational temperatures, and site occupancy, particularly for the Li sites. Production of monolithic blocks of LTO using AM techniques will also be performed in FY21.

Ion irradiation studies of the bulk and monolithic AM LTO will also be conducted, including PIE to begin to understand the materials' response to radiation. 


\subsection{TRITIUM BREEDING MATERIAL - THEORETICAL}

Phil Edmondson, edmondsonpd@ornl.gov; German Samolyuk(ORNL), Yurij Mozharivskyj (McMaster University)

\section{OBJECTIVE}

The objective of this task is to use atomistic scale modeling to explore the possibility of new materials development and understanding radiation effects in Li-based ceramics in development of solid-state breeder materials.

\section{SUMMARY}

The breeder blanket of a power generating fusion power plant will require a neutron multiplier and a tritium breeding material in order to generate the tritium required to maintain the burning plasma. Current designs use separate multiplier and breeder arrangements that generate a large temperature difference between the materials. In this task, the potential of a Li-Be compound is explored using atomic scale modeling to determine if specific compounds that have the necessary Li loading are stable enough to be formed, and to then explore their radiation stability. This approach is not expected to completely replace a two-phase multiplier/breeder system, but rather support this using a graded architecture to minimize thermal differences and improve efficiency.

In this work, we are initially focusing on $\mathrm{Li}_{2} \mathrm{Be}_{2} \mathrm{O}_{3}$ and $\mathrm{Li}_{2} \mathrm{BeSiO}_{4}$ compounds.

\section{PROGRESS and STATUS}

\section{$\underline{\mathrm{Li}_{2}} \underline{\mathrm{Be}}_{2} \underline{\mathrm{O}_{3}}$}

This ceramic was chosen to be examined due to its high Li and Be content. Density functional theory (DFT) modeling has been conducted on this material, but some lattice instabilities are observed in the current modeling and convergence has not been achieved as yet. This is likely due to an incorrect initial structure assumption as no structure has yet been reported in the literature. In parallel with this modeling effort, collaboration with researchers at McMaster University, Canada has explored the synthesis of this compound. Using a solid-state synthesis technique, they have produced small quantities of $\mathrm{Li}_{2} \mathrm{Be}_{2} \mathrm{O}_{3}$, as shown in Figure 63 and Figure 64. This material is still being characterized and the results will help update the modeling to refine the DFT calculations. 


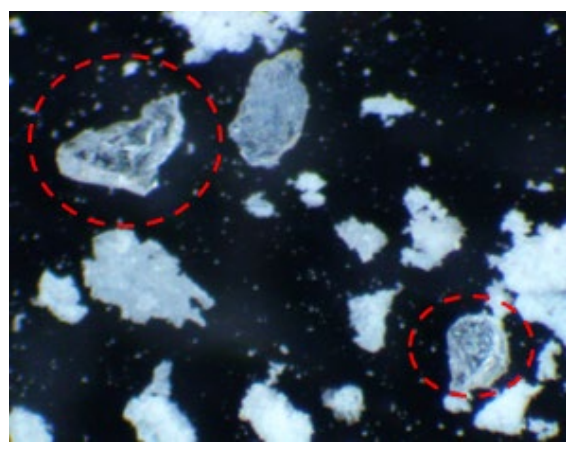

Figure 63. Optical micrograph showing the $\mathrm{Li}_{2} \mathrm{Be}_{2} \mathrm{O}_{3}$ particles (red circles) produced at McMaster University.

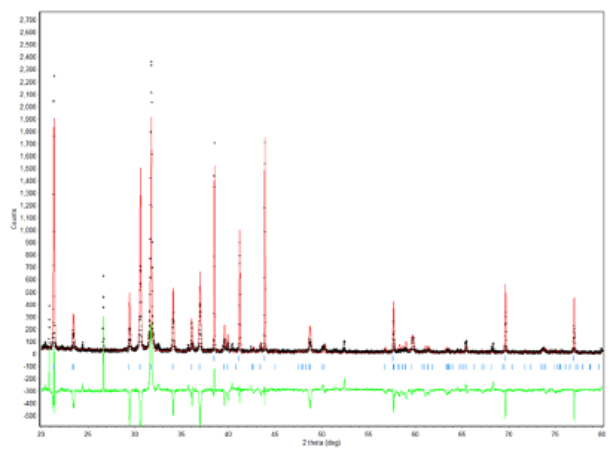

Figure 64. XRD pattern confirming $\mathrm{Li}_{2} \mathrm{Be}_{2} \mathrm{O}_{3}$ single crystal.

\section{$\underline{\text { Li-Be compounds }}$}

Multiple additional phases have also been explored using DFT approaches. In particular, the focus is on the thermal properties to determine if these will be beneficial to the system if used in a graded architecture as described above. To date, the electronic structure, formation energies, phonon dispersion, and thermal conductivity have been calculated for various materials including $\mathrm{Li}_{2} \mathrm{TiO}_{3}$ and $\mathrm{Li}_{2} \mathrm{BeSiO}_{4}$. The compounds were found to be stable, and an example of the thermal conductivities are given in Figure 65.
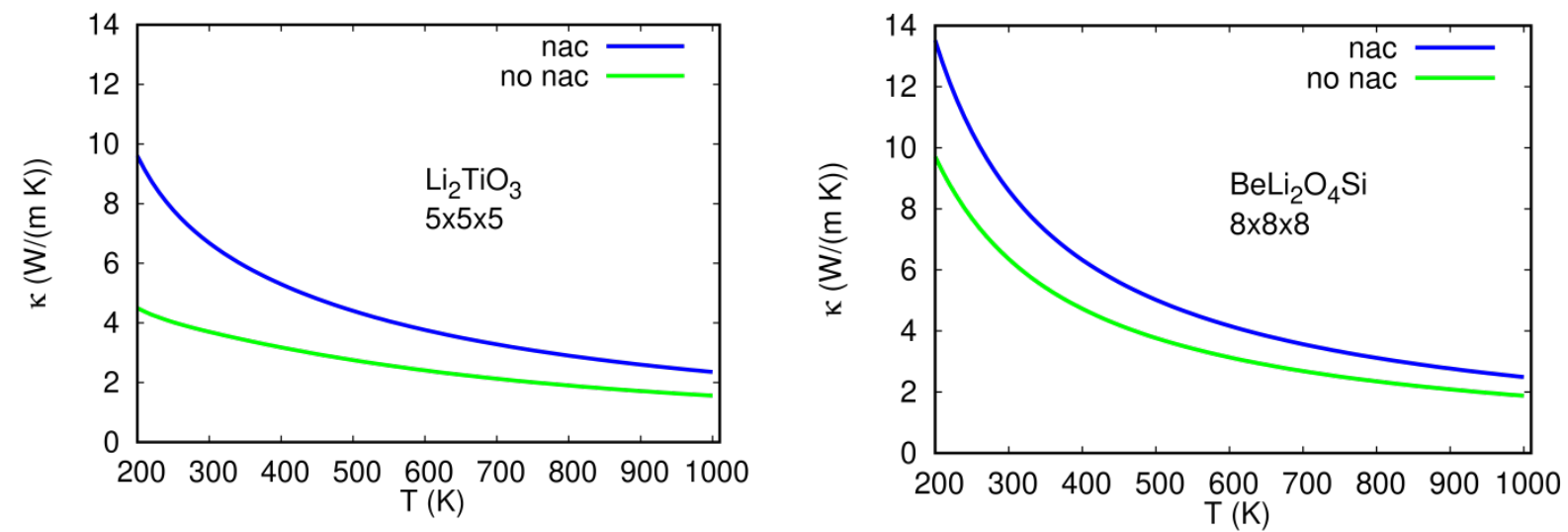

Figure 65. Thermal conductivities for $\mathrm{Li}_{2} \mathrm{Ti}_{2} \mathrm{O}_{3}$ and $\mathrm{Li}_{2} \mathrm{BeSiO}_{4}$ calculated using DFT. The unit cell size are $5 \times 5 \times 5$ and $8 \times 8 \times 8$, respectively. The calculated thermal conductivities are found to be close to that of $\mathrm{SiO}_{2}$.

\section{FUTURE PLANS}

Examination of the $\mathrm{Li}_{2} \mathrm{Be}_{2} \mathrm{O}_{3}$ material will continue in collaboration with McMaster University, along with a publication on the topic. A publication will also be finalized on the DFT modeling of the Li-Be compounds.

Calculations of the displacement energies of $\mathrm{Li}_{2} \mathrm{TiO}_{3}$, and other Li-based ceramics that are candidate materials for solid-state breeder applications will also be performed. Particularly, it is envisaged to develop a new machine learning framework for DFT based threshold displacement energy calculations. Not only will this be able to determine displacement energies in all crystallographic directions as needed for $\mathrm{Li}_{2} \mathrm{TiO}_{3}$ materials, but it will also be applicable for other materials. 


\title{
8. GASES IN MATERIALS
}

\subsection{DEUTERIUM TRANSPORT AND RETENTION PROPERTIES OF REPRESENTATIVE FUSION BLANKET STRUCTURAL MATERIALS}

\author{
Ze Chen, Brian D. Wirth (UT-Knoxville), XunxiangHu (hux1@ornl.gov) (ORNL)
}

\section{OBJECTIVE}

Reduced activation ferritic-martensitic (RAFM) steels have been developed over the past four decades for use as fusion blanket structural materials and have advantages in both mechanical properties and irradiation resistance, achieved by careful engineering of the microstructure. However, the hydrogen isotope behavior in these materials is not well understood but is important to assess since it impacts the fusion reactor safety and self-sufficient tritium fuel cycle. The objective of this work is to investigate the deuterium transport and retention in representative advanced RAFM steels, including castable nanostructured alloys (CNAs), and oxide-dispersion-strengthened (ODS) steels.

\section{SUMMARY}

A gas-driven permeation (GDP) system was used to measure the permeability, diffusivity and solubility of candidate materials, covering the temperature range $350{ }^{\circ} \mathrm{C}$ to $600^{\circ} \mathrm{C}$, and loading pressures from $1.8 \times 10^{4}$ to $1.0 \times 10^{5} \mathrm{~Pa}$. The results indicated that the deuterium permeability has little material dependence. In contrast, the deuterium diffusivity of these materials showed significant variation. The deuterium diffusivity in ODS steels is one order of magnitude lower than that in RAFM steels and CNAs, and correspondingly has an effective solubility that is 2-10 times larger than RAFM steels and CNAs. In addition, thermal desorption spectroscopy (TDS) measurements were performed to assess the deuterium retention and desorption of these materials following a static thermal deuterium charging at $450{ }^{\circ} \mathrm{C}$ for 1 hour under deuterium pressure of $1.0 \times 10^{5} \mathrm{~Pa}$. It was found that ODS steels exhibit the highest deuterium retention and have broader desorption peaks. Microstructural features contributing to deuterium retention and impacting deuterium transport are discussed to rationalize the observed deuterium behavior in the RAFM steels.

\section{PROGRESS AND STATUS}

Seven steels, Eurofer97, G91, TT3mt, FTa1, M4 Fe-10Cr, 9YWTV-PM2 and 14YWT-SM13, were investigated in this work. The chemical compositions of these materials are listed in Table 7. Disk samples with a diameter of $12.6 \mathrm{~mm}$ and a thickness of $\sim 1 \mathrm{~mm}$ were machined from bulk pieces of the studied materials. They were mechanically polished on both sides to a mirror-like finishing, followed by ultrasonic cleaning in acetone and alcohol baths.

Permeation tests were performed over the temperature range $350{ }^{\circ} \mathrm{C}$ to $600{ }^{\circ} \mathrm{C}$, and the loaded pressure varies from 140 torr to 500 torr using the gas permeation testing station. The resulting measured permeability is plotted against reciprocal temperature in Figure $\mathbf{6 6}$ (a). The permeability of all these materials is about one order of magnitude lower than that of pure alpha iron. The permeability of each of the tested materials are within a narrow range, less than one order of magnitude, implying very limited material dependence. As shown in Figure 66(a), deuterium permeability of Eurofer97 is higher than the other materials, except the $14 \mathrm{YWT}$ when the temperature is greater than $500^{\circ} \mathrm{C}$. It is also noted that the measured deuterium permeability in Eurofer97 is about 1.5 times that of the reference Eurofer97, while the permeability of the three ODS steels is consistent with the data of the reference ODS-Eurofer. 
Table 7. Chemical compositions (wt \%) of candidate advanced RAFM steels

\begin{tabular}{|c|c|c|c|c|c|c|c|c|c|c|c|}
\hline $\begin{array}{l}\text { Catego } \\
\text { ries }\end{array}$ & $\begin{array}{c}\text { Sample } \\
\text { Steels }\end{array}$ & $\mathrm{Fe}$ & $\mathbf{C}$ & $\mathbf{N}$ & $\mathbf{O}$ & Al & $\mathbf{S i}$ & $\mathbf{P}$ & $\mathbf{S}$ & $\mathbf{T i}$ & $\mathbf{V}$ \\
\hline \multirow[t]{2}{*}{ RAFM } & Eurofer 97 & Bal. & 0.11 & $22^{0.0}$ & 0.001 & 0.009 & 0.04 & $\mathrm{n} / \mathrm{a}$ & $\mathrm{n} / \mathrm{a}$ & 0.005 & 0.2 \\
\hline & G91 & Bal. & 0.08 & 0.055 & $\mathrm{n} / \mathrm{a}$ & $\mathrm{n} / \mathrm{a}$ & 0.1 & $\mathrm{n} / \mathrm{a}$ & $\mathrm{n} / \mathrm{a}$ & $\mathrm{n} / \mathrm{a}$ & 0.2 \\
\hline \multirow[t]{2}{*}{ CNA } & TT3mt & Bal. & 0.08 & $\mathrm{n} / \mathrm{a}$ & $\mathrm{n} / \mathrm{a}$ & $\mathrm{n} / \mathrm{a}$ & 0.1 & $\mathrm{n} / \mathrm{a}$ & $\mathrm{n} / \mathrm{a}$ & 0.1 & 0.1 \\
\hline & FTa1 & Bal. & 0.1 & 0.05 & 0.008 & $\mathrm{n} / \mathrm{a}$ & 0.23 & $\mathrm{n} / \mathrm{a}$ & $\mathrm{n} / \mathrm{a}$ & $\mathrm{n} / \mathrm{a}$ & 0.32 \\
\hline \multirow[t]{3}{*}{ ODS } & $\begin{array}{c}\mathrm{M} 4 \mathrm{Fe}- \\
10 \mathrm{Cr}\end{array}$ & Bal. & 0.031 & $\begin{array}{c}0.018 \\
4\end{array}$ & $\mathrm{n} / \mathrm{a}$ & 0.01 & 0.02 & $\mathrm{n} / \mathrm{a}$ & 0.031 & 0.015 & 0.18 \\
\hline & $\begin{array}{l}\text { 9YWTV- } \\
\text { PM2 }\end{array}$ & Bal. & 0.06 & $\begin{array}{c}0.017 \\
4\end{array}$ & 0.12 & 0.01 & 0.02 & 0.003 & 0.004 & 0.37 & 0.18 \\
\hline & $\begin{array}{c}\text { 14YWT- } \\
\text { SM13 }\end{array}$ & Bal. & 0.024 & 0.099 & 0.177 & 0.016 & 0.043 & $\mathrm{n} / \mathrm{a}$ & $\mathrm{n} / \mathrm{a}$ & 0.27 & $\mathrm{n} / \mathrm{a}$ \\
\hline $\begin{array}{c}\text { Catego } \\
\text { ries }\end{array}$ & $\begin{array}{c}\text { Sample } \\
\text { Steels }\end{array}$ & $\mathrm{Cr}$ & Mn & Co & $\mathbf{N i}$ & $\mathrm{Cu}$ & $\mathbf{Y}$ & $\mathbf{N b}$ & Mo & Ta & $\mathbf{W}$ \\
\hline \multirow[t]{2}{*}{ RAFM } & Eurofer 97 & 8.82 & 0.47 & $\mathrm{n} / \mathrm{a}$ & $\mathrm{n} / \mathrm{a}$ & $\mathrm{n} / \mathrm{a}$ & $\mathrm{n} / \mathrm{a}$ & $\mathrm{n} / \mathrm{a}$ & $\mathrm{n} / \mathrm{a}$ & 0.13 & 1.09 \\
\hline & G91 & 8.6 & 0.37 & $\mathrm{n} / \mathrm{a}$ & 0.09 & $\mathrm{n} / \mathrm{a}$ & $\mathrm{n} / \mathrm{a}$ & 0.07 & 0.9 & $\mathrm{n} / \mathrm{a}$ & $\mathrm{n} / \mathrm{a}$ \\
\hline \multirow[t]{2}{*}{ CNA } & TT3mt & 8.5 & 0.9 & $\mathrm{n} / \mathrm{a}$ & $\mathrm{n} / \mathrm{a}$ & $\mathrm{n} / \mathrm{a}$ & $\mathrm{n} / \mathrm{a}$ & $\mathrm{n} / \mathrm{a}$ & $\mathrm{n} / \mathrm{a}$ & 0.1 & 1.3 \\
\hline & FTa1 & 9.01 & 0.46 & $\mathrm{n} / \mathrm{a}$ & $\mathrm{n} / \mathrm{a}$ & $\mathrm{n} / \mathrm{a}$ & $\mathrm{n} / \mathrm{a}$ & $\mathrm{n} / \mathrm{a}$ & $\mathrm{n} / \mathrm{a}$ & 0.1 & 1.1 \\
\hline \multirow[t]{3}{*}{ ODS } & $\begin{array}{c}\mathrm{M} 4 \mathrm{Fe}- \\
10 \mathrm{Cr}\end{array}$ & 9.7 & 0.01 & 0.02 & $\mathrm{n} / \mathrm{a}$ & $\mathrm{n} / \mathrm{a}$ & 0.023 & $\mathrm{n} / \mathrm{a}$ & $\mathrm{n} / \mathrm{a}$ & $\mathrm{n} / \mathrm{a}$ & 0.97 \\
\hline & $\begin{array}{l}\text { 9YWTV- } \\
\text { PM2 }\end{array}$ & 8.91 & 0.01 & 0.02 & 0.01 & 0.01 & 0.07 & 0.02 & $\mathrm{n} / \mathrm{a}$ & $\mathrm{n} / \mathrm{a}$ & 1.98 \\
\hline & $\begin{array}{l}\text { 14YWT- } \\
\text { SM13 }\end{array}$ & 14.3 & 0.008 & $\mathrm{n} / \mathrm{a}$ & $\mathrm{n} / \mathrm{a}$ & $\mathrm{n} / \mathrm{a}$ & 0.19 & $\mathrm{n} / \mathrm{a}$ & $\mathrm{n} / \mathrm{a}$ & $\mathrm{n} / \mathrm{a}$ & 2.32 \\
\hline
\end{tabular}
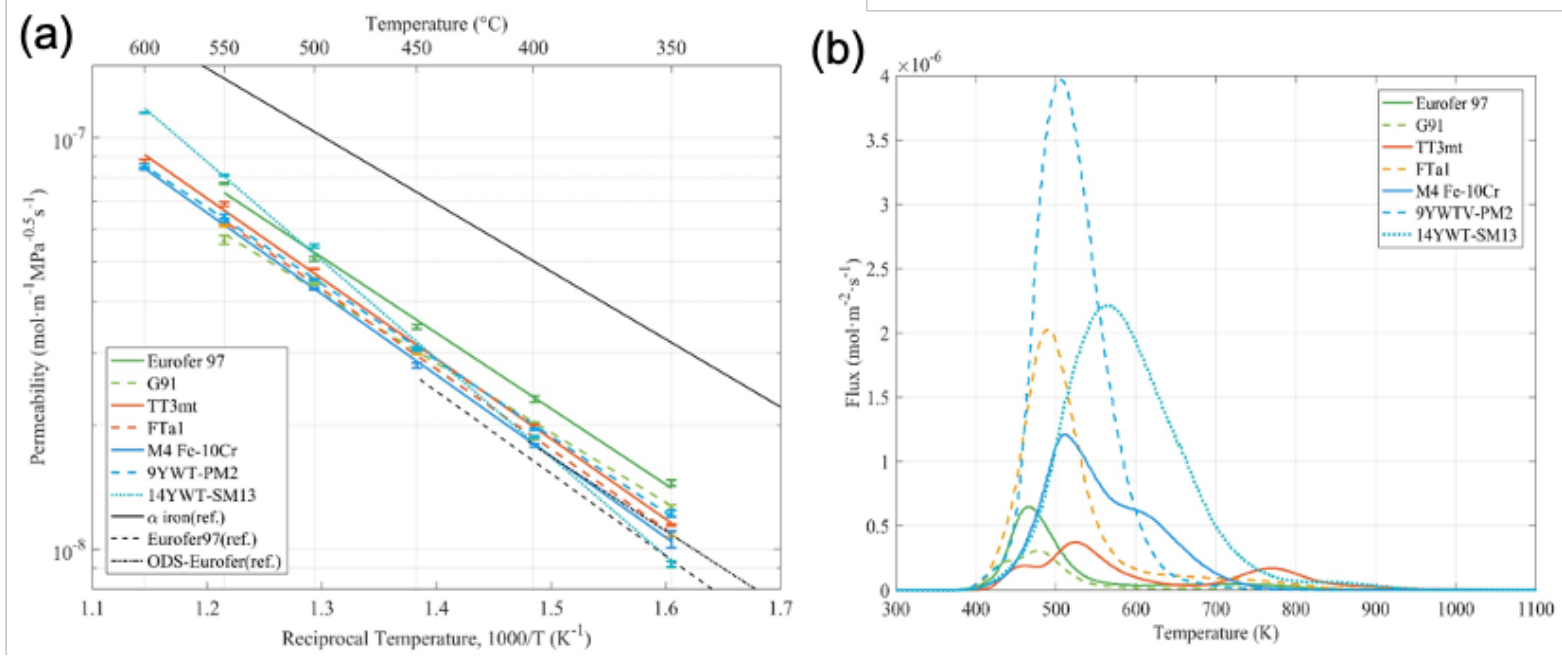

Figure 66. (a) Deuterium permeability of candidate steels measured as a function of temperature; (b) Thermal desorption spectra following static deuterium charging. 
The thermal deuterium desorption spectra following the static thermal deuterium charging is plotted in Figure 66(b) for each of these materials. During the heating process in a TDS measurement, the remaining deuterium content in the sample bulk is described as:

$$
\frac{d N}{d t}=-N v \exp \left(-\frac{E}{k_{B} T}\right)
$$

where $\mathrm{N}$ is deuterium density, $v$ is Debye frequency $\left(v=10^{13} / s\right)$, $\mathrm{E}$ is the activation energy, $k_{B}$ is the Boltzmann constant, and $\mathrm{T}$ is the corresponding temperature. Assuming a linear ramp (the ramping rate $\beta=d T / d t)$, by solving:

$$
\frac{d}{d t}\left(\frac{d N}{d t}\right)=0
$$

the activation energy corresponding to desorption peak is obtained by:

$$
\ln \left(\frac{\beta}{T^{2}}\right)=-\frac{E}{k_{B} T}+\ln \left(\frac{v k_{B}}{T}\right)
$$

Considering the relatively small local temperature range around the desorption peak, associated with the linear temperature ramp heating process, then the actual temperature ramp rate can be determined from the slope of the temperature curve measured by the in-situ thermocouple. For the RAFM steels, only one major desorption peak was observed in the deuterium desorption spectra of Eurofer97 and G91. The G91 has a lower peak temperature $447 \mathrm{~K} / 122.6 \mathrm{~kJ} \cdot \mathrm{mol}^{-1}$, in addition to a narrower FWHM and lower peak desorption flux than that of Eurofer97 $473 \mathrm{~K} / 129.3 \mathrm{~kJ} \cdot \mathrm{mol}^{-1}$, implying that the deuterium in G91 has an average weaker binding energy and less complexity of deuterium trapping sites relative to Eurofer97. For the CNAs, FTa1 has a major desorption peak at $477 \mathrm{~K} / 131.2 \mathrm{~kJ} \cdot \mathrm{mol}^{-1}$, while alloy TT3mt has a complex desorption spectra that includes an evident shoulder at $460 \mathrm{~K} / 126.4 \mathrm{~kJ}^{\prime} \cdot \mathrm{mol}^{-1}$, a peak at $525 \mathrm{~K} / 143.8 \mathrm{~kJ}$. $\mathrm{mol}^{-1}$, and a third peak at $770 \mathrm{~K} / 212.3 \mathrm{~kJ} \cdot \mathrm{mol}^{-1}$. The increased temperature of the major desorption peak is indicative of a higher binding energy of the major trapping sites, while the existence of a shoulder suggests the existence of another trapping species with a lower binding energy than the major traps. As well, the deuterium retention of FTa1 is more than two times larger than the RAFM steels and the CNATT3mt.

In general, the desorption spectra of ODS steels exhibits both higher magnitude and broader temperature range of the desorption peaks than the other RAFM steels and CNAs, indicating stronger binding between deuterium and the trapping sites and more complex trapping site species. Only one primary desorption peak is observed for 9YWTV $\left(505 \mathrm{~K} / 139.9 \mathrm{~kJ} \cdot \mathrm{mol}^{-1}\right)$ or 14YWT $\left(566 \mathrm{~K} / 157.3 \mathrm{~kJ} \cdot \mathrm{mol}^{-1}\right)$. M4 has a peak at $511 \mathrm{~K} / 140.1 \mathrm{~kJ} \cdot \mathrm{mol}^{-1}$ and a shoulder at higher temperature of $600 \mathrm{~K} / 165.0 \mathrm{~kJ} \cdot \mathrm{mol}^{-1}$. 9YWTV exhibits the highest retention rate of $1.745 \mathrm{~mol} \cdot \mathrm{m}^{-3}$, while the retention rates of M4 and 14YWT are $0.629 \mathrm{~mol}$. $\mathrm{m}^{-3}$ and $1.220 \mathrm{~mol} \cdot \mathrm{m}^{-3}$, respectively. The deuterium desorption spectra information and retention rate of all materials is summarized in Table 8 . 
Table 8. Analysis results of thermal desorption spectra of RAFM steels

\begin{tabular}{|c|c|c|c|c|c|c|}
\hline \multirow{2}{*}{$\begin{array}{l}\text { Categ } \\
\text { ory }\end{array}$} & \multirow[t]{2}{*}{ Samples } & \multicolumn{2}{|c|}{$\begin{array}{c}\text { Peak } \\
\end{array}$} & \multicolumn{2}{|c|}{ Shoulder } & \multirow{2}{*}{$\begin{array}{c}\text { Retention } \\
\left(\mathrm{mol} \cdot \mathrm{m}^{-3}\right)\end{array}$} \\
\hline & & $\begin{array}{c}\text { Temperature } \\
\text { (K) }\end{array}$ & $\begin{array}{c}\text { Activation } \\
\text { Energy } \\
\text { kJ/mol } \\
\end{array}$ & $\begin{array}{c}\text { Temperatu } \\
\text { re } \\
(\mathrm{K}) \\
\end{array}$ & $\begin{array}{c}\text { Activation } \\
\text { Energy } \\
\text { kJ/mol } \\
\end{array}$ & \\
\hline RAF & Eurofer97 & 473 & 129.3 & 1 & 1 & 0.147 \\
\hline $\mathrm{M}$ & G91 & 447 & 122.6 & / & / & 0.117 \\
\hline \multirow[t]{2}{*}{ CNA } & TT3mt & 525 & 143.8 & 460 & 126.4 & 0.184 \\
\hline & FTa1 & 477 & 131.2 & / & / & 0.401 \\
\hline \multirow[t]{3}{*}{ ODS } & $\begin{array}{l}\mathrm{M} 4 \mathrm{Fe}- \\
10 \mathrm{Cr}\end{array}$ & 511 & 140.1 & 600 & 165.0 & 0.629 \\
\hline & $\begin{array}{l}\text { 9YWTV- } \\
\text { PM2 }\end{array}$ & 505 & 139.9 & / & / & 1.745 \\
\hline & $\begin{array}{l}\text { 14YWT- } \\
\text { SM13 }\end{array}$ & 566 & 157.3 & / & / & 1.220 \\
\hline
\end{tabular}

\section{FUTURE PLANS}

Future work will focus on diffusivity tests in the lower temperature range needed to extract more accurate data on the characteristics of the hydrogen trapping sites. The diffusion behavior and trapping effect attributed to the different types of microstructural features also require further experimental observations and calculations. 


\section{ADVANCED MANUFACTURING}

\subsection{ADVANCED MANUFACTURING OF TUNGSTEN FOR DIVERTOR COMPONENTS}

Betsy Ellis (ellisea@ornl.gov), John Echols, Christopher Ledford, Jameson Hankwitz, Timothy Horn, Michael Sprayberry, Chris D. Rock, Lauren Garrison, Michael Kirka, Yutai Kato, Ryan Dehoff (ORNL)

\section{OBJECTIVE}

The objective of this project is to evaluate additive manufacturing (AM) techniques for manufacturing tungsten divertor components. Two AM techniques are being evaluated: electron beam powder bed fusion (EB-PBF), and binder jet additive manufacturing (BJAM). This report covers investigations into cracking behavior in EB-PBF tungsten, and the densification of tungsten produced through BJAM by chemical vapor infiltration.

\section{SUMMARY}

Additive manufacturing has the potential to revolutionize the design of plasma-facing components (PFCs) for fusion power, but AM of refractory metals such as tungsten is still under development. In particular, AM W is highly prone to cracking. Previous work in this project has shown that it is possible to produce dense and crack-free tungsten via EB-PBF, but the mechanism by which cracks form is unclear. We seek to understand this mechanism in order to produce crack-free AM W. more reliably

High densities of binder jetted tungsten have been achieved to a depth of approximately 100 microns, however, the closure of the surface remains a challenge for bulk densification. Studies to optimize deposition rate as a function of temperature and pressure are ongoing.

\section{PROGRESS AND STATUS}

\section{Electron beam powder bed fusion (EB-PBF)}

The Arcam Q10+ is equipped with a near-infrared (NIR) camera that takes an in-situ image of each layer of the build. These NIR images were analyzed to identify pores and combined to create a 3D visualization of the part. Using anomalies classified as porosity an area and volumetric density was calculated. (For more detail on NIR analysis, see the most recent semiannual report (DOE/ER-0313/68, Vol. 68, June 30, 2020)). 

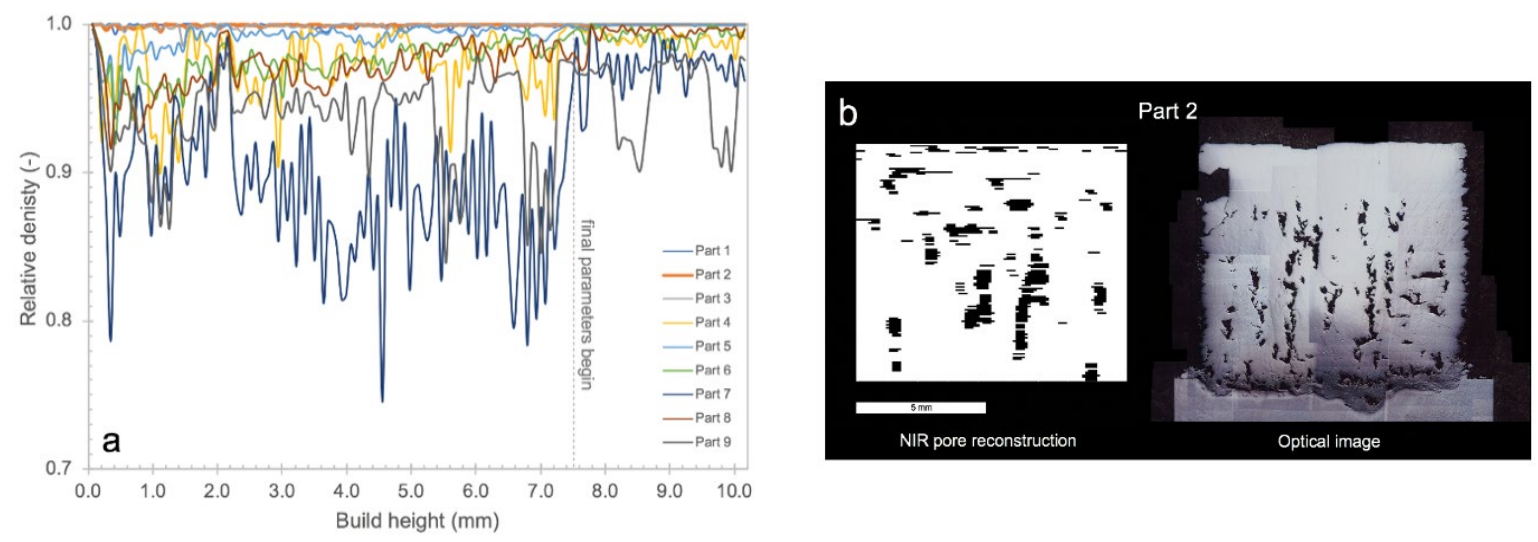

Figure 67. In-situ NIR analysis of build 2. a) Calculated relative density per layer for each part. A noticeable increase in density occurs at $7.5 \mathrm{~mm}$, after final parameters begin. b) Comparison of reconstructed part (left) and as-built part (right). For the reconstructed image, white indicates solid material and black indicates porosity.

Figure 67a shows layer wise relative density for each part in Build 2. Transition from the porous support structure to the final parameter set was complete at $7.58 \mathrm{~mm}$, and this point is indicated on the figure. A distinct change in relative density across all parts is visible at this height, and analysis of variance (ANOVA) and pairwise analysis indicates that the likelihood of creating this density change randomly was small. Figure $67 \boldsymbol{b}$ shows an $\mathrm{XZ}$ section through the full 3D reconstruction for Build 2, part 2, compared with an optical micrograph of the same part at a similar location. The reconstruction accurately captures the presence of chimney pores in the porous support region and an increase in density above the support region. Several small pores below the detection limit $(\sim 40 \mu \mathrm{m})$ do not appear in the reconstructed part, and a few single-layer pores appear in the reconstruction but not the physical part. The large hole at the left side of the sample is believed to have occurred during sectioning, and thus does not appear in the in-situ data. However, the large pore visible in the in-situ data near this region may have contributed to the formation of the hole during sectioning.

This is the first use of in-situ near-infrared layer images for 3D build reconstruction and defect detection in refractory metals. Previous work has demonstrated the efficacy of this technique for other metals, including the titanium alloy Ti64, but refractory metals such as tungsten present additional challenges. Tungsten has a relatively high emissivity at high temperatures, and the emissivity of unmelted tungsten powder is quite close to that of pores in the melted material. As it is the contrast in emissivity that allows for in-situ detection of pores, this presents a challenge. Nevertheless, the results shown above demonstrate a promising first step toward developing an in-situ defect detection algorithm for tungsten in spite of these difficulties.

Densities in the region of interest (i.e. not including the porous support structure) were calculated using this technique and are plotted in Figure 68, along with other reported values for AM W. This plot suggests that, regardless of additive manufacturing method, a minimum energy density $\left(\sim 200 \mathrm{~J} / \mathrm{mm}^{3}\right)$ is required to produce dense tungsten, and that an ambient temperature above $1000^{\circ} \mathrm{C}$, while not absolutely required, is of considerable assistance in producing dense tungsten. 


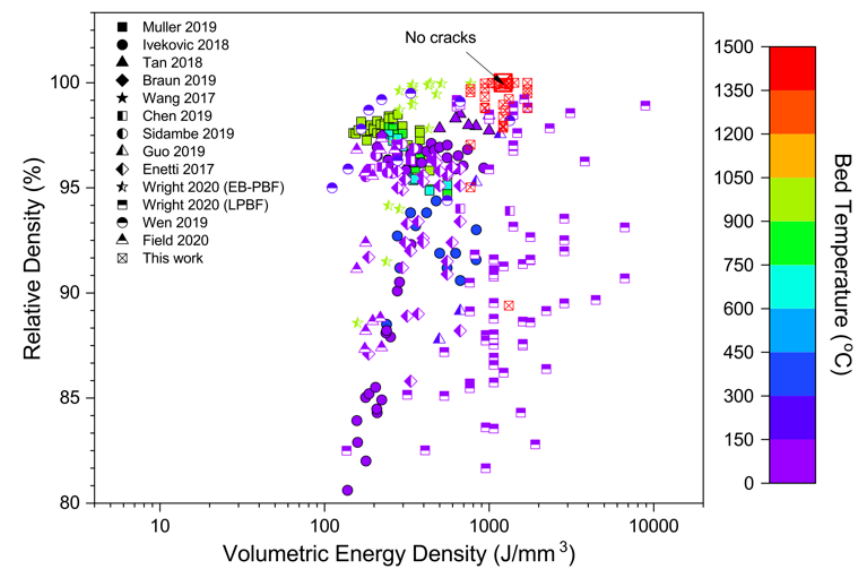

Figure 68. Summary of published results of additively manufactured tungsten. Reported relative density is plotted vs. volumetric energy density, and color indicates ambient temperature at which build was performed.

The vast majority of reported attempts to produce AM tungsten were unable to eliminate cracking. In contrast, we have produced a sample without cracks or pores. As reported in the most recent semiannual report (DOE/ER-0313/68, Vol. 68, June 30, 2020), increased preheat temperature and duration is critical in reducing cracking in AM W. We also investigated crack morphology in those builds that did show cracking, and propose that cracks propagate in the solid state, due to the orientation gradients visible at crack edges in Figure 69a, indicating plastic deformation. Figure 69c shows a string of pores coalescing into a crack, and Figure 69d shows cracks localized in the XY plane. Together, this suggests that crack nucleation is relatively infrequent, though possibly promoted by the presence of porosity, but that cracks propagate readily in the build direction along long columnar grain boundaries in the solid state.

In comparison with the other works shown in Figure 68, our work used a higher beam power, larger spot size, and smaller hatch spacing, all of which contribute to an increased degree of remelting of material. As the beam rasters across the surface, each area of material is effectively preheated by each scan of material upstream of the area of interest, and then reheated by each scan of material downstream. The effective local ambient temperature before and after melting is therefore likely to be considerably higher than the average surface temperature, and the corresponding thermal gradient therefore of lower amplitude than those associated with a small beam. These lower-amplitude gyrations should in turn reduce thermal gradients and cooling rates, inducing lower thermal stresses and resulting in lower residual stresses. This might be thought of as analogous to the dual-beam welding processes, which are well known to result in lower stresses, and should therefore lead to reduced solid-state cracking. 

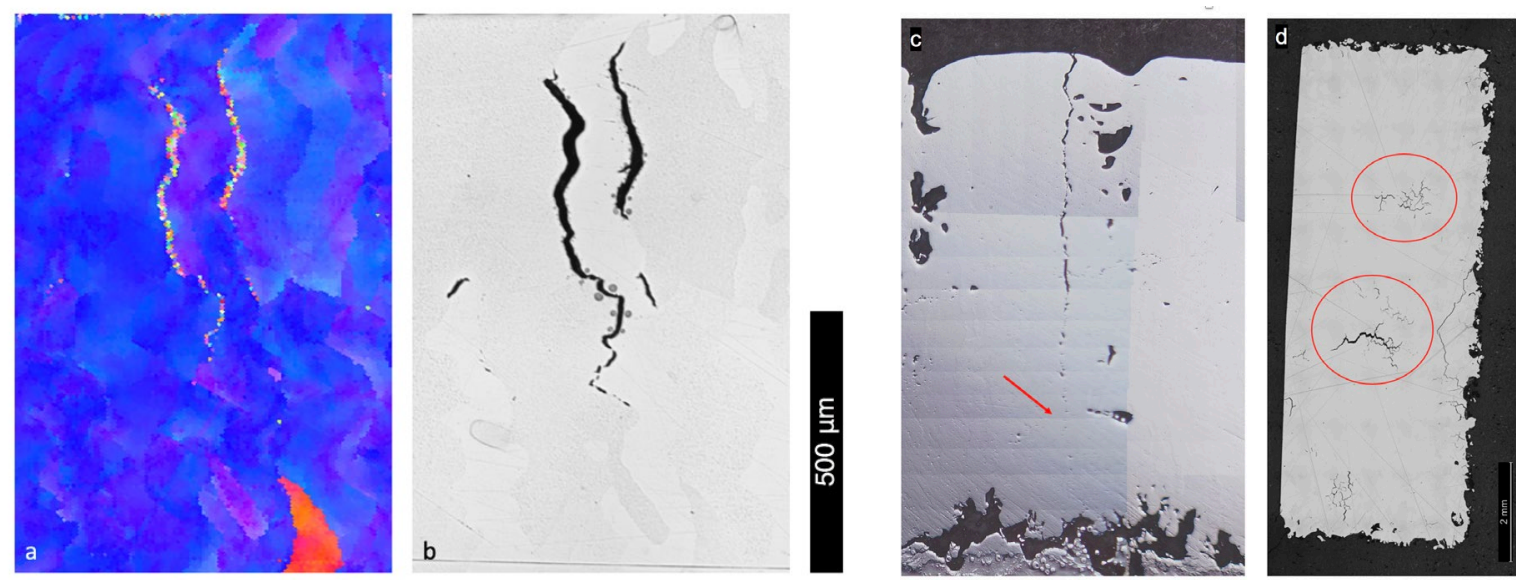

Figure 69. Study of cracking in Build 3, sample 8. a) EBSD of vertical crack, where the crack appears as random unindexed pixels and b) optical image of same crack. Several small droplets of water are visible at the edge of the crack in the optical image. c) $\mathrm{XZ}$ section showing string of pores leading to the crack in Build 1, sample 9 d) XY section of Build 3, sample 8, showing localized regions of high crack density.

Tensile tests, fractographs, and EBSD maps have been taken on EB-PBF samples both parallel and perpendicular to the build directions. Although samples still contain high porosity, the stress-strain relationships currently indicate that the material is much stronger when tension is parallel to the build direction. Figure 70 shows fractographs of tensile samples tested in both of these directions as well as representative EBSD maps of grain structures in these planes. The fractographs reveal clear fracture initiation sites in unfused material. For a more detailed discussion, see the most recent semiannual report (DOE/ER-0313/68, Vol. 68, June 30, 2020).

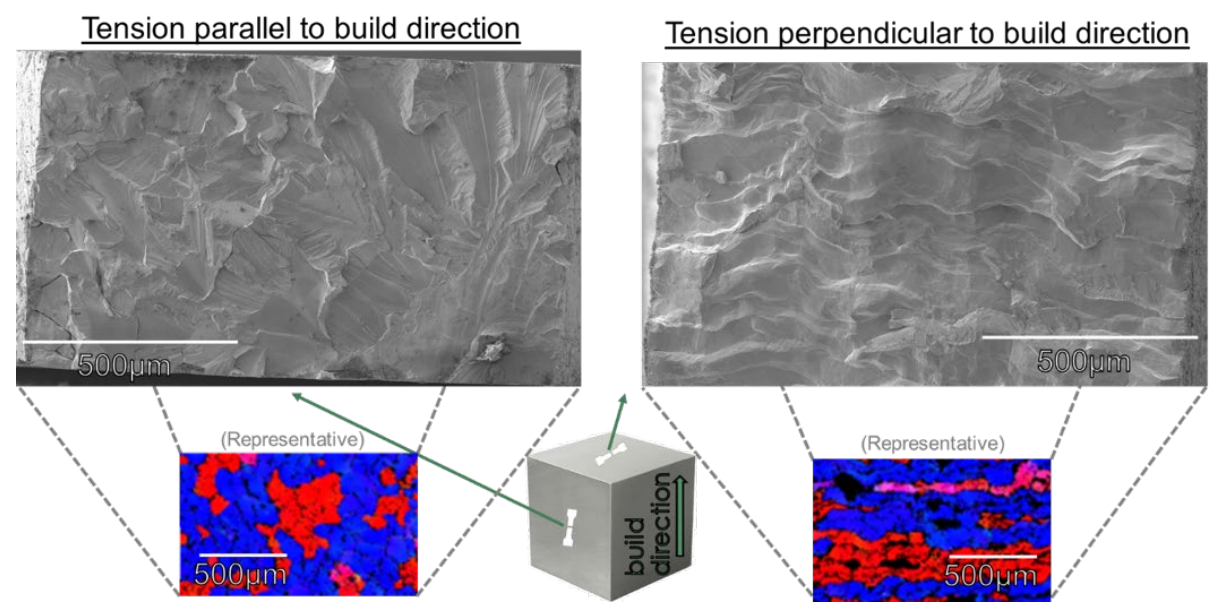

Figure 70. Fractographs and representative EBSD maps for samples from EBM with tension parallel (left) and perpendicular (right) to the build direction. 


\section{Binder jet additive manufacturing (BJAM)}

Binder jetting is also being considered as an AM route to produce fusion component materials. Conventional binder jetting produces parts by selectively depositing a liquid binding agent to join powder particles. Layers of material are bonded to produce a preform. The binding agent is then baked out at high temperature and the part is either infiltrated with liquid material or subjected to hot isostatic pressing to achieve full density. Neither of these solutions, however, is attractive to produce a full tungsten part due to recrystallization concerns. Therefore, chemical vapor infiltration is proposed.

A diagram illustrating the proposed CVI process is shown in the left half of Figure 71. Two conditions to explore densification have so far been explored, one using Mo particles, and one using W, but both with CVI W densification. The initial CVI run, with the Mo sample, was carried out at $625^{\circ} \mathrm{C}$, and although it successfully deposited $\mathrm{W}$ in the preform, the deposition rate was far too high, and the sample surface closed too quickly to allow for meaningful densification. The second run with the $\mathrm{W}$ preform, was performed at $450^{\circ} \mathrm{C}$. This second run produced high densification up to $70 \mu \mathrm{m}$ into the sample bulk and showed evidence of successful infiltration deep into the sample bulk, where limited, but extant, deposition is seen on tungsten particles. A cross-sectional SEM micrograph of this run is shown in the right half of Figure 71. Ultimately, the deposition rate at this temperature was also too high and the surface closed off before significant deposition occurred in the sample bulk.

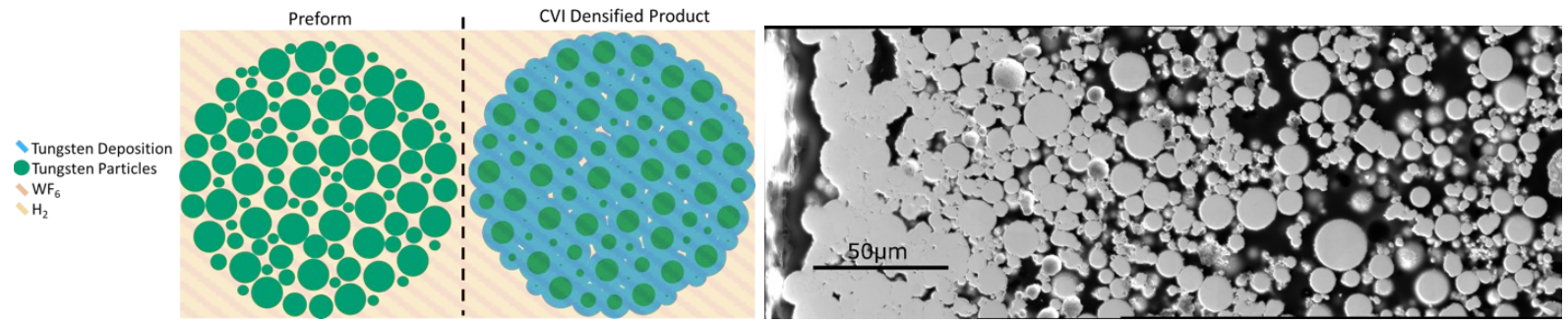

Figure 71. (left) CVI allows gaseous reactants to infiltrate the sample bulk and react, depositing tungsten on the particulate surfaces. High density is achieved by allowing the process to carry out over a long time period. (right) Composite SEM image of a cross section of a sample where CVI was performed at $450^{\circ} \mathrm{C}$. Tungsten particles in the bulk demonstrate extremely limited deposition, while high density is produced to around $70 \mu \mathrm{m}$ depth.

\section{FUTURE PLANS}

Upcoming experiments will apply the refined build and preheat parameters for EB-PBF to produce larger samples of dense and crack-free tungsten. These efforts will then be extended to produce complex tungsten geometries for in-situ testing of various PFC designs.

Trials are ongoing to optimize the deposition rate binder-jetted tungsten. Temperature, pressure, and flow rate will be varied to achieve growth sufficiently slow to produce bulk densification. 


\title{
9.2 ADDITIVE MANUFACTURING OF SILICON CARBIDE FOR NUCLEAR FUSION APPLICATIONS
}

\author{
T.Koyanagi (koyangit@,ornl.gov), Y. Katoh(ORNL)
}

\section{OBJECTIVE}

The goal of this task is to develop additive manufacturing (AM) technology for SiC ceramics for potential use in fusion reactors.

\section{SUMMARY}

Additive Manufacturing of $\mathrm{SiC}$ is a rapidly evolving technology being applied to or considered for a wide variety of applications. Among the various AM processing options, we identified a promising method available at ORNL to fabricate irradiation resistant $\mathrm{SiC}$ components with complex geometries.

\section{PROGRESS AND STATUS}

Various AM processing options have been proposed to fabricate SiC-based components with complex geometries. The current technological challenges are closely related to the intrinsic nature of the $\mathrm{SiC}$ densification process: volume shrinkage for pre-ceramic polymer pyrolysis and powder sintering; high densification temperatures for liquid phase sintering; dimensional restrictions for matrix infiltration into the green body by reaction bonding, polymer impregnation and pyrolysis, and chemical vapor infiltration (CVI); and component size for laser chemical vapor deposition. Therefore, selection of the AM processing method will depend on the component geometry.

The existing data on the effects of neutron irradiation on the properties of traditional $\mathrm{SiC}$ ceramics suggest the most promising additively manufactured SiC materials. A crystalline $\mathrm{SiC}$ system with minimal secondary phases is suggested to minimize irradiation-induced strength degradation and dimensional instability at high neutron doses. One of the promising methods includes binder jet printing followed by CVI. The method has been developed at ORNL (Journal of the American Ceramic Society 103.3 (2020): 1575-1581).

An example of an object made by this 3D AM method is shown in Figure 72. The production first involved preparing a binder jet-printed green body based on CAD. The feedstock was a mixture of a SiC powder and an organic binder. The powder was selected based on purity and a size distribution suitable for the AM. The AM process was carried out using an ExOne Company Innovent binder jet system. The printed green body then went through a binder-curing process of $6 \mathrm{~h}$ in air at $190^{\circ} \mathrm{C}$, followed by CVI for densification. CVI was carried out at $1000^{\circ} \mathrm{C}$ using a methyl trichlorosilane precursor in $\mathrm{H}_{2}$ carrier gas. CVI deposition conditions (i.e., precursor pressure, system temperature, and infiltration duration) greatly affects final density, which can range from $70 \%$ to $90 \%$ of theoretical density of $\mathrm{SiC}$.

\section{FUTURE PLANS}

A strategy for the development of AM technologies specifically for fabricating components to be used in fusion applications will be detailed in FY2021. 


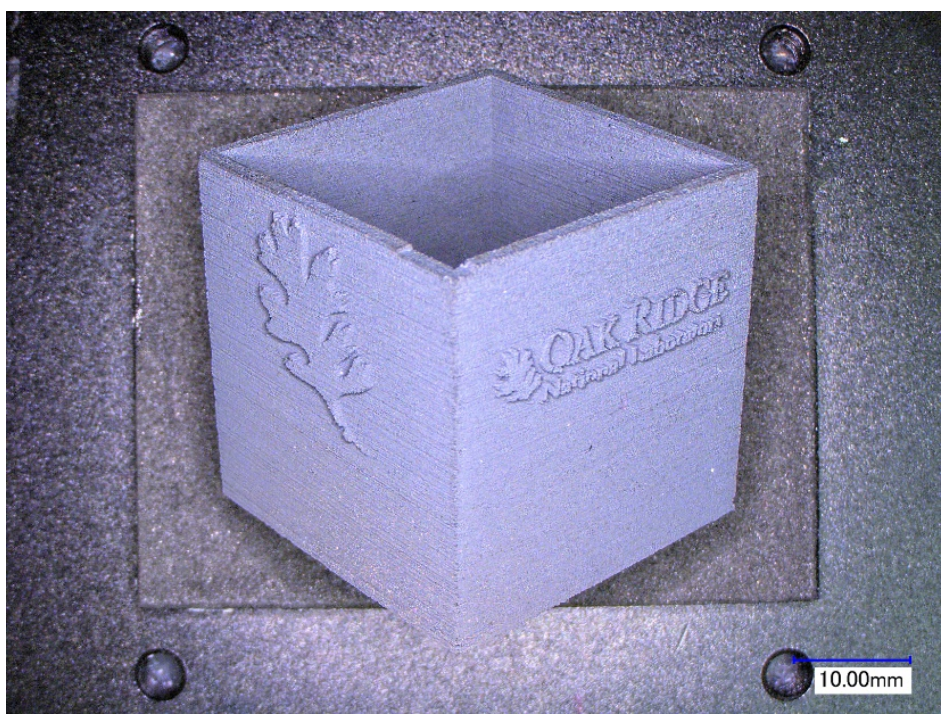

Figure 72. Additively manufactured $\mathrm{SiC}$ component with complex geometry. A combination of binder jet AM and CVI was used for the fabrication. 


\title{
10. COMPUTATIONAL MATERIALS SCIENCE
}

\subsection{MECHANICAL PROPERTIES AND RADIATION EFFECTS IN FUSION MATERIALS}

\author{
Y. Osetskiy (osetskiyyn@ornl.gov) (ORNL)
}

\section{OBJECTIVE}

The objective of this work is to obtain a better understanding of the atomic-scale mechanisms operating in fusion materials. In this task the mechanisms of radiation damage in the mechanical properties of irradiated materials are considered. Main materials studied are ferritic and tungsten-based alloys.

\section{SUMMARY}

An extensive atomic-scale study was carried out to investigate the detailed mechanisms of dislocation dynamics in the environment of radiation induced void in tungsten. Interactions between a moving $1 / 2<111>\{110\}$ edge dislocation and voids in the size range 1 to $9 \mathrm{~nm}$ diameter were modeled by MD at temperatures of $300 \mathrm{~K}$ and $600 \mathrm{~K}$. Physical parameters of the computational model such as dislocation length and density, strain rate, and their effects on the accuracy and uncertainty of simulation results were investigated. A comparison was made with the results of a similar study in bec iron. The conclusions revealed in the results obtained include:

1. Voids in $\mathrm{W}$ are strong obstacles to moving dislocations, interacting via the "Orowan-like" mechanism and cause a much higher critical resolved shear stress than that from voids in Fe. Comparative analysis of atomistic results for $\mathrm{W}$ and $\mathrm{Fe}$, within the Bacon-Kocks-Scattergood model, has revealed an important role of the void surface: void surface properties affect the final stage of the dislocation-void interaction process and thus the level of CRSS. The BKS model can consider this effect qualitatively.

2. It is suggested that the void surface energy affects the ability of screw dislocation segments to glide and cross-slip around voids. Enhanced glide and cross-slip lead to earlier dipole recombination and thus decrease in CRSS. This is an atomic-scale effect and it is more significant in W than in Fe, as was observed here.

3. Void size and density effects revealed by atomistic modeling are qualitatively described by the BKS model that can be used in estimating the void strength parameter for the dispersed barrier hardening model. Temperature effects cannot be accounted for within the BKS model; atomistic modeling produces more accurate data on high temperature strengthening.

\section{PROGRESS AND STATUS}

Interactions between the moving $1 / 2<111>\{110\}$ edge dislocation and spherical voids were modeled by molecular dynamics (MD) using the atomic scale model developed in [1]. This model considers the dynamics of a periodic array of dislocations and obstacles. In this, the main parameter is the dislocation length, $L$, which is equivalent to the distance between obstacles along the dislocation line direction $<112>$. This distance should be long enough to reproduce the correct dislocation line shape at the critical resolved shear stress (CRSS). CRSS is defined as the maximum shear stress which usually occurs just before the dislocation is released from the obstacle. For strong obstacles, like voids, interacting with edge dislocations the dislocation line shape corresponding to CRSS usually presents an extended dipole of screw dislocation segments formed in the obstacle's vicinity [1]. In this study, the same dislocation segment length, $L=42$ $\mathrm{nm}$, was used for all voids. This length is significantly longer than the largest simulated void diameter, 
$D=9 \mathrm{~nm}$. Depending on the void size the modeled system contained from $\sim 2$ million to above 6 million mobile atoms.

The results for CRSS of 1 to $9 \mathrm{~nm}$ voids at $300 \mathrm{~K}$ and $600 \mathrm{~K}$ are presented in Figure 73 as functions of the void size (Figure 73a) and the logarithm of the size (Figure 73b). The behavior is typical for voids and bubbles reported earlier for Fe $[2,3]$. CRSSs at $600 \mathrm{~K}$ are visually below the values at $300 \mathrm{~K}$ although the error bars reflecting the standard deviation do overlap. The linear behavior in semi-logarithm scale was reported earlier for voids and $\mathrm{Cu}$-precipitates in $\mathrm{Fe}$ [2] where it was also reported that the slope depends on the geometrical parameters of dislocation-obstacle, particularly on the dislocation segment length modeled $L$. Deeper understanding of strengthening behavior versus geometrical conditions was achieved in a series of dislocation-obstacle continuum modeling by Bacon, Kocks, and Scattergood (BKS) $[4,5]$ where the realistic self-interaction between dislocation segments was considered.

The results for the periodic array of strong obstacles interacting with edge and screw dislocations were fitted to the following expression for CRSS (omitting the Taylor factor):

$$
\tau_{c}=A \frac{\mu b}{L}\left[\ln \left(D^{-1}+L^{-1}\right)^{-1}+B\right]
$$

were $A=1 / 2 \pi$ and $A=1 / 2 \pi(1-v)$ for edge and screw dislocations respectively, $\mu$ and $\nu$ are the shear modulus and Poisson ratio respectively. $B$ is a constant characterizing the interaction between the dislocation and matrix-obstacle interface and, in the case of voids, relates to the surface energy. In the BKS model $[4,5] B$ was used to adjust the CRSS level to modeling results. Interestingly, in the approximation of long dislocation segments $L$, eq. (1) leads to the linear dependence of CRSS vs $\ln (D)$, the same as presented in Figure 73b. The BKS model was used here to analyze data for W and compare with those for Fe reported elsewhere [1-3]. Shear moduli for the $1 / 2<111>\{110\}$ dislocation glide system at $300 \mathrm{~K}$ and $600 \mathrm{~K}$ were estimated in this work by MD modeling. The values of $\mu$ obtained for $\mathrm{W}$ is $178 \mathrm{GPa}$ and 171 GPA at $300 \mathrm{~K}$ and $600 \mathrm{~K}$ respectively.

MD values obtained for CRSS, in units $(\mu b / L)$ are presented as a function of the harmonic mean $\left(D^{-1}+L^{-1}\right)^{-1}(D$ and $L$ are in units of the Burgers vector $b$ ) in Figure 74 together with the result of the BKS model with $B=-0.7$. This shows that the modeling results are quite well described by the BKS model. On the other hand, it should be recognized that the slope for low-temperature data, at $300 \mathrm{~K}$, looks somehow steeper than that for high-temperature, $600 \mathrm{~K}$, CRSS. That means that the slope decreases with the temperature. The BKS model includes temperature effects only through the temperature dependence of materials properties, $b$ and $\mu$, which do not affect the slope that e.g. for the edge dislocation is predicted as $1 / 2 \pi$. Nevertheless, it may in general be concluded that void strengthening in $\mathrm{W}$ is at least qualitatively described, by the BKS model. It is interesting that the surface energy parameter $B$ is negative, that significantly decreases the whole level of CRSS defined by eq. (1). In [4, 5] $B$ was found to be equal to 1.52 for voids and 0.77 for the Orowan mechanism. Zero-temperature data for voids in Fe were quite consistent with the BKS model and $B=1.52$ [6]. On the other hand, it was also demonstrated in $[3,4]$ that the CRSS value decreases with the temperature: e.g. by $>1.5$ times when the temperature increases to 300 K. Three parameters are temperature dependent in eq. (1), namely: lattice parameter (and therefore the length of the Burgers vector $b$ ), shear modulus, $\mu$, and surface energy parameter $B$. The most significant temperature effect on CRSS occurs when temperature increases from zero to a few hundred $\mathrm{K}$ whereas at $\mathrm{T}>300 \mathrm{~K}$, the temperature dependence is rather weak (see e.g. [6] for voids in Fe). Within the temperature range studied here, $300-600 \mathrm{~K}$, the temperature effects on the material parameters that contribute to eq. (1) are very weak. Thus, $b$ increases from $0.27243 \mathrm{~nm}$ to $0.27323 \mathrm{~nm}$ and $\mu$ decreases from $178 \mathrm{GPa}$ to 171 $\mathrm{GPa}$ when the temperature is increased from $300 \mathrm{~K}$ to $600 \mathrm{~K}$. 
To achieve a deeper understanding, CRSS data for $\mathrm{W}$ at $600 \mathrm{~K}$ were compared with data for Fe at $300 \mathrm{~K}$. These are similar homologous temperatures for $\mathrm{W}$ and $\mathrm{Fe}, T_{H} \approx 0.16 T_{M}$ where $T_{M}$ is the corresponding melting temperatures of $3695 \mathrm{~K}$ and $1811 \mathrm{~K}$. The comparison is presented in Figure 75. Figure 75a demonstrates that voids in W are much stronger obstacles, generate much higher CRSS and the difference between $\mathrm{W}$ and $\mathrm{Fe}$ increases as $D$ increases. However, the same data presented in the BKS model units, i.e. CRSS in $(\mu b / L)$ vs harmonic mean $\left(L^{-1}+D^{-1}\right)^{-1}$, show the qualitatively different result in Figure 75b: voids in Fe are significantly stronger and the difference weakly depends on the void size for the slopes for both $\mathrm{W}$ and $\mathrm{Fe}$ are close to that for the edge dislocation $A=1 / 2 \pi$ in eq.(1). According to eq.(1), the lower CRSS in W compared to that in Fe in Figure 75b can be explained using only the difference in properties. Actually, $\mu=171 \mathrm{GPa}$ and $b=0.2732 \mathrm{~nm}$ for $\mathrm{W}$ whereas those for Fe are $50 \mathrm{GPa}$ and 0.2489 $\mathrm{nm}$, therefore the stress unit $(\mu b / L)$ for $\mathrm{W}$ is $\sim 3.8$ times larger than that for Fe. However, even this difference is not enough and further fitting eq. (1) to MD data requires adjustment of the surface energy parameter: $B=-0.7$ for $\mathrm{W}$ and $B=0$ for Fe. A negative value of $B$ for $\mathrm{W}$ is necessary to reduce the edge dislocation line in eq.(1) to comply with a) large value of stress unit $(\mu b / L)$ for W and b) MD modeling results. This formal adjustment of MD data to BKS model parameters reflects, however, a physical meaning: the void surface properties, as they are used in the continuum modeling in $[4,5]$, are very different for $\mathrm{W}$ and $\mathrm{Fe}$. An important mechanism related to this is the ability of the screw segments, terminated at the void surface, to cross-slip and glide over the surface. This enhances the screw dipole recombination, and, therefore, reduces CRSS (see e.g. [2]). A detailed comparison of the critical dislocation line shape in $\mathrm{W}$ and $\mathrm{Fe}$ for the same voids has demonstrated that dipoles elongate more in Fe and the softening stage when the further increase in strain does not increase stress, is also much longer in Fe. The lower value of surface energy parameter $B$ in W found in fitting MD data to the BKS model consistent with these facts: lower surface energy in $\mathrm{W}$ enhances recombination of shorter screw dipoles leading to the earlier dislocation break-out from voids. Cross-slip of screw segments out of the edge dislocation slip plane $\{110\}$ reduces the dipole energy and thus the current stress and the final CRSS. The directions where segments cross-slip define the final super jog on the dislocation line. All the published studies of voids in Fe reported the super jog that is equivalent to absorption of vacancies from voids, in the geometry of the model used here, the result is dislocation climb. The results obtained here for voids in $\mathrm{W}$ are quite different for the downward dislocation climb. Climb down means the dislocation absorbed atoms from the void surface thus increasing the number of vacancies in the void and the void size. This is additional evidence that void surface properties modeled here in $\mathrm{W}$ are different from the results reported so far for Fe.

The manuscript was submitted to Tungsten, accepted for publication and the article is now in press [7].

\section{REFERENCES}

[1.] Y.N. Osetsky and D.J. Bacon, An atomic-level model for studying the dynamics of edge dislocations in metals. Modelling Simul.Mat.Sci.Eng. 11 (2003) 427.

[2.] Y.N. Osetsky, D.J. Bacon, V. Mohles, Atomic Modelling of Strengthening Mechanisms due to Voids and Copper Precipitates in alpha-Iron, Philos. Mag., 83 (2003) 3623.

[3.] Y.N. Osetsky and R.E. Stoller, Atomic-scale Mechanisms of Helium Bubble Hardening in Iron, J. of Nucl. Mater. 465 (2015) 448.

[4.] D. J. Bacon, U. F. Kocks and R. O. Scattergood, The effect of dislocation self-interaction on the Orowan stress, Philos. Mag., 28 (1973) 1241-1263.

[5.] R.O. Scattergood and D.J. Bacon, The strengthening effect of voids, Acta. Metall., 30 (1982) 1665.

[6.] Y.N. Osetsky and D.J. Bacon, Atomic-scale mechanisms of void hardening in BCC and FCC metals, Philos. Mag. 90 (2010) 945.

[7.] Y.N. Osetsky, Atomic-scale Mechanisms of Void Strengthening in Tungsten, Tungsten, (2020) accepted. 


\section{FUTURE PLANS}

This study will be continued modeling other obstacles in W such as Re-rich precipitates and other materials and environmental conditions such as temperature, strain rate and multiple obstacles. Contribution from thermally activated processes will be also studied. The final aim is to obtain a robust approach for estimation mechanical property changes in irradiated W-based materials.

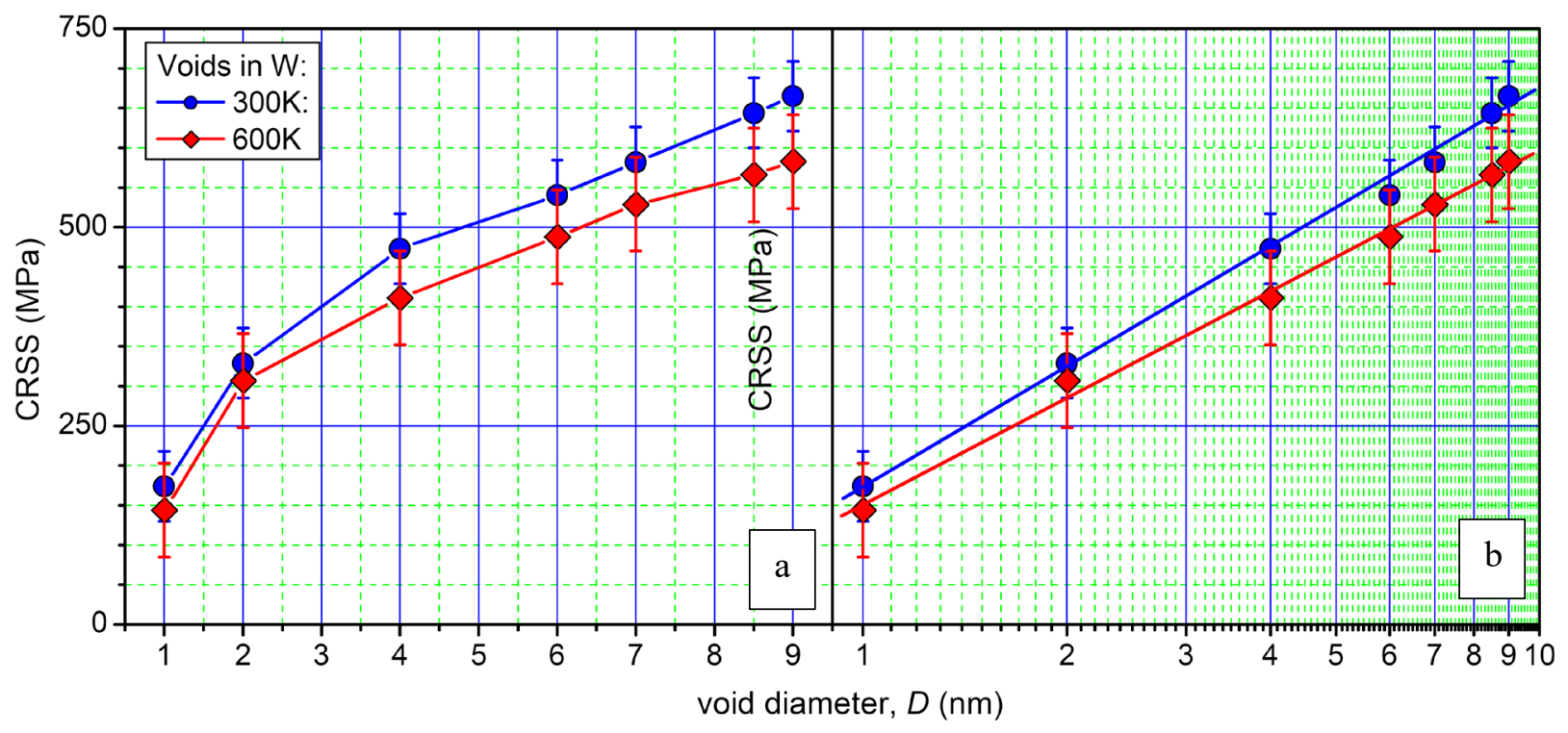

Figure 73. MD derived CRSS for voids in $\mathrm{W}$ at $300 \mathrm{~K}$ and $600 \mathrm{~K}$ as a function of void size $\mathrm{D}$ in linear and semi-logarithmic presentations. 


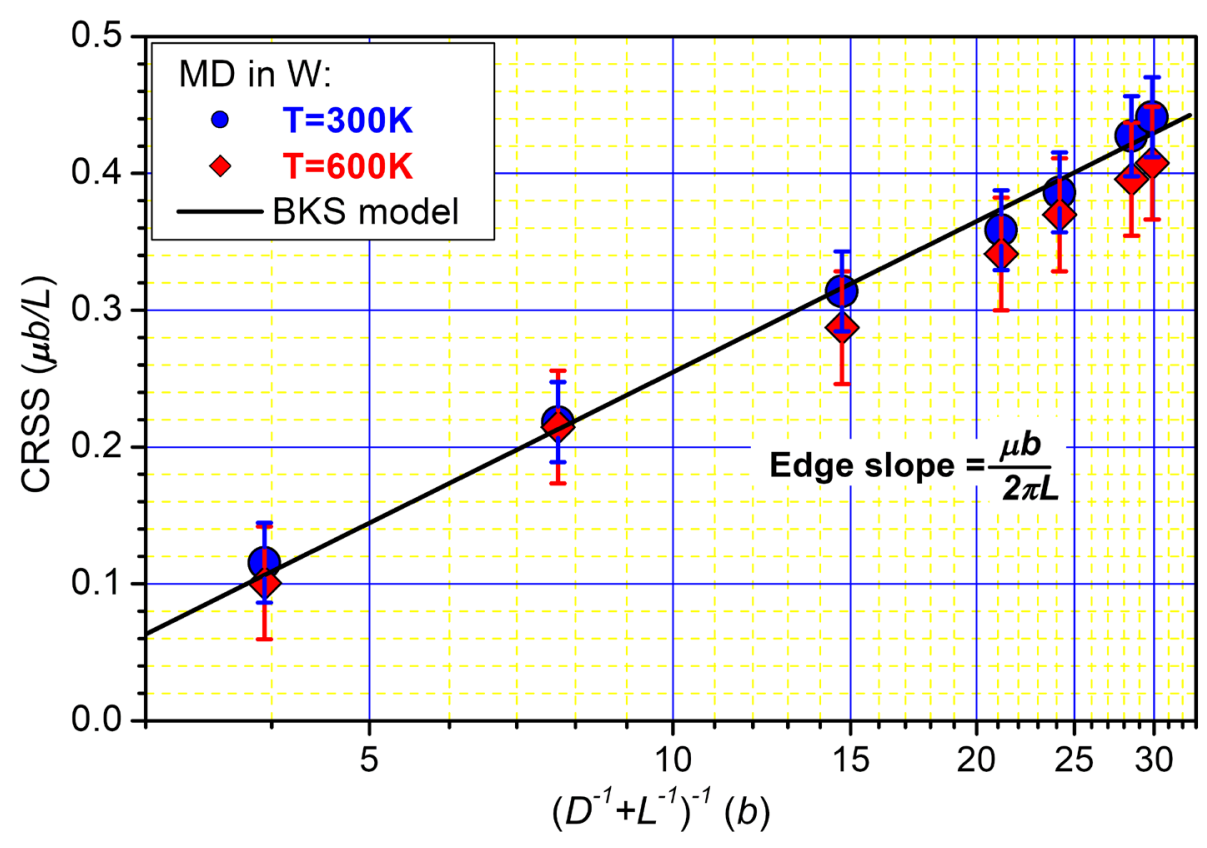

Figure 74. MD derived CRSS as a function of the harmonic mean of $D$ and $L$ for voids in $W$ at $300 \mathrm{~K}$ and $600 \mathrm{~K}$ compared with the $\mathrm{BKS}$ model with surface energy parameter $B=-0.7$.
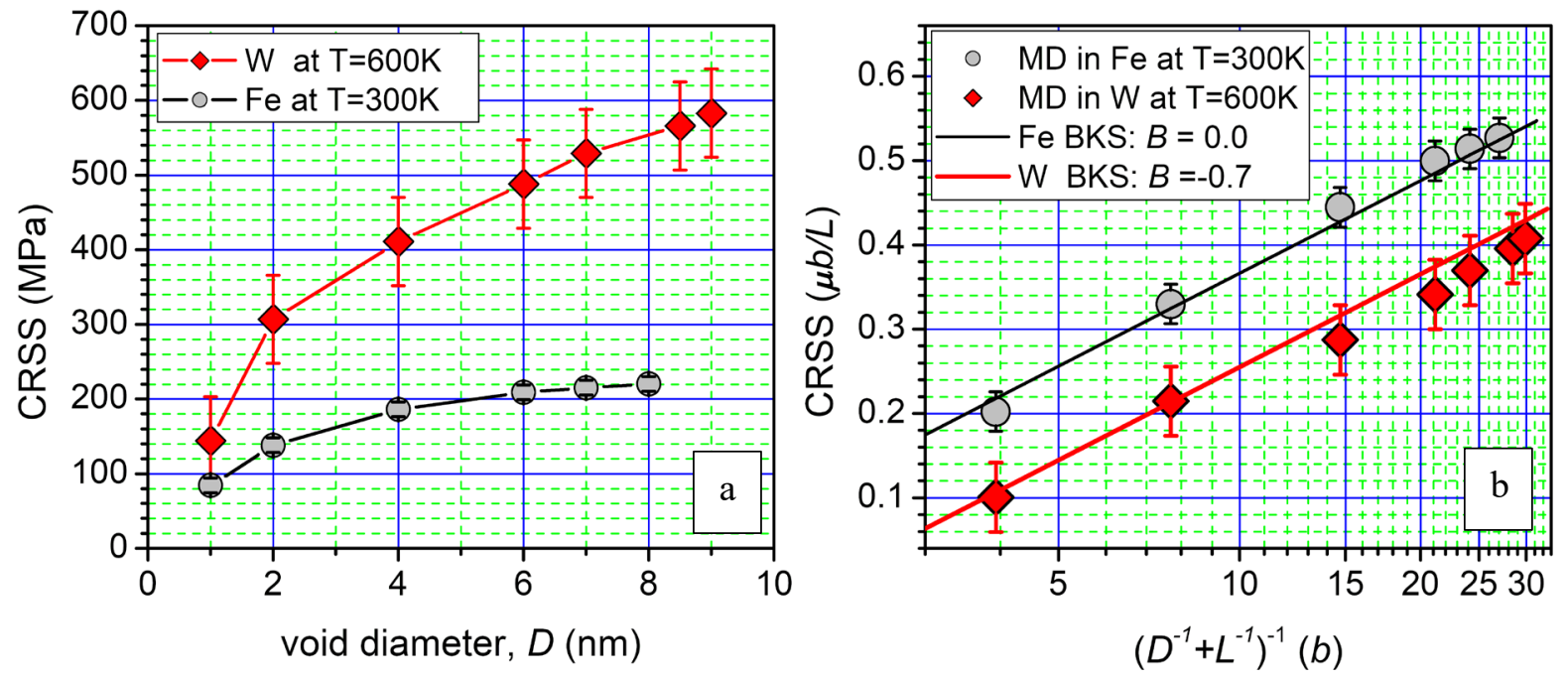

Figure 75. CRSS data for voids in $\mathrm{W}$ and Fe for the same homologous temperatures $0.16 T_{M}$ : a - absolute values of CRSS as a function of void size.

$b$ - normalized to $\mu b / L$ as a function of $D$ and $L$ harmonic mean. Solid lines indicate BKS edge dislocation model fitting with B parameters indicated in the insert. 


\title{
10.2 EQUILIBRIUM DISTRIBUTION OF POINT DEFECTS IN Fe-Y-O TAKING INTO ACCOUNT OXIDE-MATRIX INTERFACE AND PRE-EXISTING VACANCIES
}

\author{
G. Samolyuk (samolyukgd@ornl.gov), Y. Osetskiy (ORNL)
}

\section{OBJECTIVE}

The statistical mechanics approach used to calculate the equilibrium defect distribution in multiphase system developed in previous year was extend to the case of systems in quasi-equilibrium state, in this particular case - the alloy with large amount of vacancies introduced by mechanical alloying. We intended to validate two major previous findings - that the interface plays the role of sinks for nonequilibrium preexisting defects (vacancies); and the formation of significant numbers of iron vacancy-oxygen atom clusters $(\mathrm{O}: \mathrm{V})$, where oxygen atoms join preexisting iron vacancies resulting from mechanical alloying.

\section{SUMMARY}

The general statistical mechanics calculation of equilibrium distribution of defects in nonuniform system with interfaces has been developed [1,2,3]. It was then applied to the case of ODS $\mathrm{Y}_{2} \mathrm{O}_{3}$-Fe alloys. Now the model incorporates the presence of significant amount of preexisting vacancies. Also, an additional channel of oxygen interaction with the matrix, i.e. formation of iron oxide, $\mathrm{FeO}$, has been introduced. It has been demonstrated that due to high defect formation energies the ODS particles are extremely stable and main defects are $\mathrm{Fe}$ atoms that for substitute $\mathrm{Y}$ inside $\mathrm{Y}_{2} \mathrm{O}_{3}$ precipitate. Fe vacancies predominantly occupy the interface. It was found that in a contrast to the (100) interface, the Klim interface [4] doesn't play the role of vacancy sinks, at least at thermodynamic equilibrium, even if the initial estimate of vacancies formation energy at this interface is lower than in them metal bulk [4]. The (100) interface is unstable with respect to vacancy formation and should not survive during annealing. Thus, the assumption that the exceptional radiation tolerance of nanostructured ferritic alloys is due to recombination of interstitials and vacancies at the interfaces [4] is not proved in this current research. This assumption needs further investigation.

Under thermodynamic equilibrium conditions preexisting vacancies in bulk Fe do not accumulate oxygen atom [5]. This observation does not necessarily forbid the existence of a large amount of preexisting vacancy - oxygen atom clusters during initial stages of alloy formation which are far from equilibrium. We believe that this significant difference with findings presented in $[4,5]$ is the result of an assumption on the chemical potential of the system components, i.e. O, Y, Fe, made in these publications. Thus, in [4] the authors used elemental energies of components (bcc Fe, hcp Y and $\mathrm{O}_{2}$ molecule) as an estimate of chemical potential, while in a realistic situation it depends on the specific alloy, its composition and temperature. Herein we presented a consistent way to calculate chemical potential of the system.

\section{PROGRESS AND STATUS}

Most of the formalism can be found in our previous annual report, while details are published in $[3,6]$ and some important details are briefly presented below. The statistical mechanics approach has been used to obtain the system thermodynamic potential of a grand canonical ensemble. The equilibrium defect concentration is obtained by constrained minimization of the grand thermodynamic potential. The constraint is introduced to preserve the alloy composition which is defined by total number of defects. To calculate the total amount of defects the geometric relation between precipices size, total volume fraction, interface orientation and number of possible defect positions has been estimated (see Figure 76). Let fraction $\alpha$ of precipitate surface have [100] interface and $1-\alpha$ the Klim interface. The area per atom for [100] interface is $S^{[100]}=a^{2}$, where $a$ is Fe lattice parameter. If the shape of precipitate is approximated 
by a sphere of radius $N_{R} a$ the area of the interface [100] is $\Sigma^{[100]}=\alpha 4 \pi\left(N_{R} a\right)^{2}$. Thus, the number of possible vacancy position in one layer of [100] interface is

while for Klim interface

$$
N_{v}^{[100]}=\frac{\sum^{[100]}}{S^{[100]}}=\alpha 4 \pi\left(N_{R}\right)^{2},
$$

$$
N_{v}^{[112]}=\frac{\sum^{[\overline{11} 2]}}{S^{[112]}}=(1-\alpha) 4 \sqrt{\frac{2}{3}} \pi N_{R}^{2} .
$$

From the relation for number of precipitates, $m$, in the alloy with composition $\left(\mathrm{Y}_{2 / 5} \mathrm{O}_{3 / 5}\right) \mathrm{FFe}_{1-\mathrm{x}-\mathrm{y}-}$ ${ }_{\mathrm{z}} \mathrm{V}_{\mathrm{y}}\left(\mathrm{Fe}_{1 / 2} \mathrm{O}_{1 / 2}\right)_{\mathrm{z}}$, where $\mathrm{y}$ is atomic fraction of preexist vacancies and $\mathrm{z}-$ of $\mathrm{FeO}$, one can obtain $m=$ $2 x N^{3} /\left(\frac{8}{3} \pi N_{R}^{3}\right)$ and the number of possible defect positions at the interface, vacancies, for example, is

$$
N_{v}^{[100]}+N_{v}^{[112]}=x\left[\frac{3}{2} \frac{\alpha}{N_{R}}+\sqrt{\frac{3}{2}} \frac{1-\alpha}{N_{R}}\right] 2 N^{3}
$$

It should be mentioning that here we included preexisting vacancies $\mathrm{Fe}_{1-\mathrm{x}}\left(\mathrm{Y}_{2 / 5} \mathrm{O}_{3 / 5}\right)_{\mathrm{x}}$. These relations allow calculation of the total number of iron, yttrium, , and oxygen, atoms in the system; and to close the system of equations for defect concentration by preserving system composition:

$$
\begin{gathered}
\frac{N_{\mathrm{Fe}}}{N_{\mathrm{Y}}+N_{\mathrm{O}}}=\frac{1-x+1 / 2 z}{x}, \\
\frac{N_{\mathrm{Y}}}{N_{\mathrm{O}}}=\frac{2 / 5 x}{3 / 5 x+1 / 2 z}, \\
\Omega(x, y, z ; T)=0,
\end{gathered}
$$

where $\Omega(x, y, z ; T)$ is thermodynamic potential.

As was mentioned in the objective, the large number of vacancies is typical for materials prepared by mechanical alloying. Moreover, in this alloys it is assumed that they play the role of alloy stabilization element by accumulating oxygen in small clusters. It also was demonstrated that V:O cluster formation energy is very sensitive to the estimate of oxygen chemical potential [5]. In [5] it was reasonable assumed that V:O cluster in bulk iron decays not into a vacancy in bulk iron and $\mathrm{O}_{2}$ molecule, but rather releases the oxygen atom in the form of $\mathrm{FeO}$. To verify both of these assumptions the equilibrium defect distribution has been calculated in the system described by the following expression $\left(\mathrm{Y}_{2 / 5} \mathrm{O}_{3 / 5}\right) \mathrm{xFe}_{1-\mathrm{x}-\mathrm{y}-\mathrm{z}} \mathrm{V}_{\mathrm{y}}\left(\mathrm{Fe}_{1 / 2} \mathrm{O}_{1 / 2}\right)_{\mathrm{z}}$, where y is atomic fraction of preexist vacancies ( $0.15 \%$ in current research), and $\mathrm{z}(0.5 \%)$ of $\mathrm{FeO}$. Oxygen from either $\mathrm{Y}_{2} \mathrm{O}_{3}$ or $\mathrm{FeO}$ and can occupy octahedral positions in bulk Fe forming an interstitial or can form an oxygen-vacancy, $\mathrm{O}+\mathrm{v}$, in bulk Fe. However much less energy is needed to form oxygen vacancy, $\mathrm{O}: \mathrm{V}$, cluster by occupying a preexisting vacancy [5]. The result for equilibrium defect concentration are shown in Figure 77 (the preexisting vacancies in bulk iron are not shown). In Figure 77 the calculated local defect concentration is presented as a function of alloy composition, $\mathrm{x}$, at two temperatures, $\mathrm{T}=600$ and $1200 \mathrm{~K}$, and two sizes of precipitates, R, 10 and $100 \mathrm{bcc}$ Fe lattice parameters, i.e. 2.87 and $28.7 \mathrm{~nm}$, respectively. Here, the size of precipitates changes simultaneously with change of precipitates number in order to preserve composition, $\mathrm{x}$. 
Surprisingly, the local concentration of $\mathrm{V}: \mathrm{O}$ clusters is negligibly small. The reason for this is similar to the case of $\left(\mathrm{Y}_{2 / 5} \mathrm{O}_{3 / 5}\right)_{\mathrm{x}}(\mathrm{bcc} \mathrm{Fe})_{1-\mathrm{x}}$, discussed in the previous report. Oxygen chemical potential obtained from the solution of Eq. (5-6), i.e. the conditions to preserve composition of the system and guarantee zero value of grand canonical thermodynamic potential, is much lower than estimate from $\mathrm{FeO}$ formation [5]. Thus, compared to initial estimate from the $\mathrm{O}_{2}$ molecule, the oxygen chemical potential is reduced by $4 \mathrm{eV}$. This value is significantly smaller than the $7.1 \mathrm{eV}$ reduction obtained in $\left(\mathrm{Y}_{2 / 5} \mathrm{O}_{3 / 5}\right)_{\mathrm{x}}(\mathrm{bcc} \mathrm{Fe})_{1-\mathrm{x}}$, but still is not enough to produce significant $\mathrm{V}: \mathrm{O}$ cluster concentration. The difference in oxygen chemical potentials for the two systems is a result of appearance of a new channel for oxygen exchange, $\mathrm{Fe}+\mathrm{O} \leftrightarrow \mathrm{FeO}$, compared to the $\left(\mathrm{Y}_{2 / 5} \mathrm{O}_{3 / 5}\right)_{\mathrm{x}}(\mathrm{bcc} \mathrm{Fe})_{1-\mathrm{x}}$ case. Also, in contrast to results for the $\left(\mathrm{Y}_{2 / 5} \mathrm{O}_{3 / 5}\right)_{\mathrm{x}}(\mathrm{bcc} \mathrm{Fe})_{1-\mathrm{x}}$ system, the oxygen vacancies concentration in $\mathrm{Y}_{2} \mathrm{O}_{3}$ is nearly negligible, while the concentration of Fe substituting for $\mathrm{Y}$ in $\mathrm{Y}_{2} \mathrm{O}_{3}$ increased by a few orders of magnitude. In that case extra $\mathrm{O}$ and $\mathrm{Fe}$ atoms are provided by the $\mathrm{FeO}$ subsystem. In total the equilibrium defects concentration is very small, which indicates very decent stability of the system.

A manuscript describing this work was submitted to the Journal of Nuclear Materials [6].

\section{REFERENCES}

[1.] G.D. Samolyuk, B. Újfalussy, and G.M. Stocks, "The distribution alloying elements in alnico 8 and 9 magnets: Site preference of ternary $\mathrm{Ti}, \mathrm{Fe}, \mathrm{Co}$, and $\mathrm{Ni}$ additions in $\mathrm{DO}_{3} \mathrm{Fe}_{3} \mathrm{Al}, \mathrm{Co}_{3} \mathrm{Al}$, and $\mathrm{Ni}_{3} \mathrm{Al}$ based intermetallic phases." Journal of Applied Physics, 2014. 116(17): p. 173908.

[2.] G.D. Samolyuk, and Y.N. Osetsky, "Thermodynamic approach to the stability of multi-phase systems: application to the $\mathrm{Y}_{2} \mathrm{O}_{3}-\mathrm{Fe}$ system." Journal of Physics: Condensed Matter, 2015. 27(30): p. 305001 .

[3.] G. D. Samolyuk, M. Eisenbach, D. Shin, Y. N. Osetsky, A. Shyam, and J. R. Morris, "Equilibrium solute segregation to matrix $-\theta^{\prime}$ precipitate interfaces in Al-Cu alloys from first principles." Phys. Rev. Materials, 2020. 4: p. 073801.

[4.] J. Brodrick, D.J. Hepburn, and G.J. Ackland, "Mechanism for radiation damage resistance in yttrium oxide dispersion strengthened steels." Journal of Nuclear Materials, 2014. 445(1): p. 291297.

[5.] C.L. Fu, M. Krčmar, G. S. Painter, and X.-Q. Chen, "Vacancy Mechanism of High Oxygen Solubility and Nucleation of Stable Oxygen-Enriched Clusters in Fe." Physical Review Letters, 2007. 99(22): p. 225502.

[6.] G. D. Samolyuk, Y. N. Osetsky, "Equilibrium distribution of point defects in Fe-Y-O as a typical representative of nanocluster-strengthened alloys," Journal of Nuclear Materials, under review.

\section{FUTURE PLANS}

The new approach will be used to study stability of oxide strengthened alloys with realistic size distributions of oxide particles and material density after manufacturing. 


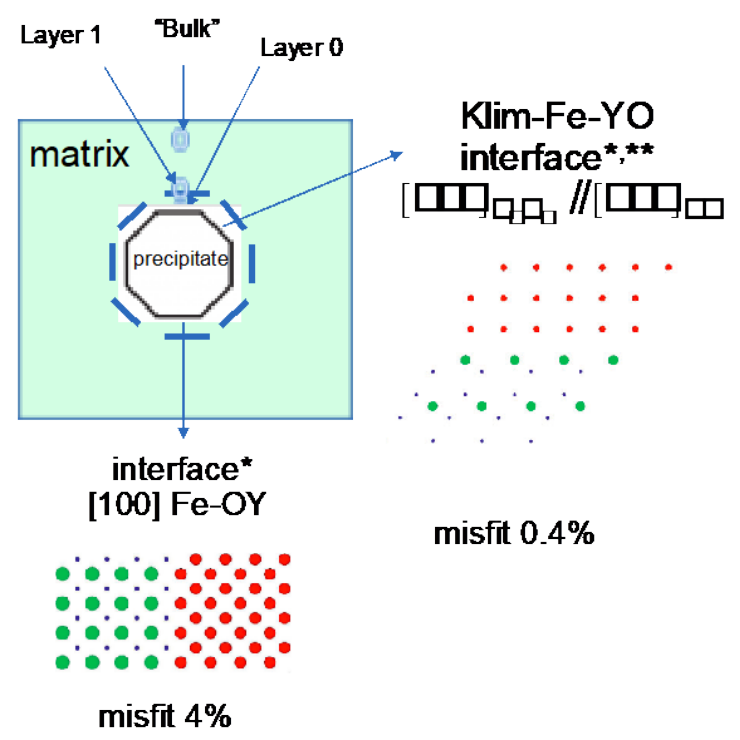

Figure 76. Structure of ODS precipitate interface. 

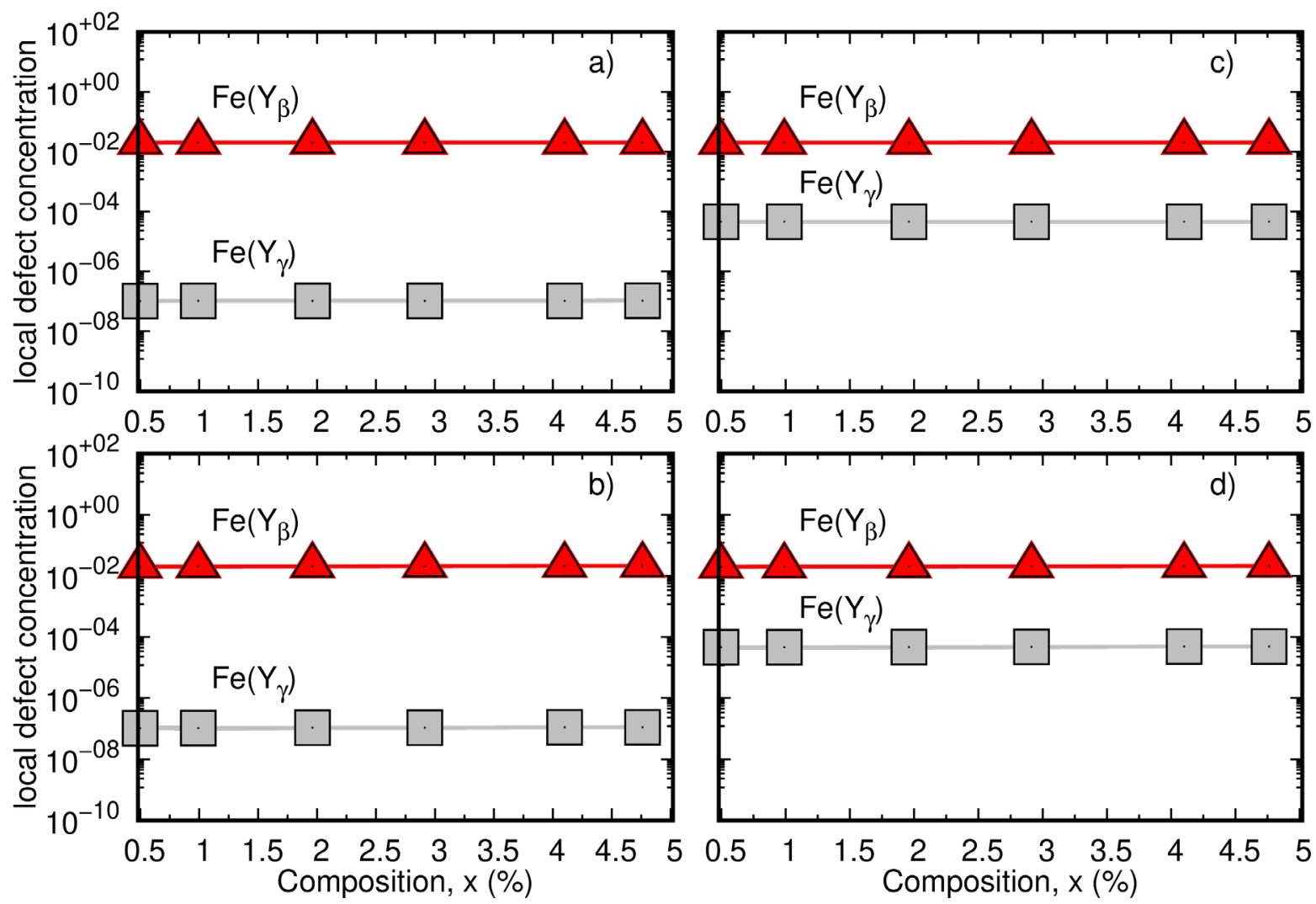

Figure 77. Local defect concentration in $\left(\mathrm{Y}_{2 / 5} \mathrm{O}_{3 / 5}\right) \times \mathrm{xe}_{1-\mathrm{x}-\mathrm{y}-\mathrm{z}} \mathrm{V}_{\mathrm{y}}\left(\mathrm{Fe}_{1 / 2} \mathrm{O}_{1 / 2}\right)_{\mathrm{z}}$ as a function of composition $x$ for set of ODS particle sizes and temperatures with $y=0.15 \%$ and $z=0.5 \%$. The ODS particle sizes and temperatures are: a) particle radius $\mathrm{R}=\mathbf{1 0 0}$ (in bec Fe lattice parameters) and $T=600 \mathrm{~K}$, b) $R=10$ and $T=600 \mathrm{~K}$, c) $R=100$ and $T=1200 \mathrm{~K}$, d) $R=10$ and $T=1200 \mathrm{~K}$. The ODSmatrix are joined by Klim interface only. The preexisting vacancies in bulk iron are not shown. 


\section{INTERNATIONAL COLLABORATIONS}

\subsection{US-JAPAN (QST) COLLABORATIONS ON STRUCTURAL MATERIALS}

J.W. Geringer (geringerjw@ornl.gov), X. Cheng, A. Bhattacharya, Y. Katoh (ORNL), T. Nozawa, M. Ando, T. Kato, H. Tanigawa (QST, Japan)

\section{OBJECTIVE}

This long-standing collaboration between the U.S. DOE and the National Institutes for Quantum and radiological Science and Technology (QST) of Japan jointly pursues activities using the advanced capabilities for materials irradiation and post-irradiated examination at ORNL, especially the HFIR, the hot cells, and LAMDA. The focus is on ferritic steels and other advanced materials, especially the development of the materials database for the design of facilities beyond ITER. The goals include achieving DEMOrelevant performance data on structural materials neutron irradiated in HFIR to high levels of displacement damage.

\section{SUMMARY}

The DOE-QST collaboration continues to steadily build the materials data bases for the RAFM alloys that include F82H, ODS and Eurofer97 steels and other materials such as nuclear grade SiC composites and copper alloys. This database is being used by QST to predict changes in mechanical performance of components of a DEMO fusion reactor.

\section{PROGRESS AND STATUS}

During FY 2020, evaluation continued on a series of irradiated RAFM steel specimens designed to evaluate the effects of $\mathrm{He}$ on the damage mechanisms in the high dose regime (up to $80 \mathrm{dpa}$ ). Microstructural examination is used to not only elucidate the mechanical response at varying levels of He accumulations in the same dose-temperature regime but also to correlate this response to the development of the microstructure including bubble formation and coarsening mechanisms in the alloy. Additional postirradiation examination includes hardness, tensile and fracture toughness tested on specimens from the JP28/29 capsules reported in Section 2.3. It was found that HFIR irradiation converted nano-oxides in ODS steels into "sponges" like feature, consisted with $\mathrm{Al}, \mathrm{Y}, \mathrm{Si}, \mathrm{O}$ rich amorphous shell and Fe-Cr crystalline islands (Section 2.7). During FY20 moderate effort was spent on investigating the interfacial bonding strength of $\mathrm{SiC}$ with some electron microscopy observation of unirradiated $\mathrm{SiC} / \mathrm{SiC}$ composites, Section 3.1 .

The shipping, disassembly and irradiation temperature evaluation for capsule F13A5 and the holders of JP29-8, JP29-9, and RB19J were also completed during this period. Additional disassembly of capsules F8B1, F8B2, F13B5 and JP28-13 as well as shipping capsules FMP02 thru -05 were completed and reported in Section 14.5. The thermometry of the disassembled capsules will be evaluated during the first quarter of FY21. The status of HFIR capsules that will continue irradiation in FY 2021, including the F13-rabbit capsule series containing F82H specimens and the SCF and JCR series including SiC specimens, is reported in Section 14.6. Pre-irradiation activities this year included the design of a new irradiation campaign for target temperatures of 300, 400 and 500C to fluences of 5, 20, 50 and $80 \mathrm{dpa}$. Assembly of the FH-51, -61 and -62 capsules were completed and await welding for HFIR irradiation scheduled in FY 2021.

ORNL hosted three QST assignees, T. Nozawa, T. Tanigawa, and T. Kato, for two short stays during the first half of FY 2020. All other FY 2020 assignments were cancelled due to the COVID-19 restrictions. 


\section{FUTURE PLANS}

The focus of the DOE-QST collaboration will continue on post irradiation examination on material from the JP28/29 and the F8-, F11- and F13- series capsules. Some evaluation on the remaining 15J and 19J capsule steel specimens and $\mathrm{Cu}$ specimens from the FMP-capsules is also planned. 


\title{
11.2 US-JAPAN FRONTIER PROGRAM
}

\author{
J.W. Geringer (geringerjw@ornl.gov), L. Garrison, B. Pint, C. Kessel, Y. Katoh (ORNL)
}

\section{OBJECTIVE}

In April 2019, the US/Japan Fusion Research Collaboration started a new Project, FRONTIER (Fusion Research Oriented to Neutron irradiation effects and Tritium behavior at material IntERfaces), with the objective of evaluating Reaction Kinetics and Neutron Irradiation Effects at Interfaces in DEMO Divertor Systems. FRONTIER consists of four tasks; (1) evaluate irradiation effects on reaction dynamics at plasmafacing material/structural material interfaces, (2) perform tritium transport through interface and reaction dynamics in accidental conditions, (3) measure corrosion dynamics at liquid-solid interfaces under neutron irradiation for liquid divertor concepts and (4) engineering modeling. Project participants include ORNL, INL, SNL, NIFS and Japanese Universities. ORNL leads tasks one, three and four.

\section{SUMMARY}

During the FY 2020 the FRONTIER efforts continued with focus on maturing the bonded or joined plasma facing materials, the development of irradiation capsules to support the irradiation matrices for the various tasks, the development of a flowing Sn compatibility test and the examination of a specific concept that focusses on liquid lithium, divertor only LM PFC and flowing liquid metal, to define a more detailed engineering design model.

\section{PROGRESS AND STATUS}

\section{$\underline{\text { Task } 1}$}

The aim of Task 1 is to understand neutron-induced microstructure changes and the consequent effects on mechanical and heat transfer properties of interfaces between plasma-facing material and structural material.

The material development efforts in the US largely focus on basic joints, laminate composites and particle reinforced $\mathrm{W}$ alloys. Attention is given to composites including $\mathrm{F} 82 \mathrm{H}-\mathrm{W}$ laminates, $\mathrm{W}_{\mathrm{f}}-\mathrm{W}, \mathrm{W}-\mathrm{Cu}$ sintered and additive manufactured $\mathrm{W}-\mathrm{Cu}$. The purpose of the particle reinforced $\mathrm{W}$ is to add second phase additions to the $\mathrm{W}$ matrix that may enhance strength and ductility through control of grain size and altered impurity distribution.

Japan is focused on eight fundamental material joining efforts for W-bonded materials including diffusion bonding with $\mathrm{Cu}, \mathrm{SiC}$, ODS, W and vanadium. Direct diffusion bonding of $\mathrm{SiC}$ to $\mathrm{W}$ was successfully developed and additional focus is now on developing K-doped W laminated composites. Fracture surfaces of the developed SiC Fiber Reinforced W Composites were examined. Direct brazing between W and GlidCop ${ }^{\circledR}$ (ODS-Cu alloy), with filler elements such as Ni and $\mathrm{P}$ that were distributed into the GlidCop ${ }^{\circledR}$, was developed. Additional underwater explosive welding and vacuum plasma spraying with friction stir processing with $\mathrm{F} 82 \mathrm{H}$ materials, require further exploration.

During FY2020 several materials have been developed and fabricated to be irradiated for 1 and 3 HFIR cycles. The first phase irradiations include capsules designed for $3 \mathrm{~mm}$ disc specimens, $6 \mathrm{~mm}$ disc specimens and tungsten fracture toughness specimens. Status of the irradiation capsule designs is included in Sections 14.1 and 14.2 of this report. 
During FY2020, a shipment of previously irradiated tungsten specimens was prepared for Japan's IMROarai facility. The shipment was delayed to the outbreak of the COVID-19 pandemic and the unavailability or slowdown of accessible resources. Two shipments are planned, one for FY2021 and the second likely in FY2022.

\section{$\underline{\text { Task } 3}$}

The purpose of this task 3 is to study the corrosion characteristics of liquid $\mathrm{Sn}$ for a divertor coolant, including effects of neutron irradiation. The goal is to further explore and develop this concept and to determine if an oxide barrier layer can inhibit corrosion in $\mathrm{Sn}$ at up to $400^{\circ} \mathrm{C}$.

The current plan is to irradiate specimens in liquid Sn in HFIR to study the effect of irradiation on the reaction kinetics. This type of experiment has not been conducted before and would answer a significant scientific question about the effect of irradiation on liquid metal corrosion. Capsule development started during FY2020 and progress is reported in Section 14.3.

A flowing Sn compatibility test will operate with a peak temperature of $400^{\circ} \mathrm{C}$. Both the US and Japan domestic programs have static Sn results which indicate that pre-oxidized $\mathrm{FeCrAl}$ shows promising compatibility in $\mathrm{Sn}$ at $400^{\circ}-500^{\circ} \mathrm{C}$. Thus, a flowing test is warranted to confirm these results where the temperature gradient may drive mass transfer due to temperature-dependent solubility. The thermal convection loop has been fabricated from APMT (FeCrAlMo) tubing.

\section{Task 4}

Task 4 aims to consolidate the results of each task by engineering modeling of the plasma facing component system. At present a water-cooled tungsten material is the main candidate divertor system, but resistance to unexpected large heat loading is low. Against this backdrop, this task conducts an engineering intercomparison study on gas-cooled solid divertor and liquid divertor to assess their feasibility.

Due to the uncertainty that solid PFCs can survive plasma-material interactions at reactor scale, liquid metals (LMs) will be explored as an alternative solution. A new US LM PFC program began in FY2020 to develop and evaluate a LM PFC concept for a FNSF or compact pilot plant core plasma via engineering design, plasma interface calculations, and appropriate lab experiments to address critical aspects. A specific concept that focusses on liquid lithium, divertor only LM PFC and flowing liquid metal, will be examined to define a more detailed engineering design model.

The first FRONTIER steering committee meeting was held at ORNL in January 2020. In addition, four workshops were planned for between Japan and US FY2020. However, most were converted to virtual workshops due the COVID-19 pandemic.

\section{FUTURE PLANS}

FY2021 efforts will continue on the examination and evaluation of the non-irradiated materials, performing flowing Sn tests using the flowing loop, and the development of engineering models to evaluate the feasibility of the different divertor concepts. It is planned that the first irradiations will start during this period and that the first shipment containing select irradiated tungsten specimens will be sent to the Japan IMR-Oarai facility. 


\subsection{US-EUROFUSION PROJECT}

J.W. Geringer (geringerjw@ornl.gov), A. Bhattacharya, X. Chen, Tim Graening, Y. Katoh (ORNL), L.L. Snead, M. Reith (KIT)

\section{BACKGROUND}

The Karlsruhe Institute of Technology (KIT), as a EUROfusion project seeks to provide blanket, baseline, design-relevant data and basic material properties evaluation of EUROFER material variants. ORNL is under contract to assist the Neutron Irradiation and Material Data task by preparation, irradiation and PIE of these steels to determine their suitability for use in fusion energy systems. This requires the use of several unique ORNL facilities including HFIR and the Irradiated Materials Examination and Testing (IMET) hot cell facility.

\section{STATUS}

In FY2020 and in collaboration with the US, microstructural characterization and investigation including light optical microscopy (LOM), TEM, energy dispersive X-ray spectroscopy (EDX), and study of fracture surfaces on the materials irradiated and tested for Phase 1a, continued. This work is reported in Sections 2.4 and 2.5 .

In FY 2020 ORNL developed a new proposal, Phase 2, to investigate helium effect in RAFM steels. This proposal was approved, but not yet funded. It was decided to delay Phase 2 and instead give priority to a new scope, Phase 3, developed during FY2020. 


\subsection{IAEA SMALL SPECIMEN TEST TECHNIQUE (SSTT) DEVELOPMENT: MASTER CURVE FRACTURE TOUGHNESS ROUND ROBIN TEST PLAN}

X.Chen (chenx2@,ornl.gov), M. A. Sokolov(ORNL)

\section{OBJECTIVE}

This task will develop reliable fracture toughness testing and analysis methods for small size specimens. Under the framework of the International Atomic Energy Agency (IAEA) Coordinated Research Projects (CRP), the ultimate goal is standardization of fracture toughness test technique for small size specimens.

\section{SUMMARY}

The IAEA CRP for standardization of SSTT for fusion addresses the following main tasks:

- Design of meaningful Round Robin tests for establishing best practices of SSTT to cover five mechanical test areas, including tensile, creep, low cycle fatigue, fracture toughness, and fatigue crack growth rate.

- Analysis of SSTT results focusing on fusion reference structural materials, i.e., reduced activation ferriticmartensitic (RAFM) steels.

- Establishment of guidelines for common practice in the use of SSTT.

ORNL's participation in this project will focus on rationalizing the specimen size effects on tensile and fracture toughness of RAFM steels. Recommendations will be made towards the limitation of specimen downsizing as well as best practices for using SSTT for Fusion application. As of the end of FY20, the test matrix has been finalized among the participants of the CRP. Raw materials have been distributed to participants for specimen machining and testing. It is anticipated that testing will be completed by the first half of FY21.

\section{PROGRESS AND STATUS}

ORNL is leading the Maser Curve Round Robin tests with participation from the Centre for Energy, Environment and Technology (CIEMAT) and UK Atomic Energy Authority (UKAEA). The materials used in the round-robin testing are Eurofer 97 batch-3 and F82H-BA12. The test matrix and specimen sizes and geometries have been finalized with the details that can be found in Ref. [1]. A wide variety of specimen sizes and geometries are covered, allowing full investigation of the specimen size effect on measured fracture toughness. Each participating laboratory is performing specimen machining independently while all test results will be reported using a standardized spreadsheet. Test guidelines based on the ASTM E1921 standard and best practices from each participating laboratory have been published [1] and will be strictly followed.

\section{FUTURE PLANS}

Specimen machining is ongoing and expect to be completed in October 2020. The testing will commerce afterward and it is anticipated that testing will be completed in the first half of FY21.

\section{REFERENCES}

[1] X. Chen et al., "Guidelines for IAEA Small Specimen Test Techniques Master Curve Fracture Toughness Testing”, ORNL/LTR-2020/27, July 2020. 


\section{MATERIALS ENGINEERING}

\subsection{MATERIALS ENGINEERING SUPPORT FOR THE FNSF CONCEPTUAL DESIGN}

Arthur Rowcliffe (art.rowcliffe@gmail.com) (MPI Business Solutions, Inc.)

\section{OBJECTIVE}

This task is directed at identifying potential solutions to the selection and definition of structural materials for the FNSF power core components and for the lifetime components such as the vacuum vessel, structural ring and the low temperature neutron shield. A parallel activity is maintaining a strong connection between the fusion materials program and the design studies for the next-step FESS activities

\section{PROGRESS AND STATUS}

Efficient neutron shielding of the FNSF magnets is achieved via the deployment of non-structural shielding plates located in the ribbed structure between the face plates of the helium-cooled structural ring (SR), vacuum vessel (VV) and the water-cooled low temperature shield (LTS). The selection of a borated RAFM steel containing 3wt.\% B and monolithic WC for the shielding plate materials was based entirely on nuclear requirements. Materials-engineering issues which will need to be addressed to validate these choices are summarized below.

\section{Borated RAFM shield plates}

a) Identification of a viable fabrication route to ensure dissolution of $3 \mathrm{wt} . \% \mathrm{~B}$ and redistribution as a fine scale homogeneous dispersion of borides to ensure maximum shielding efficiency and longterm microstructural stability under the neutron irradiation and temperature operating conditions of the SR,VV and LTS.

b) Assessment of the impact of $\mathrm{He}$ and $\mathrm{Li}$ generation from the $\mathrm{B}^{10}(\mathrm{n}, \alpha) \mathrm{Li}^{7}$ reaction; He production in the inboard (IB) SR, IBVV and IBLTS shield locations are 700, 1500 and 10,600 appm/FPY respectively. The Li generation rate at the IBVV location is 0.1 at $\%$ after 6 FPY operation which raises the possibility of significant levels Li injection and grain boundary penetration at the surface layers of the structure to which the shield is bolted.

c) While shielding plates have no structural function, they are subjected to mechanical restraint from the bolting methods adopted during assembly. Figure 78 illustrates the design of the shielding plate assembly for ITER. ${ }^{1}$ Radiation-induced changes in mechanical behavior and dimensional stability in experiments will need to be assessed for the appropriate He/dpa conditions.

WC shield plates

a) The extreme brittleness of $\mathrm{WC}$ plate materials presents the potential for crack initiation during assembly and bolting and during operational disruption loads. The required dimensions of WC shield plates have not been determined at this stage, but commercial availability of appropriate dimensions could be an issue.

b) The projected operating temperature and neutron dose for the SR shield will result in significant radiation hardening in $\mathrm{WC}$. 


\section{$\underline{\text { Alternative materials options }}$}

Austenitic stainless steels containing both boron and gadolinium are deployed for fission reactor shielding applications. In principle, Gd-bearing RAFMs could also be fabricated via PM processing for fusion use; the potential for replacing B with Gd to eliminate issues with $\mathrm{He}$ and $\mathrm{Li}$ generation needs to be assessed. Composite materials based on WC and WB dispersed in a ferritic steel matrix are under development in the UK Tokamak Energy project ${ }^{2}$ and could provide a viable approach to overcoming the inherent brittle behavior of monolithic WC shields for FNSF.

\section{FUTURE PLANS}

Continue to maintain the interface between the Fusion Materials Program and FESS-FNSF; evaluate shielding materials options to meet the requirements of Compact Power Plant designs; and examine materials options for RF actuators.

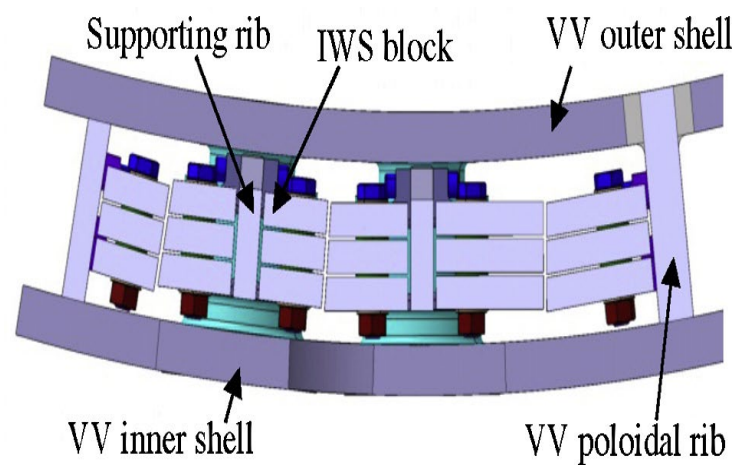

Figure 78. Schematic layout of the vacuum vessel in-wall shield plates for ITER.

\section{REFERENCES}

[1.] X. Wang et al. "Design of ITER Vacuum Vessel in-wall Shielding”, Fus.Eng.Des.89 (2014)18141819.

[2.] C.G. Windsor et al. "Design of cemented tungsten carbide and boride-containing shields for a fusion power plant” Nucl. Fusion 58 (2018) 076014. 


\section{EXPERIMENTAL TECHNIQUES AND LABORATORY SYSTEMS}

\subsection{DEVELOPMENT OF MINIATURE MECHANICAL TESTS FOR TUNGSTEN-BASED MATERIALS}

\section{M. Garrison (garrisonlm@ornl.gov), N. Reid (ORNL)}

\section{OBJECTIVE}

The aim of this work is to develop miniature mechanical test methods that can be used to evaluate neutronirradiated tungsten and tungsten composite samples. Successful methods will be used in LAMDA.

\section{SUMMARY}

Three-point bending will be used with tungsten-based samples to observe failure modes under flexural stress. The test is conventionally performed on beams with rectangular cross section. This test has been adapted for disc specimens at the plane of symmetry in the center of the sample. Because of its simplicity and economy, it is a fitting test to use on samples with TEM disc geometry that have been irradiated in HFIR. A fixture has been modeled, designed and procured for testing of tungsten materials in LAMDA.

\section{PROGRESS AND STATUS}

A simple illustration of the three-point disc bend test is shown in Figure 79 [1]. After the bend test, the specimen failure mode can be evaluated via scanning electron microscopy. This technique is useful to measure irradiation induced embrittlement [2]. For a real test, as compared to the schematic in Figure 79, a fixture was designed to ensure the disc is centered and that all three rods touching the sample are flat and parallel. In addition, a mathematical model has been used to relate load-deflection curves from the test frame to stress-strain diagrams in bending.
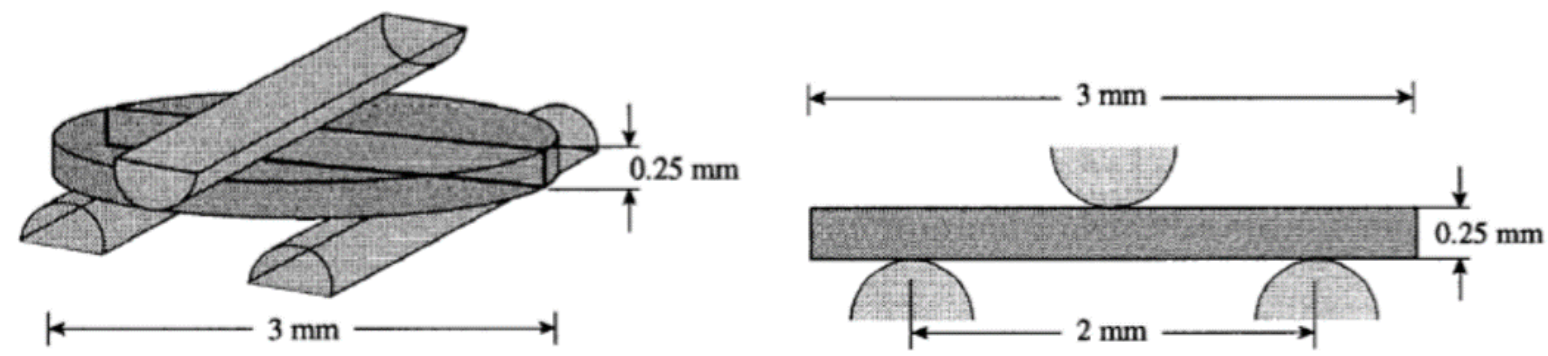

Figure 79. Three-point bend test schematic, where the distance between the two pins is $2 \mathbf{m m}$, the total width of the sample is $3 \mathbf{~ m m}$, and the radius of curvature for the supports is $0.25 \mathrm{~mm} \mathrm{[1]}$.

A basic finite element deformation analysis was performed (Figure 80) to evaluate the mechanical stress field of disk bend specimens; however, a more complete study of the deformation analysis will be completed using ANSYS software. The experimental setup for this stress analysis was performed using 7 bodies with sliding contacts and no separation. Experimental data from unalloyed polycrystalline tungsten was used as inputs. A coarse mesh was used in this model to minimize computational time. The deformation in the direction of load and the maximum tensile stress on the bottom elements of the disk at the center of symmetry agree well with the analytical analysis performed previously. The rods that are in contact with tungsten will be tungsten carbide, selected to be able to handle large contact pressure with minimal deformation. Based on this model, the tungsten disk will undergo plastic deformation at a mere 15-25 
microns of deflection at a load near $200 \mathrm{~N}$ for a $0.25 \mathrm{~mm}$ thick tungsten disk. Due to the second power proportionality between load and thickness, this value is approximately $800 \mathrm{~N}$ for a $0.50 \mathrm{~mm}$ thick disk specimen. The stress state is uniform except near the rounded edges of the disk; the majority of the disk experiences bending in the same way that a beam would (Figure 80b).

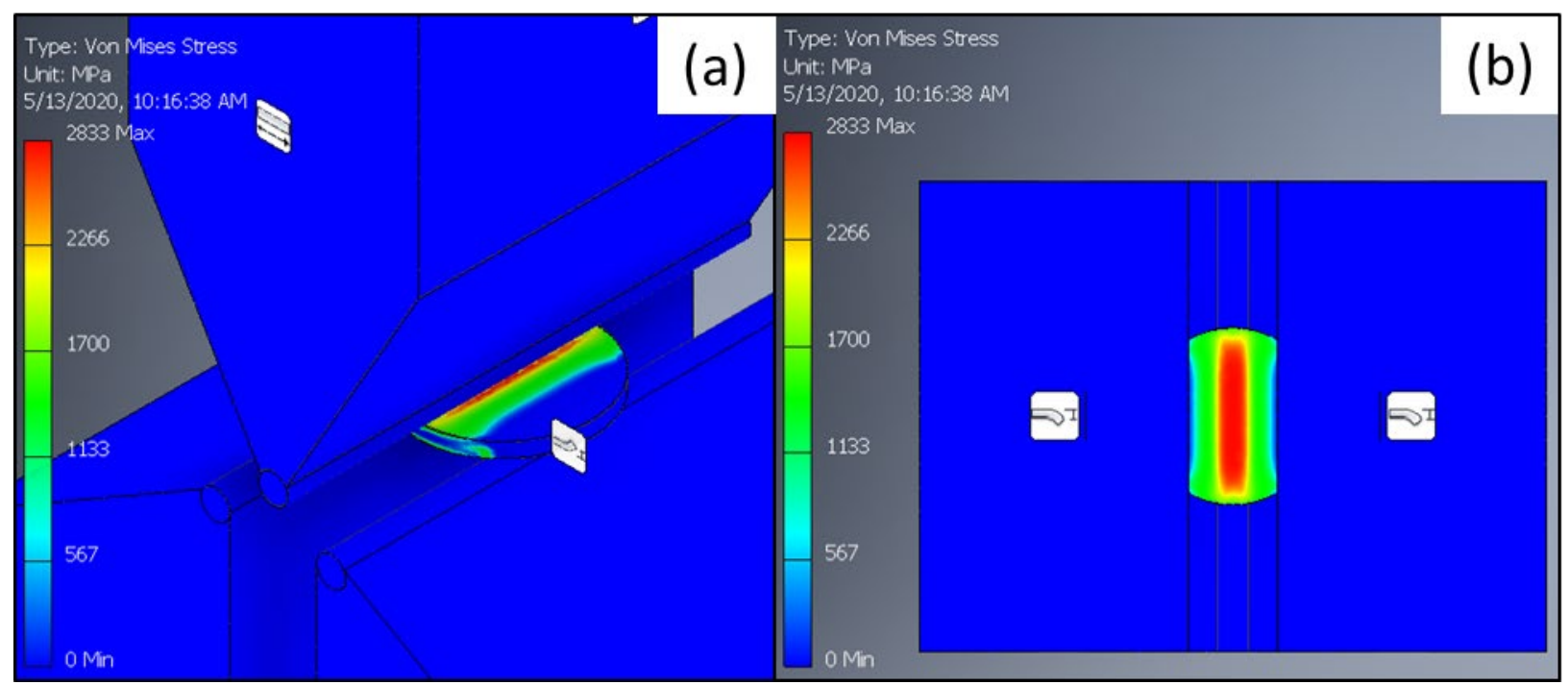

Figure 80. Stress analysis of a simplified model of miniature three-point bend loading on a diskshaped specimen. (a) Orthographic view, (b) bottom view.

A bend test fixture has been designed and fabricated to enable testing of specimens that are $3 \mathrm{~mm}$ in diameter, which is the typical size for transmission electron microscopy (TEM) disks. The fixture has precisely engineered tolerance and minimal machine compliance (Figure 81). The deformation of the tension side of the disk can be measured in-situ through an opening at the bottom of the fixture. Postmortem examination of the fracture surfaces will be performed to determine fracture mode.

The construction of the fixture was inspired by and reflects that of the shear punch fixture already used in the LAMDA laboratory. The loading nose fits through the central slot in the upper half, which is thick enough to constrain loading nose movement to vertical only. The bottom half has the two lower supports for the three-point bend at its center. Testing with various centering methods will establish the best method of placing the disk in the exact center of the supports prior to testing. The fixture is self-contained and can be inserted into the testing frame without requiring a mechanical connection to the frame. Much like the shear punch test, any major movements that may move the inner pieces must be avoided to risk invalidating the test. Centering methods using the clamping mechanism of the upper to lower halves will be considered to keep the disk from moving after it has been centered.

Initial qualification testing will use AISI 347 stainless steel and grade 70 carbon steel disk specimens of thicknesses 0.25 and $0.50 \mathrm{~mm}$. Five tests of each condition will have statistical significance, and flexural strength and strain experimental values will be compared to theoretical values. 


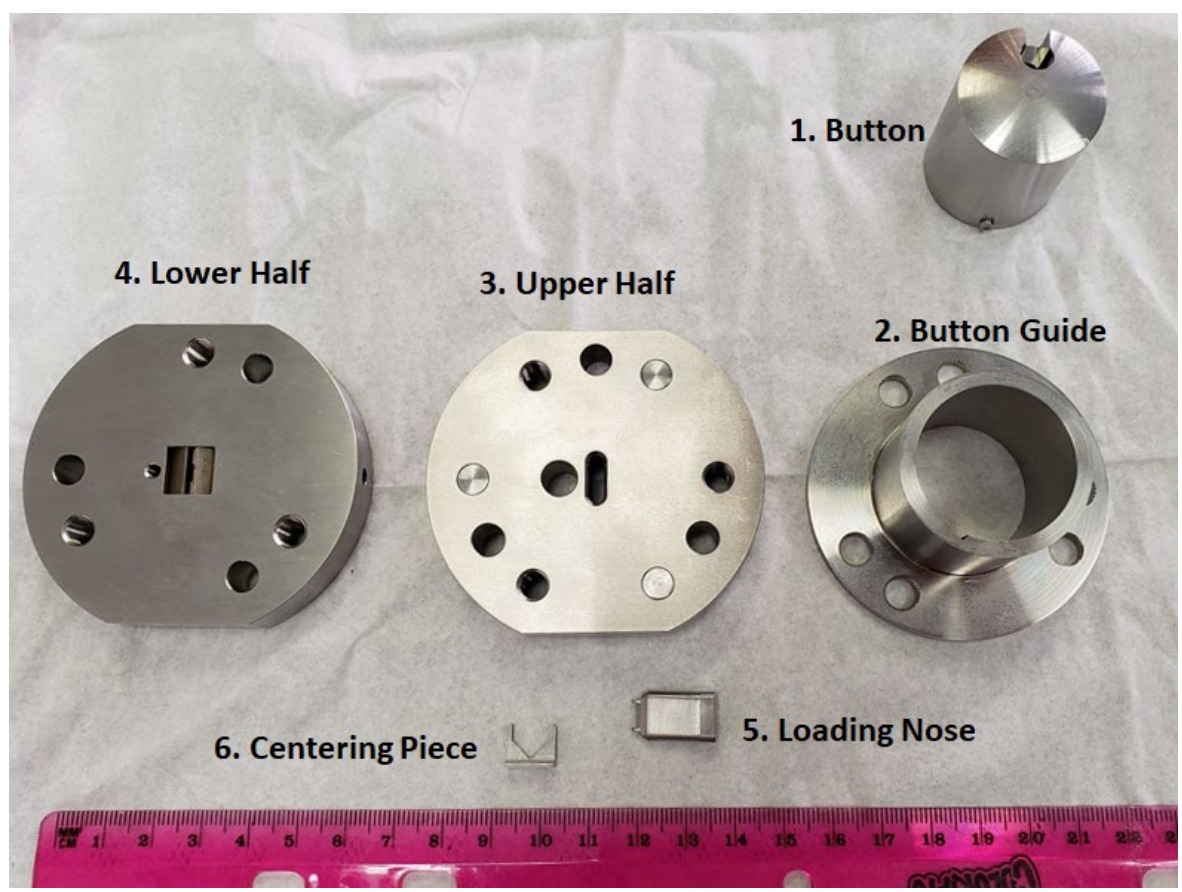

Figure 81. Image of the three-point bend fixture for use in LAMDA universal testing frames. Load is applied to the button, which moves with restricted displacement in button guide. Loading nose is situated in upper half, and the affixed tungsten carbide rod transfers the load to the disk, which is situated in the supports that are centered in the lower half.

\section{REFERENCES}

[1] Ueda, K., Satou, M., Hasegawa, A., \& Abe, K. (1997, 7). Mechanical Properties of Mo and TZM Alloy Neutron-Irradiated at High Temperatures. Science Reports of the Research Institutes Tohoku University Series A-Physics, 45.

[2] Ueda, K., Satou, M., Hasegawa, A., \& Abe, K. (1998). Deformation analysis of small size bend specimens by FEM calculation to estimate irradiation induced embrittlement of Mo and W. Journal of Nuclear Materials, 258-263, 466-470 


\subsection{ADVANCED MICROSTRUCTURE CHARACTERIZATION OF DIBORIDES}

Phil Edmondson, edmondsonpd@ornl.gov (ORNL)

\section{OBJECTIVE}

The overarching objective of this work is to provide advanced microstructural analysis support to other portions of the Fusion Materials research program to advance the understanding of materials for fusion applications.

\section{SUMMARY}

Ceramic diborides, either $\mathrm{TiB}_{2}$ or $\mathrm{ZrB}_{2}$, have been proposed as possible materials for use in a nuclear fusion environment yet their response to irradiation is poorly known and little understood. Previous research conducted at ORNL has focused on transmission electron microscopy related microstructural characterization of irradiated material to understand the temperature-dose relationship on dislocation evolution within the matrix. However, in addition to the displacement damage caused by the interaction of energetic neutrons with the matrix, boron reacts very strongly with neutrons causing transmutation to occur reducing the $\mathrm{B}$ content and forming $\mathrm{He}$ and Li. Over this reporting period, detailed atom probe tomography (APT) examination of an unirradiated $\mathrm{TiB}_{2}$ specimen has been conducted to determine the correct experimental parameters with which to characterize irradiated material, thus, to understand and correctly observe the rate of B burnup. This calibration-type study is essential in APT examination of ceramics due to the strong influence the experimental parameters can have on observed chemistry and microstructure.

\section{PROGRESS AND STATUS}

Specimens of the unirradiated $\mathrm{TiB}_{2}$ material were prepared at ORNL's LAMDA laboratory using standard focused ion beam (FIB) techniques, resulting in the production of approximately 8 needle-shaped specimens. These were transferred to the LEAP 4000X HR atom probe at ORNL for examination. The base parameters for data acquisition were a specimen temperature of $50 \mathrm{~K}$, a detection rate of 0.5 , and a pulse repetition rate of $200 \mathrm{kHz}$. The laser power was varied between 50 and $400 \mathrm{pJ}$ in a systematic manner to investigate the influence of the laser power on the observed chemistry and microstructure.

A graph showing the laser power and specimen voltage as a function of ion sequence is shown in Figure 82. This graph shows each change in laser power and how the voltage compensated for that change. By moving the laser power up and down repeatedly, the hysteresis in the system can be evaluated and accounted for as part of this calibration. (The observed spike in laser power at approximately $8 \mathrm{M}$ ions was due to a typing error in setting the laser power.) The detection rate is shown in Figure $\mathbf{8 3}$ and confirms that there was no significant variance from the set rate and the dataset is valid.

Detector hit maps from two difference laser powers (75 and $250 \mathrm{pJ})$ are shown in Figure 84. The detector histogram for $75 \mathrm{pJ}$ shows a uniform distribution of ion hits across the detector, whereas the $250 \mathrm{pJ}$ histogram shows a "hot spot" in the left-hand-side of the detector. This "hot spot" appeared and disappeared 
with varying laser power showing that this was an artifact of the data collection parameter set.

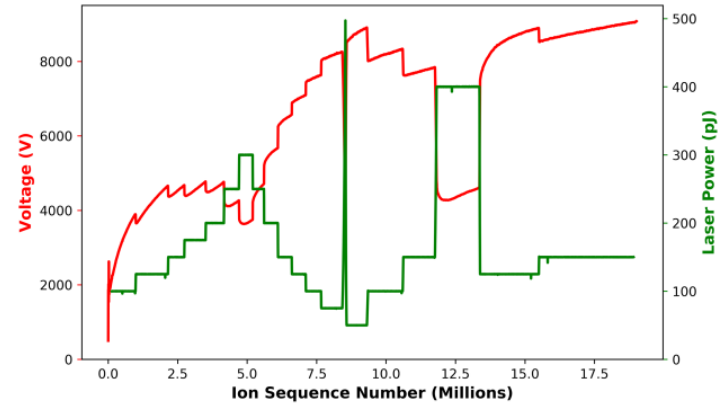

Figure 82. Plot showing the laser power (green) and voltage power (Red) over the course of the APT calibration experiment.

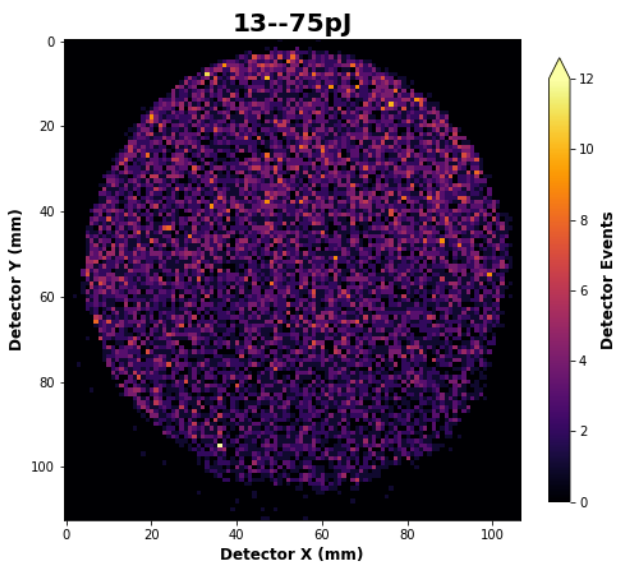

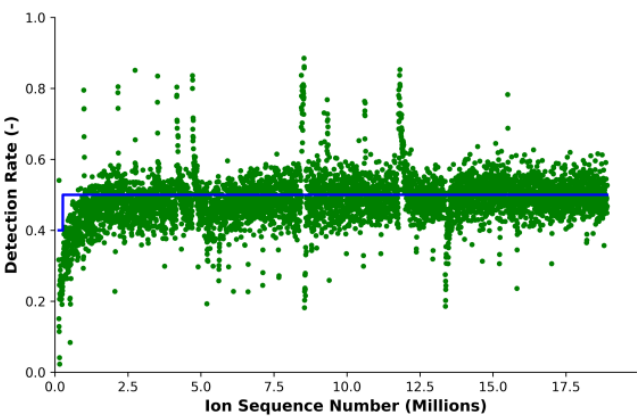

Figure 83. Detection rate as a function of ion sequence showing no significant variance.

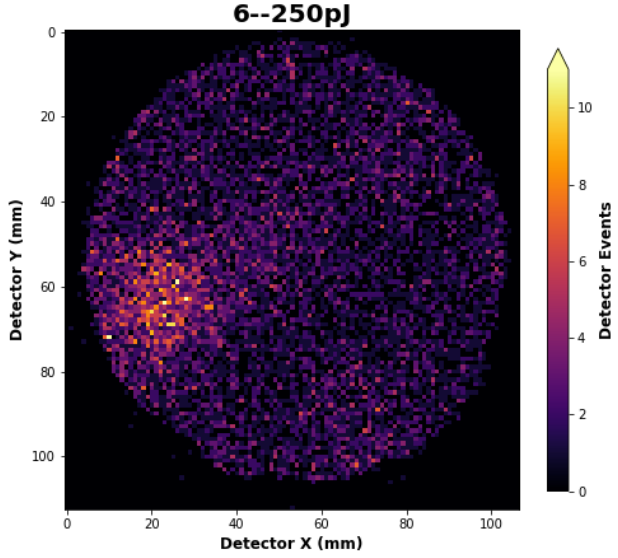

Figure 84. Detector histograms for specific laser powers: 75pJ (left) and 250pj (right).

Investigation of the ratio of the isotope peaks (graphs not shown) shows that at the laser power of 75-100 $\mathrm{pJ}$ the ratio for the ${ }^{10} \mathrm{~B}$ and ${ }^{11} \mathrm{~B}$ remains relatively constant. All these results indicate that the optimum collection parameters for $\mathrm{TiB}_{2}$ is a specimen temperature of $50 \mathrm{~K}$, a detection rate of 0.5 , pulse repetition rate of $200 \mathrm{kHz}$, and a laser power of between 75-100 pJ. The acquisition of these results discussed above will also allow for very detailed analysis of the irradiated $\mathrm{TiB}_{2}$ in order to understand the $\mathrm{B}$ burnup as a function of neutron fluence.

Following determination of these collection parameters, several APT datasets were obtained of the unirradiated material to be used as a baseline in comparing future analysis of irradiated material. Atom maps of $\mathrm{Ti}$ and $\mathrm{B}$ are shown in Figure 85 and show the homogeneous distribution of both species throughout the matrix.

\section{FUTURE PLANS}

Determination of the correct ranging of the ion spectrum in the APT data is also required and will be completed in early FY21. Future plans also include the acquisition and analysis of data from the irradiated material with specimens that have been prepared and are awaiting evaluation. Following completion of the 
data acquisition and analysis, a manuscript will be written on the calibration experiment, and on the effect of the irradiation on the material system. It is also tentatively planned to perform the same analysis for the $\mathrm{ZrB}_{2}$.
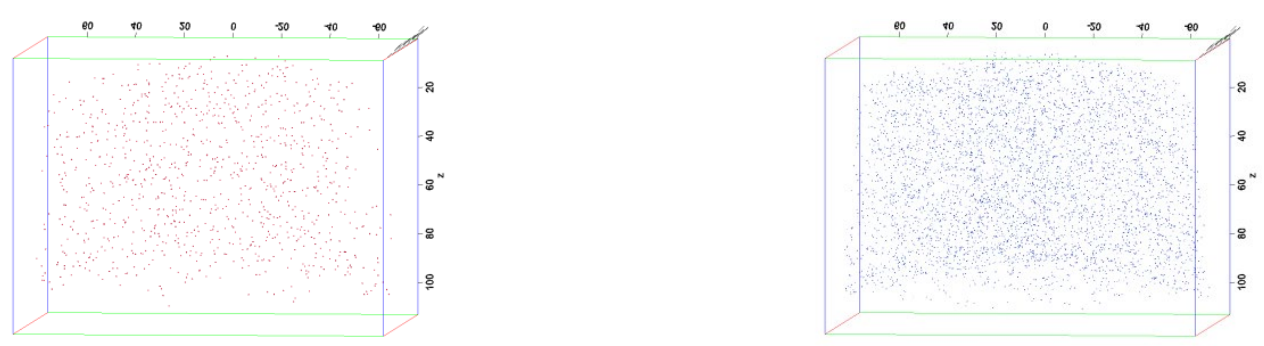

Figure 85. Atom maps for Ti (left) and B (right) from a dataset collected with optimized APT parameters showing a uniform distribution of species throughout the matrix in the unirradiated state. The scale shown is in $\mathrm{nm}$. 


\subsection{FRACTURE MECHANICS LABORATORY TEST SYSTEMS}

\section{Chen (chenx2@ornl.gov) (ORNL)}

\section{OBJECTIVE}

This report provides an update of the latest test systems in the Fracture Mechanics Laboratory (FML) at Building 4500S of Oak Ridge National Laboratory.

\section{LABORATORY STATUS}

Fracture Mechanics Laboratory (FML) at Building 4500S of ORNL is equipped with critical capabilities for characterizing structural materials for the ORNL Fusion Materials Research program. This report provides an update of the currently available equipment in the FML, with, the following major equipment available in the FML at the end of FY20:

- Three Lindberg/Blue M box furnaces for thermal aging and heat treatment (Figure 86).

- Four servo-hydraulic frames with a load capacity of 10-kip, 22-kip, 50-kip, and 300-kip, respectively for mechanical testing (Figure 87).

- One Charpy impact machine for testing both full-size and sub-size (half- and third-size) Charpy specimens with an impact energy capacity of 407 joules and a testing temperature range of -196 to $1000^{\circ} \mathrm{C}$ for Charpy impact testing (Figure 88).

- One Instron Charpy impact machine with the MPM in-situ heating/cooling stage for testing both full-size and ASTM miniature size Charpy specimens with an impact energy capacity of 450 joules and a testing temperature range of -196 to $200^{\circ} \mathrm{C}$ for Charpy impact testing (Figure 89).

- One Mitutoyo QI-A2010D Quick Image 2D measuring microscope for measuring dimensions from a 2D object (Figure 90).

- One Buehler Wilson ${ }^{\circledR}$ VH3100 Vickers full-automatic hardness tester for Vickers hardness testing (Figure 91).

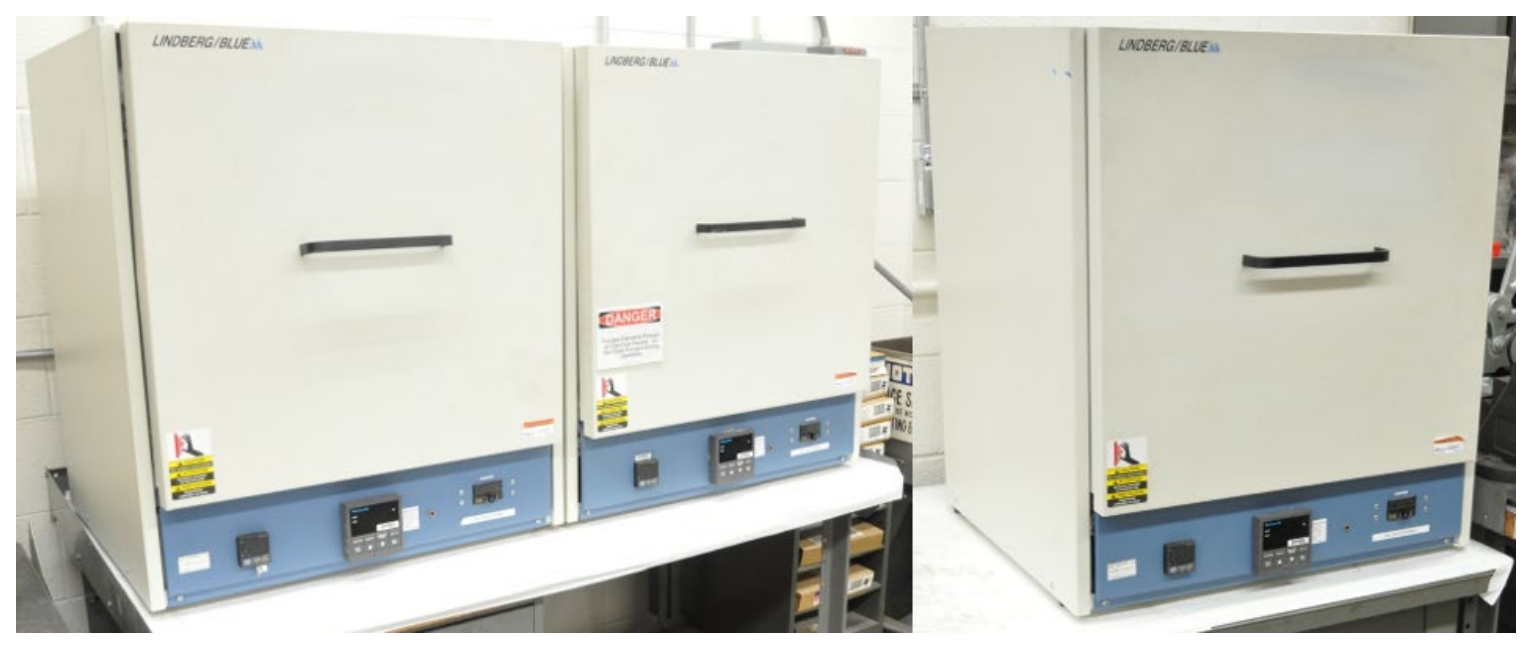

Figure 86. Lindberg/Blue $M$ box furnaces. 

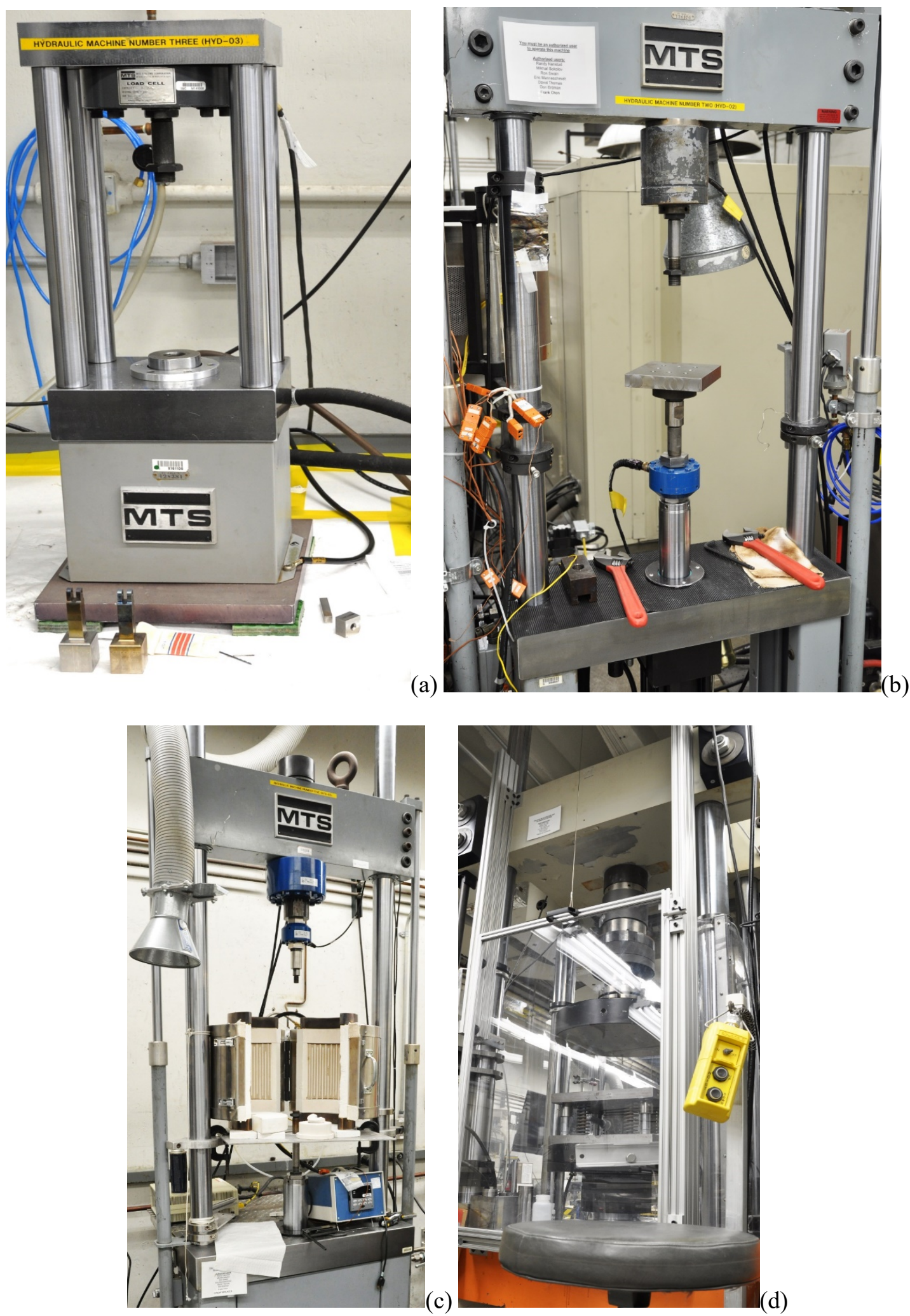

Figure 87. Servo-hydraulic frames. Load capacities: (a) 10-kip, (b) 22-kip, (c) 50-kip, and (d) 300kip. 


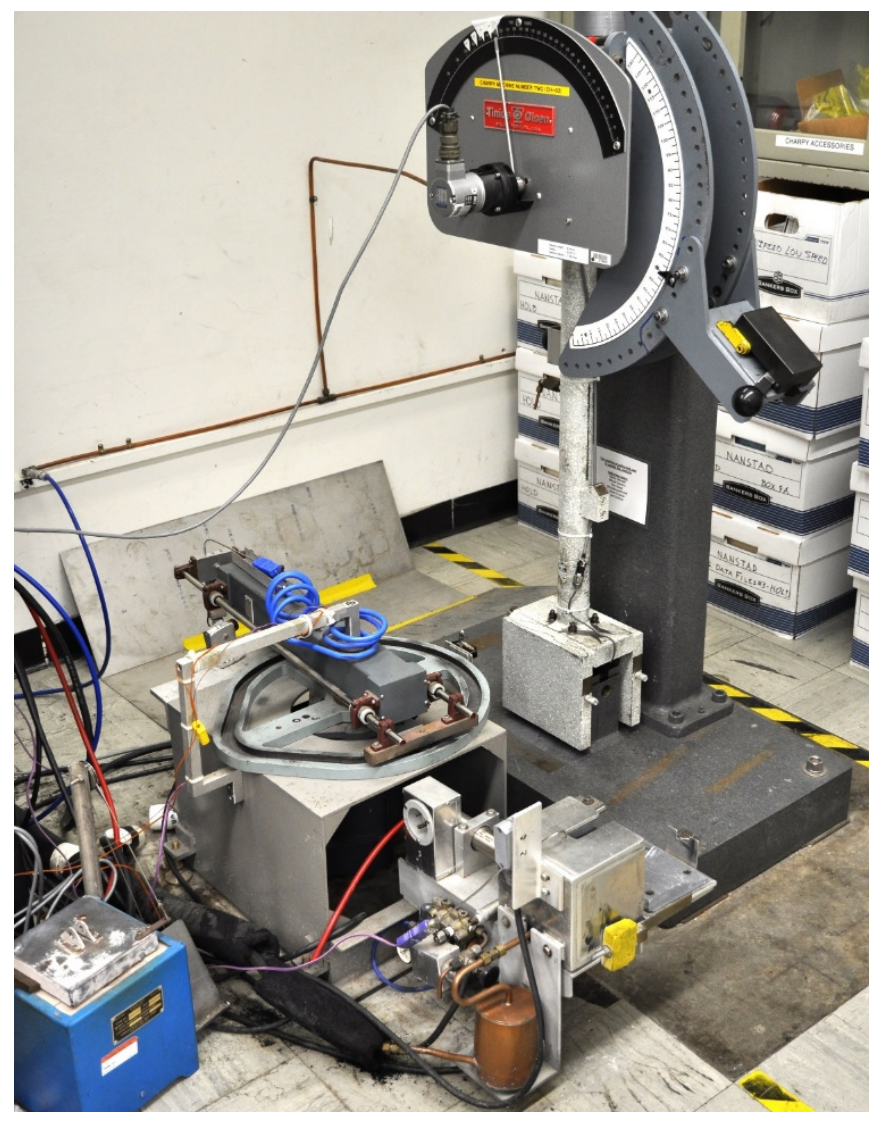

Figure 88. South laboratory Charpy impact frame with 407 joules capacity. 


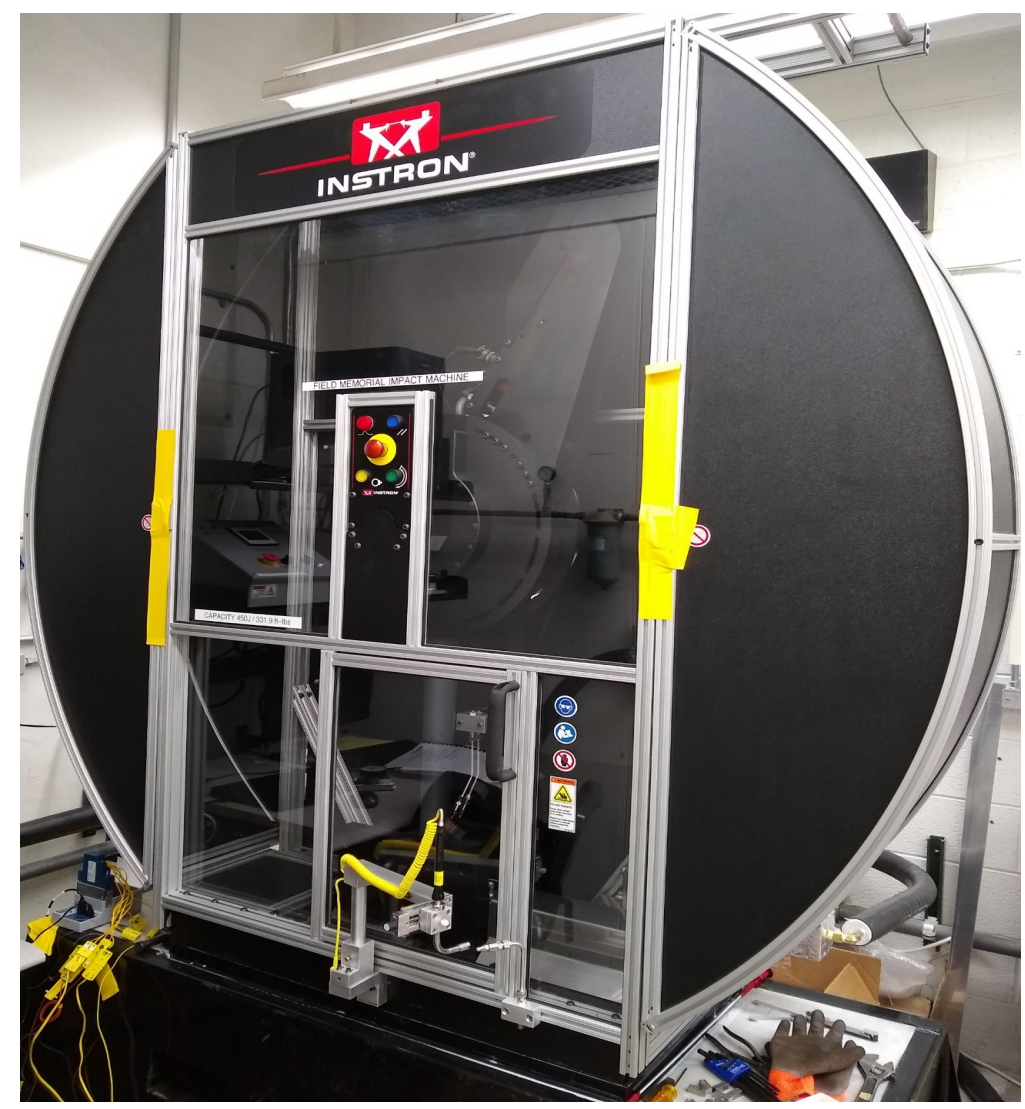

Figure 89. Instron Charpy impact frame with in-situ heating/cooling stage.

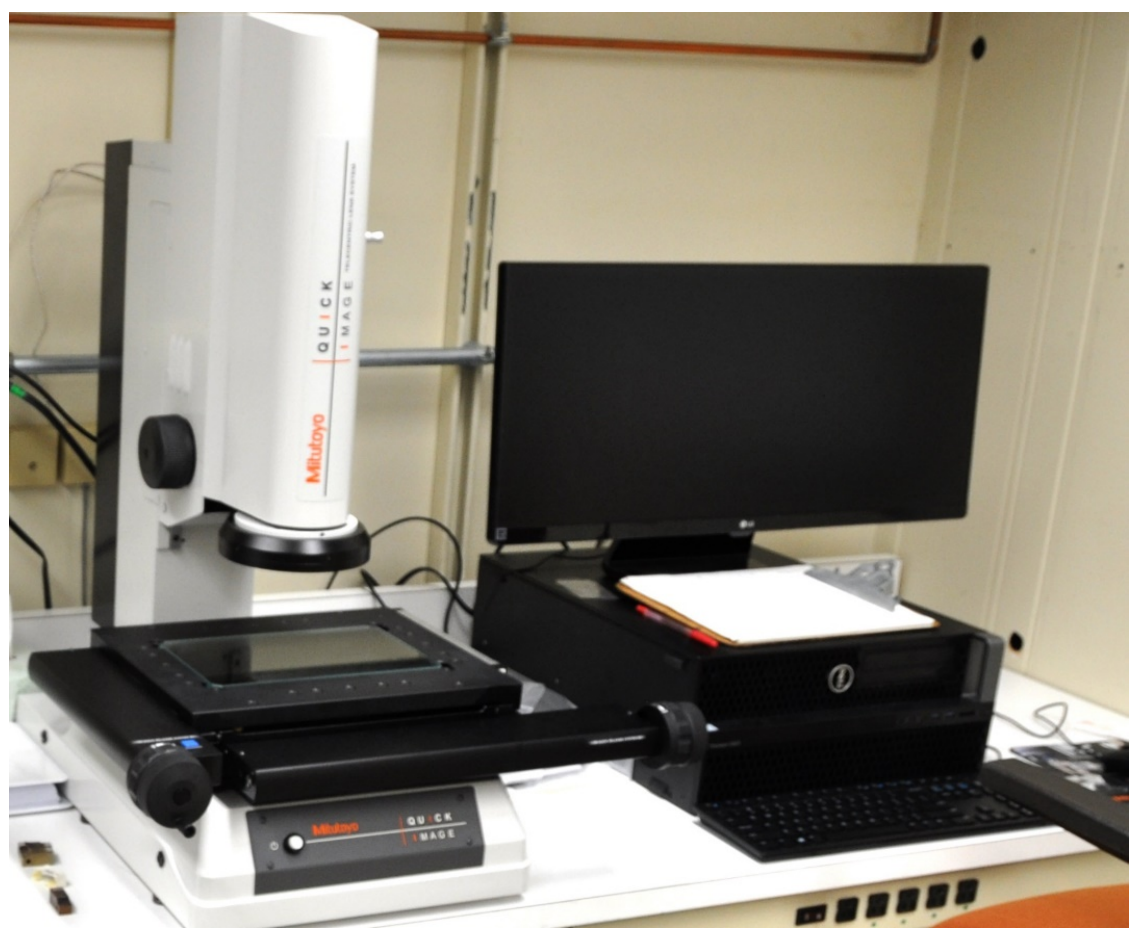

Figure 90. Mitutoyo 2D measuring microscope. 


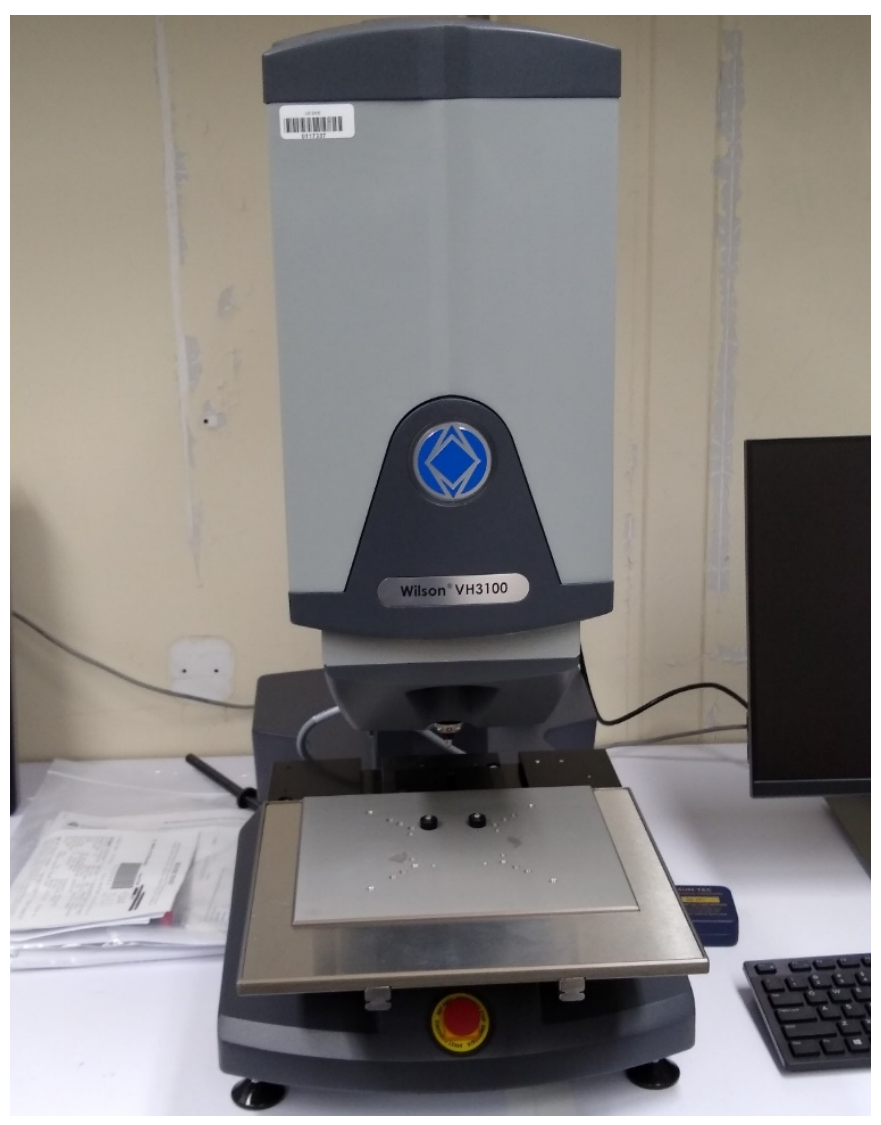

Figure 91. Buehler VH3100 Vickers full-automatic hardness tester. 


\subsection{UPDATE OF IRRADIATED MATERIALS EXAMINATION AND TESTING FACILITY SYSTEMS}

X.Chen (chenx2@ornl.gov), J.Reed,E.Manneschmidt (ORNL)

\section{OBJECTIVE}

This report provides the status of updates to test systems in the Irradiated Materials Examination and Testing Facility (IMET) in Building 3025E of the Oak Ridge National Laboratory.

\section{SUMMARY}

As of the end of FY20, the following maintenance and upgrade work has been performed on Fusion-related test systems in IMET:

1) Cell 1 Instron frame first annual maintenance completed

2) Cell 1 Instron frame SSJ3 tensile fixture upgraded

3) Design and fabrication of new fixtures for hardness testing of miniature bend bar and SSJ3 specimens

4) Design and fabrication of new fixtures for SEM examination of miniature bend bar and SSJ3 specimens

The maintenance and upgrade work will facilitate future post-irradiation evaluation (PIE) activities at IMET for the Fusion Materials Research program.

\section{IMET UPGRADES}

The cell 1 Instron frame was commissioned in April 2019 and has been successfully used for the EUROfusion $2.5 \mathrm{dpa}$ and the US- Japan-QST tensile testing campaigns for specimens from HFIR capsules JP28/29 and RB15J. In FY20-Q4, we performed the first annual maintenance work on the system including cleaning the inside of the vacuum chamber, turbopump lubricant replacement, chiller coolant flush, and the $5-\mathrm{kN}$ load cell calibration. A specialized calibration load cell was procured, and dedicated fixtures were designed and fabricated for the load cell calibration. All maintenance works were completed during two cell entries.

Based on user experiences and feedback from the EUROfusion 2.5 dpa and JP28/29 and RB15J tensile testing campaigns, we designed and fabricated two new SSJ3 tensile fixtures to improve the efficiency of tensile PIE and minimize the chance of losing ruptured specimens. The photos of the newly designed room temperature and elevated temperature fixtures are shown in Figure 92. Initial trial testing proved that the new fixtures have resolved all issues experienced with earlier fixture designs. 


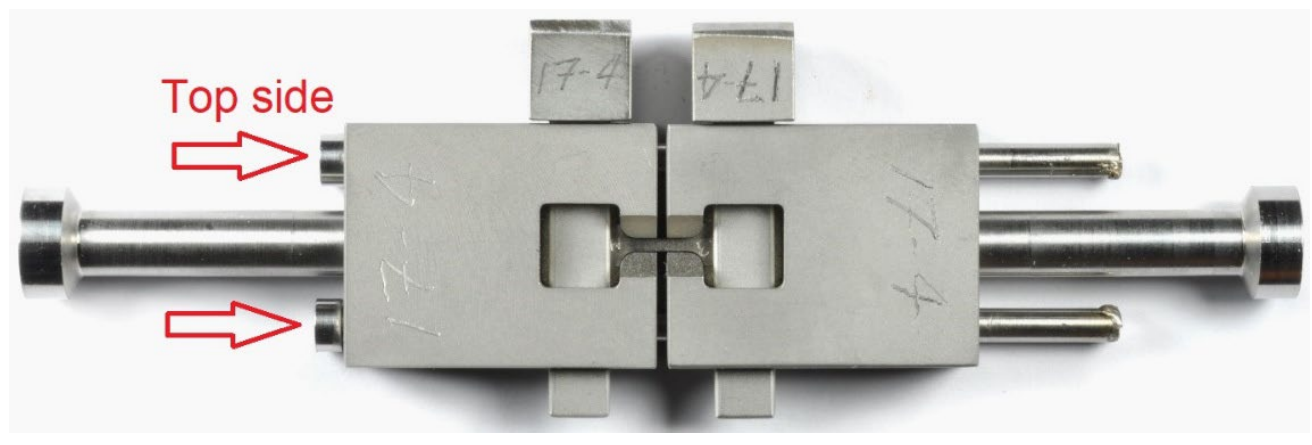

(a)

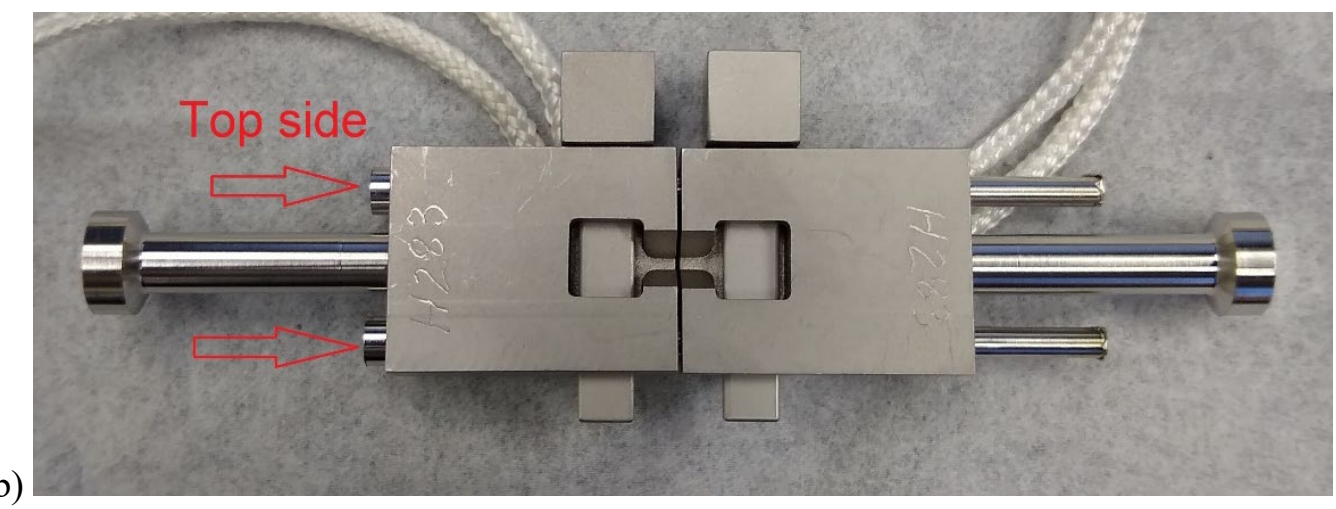

Figure 92. Newly designed and fabricated SSJ3 tensile fixtures for room temperature testing in (a) and elevated temperature testing in (b).

To streamline in-cell hardness testing and fractography at IMET, four new stages were designed and machined. These stages were for the Mitutoyo HV120B hardness tester and the JEOL 6010LA scanning electron microscope (SEM). Figure 93 shows the two stages created for the hardness tester. The cut-outs are sized to hold an SS-J3 or M4/M5-PCCVN specimen with minimal shifting when the stage is being moved. One major improvement over the previous plate stage is that the M4/M5-PCCVN specimen can lay in line with the hardness tester's direction of motion, which will make taking multiple precise measurements on a single specimen more efficient.

(A)

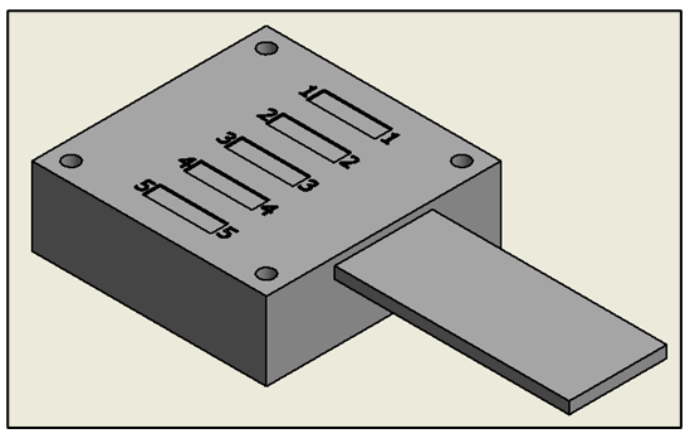

(B)

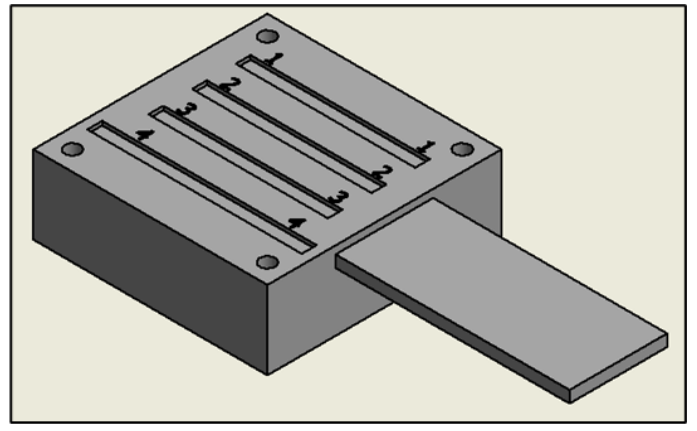

Figure 93. Mitutoyo HV120B hardness stage for (A) SS-J3 and (B) M4-PCCVN and M5-PCCVN. 
Previously the only stage for the JEOL 6010LA SEM was a round puck with carbon tape on it. As a result, to image the fracture surface the end of a specimen would be pressed into the carbon tape and carefully moved to the SEM. This transfer was between two hot cells via a drawer and if the tape adhesive wasn't strong enough, the specimen could fall over. The operator would then have to move the puck back to the original cell and start the process over. Figure 94 shows two new blocks that were designed to sit within the round puck and hold tested SS-J3 or M4-PCCVN specimens with the fracture surface facing up. The depth of these holes is approximately half the length of a tested specimen, thus allowing them to be secure while moving and easily removable after imaging.

(A)

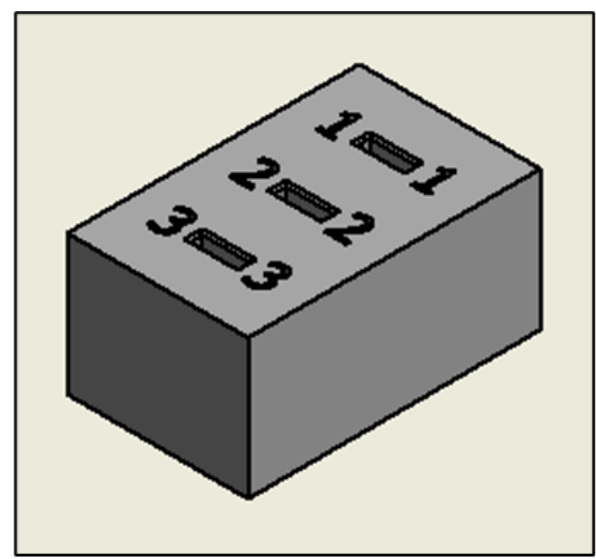

(B)

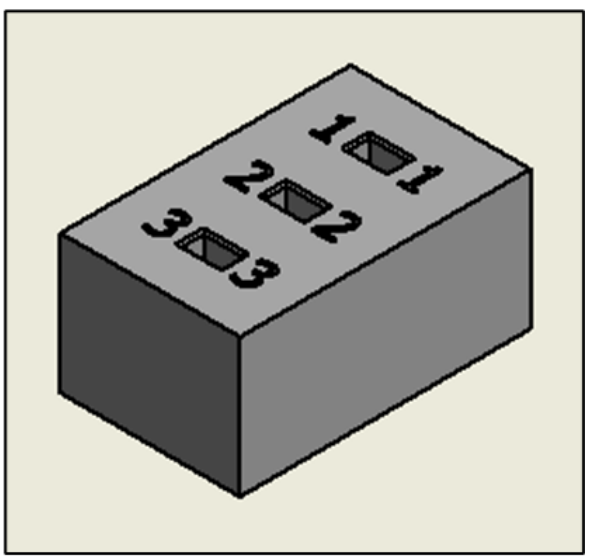

Figure 94. JEOL JV-6010 SEM stage for fractography of (A) SS-J3 and (B) M4-PCCVN. 


\subsection{NEW AND UPGRADED CAPABILITIES OF LAMDA}

PhilEdmondson, edmondsonpd@ornl.gov (ORNL)

\section{OBJECTIVE}

This task ensures that the test and analysis systems in LAMDA available to the Fusion Materials program remain state-of-the-art to facilitate world-leading research.

\section{SUMMARY}

The Low Activation Materials Development and Analysis (LAMDA) laboratory at ORNL is a world-class facility for the examination and characterization of materials with low radiological threat to develop the understand materials' response to irradiation. LAMDA contains several thermo-physical property measuring systems, along with several state-of-the-art electron microscopes. The microscopes include scanning electron microscopes, dual-beam scanning electron microscope-focused ion beam systems, and transmission electron microscopes. Constant evaluation of the infrastructure and facilities available in LAMDA is required to ensure it maintains the status as a world-class facility.

\section{PROGRESS AND STATUS}

Software investment in FY2020 was focused on capabilities in tomographic characterization, specifically in the Avizo package. Avizo is a visualization, analysis and segmentation tool that is used to create high quality images of 2D or 3D image data sets. This software is capable of creating animations of simulations and of filtering experimentally obtained images. This FY, several Avizo extensions have been procured:

- Avizo XFiber. Provides tools to analyze fibers, filaments, and other network structures.

- Avizo XLab. An extension capable of simulating the physical properties from segmented 3D models. It is capable of calculating the absolute permeability, molecular diffusivity, electric conductivity and thermal conductivity of a 3D model.

- Avizo XPore Network Modeling. This module extends the capabilities of Avizo to analyze pores through different metrics. Furthermore, this extension can generate so-called pore network models of porous materials. Pore network models are useful simplified representations of the pore structure of a material and are also capable of estimating the effective permeability of 3D models.

- Avizo XWind. This extension includes additional tools to create, analyze and visualize computational simulations from continuum mechanics and computational fluid dynamics models. It also provides robust tools for the creation of finite element based meshes for microstructural based simulations.

An additional technician has been hired to oversee the operations of the focused ion beam systems. This technician will conduct specimen preparation experiments for further examination using other microscopy techniques such as transmission electron microscopy. The other primary activity is to conduct routine maintenance to ensure maximum operational efficiency of the several microscopes.

\section{FUTURE PLANS}

The equipment in LAMDA will be continuously evaluated, as will new capabilities that come to market. Investments in the laboratory systems will be made on an as-needed basis. 


\section{HFIR IRRADIATION PROGRAM}

\subsection{CAPSULE DESIGN FOR FRONTIER TASK 1 HFIR IRRADIATIONS}

N.Russell (russellng@ornl.gov), A. Schrell, P. Champlin (ORNL)

\section{OBJECTIVE}

The US-Japan Frontier Task 1 irradiation program plans to irradiate $\sim 14$ capsules in the HFIR core with design temperatures ranging from $300^{\circ} \mathrm{C}$ to $800^{\circ} \mathrm{C}$. Loading will include tungsten and tungsten composite materials and specimen types to meet objectives of the Fusion Materials program.

\section{STATUS}

The Fusion 2020 Frontier Task 1 irradiation program has two different capsule designs to accommodate 3 $\mathrm{mm}$ disk specimens and fracture toughness specimens. Each of these capsules are designed to reach average specimen target temperatures of $300^{\circ} \mathrm{C}, 500^{\circ} \mathrm{C}$, and $800^{\circ} \mathrm{C}$ with reactor exposures of 1 or $3 \mathrm{HFIR}$ cycles. Images of the thermal analyses for the two capsule formats are shown in Figure 95.
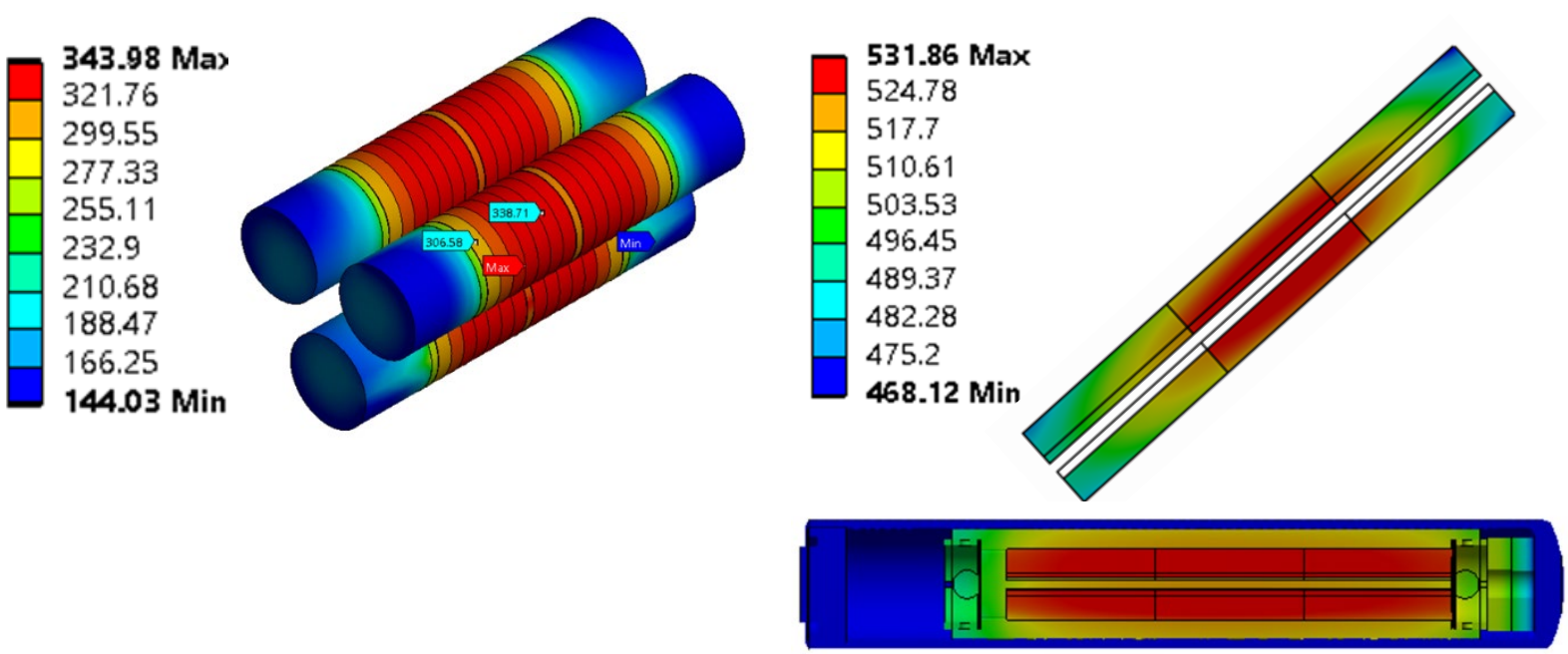

Figure 95. Representative thermal analysis of Frontier Task 1 tungsten irradiation capsules with 3 mm disk design (left) and fracture toughness design (right) for irradiation in HFIR.

\section{PROGRESS AND REMAINING WORK}

The $3 \mathrm{~mm}$ disk and fracture toughness capsule formats are new designs that cannot be bound by existing calculations. The designs and neutronics information are being finalized. With the completion of the designs, the parts can be ordered, and the safety calculations will be written. The capsules are planned for irradiation in HFIR in early calendar year 2021. 


\subsection{CAPSULE DESIGN FOR FRONTIER TASK 2 HFIR IRRADIATIONS}

P. Champlin (champlinpa@,ornl.gov), N. Russell (ORNL)

\section{OBJECTIVE}

Task 2 of the US-Japan Frontier collaboration irradiation program plans to irradiate $\sim 13$ capsules in HFIR with design temperatures ranging from $300^{\circ} \mathrm{C}$ to $800^{\circ} \mathrm{C}$. Loading will include tungsten and tungsten composite materials and specimen types to meet objectives of the Fusion Materials program.

\section{STATUS}

The Fusion 2020 Frontier Task 2 irradiation program plans to irradiate $6 \mathrm{~mm}$ tungsten disk specimens. The design uses a flat disk configuration for better temperature distribution. The design has target average specimen temperatures of $300^{\circ} \mathrm{C}, 500^{\circ} \mathrm{C}$, and $800^{\circ} \mathrm{C}$ and will be irradiated in HFIR for 1 or 3 cycles. The design incorporates a tungsten coating on the $\mathrm{SiC}$ in contact with the specimens to ensure that no reaction will occur with the specimens. Images of the thermal analysis for the $6 \mathrm{~mm}$ format are shown in Figure 96.

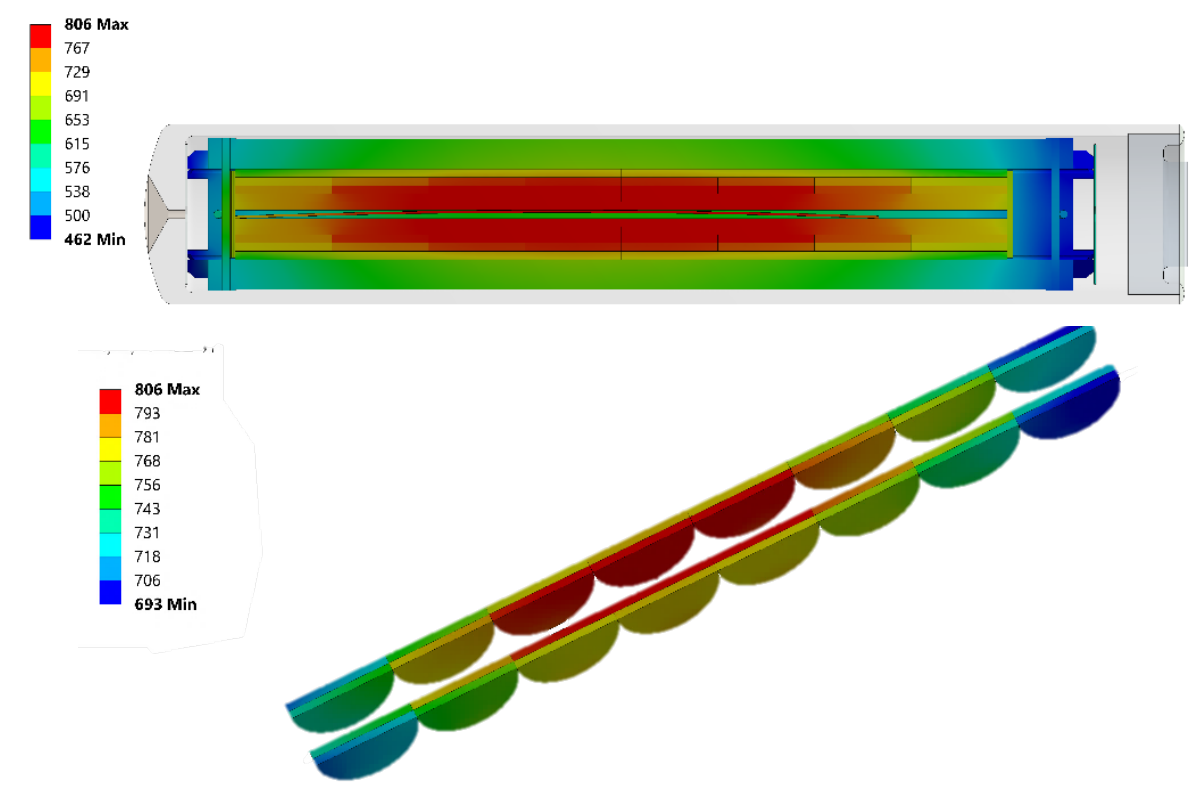

Figure 96. Representative thermal analysis of Frontier Task 2 tungsten irradiation capsules design with 6 mm disks for irradiation in HFIR.

\section{PROGRESS AND STATUS}

This capsule design to accommodate $6 \mathrm{~mm}$ disks has been adapted from an existing design that bounds the use of the tungsten specimens. The design is currently being finalized and checked. Once the design has been checked, parts can be ordered. These capsules are planned for irradiation at the beginning of calendar year 2021. 


\subsection{CAPSULE DESIGN FOR FRONTIER TASK 3 HFIR IRRADIATIONS}

\section{N. Russell (russellng@ornl.gov) (ORNL)}

\section{OBJECTIVE}

The US-Japan Frontier collaboration, Task 3, plans to irradiate $\sim 6$ capsules at a design temperature of $400^{\circ} \mathrm{C}$. These capsules will be loaded with $\mathrm{FeCrAl}$ alloy tensile specimens and solid $\mathrm{Sn}$ shot that will melt at the irradiation temperature. The goal of the experiment is to evaluate any effects of irradiation on the corrosion/compatibility of this alloy with liquid Sn.

\section{STATUS}

The Fusion 2020 Frontier Task 3 irradiation program plans to irradiate FeCrAl alloy tensile specimens submerged in molten $\mathrm{Sn}$ to determine corrosion effects of the irradiation. The design uses a sealed molybdenum holder to provide a secondary containment of the $\mathrm{Sn}$ within the aluminum housing. The design has a target average specimen temperature of $400^{\circ} \mathrm{C}$ and each capsule will be in reactor for 1 HFIR cycle. For ease of modeling and to optimize the costs, two models were employed. The first is a conduction only model, where the molten $\mathrm{Sn}$ is assumed to be solid and therefore conduction heat transfer is the only form of heat transfer. This model gives the hottest bounding case for the experiment. The second is a convection only model, where the Sn and specimens are removed. The amount of heat produced by these components is applied directly to the inside wall of the holder. This assumes only convection heat transfer within the capsule for the coldest bounding case. Images of the thermal analysis for the molten Sn corrosion design are shown in Figure 97.
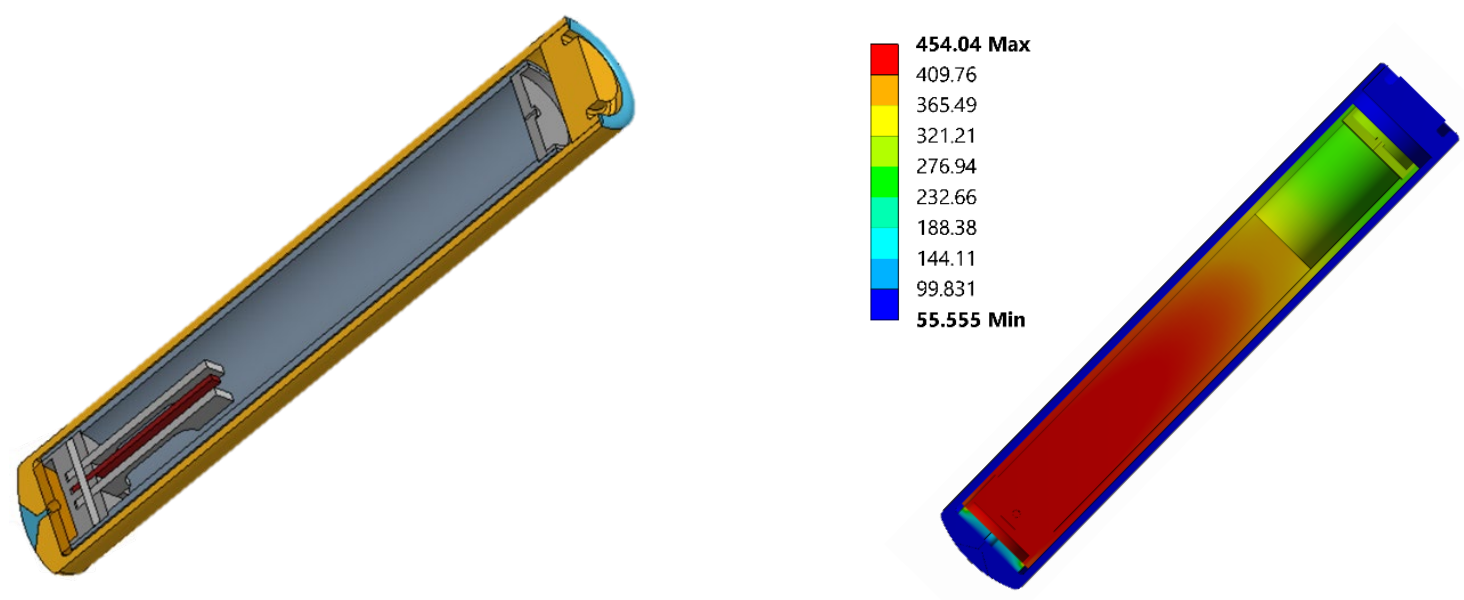

Figure 97. CAD representation (left) with $\mathrm{Sn}$ hidden for ease of viewing and representative thermal analysis conduction model (right) of Frontier Task 3 molten Sn corrosion irradiation capsules for irradiation in HFIR. 


\section{PROGRESS AND REMAINING EFFORT}

The preliminary design of these capsules has been finished and is being reviewed by HFIR. Once HFIR has approved the use of molten $\mathrm{Sn}$ in the reactor, the design will be finalized, and a safety calculation can be written. 


\subsection{CAPSULE DESIGN TO IRRADIATE F82H FOR THE ORNL-QST COLLABORATION}

\section{N.Russell (russellng@ornl.gov) (ORNL)}

\section{OBJECTIVE}

The US/DOE - Japan/QST collaboration on irradiation effects on materials plans to irradiate 21 capsules in HFIR with design temperatures of $300^{\circ} \mathrm{C}, 400^{\circ} \mathrm{C}$, and $500^{\circ} \mathrm{C}$. These irradiations will include 3 low dose ( $5 \mathrm{dpa}$ ) capsules and 18 high dose ( 50 and $80 \mathrm{dpa}$ ) capsules. Specimen loading will include F82H specimens using tensile and bend bar geometries.

\section{SUMMARY}

The Fusion 2020 QST F82H irradiation program plans to irradiate 21 rabbit capsules in HFIR. Three of these capsules ( 1 tensile and 2 bend bar) are low dose ( $5 \mathrm{dpa}$ ) capsules that will be irradiated first to verify that target temperature can be successfully achieved. With successful irradiation, the next 18 capsules (6 tensile and 12 bend bars) for high dose (50 and $80 \mathrm{dpa}$ ) will begin. These capsules are using the general SSJ tensile (GENTEN) and general M4PCCVN multi-notch bend bar (GENBEN) designs.

\section{PROGRESS AND STATUS}

The designs are approved for use in the HFIR reactor and the holder design diameters have been approved for use by the project US and Japan program representatives. Currently, the low dose tensile capsule (FH51) is being built and is planned for starting irradiation in HFIR cycle 491. The component and specimen layout before assembly is shown in Figure 98. The low dose bend bar capsules (FH61 and FH62) are ready to build but the capsule design team is waiting for the specimens to be delivered before building can start. Tentative start for irradiation of these capsules is HFIR cycle 492. The remaining high dose rabbit capsules will be built and inserted upon successful irradiation and temperature verification of the low dose capsules.

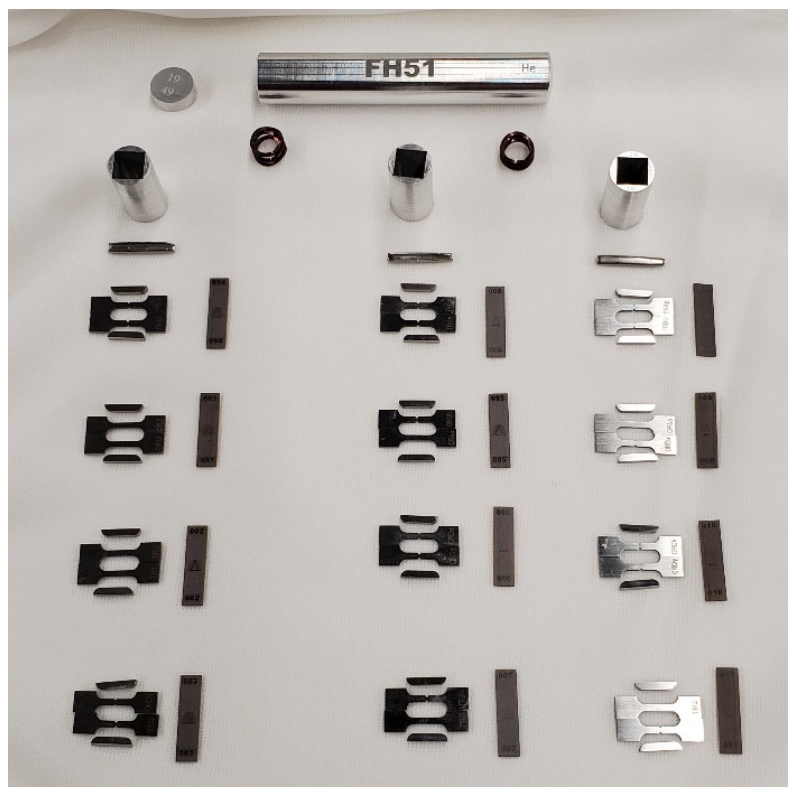

Figure 98. Components and specimens for the FH51 low dose tensile capsule prior to assembly. 


\title{
14.5 HFIR IRRADIATION PROGRAM: CAPSULE DISASSEMBLY AND SPECIMEN RECOVERY
}

\author{
J. D. Reed(reedjd@ornl.gov J.W. Geringer, C. On, X. Chen (ORNL), T. Nozawa (QST)
}

\section{SUMMARY}

Four irradiated fusion material program HFIR rabbit capsules (F13A5, F8B1, F8B2, and F13B5) were disassembled during FY 2020. All capsules contained F82H specimen, silicon carbide thermometry (TM), and the parts used to keep the specimen and thermometry near the center of the capsule during irradiation. All capsules had a target irradiation temperature of $300^{\circ} \mathrm{C}$. F13A5 was irradiated for 9 cycles, F8B1 and F8B2 for 28 cycles, and F13B5 for 18 cycles. Disassembly was in the hot cells of the onsite Irradiated Materials Examination and Testing (IMET) facility. All disassembly procedures were developed and discussed with the hot cell operators before starting to ensure all necessary materials are present and to allow the scheduled disassembly to avoid predictable problems.

\section{DISSASSEMBLY AND DISPOSITION}

Capsule F13A5 contained four M4PCCVN specimens and two TMs. The disassembly process was as follows: cut end cap off irradiation capsule, shake specimen capsule out, remove internal material, identify specimens and TMs, store specimens at IMET and ship TMs to the low activation materials development and analysis (LAMDA) facility. Attempts to shake the specimens and TMs out of the specimen capsule were ultimately unsuccessful, so a pair of tweezers was used to gently push the internals out onto the tray for sorting and identification. Figure 99 shows the F13A5 components disassembled and awaiting identification. M4PCCVN specimens were later tested and photographed at IMET, and the TMs were measured and analyzed in LAMDA.

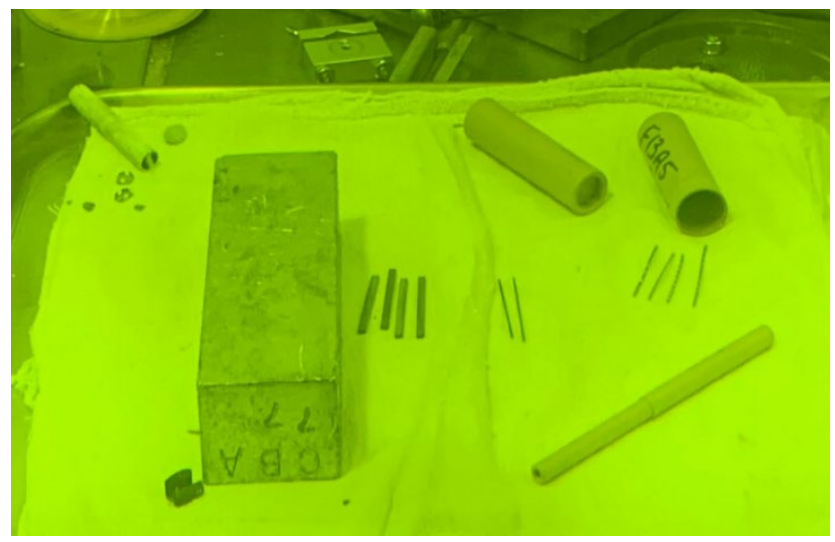

Figure 99. Image of disassembled F13A5 components. Four M3PCCVN bars are pictured center with $\mathrm{SiC}$ TMs to the right of them.

Disassembly of F8B1, F8B2, and F13B5 were performed within the same week as F13A5. Each capsule housed multiple SS-J3 tensile specimens and TMs. These capsules had been stored at IMET for about seven years before disassembly, and as a result the housing of the capsules had oxidized and the cardboard fiber tubes they were stored in disintegrated. Oxidation of all capsules made identification difficult, and the disintegration of the fiber tube left resin deposits on F8B1 and F8B2 which further complicated identification efforts. Condition of the capsules is shown in Figure 100 and Figure 101. Although F13B5 didn't have resin deposits, it was damaged during HFIR irradiation cycle 465. This damage resulted in a dark, almost rusted and worn appearance of the housing which made the identifying marks difficult to see. 
Due to this damage, some internal parts (not the specimens or TMs) of F13B5 were damaged. Figure 102 shows the F13B5 housing after cutting and removing the specimen holder, with the top and bottom support disk and centering thimble shown on the right and left side of the housing. The fragments on the right side of the image were the top support disk that broke during irradiation.

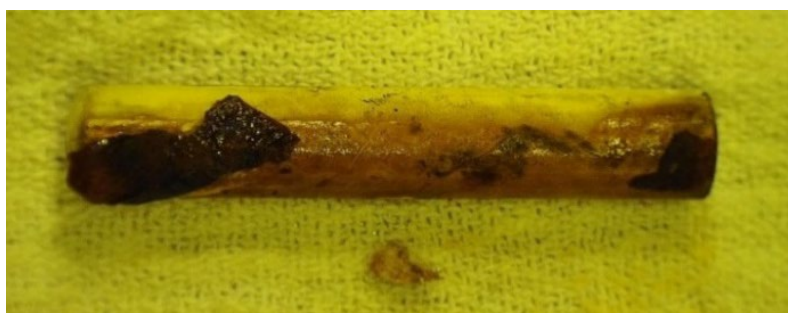

Figure 100. Irradiation capsule F8B1. Dark brown markings believed to be resin residue from fiber tube disintigration.

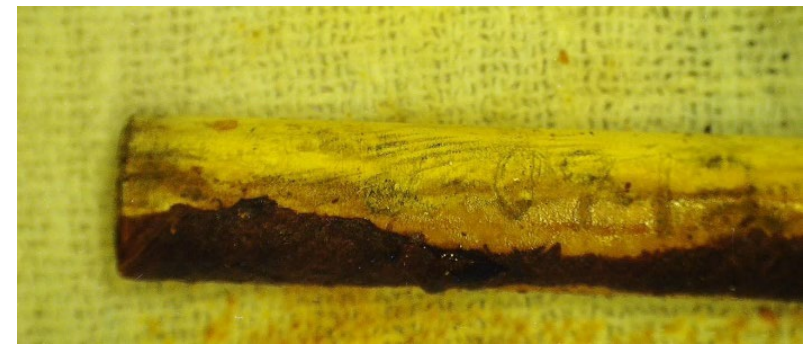

Figure 101. Irradiation capsule F8B2. Dark brown at bottom of tube believed to be resin residue from fiber tube disintegration.

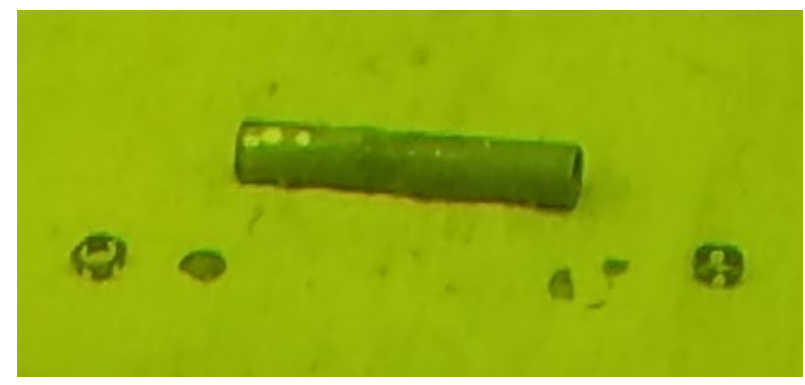

Figure 102. Irradiation capsule F13B5. The worn housing and broken right support disk are a result of damage suffered during irradiation.

Similar disassembly procedures were used for each irradiation capsule (F8B1, F8B2, and F13B5): cut end cap off irradiation capsule, shake specimen capsules loose, use a paint pen to mark the internals while they're still inside the specimen capsule, dislodge internal material from specimen capsule, identify all parts, store and ship to testing location. For all three disassembly's a white paint pen was used to mark the end of the specimen capsule closest to the housing end cap and a yellow paint pen was used to mark the opposite end, as shown in Figure 103. Since each capsule had three rows of specimens and TMs, these paint markings were used to preserve orientation and determine arrangement of specimens and TMs within the capsule. Figure 104 shows how sorting was performed based on these paint markings. All internal material came out with just shaking, so no tweezers were needed to dislodge specimens or TMs. The SSJ3 specimens from the three capsules will remain at IMET for testing and fractography, while the TMs from all capsules have been sent to LAMDA for evaluation. 


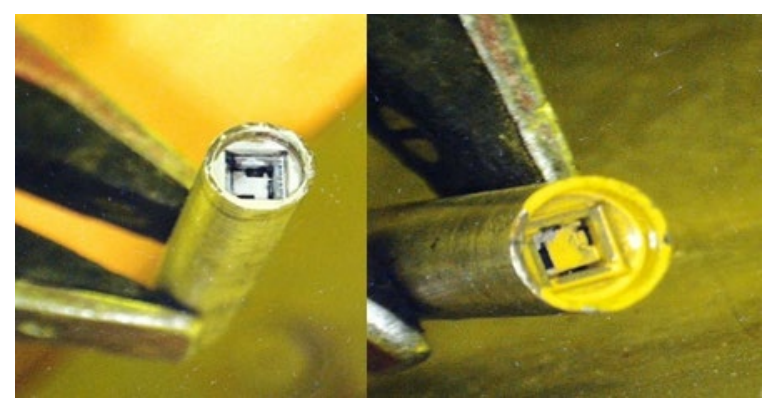

Figure 103. Paint pen marking used to preserve orientation and determine arrangement of specimen within the capsule.

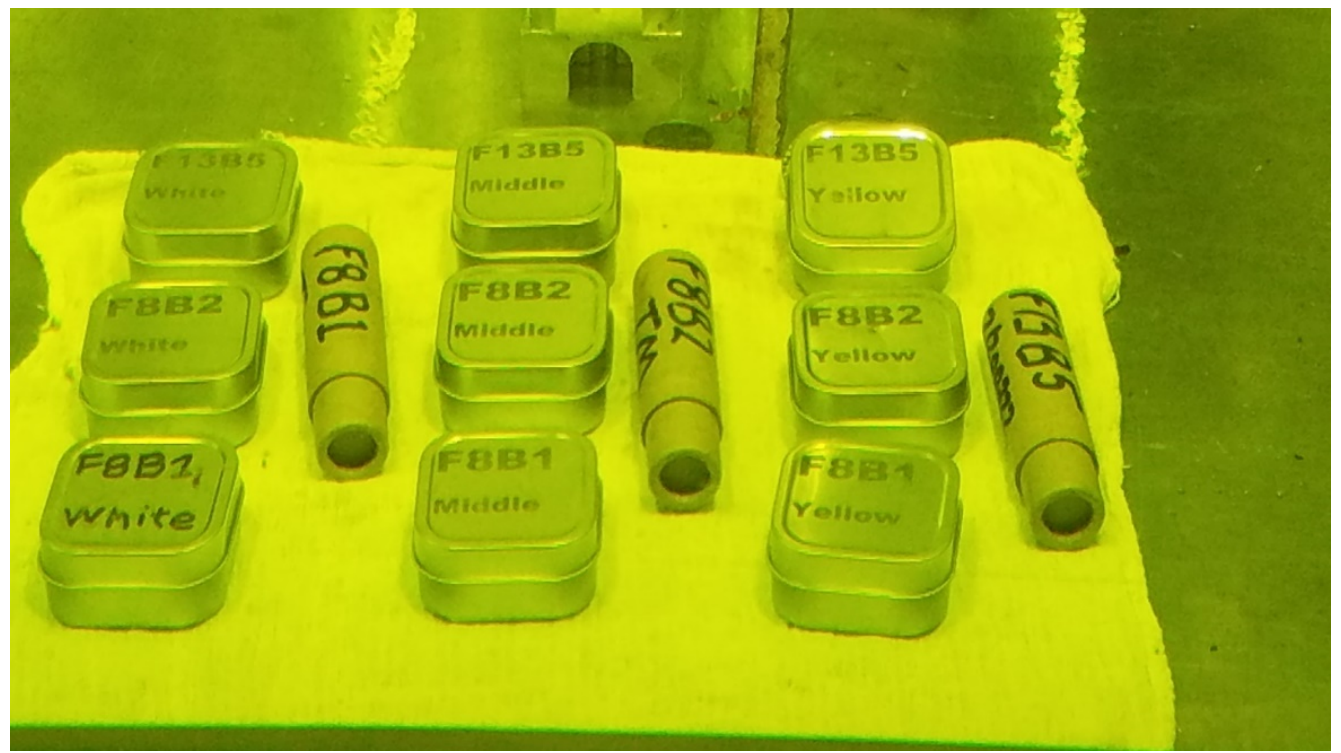

Figure 104. Specimens were divided into white, middle, and yellow rows based on the paint pen markings made during disassembly. The metal cans contain specimen from these rows for storage at IMET and the fiber tubes contain TMs to be shipped to LAMDA. 


\subsection{HFIR IRRADIATION EXPERIMENTS}

C.On(onc1@ornl.gov,J.W. Geringer, J.L.McDuffee (ORNL)

\section{SUMMARY}

Neutron irradiation experiments were performed in support of the research and development of fusion reactor materials using various materials irradiation facilities in the High Flux Isotope Reactor (HFIR). The reactor operating history for the fiscal year is detailed in Table 9.

Table 9. HFIR Operating Record for FY2020

\begin{tabular}{|c|c|c|}
\hline Cycle Number & Cycle End Date & Power (MWD) \\
\hline 484 & Nov. 24, 2019 & 2188.57 \\
\hline $485^{*}$ & Jan. 19, 2020 & 2139.36 \\
\hline 486 & February 24 & 2126.02 \\
\hline 487 & May 23 & 2136.99 \\
\hline $488^{*}$ & July 7 & 2164.62 \\
\hline 489 & September 12 & 2154.24 \\
\hline
\end{tabular}

*Cycles were in two parts, due to reactor scrams

All fusion materials program irradiation experiments during FY2020 used the nominally two-inch rabbit capsules, with no full-length target rod nor instrumented reflector position capsules in that period. Thirtyfour target zone rabbit capsules remain in the reactor to complete the scheduled irradiations. Table 10 lists the experiments loaded into HFIR in FY2020, with bold type face indicating the eleven short-term irradiations completed in the year. The capsules listed in Table 11 were inserted before FY2020 and will continue in FY2021 and beyond. Table 10 and Table 11 give condensed information on the material, specimen type, temperature, fluence, and period of irradiation. 
Table 10. New Irradiation Capsules Starting Irradiation in FY2020. The eleven that completed irradiation are indicated in bold.

\begin{tabular}{|c|c|c|c|c|c|c|c|c|}
\hline $\begin{array}{l}\text { Experiment } \\
\text { Designation }\end{array}$ & $\begin{array}{l}\text { Primary } \\
\text { Materials }\end{array}$ & $\begin{array}{l}\text { Specimen } \\
\text { Types }\end{array}$ & $\begin{array}{l}\text { Irradiation } \\
\text { Temperature } \\
\left({ }^{\circ} \mathrm{C}\right)\end{array}$ & $\begin{array}{c}\text { Max } \\
\text { Exposure } \\
\text { (dpa) }\end{array}$ & $\begin{array}{l}\text { Number } \\
\text { of Reactor } \\
\text { Cycles }\end{array}$ & \multicolumn{3}{|c|}{$\begin{array}{l}\text { HFIR Cycles } \\
\text { Start - End }\end{array}$} \\
\hline JCR11-03 & $\mathrm{SiC} / \mathrm{SiC}$ & Mini bend bars & 950 & 200 & 100 & 487 & - & 586 \\
\hline FMP01* & Cu Alloys & Tensile/MPC** & 100 & 5 & 3 & 485 & - & 487 \\
\hline FMP02* & F82H & Tensile & 250 & 5 & 3 & 484 & - & 486 \\
\hline FMP03* & F82H & Tensile & 200 & $5-7$ & 3 & 484 & - & 486 \\
\hline FMP04* & F82H & Tensile/MPC $* * *$ & 300 & 5 & 3 & 484 & - & 486 \\
\hline FMP05* & F82H & Tensile/MPC** & 350 & 5 & 3 & 484 & - & 486 \\
\hline FMP06* & F82H & Tensile/MPC** & 300 & $5-7$ & 3 & 484 & - & 486 \\
\hline FMP07 & $\mathrm{F} 82 \mathrm{H}$ & Tensile & 300 & 20 & 11 & 487 & - & 497 \\
\hline FMP08 & F82H & Tensile & 300 & 80 & 45 & 487 & - & 531 \\
\hline FМР09* & F82H & Tensile/MPC ${ }^{* *}$ & 350 & $5-7$ & 3 & 484 & - & 486 \\
\hline FMP10* & F82H & Tensile/MPC** & 385 & $5-7$ & 3 & 484 & - & 486 \\
\hline FMP11 & $\mathrm{F} 82 \mathrm{H}$ & Tensile & 385 & 20 & 11 & 488 & - & 498 \\
\hline FMP12 & $\mathrm{F} 82 \mathrm{H}$ & Tensile & 385 & 80 & 45 & 488 & - & 532 \\
\hline FMP13* & F82H & Tensile & 450 & 5-7 & 3 & 484 & - & 486 \\
\hline FMP14 & $\mathrm{F} 82 \mathrm{H}$ & Tensile & 525 & 20 & 11 & 484 & - & 494 \\
\hline FMP15* & F82H & Tensile/MPC ** & 650 & $5-7$ & 3 & 484 & - & 486 \\
\hline FMP16 & $\mathrm{F} 82 \mathrm{H}$ & Tensile/MPC** & 650 & 20 & 11 & 484 & - & 494 \\
\hline FMP17 & $\mathrm{F} 82 \mathrm{H}$ & Tensile/MPC** & 650 & 80 & 45 & 484 & - & 528 \\
\hline FMP19* & $\mathrm{CeO}_{2}, \mathrm{~W}$ & Discs & 500 & 1.6 & 1 & 487 & - & 487 \\
\hline FMP22 & $\mathrm{F} 82 \mathrm{H}$ & Bend Bars & 300 & 20 & 11 & 488 & - & 498 \\
\hline FMP23 & $\mathrm{F} 82 \mathrm{H}$ & Bend Bars & 300 & 80 & 45 & 488 & - & 532 \\
\hline
\end{tabular}

*Completed irradiation this reporting period

**MPC $=$ Multi-Purpose Coupon 
Table 11. The HFIR fusion materials program rabbit capsules to continue irradiation in FY2021

\begin{tabular}{|c|c|c|c|c|c|c|c|c|}
\hline $\begin{array}{l}\text { Experiment } \\
\text { Designation }\end{array}$ & $\begin{array}{l}\text { Primary } \\
\text { Materials }\end{array}$ & $\begin{array}{l}\text { Specimen } \\
\text { Types }\end{array}$ & $\begin{array}{l}\text { Irradiation } \\
\text { Temperature } \\
\left({ }^{\circ} \mathrm{C}\right)\end{array}$ & $\begin{array}{c}\text { Max } \\
\text { Exposure } \\
\text { (dpa) }\end{array}$ & $\begin{array}{l}\text { Number } \\
\text { of Reactor } \\
\text { Cycles }\end{array}$ & \multicolumn{3}{|c|}{$\begin{array}{l}\text { HFIR Cycles } \\
\text { Start - End }\end{array}$} \\
\hline F13B4 & $\begin{array}{c}\text { FeCrAlY } \\
\text { Steel }\end{array}$ & Tensile & 300 & 50 & 29 & 451 & - & 497 \\
\hline JCR11-05 & $\mathrm{SiC} / \mathrm{SiC}$ & Mini bend bars & 950 & 200 & 115 & 444 & - & 568 \\
\hline JCR11-07 & $\mathrm{SiC} / \mathrm{SiC}$ & Mini bend bars & 950 & 100 & 47 & 444 & - & 492 \\
\hline JCR11-08 & $\mathrm{SiC} / \mathrm{SiC}$ & Mini bend bars & 950 & 200 & 115 & 444 & - & 560 \\
\hline JCR11-11 & $\mathrm{SiC} / \mathrm{SiC}$ & Mini bend bars & 950 & 100 & 55 & 448 & - & 524 \\
\hline SCF4 & $\mathrm{SiC} / \mathrm{SiC}$ & $\begin{array}{l}\text { Miniature } \\
\text { flexure bar }\end{array}$ & 250 & 100 & 90 & 457 & - & 547 \\
\hline SCF5 & $\mathrm{SiC} / \mathrm{SiC}$ & $\begin{array}{l}\text { Miniature } \\
\text { flexure bar }\end{array}$ & 250 & 200 & 45 & 457 & - & 511 \\
\hline SCF8 & $\mathrm{SiC} / \mathrm{SiC}$ & $\begin{array}{l}\text { Miniature } \\
\text { flexure bar }\end{array}$ & 600 & 100 & 45 & 457 & - & 502 \\
\hline SCF9 & $\mathrm{SiC} / \mathrm{SiC}$ & $\begin{array}{l}\text { Miniature } \\
\text { flexure bar }\end{array}$ & 600 & 200 & 90 & 457 & 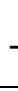 & 548 \\
\hline SCF11 & $\mathrm{SiC} / \mathrm{SiC}$ & $\begin{array}{l}\text { Miniature } \\
\text { flexure bar }\end{array}$ & 950 & 100 & 57 & 458 & - & 517 \\
\hline ES01 & $\begin{array}{c}\text { EUROFER } \\
97\end{array}$ & Tensile/MPC** & 220 & 20 & 12 & 479 & - & 491 \\
\hline ES02 & $\begin{array}{c}\text { EUROFER } \\
97\end{array}$ & Tensile/MPC** & 275 & 20 & 12 & 480 & 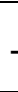 & 492 \\
\hline ES03 & $\begin{array}{c}\text { EUROFER } \\
97 \\
\end{array}$ & Tensile/MPC** & 275 & 20 & 12 & 479 & - & 491 \\
\hline ES04 & $\begin{array}{c}\text { EUROFER } \\
97 \\
\end{array}$ & Tensile/MPC** & 300 & 20 & 12 & 479 & - & 491 \\
\hline ES05 & $\begin{array}{c}\text { EUROFER } \\
97 \\
\end{array}$ & Tensile/MPC ** & 325 & 20 & 12 & 479 & - & 491 \\
\hline ES06 & $\begin{array}{c}\text { EUROFER } \\
97\end{array}$ & Tensile/MPC** & 350 & 20 & 12 & 479 & - & 491 \\
\hline ES07 & $\begin{array}{c}\text { EUROFER } \\
97 \\
\end{array}$ & Tensile/MPC** & 375 & 20 & 12 & 479 & - & 491 \\
\hline ES11 & $\begin{array}{c}\text { EUROFER } \\
97\end{array}$ & Bend bars & 220 & 20 & 12 & 479 & - & 492 \\
\hline ES12 & $\begin{array}{c}\text { EUROFER } \\
97 \\
\end{array}$ & Bend bars & 240 & 20 & 12 & 479 & - & 492 \\
\hline ES13 & $\begin{array}{c}\text { EUROFER } \\
97\end{array}$ & Bend bars & 275 & 20 & 12 & 479 & 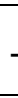 & 492 \\
\hline ES14 & $\begin{array}{c}\text { EUROFER } \\
97\end{array}$ & Bend bars & 300 & 20 & 12 & 479 & - & 492 \\
\hline ES15 & $\begin{array}{c}\text { EUROFER } \\
97 \\
\end{array}$ & Bend bars & 325 & 20 & 12 & 479 & - & 494 \\
\hline ES16 & $\begin{array}{c}\text { EUROFER } \\
97\end{array}$ & Bend bars & 350 & 20 & 12 & 479 & - & 494 \\
\hline ES17 & $\begin{array}{c}\text { EUROFER } \\
97 \\
\end{array}$ & Bend bars & 375 & 20 & 12 & 479 & - & 494 \\
\hline
\end{tabular}




\section{AWARDS, HONORS AND RECOGNITION}

\subsection{AWARDS DURING FY2020}

- Yutai Katoh received the 2019 UT-Battelle Distinguished Researcher Award (November 2019)

- Takaaki Koyanagi received the Global Star Award from The Engineering Ceramics Division of The American Ceramics Society at 2020 International Conference on Advanced Ceramics and Composites (Jan 26-31, 2020, Daytona Beach FL)

- Yutai Katoh received the Mishima Award of the American Nuclear Society, "for being a leading architect of today's nuclear grade ceramic composites," (Nov 17-21, Washington, DC) 


\subsection{PUBLICATION HONORS IN FY2020}

Two publications from the ORNL Fusion Materials Program were among the 25 Most Cited Articles published in Journal of Nuclear Materials since 2017

- Koyanagi, T., Kumar, N. K., Hwang, T., Garrison, L. M., Hu, X., Snead, L. L., \& Katoh, Y.. Microstructural evolution of pure tungsten neutron irradiated with a mixed energy spectrum, Journal of Nuclear Materials, 490 (2017)66-74

- Koyanagi, T., Katoh, Y., Nozawa, T., Snead, L. L., Kondo, S., Henager Jr, C. H., Ferraris M., Hinoki T., \& Huang, Q. Recent progress in the development of SiC composites for nuclear fusion applications, Journal of Nuclear Materials, , 511 (2018) 544-555

- While not Fusion Program articles, three more of the 25 included ORNL authors who spend part time on fusion tasks - Field, Howard, Hoelzer, Sridharan, Stoller, Yamamoto and Zinkle 


\subsection{PROFESSIONAL RECOGNITION IN FY2020 AND CONTINUING}

Anne Campbell

Philip Edmondson

$\underline{\text { Kevin Field }}$

$\underline{\text { Lauren Garrison }}$
Organizing Committee, MiNES

Organizing Committee, ICACC

Organizing Committee, MiNES

Cochair, DPP-CPP

Publicity Chair, ICFRM 19
October 2019

January 2020

October 2019

2019,2020

October 2019

\section{Yutai Katoh}

Co-organizer, Materials Science \& Technology (MS\&T) 2019

International Advisory Committee, ICFRM-19
October 2019

October 2019

International Advisory Board, Materials Challenges in Alternative \& Renewable Energy (MCARE 2020), July 2021

International Steering Committee, The $8^{\text {th }}$ International Ceramic Congress (ICC-8) April 2021, Busan, Korea

International Steering Committee, Pacific Rim Conference on Ceramic and Glass Technology, (PACRIM 14), May 2021, Vancouver

International Advisory Board, International Ceramics Congress and Forum on New Materials (CIMTEC 2021) June 2021, Italy

Takaaki Koyanagi Organizing Committee, ICACC January 2020

Chad Parish Secretary \& Executive Committee, The Microanalysis Society International Advisory Committee, ICFRM-20

October 2021, Granada, Spain 


\section{PUBLICATIONS AND PRESENTATIONS IN FY 2020}

\subsection{PAPERS PUBLISHED IN FY 2020}

Arunodaya Bhattacharya, Steven J. Zinkle, "Cavity swelling in irradiated materials," Chapter in Comprehensive Nuclear Materials Editors: Rudy J.M. Konings, Roger E. Stoller, Elsevier, (2020) 2nd edition, vol. 1, pp. 406-455; http://dx.doi.org/10.1016/B978-0-12-803581-8.11599-1

T. Nozawa, H. Sakasegawa, X. Chen, T. Kato, J.W. Geringer, Y. Katoh, H. Tanigawa, "Non-contact strain evaluation for miniature tensile specimens of neutron-irradiated F82H by digital image correlation," Fusion Engineering and Design 157 (2020) 111663

Xiang Chen, Mikhail A. Sokolov, Arunodaya Bhattacharya, Logan N. Clowers, Tim Graening, Yutai Katoh, Michael Rieth, "Master Curve Fracture Toughness Characterization of Eurofer97 Steel Variants Using Miniature Multi-Notch Bend Bar Specimens for Fusion Applications," Proceedings of the ASME PVP2019-93797 Volume 1: Codes and Standards. San Antonio, Texas, USA. July 14-19, 2019. V001T01A036. ASME. https://doi.org/10.1115/PVP2019-93797

Xiang (Frank) Chen, Mikhail A. Sokolov, Janet Robertson, Masami Ando, Josina W. Geringer, Hiroyasu Tanigawa, Yutai Katoh, "Effects of HFIR neutron irradiation on fracture toughness properties of standard and Ni-doped F82H,” Journal of Nuclear Materials 542, 15 December 2020, 152501;

https://doi.org/10.1016/j.jnucmat.2020.152501

T. Nozawa, H. Sakasegawa, X. Chen, T. Kato, J.W. Geringer, Y. Katoh, H. Tanigawa, Non-contact strain evaluation for miniature tensile specimens of neutron- irradiated $\mathrm{F} 82 \mathrm{H}$ by digital image correlation, Fusion Eng. Des. 157 (2020) 111663. doi:10.1016/j.fusengdes.2020.111663.

Philip D Edmondson, Baptiste Gault and Mark R Gilbert, "An atom probe tomography and inventory calculation examination of second phase precipitates in neutron irradiated single crystal tungsten," Nuclear Fusion 60 (2020) 126013; https://doi.org/10.1088/1741-4326/abb149

L.M. Garrison, A.S. Sabau, B. Gregory, J.W. Geringer, Y. Katoh, Y. Hamaji, A. Hasegawa, Plasma-arc lamp high heat flux cycling exposure of neutron irradiated tungsten materials, Physica Scripta T171 (2020) 14077; doi:10.1088/1402-4896/ab47b1.

T. Miyazawa, L.M. Garrison, J.W. Geringer, M. Fukuda, Y. Katoh, T. Hinoki, A. Hasegawa, "Neutron irradiation effects on the mechanical properties of powder metallurgical processed tungsten alloys" Journal of Nuclear Materials 529 (2020) 151910; doi:10.1016/j.jnucmat.2019.151910

M. Shimada, Y. Oya, W.R. Wampler, Y. Yamauchi, C.N. Taylor, L.M. Garrison, D.A. Buchenauer, and Y. Hatano, "Deuterium Retention in Neutron-Irradiated Single-Crystal and Polycrystalline Tungsten," Fusion Engineering and Design 136 Part B (2018) 1161-1167

Eric Lang, Nathan Reid, Lauren Garrison, Chad Parish, J.P. Allain. "Pre-irradiation comparison of Wbased alloys for the PHENIX campaign: microstructure, composition, and mechanical properties," Fusion Science and Technology, 75 (2019) 533-541

Nathan C. Reid, Lauren M. Garrison, Chase N. Taylor, and Jean Paul Allain, "Elemental Characterization of Neutron Irradiated Tungsten Using the GD-OES Technique," Fusion Science and Technology, 75 (2019) 510-519 
C. Li, X. Hu, T. Yang, NAP Kiran Kumar, B.D. Wirth, S.J. Zinkle, "Neutron irradiation response of a Cofree high entropy alloy," Journal of Nuclear Materials 527 (2019) 151838

Guiyang Huang, Xunxiang Hu, Brian D. Wirth, "First-principles investigations of hydrogen trapping in Y2O3 and the Y2O3|bcc Fe interface," Journal of Physics: Condensed Matter, 32 (2020) 495001; https://doi.org/10.1088/1361-648X/abb17e

Guinevere Shaw, Wendy Garcia, Xunxiang Hu, Brian Wirth, "Investigating Helium - Deuterium Synergies in Plasma-Exposed Tungsten using Laser Ablation Techniques," Physica Scripta T171 (2020) 014029

J. Jun, P. F. Tortorelli, "Corrosion in Other Liquid Metals (Li, PbLi, Hg, Sn, Ga)," Chapter 4.18 in Comprehensive Nuclear Materials (Second Edition), Editors: Rudy J.M. Konings, Roger E. Stoller, Elsevier, 2020, pp 515-527

J. Jun, K. A. Unocic, M. J. Lance, H. M. Meyer and B. A. Pint, "Compatibility of FeCrAlMo with flowing PbLi at $500^{\circ}-650^{\circ} \mathrm{C}$," Journal of Nuclear Materials, 528 (2020) 151847

C.E. Kessel, D. Andruczyk, J.P. Blanchard, T. Bohm, A. Davis, K. Hollis, P.W. Humrickhouse, M. Hvasta, M. Jaworski, J. Jun, Y. Katoh, A. Khodak, J. Klein, E. Kolemen, G. Larsen, R. Majeski, B.J. Merrill, N.B. Morley, G.H. Neilson, B. Pint, M.E. Rensink, T.D. Rognlien, A.F. Rowcliffe, S. Smolentsev, M.S. Tillack, L.M. Waganer, G.M. Wallace, P. Wilson, S.J. Yoon, Critical Exploration of Liquid Metal Plasma-Facing Components in a Fusion Nuclear Science Facility, Fusion Sci. Technol. 75 (2019) 886-917; doi:10.1080/15361055.2019.1610685

Yutai Katoh, Lance L. Snead, "Silicon carbide and its composites for nuclear applications - Historical overview," Journal of Nuclear Materials 526 (2019) 151849; doi:10.1016/j.jnucmat.2019.151849

L.L. Snead, Y. Katoh, T. Nozawa, Radiation Effects in SiC and SiC-SiC, Chapter in: Konings, Rudy JM and Stoller Roger E (eds.) Comprehensive Nuclear Materials 2nd edition, vol. 3, pp. 437-461. Oxford: Elsevier, doi:10.1016/B978-0-12-803581-8.11781.3.

A. Lumsdaine, R. Maingi, K. Field, S. Gourlay, D. Humphreys, Y. Katoh, C. Kessel, X. Wang, Perspectives on the FESAC Transformative Enabling Capabilities : Priorities, Plans and Status, Fusion Eng. Des. 155 (2020) 111529. doi:10.1016/j.fusengdes.2020.111529.

T. Koyanagi, Y. Katoh, T. Hinoki, C. Henager, M. Ferraris, S. Grasso, "Progress in development of SiCbased joints resistant to neutron irradiation," Journal of the European Ceramic Society, 40 (2020) 10231034; doi:10.1016/j.jeurceramsoc.2019.10.055

T. Koyanagi, Y. Katoh, T. Nozawa, "Design and strategy for next-generation silicon carbide composites for nuclear energy," Journal of Nuclear Materials 540 (November 2020), 152375; https://doi.org/10.1016/j.jnucmat.2020.152375

S. Agarwal, T. Koyanagi, A. Bhattacharya, L. Wang, Y. Katoh, X. Hu, M. Pagan and S.J. Zinkle, "Neutron irradiation-induced microstructure damage in ultra-high temperature ceramic TiC", Acta Materialia 186 (2020) 1-10. https://doi.org/10.1016/j.actamat.2019.12.022 
D.J. Sprouster, L.L Snead, E. Dooryhee, S.K. Ghose, T. Koyanagi and Y. Katoh, "Pair Distribution Function Analysis of Neutron-Irradiated Silicon Carbide", Journal of Nuclear Materials 527 (2019) 151798

C.P. Massey, P.D. Edmonson, K.A. Unocic, Y. Yang, S.N. Dryepondt, A. Kini, B. Gault, K. Terrani and S.J. Zinkle, "The effect of $\mathrm{Zr}$ on precipitation in oxide dispersion strengthened FeCrAl alloys," Journal of Nuclear Materials, 533, (2020) 152105

Yuri Osetsky, Rodney David, “Atomic-Level Dislocation Dynamics in Irradiated Metals,” In:

Comprehensive Nuclear Materials $2^{\text {nd }}$ edition, vol. 1, Editors: Rudy J.M. Konings, Roger E. Stoller, Elsevier, 2020, pp. 663-688; http://dx.doi.org/10.1016/B978-0-12-803581-8.00662-7

E. Zarkadoula, G. Samolyuk, Y. Zhang, W.J. Weber, "Electronic stopping in molecular dynamics simulations of cascades in 3C-SiC", Journal of Nuclear Materials 540 (2020) 152371; https://doi.org/10.1016/j.jnucmat.2020.152371

L. Tan, T. Graening, X. Hu, W. Zhong, Y. Yang, S.J. Zinkle, Y. Katoh, "Effects of carbonitrides and carbides on microstructure and properties of castable nanostructured alloys," Journal of Nuclear Materials, 540 (2020) 152376; doi:10.1016/j.jnucmat.2020.152376.

L. Tan, W. Zhong, T. Chen, "Microstructural stability of tantalum-alloyed ferritic-martensitic steel with neutron irradiation to $7.4 \mathrm{dpa}$ at $\sim 490^{\circ} \mathrm{C}$," Materialia 9 (2020) 100608

W. Zhong, L. Tan, "Radiological analysis and transmutation calculation of representative castable nanostructured alloys," Fusion Engineering and Design 160 (2020) 111899

H. Wang, T. Koyanagi, J.W. Geringer, A.A. Campbell, Y. Katoh, "Determination of neutron irradiation temperatures of SiC using electrical resistivity method," Journal of Nuclear Materials, 540 (2020) 152370; doi:10.1016/j.jnucmat.2020.152370.

L. Wang, C. Zheng, B. Kombaiah, L. Tan, D.J. Sprouster, L.L. Snead, S.J. Zinkle, Y. Yang, "Contrasting roles of Laves- $\mathrm{Cr}_{2} \mathrm{Nb}$ precipitates on the creep properties of novel $\mathrm{CuCrNbZr}$ alloys," Materials Science and Engineering A 779 (2020) 139110

J. Brechtl, H. Wang, N.A.P. Kiran Kumar, T. Yang, Y-R Lin, H. Bei, J. Neuefeind, W. Dmowski, and $\underline{\mathrm{S}}$, J. Zinkle, "Investigation of the thermal and neutron irradiation response of BAM-11 bulk metallic glass," Journal of Nuclear Materials, 526 (2019) article 151771. https://doi.org/10.1016/j.jnucmat.2019.151771.

J. Brechtl, S. Agarwal, M. L. Crespillo, T. Yang, H. Bei, and S. J. Zinkle, "Investigation of the mechanical and microstructural evolution of a $\mathrm{Cu}$ based bulk metallic glass during ion irradiation", Intermetallics 116 (2020) 106655. https://doi.org/10.1016/j.intermet.2019.106655

J. Brechtl, M.L. Crespillo, S. Agarwal, H. Bei and S.J. Zinkle, "Effects of irradiation spectrum on the microstructural and mechanical properties of bulk metallic glasses", Journal of Nuclear Materials, 533 (2020) 152084. https://doi.org/10.1016/j.jnucmat.2020.152084 


\subsection{REPORTS ISSUED IN FY 2020}

F.W. Wiffen, Y. Katoh, S. Melton, "Fusion Materials Research at Oak Ridge National Laboratory in Fiscal Year 2019," ORNL/TM-2020/1456, February 2020

A.Bhattacharya, X. Chen, T. Graening, J. Reed, J.W. Geringer, Katoh, “ Post-irradiation examination of Eurofer97 steel variants irradiated to $2.5 \mathrm{dpa}, \sim 300^{\circ} \mathrm{C}$ in HFIR for the EUROfusion program," 2020, ORNL/SPR-2020/1440. (A EUROfusion Report-Sponsor Controlled)

X. Chen, R. Hernandez Pascual, M. Serrano, D. Andrew, H. Nolles, M.A. Sokolov, "Guidelines for IAEA Small Specimen Test Techniques Master Curve Fracture Toughness Testing," ORNL/LTR-2020/27, July 2020 


\subsection{PAPERS SUBMITTED IN FY 2019 -2020 (Currently awaiting publication)}

Arunodaya Bhattacharya, Jean Henry, Estelle Meslin, Brigitte Decamps, "The effect of helium on dislocation loop microstructure in FeCr ferritic alloys," under review for Acta Materialia

Yan-Ru Lin, Arunodaya Bhattacharya, Da Chen, Ji-Jun, Kai, Jean Henry, Steve Zinkle, "Temperature dependent void swelling behavior in Fe and $\mathrm{FeCr}$ ferritic alloys," under review for Acta Materialia

Xiang Chen, Logan N. Clowers, Tim Graening, Arunodaya Bhattacharya, Anne A. Campbell, Janet Robertson, Josina W. Geringer, Mikhail A. Sokolov, Yutai Katoh, Michael Rieth, "Post-irradiation Evaluation of Eurofer97 Fracture Toughness Using Miniature Multinotch Bend Bar Specimens," accepted, ASME PVP2020-21312

Elizabeth A.I. Ellis, Michael A. Sprayberry, Christopher Ledford, Jameson P. Hankwitz, Michael M. Kirka, Chris D. Rock, Timothy J. Horn, Yutai Katoh, Ryan R. Dehoff; and "Processing of Tungsten Through Electron Beam Melting," submitted and in revision for Journal of Nuclear Materials

P.D. Edmondson, "An elemental and molecular filtering method for atom probe desorption maps," submitted to MethodsX

P.D. Edmondson, B Gault, M R Gilbert, "An atom probe tomography and inventory calculation examination of second phase precipitates in neutron irradiated single crystal tungsten," submitted to Nuclear Fusion

Cuncai Fan, Congyi Li, Chad M. Parish, Yutai Katoh, Xunxiang Hu. "Helium effects on the surface and subsurface evolutions in single-crystalline tungsten," in revision for Acta Materialia, August 2020

Takeshi Miyazawa, Lauren M. Garrison, Josina W. Geringer, John R. Echols, Makoto Fukuda, Yutai Katoh, Tatsuya Hinoki, and Akira Hasegawa, "High-temperature tensile properties of powdermetallurgical-processed tungsten alloys after neutron irradiation near recrystallization temperatures," submitted to Journal of Nuclear Materials, April 2020

Masafumi Akiyoshi, Lauren M. Garrison, Josina W. Geringer, Hsin Wang, Akira Hasegawa, Shuhei Nogami, and Yutai Katoh. "Thermal diffusivity of irradiated tungsten and tungsten rhenium alloys," submitted to Journal of Nuclear Materials, April 2020

Katherine Haynes, Xunxiang Hu, Congyi Li, Brian Wirth, Christopher Hatem, and Kevin Jones, "Influence of Dose Rate on Defects Formed in Silicon during Elevated Temperature Helium Implantation," submitted to Nuclear Inst. and Methods in Physics Research, B

Ze Chen, Xunxiang Hu, Minyou Ye, and Brian D. Wirth, "Deuterium transport and retention properties of representative fusion blanket structural materials", submitted to Journal of Nuclear Materials, August 2020

Jamieson Brechtl, Shradha Agarwal, Xunxiang Hu, Di Chen, Matt Chancey, Hongbin Bei, Yongqiang Wang, Steven Zinkle, "Helium diffusion in amorphous and crystallized bulk metallic glasses," in revision for Journal of Nuclear Materials

Chase N. Taylor, Masashi Shimada, Joseph M. Watkins, Xunxiang Hu, Yasuhisa Oya, "Neutron irradiated tungsten bulk defect characterization by positron annihilation spectroscopy," in revision for Nuclear Materials and Energy 
Y. Katoh, L.L. Snead, "Radiation Effects in SiC and SiC-SiC," Comprehensive Nuclear Materials $2^{\text {nd }}$ Edition, Elsevier

D. J. Sprouster, J. R. Trelewicz, L. L. Snead, X. Hu, D. Morrall, T. Koyanagi, C.M. Parish, L. Tan, Y. Katoh, and B.D. Wirth, "Advanced synchrotron characterization techniques for fusion materials science," in revision for Journal of Nuclear Materials

H. Li, T. Koyanagi, C. Ang, Y. Katoh, "Electric current-assisted direct joining of silicon carbide," accepted by Journal of the European Ceramics Society

T. Koyanagi, Kurt Terrani, Shay Harrison, Jian Liu, Yutai Katoh, "Additive manufacturing of silicon carbide for nuclear applications," submitted and in review for Journal of Nuclear Materials

D. Morrall, M. Baldwin, R. Doerner, and C. Parish, "Evaluation of bubble layers in tungsten after He plasma exposure," submitted to Nuclear Fusion

Yuri Osetsky, "Atomic scale mechanisms of void strengthening in tungsten," accepted for Tungsten, (2020)

J. Coburn, T. Gebhart, C. Parish, E. Uterberg, J. Canik, M. Barsoum, M. Bourham, "Surface Erosion of Plasma-Facing Materials Using an Electrothermal Plasma Source and Ion Beam Micro-Trenches," submitted to Fusion Science and Technology (2019)

G Samolyuk, Y Osetsky, "Equilibrium distribution of point defects in Fe-Y-O as a typical representative of nanocluster-strengthened alloy," submitted and in review for Journal of Nuclear Materials

L. Tan, J.D. Poplawsky, Y. Yang, "Effects of niobium and tantalum on the microstructure and strength of advanced ferritic-martensitic steels," submitted to Scripta Mater.

W. Zhong, L. Tan, "Radiological analysis and transmutation calculation of representative castable nanostructured alloys," submitted to Fusion Engineering and Design 


\subsection{PRESENTATIONS DELIVERED}

At MS\&T 19. Portland, OR, September 29-October 3, 2019

\section{Invited Presentation}

Y. Katoh, T. Koyanagi, X. Hu, G. Singh, K.A. Terrani, J.W. Geringer, A.L. Qualls, Y. Lee, S. Raiman, L.L. Snead, B.D. Wirth, C. Deck, P. Xu, C. Sauder, S. Gonczy, M. Jenkins, "Silicon Carbide-based CMC for Nuclear Applications - Opportunities and Challenge"

\section{Oral Presentation}

Xunxiang Hu, Chad Parish, Kun Wang, Takaaki Koyanagi, Benjamin Eftink, Yutai Katoh,

"Transmutation-induced Precipitation in Tungsten Irradiated with a Mixed Energy Neutron Spectrum"

\section{At MiNES 2019, Baltimore, MD, October6-10, 2019}

A. Bhattacharya, , A.R. Lupini, S.M. Levine, D.T. Hoelzer, Y.Katoh, S.J. Zinkle, "High dose neutron irradiation-induced microstructure evolution in ODS alloys"

At the 6th International Symposium on Liquid Metals Applications for Fusion, Urbana, IL, September 30-October 3, 2019

\section{Oral presentation}

J. Jun and B. A. Pint, "Compatibility of Alumina-Forming Steels in liquid Li, Sn and Sn-20at\%Li"

At ICFRM 19, The $19^{\text {th }}$ International Conference on Fusion Materials, La Jolla, CA, October 27November 1,2019

\section{Plenary Presentation}

Y. Katoh, "Project PHENIX for Technological Assessment of Plasma Facing Components for DEMO Reactors: Summary of Materials Research Accomplishments"

\section{Invited Preconference Tutorial}

C. Parish, "STEM and AEM Applications in Fusion Materials"

\section{Invited Oral Presentations}

A. Bhattacharya, "Irradiation Effects and Advanced Characterization of Neutron and Ion Irradiated Titanium Diboride"

S. Dryepondt, C.P. Massey, P.D. Edmonson, K.A. Unocic, D. T. Hoelzer, Y. Yang and S. J. Zinkle, "Long-Term Creep Resistant ODS FeCrAlZr Alloys With Improved Pb-Li Compatibility"

K. Field, "Structure-Property Relationships for 12-18\%Cr ODS And 9\% Cr RAFM Steels Irradiated To High Dose (> $40 \mathrm{dpa}$ ) at Fusion Relevant Temperatures" 
Lauren M. Garrison, Adrian S. Sabau, Masafumi Akiyoshi, Chad Parish, Benjamin Gregory, Josina W. Geringer, Yutai Katoh, Yukinori Hamaji, and Akira Hasegawa. "Thermal, Mechanical, and Microstructural Changes in Plasma-Arc Lamp High Heat Flux Exposed Neutron Irradiated Tungsten."

X. Hu, "Overview of Transmutation-Induced Precipitation in Tungsten during Neutron Irradiation"

T. Koyanagi, Y. Katoh, Y. Ying, B. Jolly, R. Lowden, C. Ang, J. Kabel, P. Hosemann, T. Nozawa, L. Snead, "Design and Strategy for Next Generation Silicon Carbide Composites for Fusion Energy"

Y. N. Osetsky, "What is the Maximum Possible Strengthening Due to Localized Obstacles in Ferritic Alloys?"

C. Parish, A. Bhattacharya, "High-Throughput Phase-Chemistry Mapping of Nano-Precipitates in RAFM Steels by Transmission Kikuchi Diffraction and Analytical Electron Microscopy"

M. Sokolov, "IAEA Coordinated Research Project on Small Specimen Test Techniques For Fusion Applications"

L. Tan, "Development of Castable Nanostructured Alloys as U.S. Reduced Activation Ferritic-Martensitic Steel"

\section{Contributed Oral Presentations}

X. Chen, M.A. Sokolov, J. Robertson, L.N. Clowers, J.W. Geringer, Y. Katoh, H. Tanigawa, "Effects of Neutron Irradiation on Fracture Toughness Properties of Standard and Ni-doped F82H Steels"

Y. Yang, "Tensile and Thermal Creep Behavior of a Novel Copper Alloy for Fusion Energy Applications"

\section{Poster Presentations}

Arunodaya Bhattacharya, Xiang Chen, Josina W. Geringer, Tim Graening, Yutai Katoh, Michael Rieth, "Microstructure and Property Degradation of EUROFER 97 in Non-Standard Metallurgical Conditions"

Samara M. Levine, Arunodaya Bhattacharya, Andrew R. Lupini, David T. Hoelzer, Josina W. Geringer, Yutai Katoh, Steven J. Zinkle, "Dispersoid Nanostructure of PM2000 ODS Steel After $>80$ dpa Neutron Irradiation"

Y. Zhao, A. Bhattacharya, P.D. Edmondson, C. Massey, C. Pareige, J. Henry, S.J Zinkle, "Dose rate and temperature effect on irradiation enhanced $\alpha$ ' phase separation in high purity $\mathrm{FeCr}$ alloys"

Y.R. Lin, A. Bhattacharya, J. Henry, S.J. Zinkle, "Void swelling in high purity Fe and FeCr alloys : Peak swelling temperatures and carbon effect"

Y. Li, A. Bhattacharya, Y. Zhao, J. Henry, S.J. Zinkle, "Effect of Cr and C on dislocation loops in heavy ion irradiated ultra high purity $\mathrm{FeCr}$ alloys" 
Anne A. Campbell, Jordan D. Reed, Josina W. Geringer, Kurt R. Smith, Padhraic L. Mulligan, Yutai Kato, Masami Ando2, Dai Hamaguchi2 "Irradiation Creep of F82H Measured Using Pressurized Tubes Irradiated in the HFIR"

X. Chen, A. Bhattacharya, T. Graening, A.A. Campbell, L.N. Clowers, M.A. Sokolov, J. Robertson, J.W. Geringer, K.D. Linton, Y. Katoh, M. Rieth, "Post-Irradiation Evaluation of Eurofer97 Fracture Toughness Using Miniature Multinotch Bend Bar Specimens"

John Echols, Lauren M. Garrison, Yutai Katoh, Masafumi Akiyoshi, "Electrical Resistivity of Irradiated Tungsten"

John R. Echols, A.L.Winfrey, "Evaluation of Tungsten Surface Damage over High Heat Flux Exposure Range with the Helios Device"

Matheus A Tunes, Stephen E Donnelly, Philip D Edmondson, “Accelerated Radiation Effects in MAX Phases at High Temperatures"

P. Edmondson, "Radiation Effects in High Temperature Superconductors: Current Progress and Perspectives"

Elizabeth A.I. Ellis, Michael M. Kirka, Chase B. Joslin, Lauren M. Garrison, Christopher Ledford, Sullivan Figurskey, Chris Rock, Timothy Horn, Yutai Katoh, Ryan R. Dehoff, "Additive Manufacturing of Model Tungsten Fusion Components"

Lauren M. Garrison, John Echols, Nathan Reid, Takeshi Miyazawa, Yutai Katoh, Wilna Geringer, Masafumi Akiyoshi, Xiang Chen, Tim Graening, Akira Hasegawa, Tatsuya Hinoki, Eric Lang, Chad Parish, Hsin Wang. "Mechanical and Thermal Property Changes In Irradiated Tungsten"

Josina W. Geringer, Xiang Chen, Philip Edmondson, Xunxiang Hu, Hsin Wang, Anne Campbell, Arunodaya Bhattacharya, Kory Linton, Yutai Katoh, "Recent Enhancement of ORNL PIE Capabilities"

David T. Hoelzer, Ian A. Stinson and Caleb P. Massey, "Investigating the Benefit of $1 \% \mathrm{~W}$ on the Microstructure and Mechanical Properties of ODS Fe-10Cr Alloys"

Richard H. Howard, Ryan C. Gallagher, Josina W. Geringer, Yutai Katoh, "Using Surface Response Methods to Rapidly and Efficiently Design HFIR Fusion Materials Irradiation Capsules"

Xunxiang Hu, Lizhen Tan, David T. Hoelzer, Yutai Katoh, Guiyang Huang, Ze Chen, Brian D. Wirth, "Deuterium Retention in Advanced Steels for Fusion Structural Applications"

J. Jun, K. A. Unocic, M. Romedenne, and B. A. Pint, "Compatibility of Alumina-forming Steel in Flowing PbLi at $600^{\circ}-700^{\circ} \mathrm{C}$ with Temperature Gradients"

J. Jun, M. Romedenne, and B. A. Pint, "Liquid Metal Compatibility of Plasma-Facing Components"

C.E. Kessel and A.F. Rowcliffe, "Design-Materials Interface for Fusion Nuclear Facilities"

T. Koyanagi, H. Wang, Y. Lee, Y. Katoh, "Effects of Neutron Irradiation on Electrical Properties of High-Purity SiC Ceramics" 
T. Koyanagi, Y. Katoh, C. Petrie, G. Singh, X. Hu, J. Arregui-Mena, C. Deck, K. Terrani, "Response of SiC Composites to Neutron-Irradiation with a High Heat Flux: Experiments and Modeling"

C.P. Massey, David T. Hoelzer, S. Dryepondt, and S. J. Zinkle, "Processing-Microstructure-Properties Relationships: A Comparison Between Ferritic ODS FeCr and ODS FeCrAl Alloys"

C. On, J.W. Geringer, J.L. McDuffee, P.L. Mulligan, R.H. Howard, Y. Katoh, "HFIR Irradiation Engineering Used for Fusion Materials"

Y. N. Osetsky, "Dynamics of Interstitial Defects in Tungsten-Rhenium Alloys"

Chad Parish, "The Interplay between Helium Plasma and Tungsten Microstructure in PMI"

Chad Parish, "Effects of Helium Exposure on Tungsten Mechanical Behavior"

G. D. Samolyuk and Y. N. Osetsky, "Equilibrium Distribution of Point Defects in Systems with Nanoclusters - Fe-Y-O as a Typical Representative of ODS Alloys - Importance of Vacancies"

G. D. Samolyuk and Y. N. Osetsky, "Stability of Phases in the W-Re-Os System under Irradiation"

Roger Stoller, Yuri Osetsky, Alexander Barashev, “The Role of Over Pressurized Helium Bubbles in Iron in Microstructure Evolution under Irradiation"

Yukinori Yamamoto, Roger G. Miller, Arthur F. Rowcliffe, "Design of Advanced Bainitic Steels with Improvement in Cross-Weld Properties"

At the 44th International Conference on Advanced Ceramics and Composites, Davtona Beach, Florida, Januarv 27-31,2020,

Y. Katoh, T. Koyanagi, Y. Yang, B. Jolly, L.L. Snead, C. Ang, T. Nozawa, "Design and Strategy for Next Generation Silicon Carbide Composites for Nuclear Energy"

At the TMS Annual Meeting, San Diego, February 23-27, 2020

Invited Presentation

Chad Parish, Daniel Morrall, Yutai Katoh, Arunodaya Bhattacharya, Andrew Lupini, Philip Edmondson,

"Applications of Advanced Electron Microscopy to Understand Irradiation Damage of Fusion and Fission Materials"

\section{Oral Presentations}

Elizabeth A.I. Ellis, Michael M. Kirka, John R. Echols, Lauren M. Garrison, Christopher Ledford, Sullivan M. Figurskey, Chris D. Rock, Timothy J. Horn, Yutai Katoh, and Ryan R. Dehoff, "Texture Management in EBM Tungsten Plasma-Facing Components for Fusion Reactors"

Lauren Garrison, Chad Parish, Maxim Gussev, John Echols, Johann Riesch," Microstructure and Mechanical Properties of Neutron Irradiated Tungsten Fibers for Fusion Applications" 
Sara Wonner, Lauren Garrison, "Mechanical Testing of Tungsten-Steel Laminate Composites for use in Fusion Applications"

Matthew Weinstein, Lauren Garrison, Maxim Gussev, Nate Reid, Carol Lin, Johann Riesch, "Mechanical Testing of Steel and Tungsten Fibers for Use in Composites for Fusion Applications"

John Echols; Lauren Garrison; Elizabeth Ellis; Yutai Katoh; Michael Kirck; Ryan Dehoff; Timothy Horn; Christopher Rock; Christopher Ledford; Sillivan Figurskey, "Mechanical and Thermal Properties of Electron Beam Melting Additively Manufactured Tungsten for Fusion Energy Applications"

\section{Poster Presentations}

Nathan Reid, Lauren Garrison, Yutai Katoh, Jean Paul Allain. "Tungsten Transmutation Products from Mixed Spectrum Neutron Irradiation"

Daniel Morrall, Cierra DellaRova, Russell Doerner, Matthew Baldwin, Chad Parish," Evaluation of Bubble Layers in Single- and Poly-crystal Tungsten after Helium Exposure"

At the 31st Symposium on Fusion Technology (SOFT2020), September 20-25, 2020, Virtual Edition

B. A. Pint, J. Jun, M. Romedenne, "Materials Compatibility in Flowing $\mathrm{Pb}-\mathrm{Li}$ at $600^{\circ}-700^{\circ} \mathrm{C}$ "

Microscopy and Microanalysis Conference, August 3-7, 2020, virtual event

Oral Presentation

Daniel Morrall, Chad Parish, "Focused ion beam surface preparation for plasma facing materials"

GIMRT Joint International Symposium on Radiation Effects in Materials and Actinide Science, Sep. 30-Oct. 3, 2020, virtual event

\section{Invited "Plenary" Presentation}

T. Koyanagi, Kurt Terrani, Shay Harrison, Jian Liu, Yutai Katoh, “Additive manufacturing of silicon carbide for nuclear applications" 